

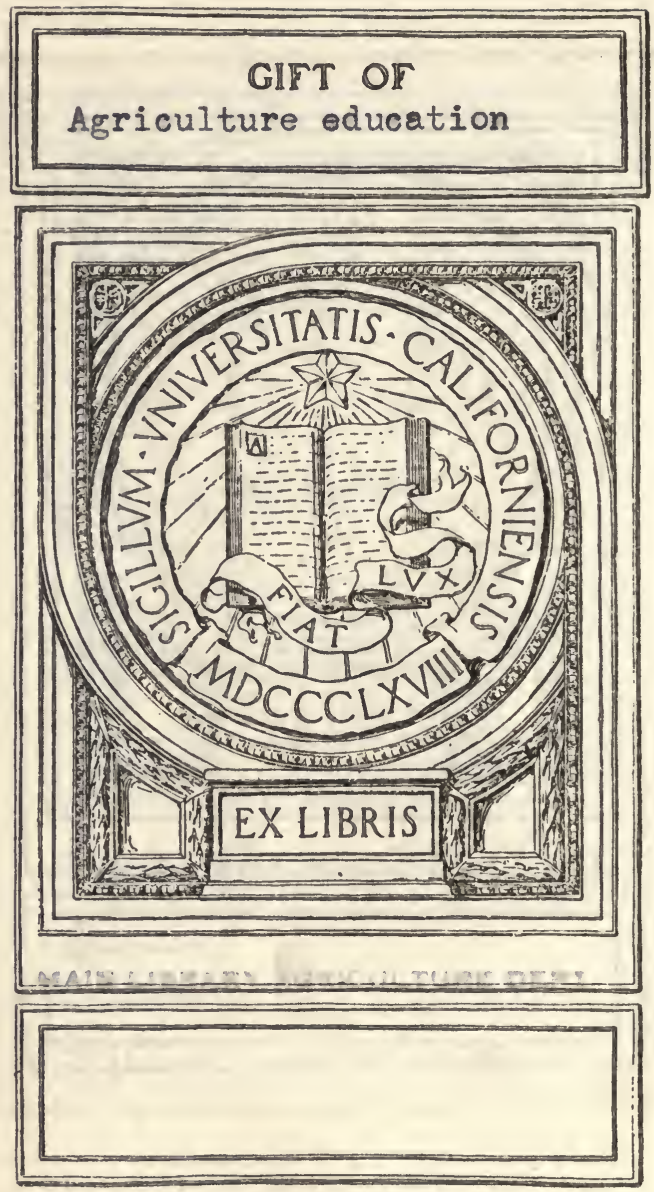


$$
\text { z-Thuidou }
$$

$$
\begin{aligned}
& 121
\end{aligned}
$$

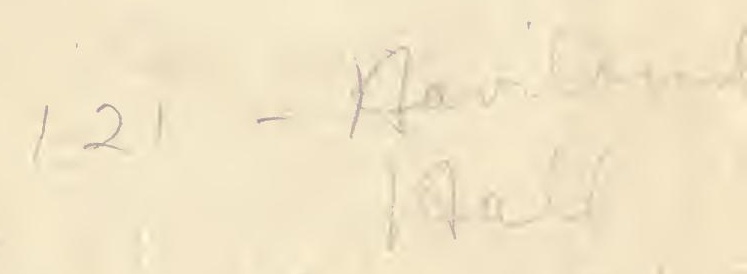

$$
\begin{aligned}
& \therefore \text {. Xee } 21-1
\end{aligned}
$$





\section{GENERAL SCIENCE \\ AND THE \\ ECONOMICS OF DAILY LIFE \\ BROWNELL}





\title{
A TEXTBOOK IN
}

\section{GENERAL SCIENCE}

\section{AND THE}

\section{ECONOMICS OF DAILY LIFE}

BY

HERBERT BROWNELL, B. Sc.

PROFESSOR OF SCIENCES 'IN SECONDARY EDUCATION, TEACHERS COLlEGE, UNIVERSITY OF NEBRASKA, LINCOLN; AUTHOR OF "LESSONS IN

PHYSICS", "LESSONS IN CHEMISTRY", AND "LABORATORY LESSONS IN GENERAL SCIENCE"

WITH 118 , ILLUSTRATIONS

\author{
PHILADELPHIA \\ P. BLAKISTON'S SON \& CO.




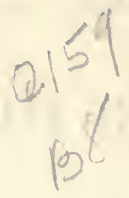

Copyright, igi 8, by P. Blakiston's Son \& Co. $a+k^{5}$

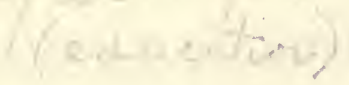

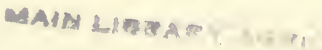
SPESTO

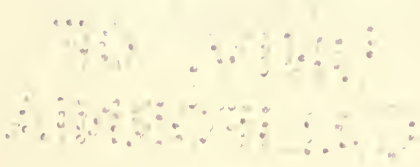

THF MA PI, E PRESS YORK PA 


\section{PREFACE}

A science, as the term is usually employed, implies a grouping of the facts and phenomena of some one field of human knowledge according to certain general statements known as theories and laws. Botany, for instance, is a classification of man's knowledge of plants, and of the conditions for their growth. It makes possible the study of plants in groups rather than one by one.

But in General Science as a high school subject selections of topics for study are made from any and all of the secondary school sciences. These topics are studied for the general purpose of giving scientific explanations to whatever affects daily life in so far as they lend themselves readily to elementary scientific discussions. Some theory is given as needed in these explanations, but there is little or no regard to whether the facts and explanations have to do with any one science or another. Sufficient experimental phenomena are to be provided in laboratory exercises and classroom demonstrations. The topics are supposed to be more or less familiar through the common experiences of childhood and youth, and of such a nature as to foster a scientific spirit.

This text seeks to relate for schoolroom uses the teachings of science and the common experiences of life. Its discussions are designed to stimulate a desire on the part of pupils for information concerning everyday phenomena readily obtainable from high school science texts, and from reference books suited for use in elementary science teaching.

Some of the discussions of the text though elementary in character will present difficulties for beginners. But the 
author believes it advantageous early in the course to make some use of the theories of high school science in order to give scientific unity to explanations of various common phenomena. Care has been exercised to distinguish sharply at all times between fact and theory, and to make clear the restrictions that must accompany the use of theories whether in school or elsewhere.

Enough of a knowledge of the differentiated high school sciences should be gained in a general science course to serve as a real introduction to them. This will enable pupils later to make an intelligent choice of which of these sciences they care to pursue.

However skillfully information for beginners in science may be selected and presented, it will fail very largely of its purposes as "knowledge-making material" if no need for it has arisen in the minds of pupils, and if no apparent use for it exists. Where a desire for knowledge is based on needs that have been experienced, it calls forth effort in the schoolroom even as it does in the larger field of life experiences. A purpose of the text is to arouse and in some large measure to guide the desires of pupils for a scientific understanding of life's problems, and to furnish some of the material and conditions necessary to secure these ends.

Perhaps foremost of all the ends sought in the teachings of General Science is an habitual scientific attitude of the pupils - the state of mind that demands the facts in all cases; that discriminates in the relative importance and pertinence of facts; that can so associate them as to get their chief significance whether in specific relationships or in general applications; that does not rest satisfied with "glittering generalities" but tests them out to ascertain if theory fits facts when applied to known conditions and existing situations. In other words, the facts of the discussions in General Science, valuable as they may be in themselves, are to be 
used for the larger purpose of establishing a scientific procedure in the affairs of life.

The author desires to express his deep appreciation of the helpful suggestions and criticisms of those who have read the manuscript for this text, or portions of it. Special acknowledgments are due Dr. R. J. Pool of the Department of Botany; Professor H. C. Filley of the Department of Farm Management; Professor Alice M. Loomis of the Department of Home Economics; Professor George E. Loveland, Director of the U. S. Weather Bureau; Professor G. D. Swezey of the Department of Astronomy; and Dr. R. A. Lyman of the Department of Physiology, all of the University of Nebraska, together with Professor B. C. Hendricks of the Department of Physics in the State Normal School at Peru, Nebraska. He is under special obligation to Professor A. E. Sheldon, Lecturer on Political History and Secretary of the State Historical Society, and to Mrs. Sheldon, for their very helpful criticisms in their readings of the manuscript. The author assumes, however, all responsibility for errors that may have crept into the text.

Aside from acknowledgments made in connection with single illustrations, the author wishes to express his appreciation for other illustrations from:

U. S. Forest Service,-Figs. 37 40, 76, 83, 84, 86, 88 ,

U. S. Weather Bureau,-Figs. 32, 48, ro2.

U. S. Public Health Service,-Figs. 15, 2 I, 25.

U. S. Public Roads and Engineering,-Figs. 29, 69.

U. S. Reclamation Service,-Figs. 38, 39.

U. S. Geological Survey,-Figs. 92, I I 2 .

Division of Publications, U. S. Department of Agriculture,I $8,24,26,2728,36,47,6768,73,75,77,79,80,81,82,85,93$, $95,96,97,98,103,104,105$, 106, 107, 108, г11. 



\section{CONTENTS}

I. Some Lessons on the Human Body.

PAGE

The Hand . . . . . . . . . . . . . . . . . . 2

The Mouth. . . . . . . . . . . . . . 4

The Eye. . . . . . . . . . . . . . ro

II. Heat in Relation to the Human Body.

Combustion . . . . . . . . . . . . . . I6

Pure Air, and Breathing .......... . . . I9

The Human Body as an Engine, and the Regulation of Body

Temperature ............ 25

III. Health AND Well-being.

Keeping Well ............... . 3I

Infection . . . . . . . . . . . . . 36

Sanitation . . . . . . . . . . . . . 45

The Water Supply and Health . . . . . . . . . 52

General Health Problems. . . . . . . . . . . 57

Life, Growth, Rest, and Recreation . . . . . . . . . 64

Stimulants and Narcotics . . . . . . . . . . . 72

General Science and Right Living . . . . . . . . . 80

IV. WATER AND Its Uses.

Some Properties of Water . . . . . . . . . . . 85

Vaporization and Condensation . . . . . . . . . . 90

Heat of Vaporization and of Fusion . . . . . . . . . . . . 94

Solution, Diffusion, Absorption, and Osmosis . . . . . . . . 97

Streams, Valley Formation, and Surface Erosion . . . . . . I02

V. The Atmosphere.

Properties and Uses of Air . . . . . . . . . . . . Iro

Pressure Exerted by the Atmosphere, and Effect of Pressure on

Gases . . . . . . . . . . . . . . . II4

Applications of Atmospheric Pressure . . . . . . . . . Ir8

Currents in the Atmosphere, and Their Relation to Atmospheric

Pressure . . . . . . . . . . . . . I23

Areas of High and Low Pressure. . . . . . . . . . I 28 
VI. Weather and Climate.

Weather in the Affairs of Men

Weather as Affected by Highs and Lows .

The Thermometer, and Heat Transmission

Solar Heating.

VII. Matter and Force.

Some Properties of Matter, and Changes in Matter Due to Force I5 I

VIII. WORK AND MACHINES.

Meaning of the Terms Work and Energy. . . . . . . . . I60

*Levers and Pulleys . . . . . . . . . . . . . . . I63

Electromagnets . . . . . . . . . . . . . . I68

IX. Some Chemistry of Everyday Life.

A Review of Some Chemical Changes . . . . . . . . . . I73

*The Chemistry of Cleaning . . . . . . . . . . . . 177

*Acids, Bases, and Salts . . . . . . . . . . I80

*Electricity and Chemical Changes . . . . . . . . I84

*Limestone and Other Carbonates. . . . . . . . . . . 190

${ }^{*}$ The Chief Among Metals . . . . . . . . . . . . . I96

X. At Our Homes.

Rooms of the House, Their Furnishings, and the Cost of Living 206

Fuel and Lights for Modern Homes . . . . . . . . . . 214

Some Foodstuffs. . . . . . . . . . . . . . . . 2I9

*The Carbohydrates. . . . . . . . . . . . . . 226

Fires, Burns, and Various Accidents . . . . . . . . . . 233

XI. Surroundings of the Home.

The Garden, and Its Care . . . . . . . . . . . 24I

Soil Conditions for Plant Growth . . . . . . . . . . 247

Tree Planting. . . . . . . . . . . . . 254

Trees of the Neighborhood . . . . . . . . . . . 259

Some Plant Studies . . . . . . . . . . . . 263

Usefulness of Plants to Man . . . . . . . . . 268

Birds Around Our Homes . . . . . . . . . . . . . 275

XII. Some Conditions Affecting Industrial Life.

Changes in Manner of Living . . . . . . . . . . 28I

Social and Economic Conditions Affecting the Wage Earner. . 290

* See page 372 . 
XIII. The FARM.

Poultry and Eggs . . . . . . . . . . . 297

The Horse . . . . . . . . . . . . . . . . . 304

Cows, and the Dairy Industry . . . . . . . . . 307

Lessons on Corn. . . . . . . . . . . . . . 312

Apple Raising as an Industry . . . . . . . . . . 319

Wheat, and Wheat Growing ........ . 325

Origin and Nature of Soils . . . . . . . . . 332

XIV. Phenomena of Light.

Shadows and Eclipses . . . . . . . . . . 336

*Images by Reflection in Plane Mirrors . . . . . . . . 338

*Color Phenomena. . . . . . . . . . . . . . . . 342

XV. The Earth as a Planet.

Day and Night, and the Earth's Rotation . . . . . . . . 349

Rotation Combined With Revolution, and Changes in Seasons $35^{\mathrm{I}}$

The Moon, and Its Phenomena . . . . . . . 355

*Time, and Time-keeping, and Standard Time . . . . . . 359

XVI. The Heavens. . . . . . . . . . . . . . . 364 Appendix.

Suggestions to Teachers .......... . 370

Reference Books ............. . 372

* See page 372. 



\section{GENERAL SCIENCE}

\section{SOME LESSONS ON THE HUMAN BODY ${ }^{1}$}

\section{INTRODUCTION}

We expect a surgeon to have an intimate knowledge of human anatomy, and a physician to be skilled in human physiology. But enough of the anatomy and physiology of the human body should be taught in schools so that instruction in hygiene as a study of health conditions will be better understood by every one, and its teachings better observed. The importance of an understanding of health conditions, and of their control, is emphasized in the lessons that follow, as are the relations between good health and the happiness of mankind. The lessons on the Hand, Mouth, and Eye are given because of the peculiar usefulness to man of these important organs of his body. No one should be ignorant of their structure and uses and care. A large part of the knowledge of the world around us is gained through the eyes and hands, and life's activities are largely dependent upon their services. Then, too, the progress of man in civilization and much of his enjoyment is intimately associated with oral speech in which the structure of the

${ }^{1}$ In Zoology as a study of all forms of animals, including human beings, anatomy deals largely with the structure of the body, while physiology has to do with the activities of the various organs. Botany as a study of plants likewise has its subdivisions of anatomy and physiology. Biology is the science of living bodies, and includes both Botany and Zoology. 
mouth plays a most iniportant part. Some knowledge of Human Physiology as studied in schools is presupposed in these lessons.

\section{The HAND}

The bones of the hand serve as a framework, giving to it both form and strength. The many joints of the hand and
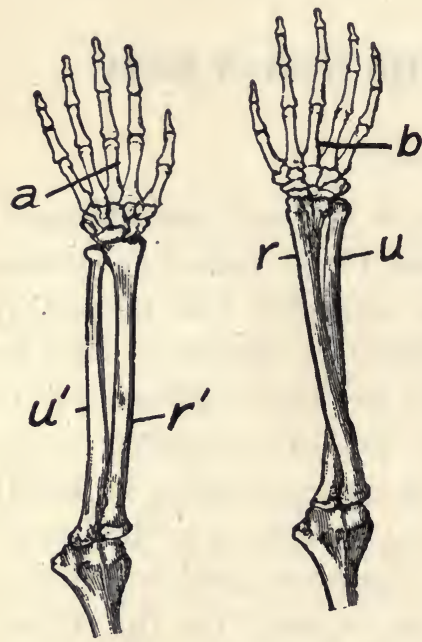

FIG. I.-Bones of the right forearm. $a$, palm; $b$, back of hand; $r, r^{\prime}$, radius; $u, u^{\prime}$, ulna. wrist make possible a great variety of movements, and a wide adaptability in uses. The bones are held together at the joints by ligaments, and the surfaces of bones that move upon each other are covered by cartilage. A study of both cartilage and ligaments can be made from a joint obtained at a meat shop.

Motion in the parts of the hand and wrist is accomplished by means of muscles, the "lean meat" of animals. Sometimes the muscles are attached directly to the bones, seeming to grow out of the bone itself. In the wrist and hand the movement of cord-like tendons beneath the skin may be seen and felt. The muscles here are at some distance from the bones moved by them, and are connected to the bones by the tendons.

To cause these muscles to act, moving the hand and fingers or holding them at rest as a person desires, the muscles are provided with nerves. In the skin of the inner part of the hand and fingers the terminal fibres of the nerves are so close that the hand through care and training may acquire a 
marvelous delicacy of touch. The blind learn to read through their finger tips, and players of the violin and other musical instruments. seem almost to think with their fingers, so intimate is the relation of muscle and mind through the nerves.

The hair, finger nails, and outer layers of the skin are all destitute of blood vessels. Growth in them occurs only at their under surfaces and inner ends. The tendons and ligaments, too, get a scant supply of blood, and their repair is slow after accidents where a sprain has occurred, or when they have been torn from the bone. Either condition may be more serious than a broken bone, or the dislocation of bones at a joint.

The finger nails serve to support and protect the ends of the fingers, and to enable a person to pick up small objects more readily. At all times they should be kept neatly trimmed, and scrupulously clean. The fold of skin at the base of the nail should be kept pushed back instead of being cut off. Food should never be handled with unwashed hands, nor the finger tips touched to the tongue.

The hand is man's chief instrument for labor. He uses it for feeding and dressing himself. It is a weapon for selfdefense, and is a means for fashioning tools, implements, clothing, and for preparing his food. It is in almost constant use during man's waking hours, ministering to his needs and executing his desires.

\section{SUMMARY}

In shapeliness, structure, and adaptability the hand is a wonderful tool fashioned for man's use. In its varied movements is illustrated the fact that the muscles are the organs of motion in the body. These muscles move in obedience to impulses sent outward to them from nerve centers, the chief of which is the brain.

The ability of man to labor and to care for himself is seriously impaired when he is deprived of his hands. His mind, too, is robbed of 
the stimulus of directing those activities in which the hands are employed, and of those reactions which result from expression of thought through hand work.

\section{The Mouth}

The cavity known as the mouth is not only the beginning of the digestive canal, but it is one of the chief organs of

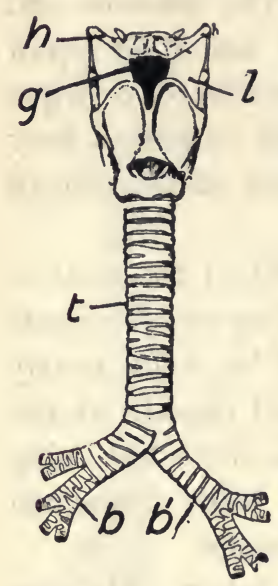

FIG. 2,- $\mathrm{H}$ y oid bone, $h$; trachea, $l$; bronchi, $b, b^{\prime}$; larynx, $l$; glottis, $g$. speech. In Physics from the study.of sound we learn something of the uses of the mouth and its adjacent parts in talking and in singing. Complete control of the muscular parts of the mouth and its connected cavities is necessary to a singer in order to give utterance to sounds in their proper relationship in the musical scale.

Just above the $\operatorname{larynx}$, and embedded in the tissues, there may be felt on either side of the neck the small semi-elliptical hyoid bone. From it many of the muscular fibres of the tongue arise. It does not connect with other bones of the skeleton-the only case of the kind in the body. As a movable base it gives to the tongue an exceedingly wide range of movement. Back of the mouth cavity and the attached end of the 'tongue is another cavity with muscular walls known as the pharynx (făr'-1̆nks). This is the upper enlarged extremity of the muscular food tube, or œsophagus, which leads to the stomach. Food and drink, when forced by the tongue back into the pharynx, pass over the glottis, or entrance to the larynx, and are kept from getting into it by a cartilaginous cover known as the epiglottis. Coughing, strangling, and choking mark spasmodic efforts to dislodge food or drink that gets into the glottis. Once within 
the pharynx, food and drink are beyond a person's control. Their movement along through the remaining thirty or more feet of the food canal is due to the vigorous activity of the muscular coats of the œesophagus, stomach, and intestines.

Taste and smell add much to the enjoyment of living. But the distribution of the nerves of these two senses in the nasal and mouth cavities indicates that their primary purpose is to give warning against the introduction into the body of food, drink, or air that is unwholesome or harmful. Not all harmful substances have a bad taste or odor, nor are all substances with disagreeable taste or odor harmful. However, the products of decay in foods when not disguised by spices and flavorings are likely to give evidence of their presence by an unnatural odor or taste.

The tonsils are peculiarly exposed to infection. Their location in the throat is such that they are in contact with the air breathed, and with food and drink on its way to the stomach. Their structure, too, is such as to make them susceptible to attacks of germ diseases. Any "soreness" of the throat, and any "patches" upon the tonsils, may necessitate prompt medical treatment. Many of the fatal ailments of childhood manifest themselves in their earlier stages by an inflamed condition of the throat, and more or less of swelling and soreness there. All "colds", should be regarded with suspicion, and proper care and precautions taken from their first appearance.

Although air is made to pass in and out of the mouth when talking and singing, and when playing upon some musical instruments, in all ordinary breathing the air should pass to and from the lungs through the nose. In this way cold air becomes somewhat warmed before reaching the lungs. Dust present in the air is largely. stopped in the nose, collecting on the surface of the moist mucous lining of the nasal cavity and on the hairs just inside the nostrils. 
A child who habitually breathes through the mouth may be afflicted with adenoids, and their removal may become necessary. Catarrh is a persistent congested condition of the mucous lining of the nasal cavity, and may cause deafness.

The thorough mastication and insalivation of food is an essential stage in the process of dissolving it. 'This process is known as digestion. Water or other drinks used to wash down the food do not take the place of the saliva. Man, unlike birds and domestic fowls, has no gizzard to do what the teeth should have done.

The saliva contains small portions of a so-called digestive ferment which brings about chemical changes in starchy foods, converting the starch into a form of sugar which dissolves easily. The other digestive fluids also cause chemical changes in foods through the action of the ferments which they contain. A nervous or excited state, or extreme weariness in body or mind, interferes with and may stop the secretion of these digestive fluids ${ }^{1}$, thus impairing digestion. One should not eat at such times, but wait until rested and quieted. A happy frame of mind favors digestive processes. Mealtime should be a time of mirth and social enjoyment, and never a time for controversy'and settlement of disputes, or for administering family discipline. The sight, smell, and taste of appetizing food, and a state of unsatisfied hunger, maintains the flow of the digestive fluids. The flow lessens when these conditions cease to exist. Many people attempting to speak in public experience difficulty from dry lips and mouth. Their nervousness causes a lessened flow of saliva.

A dry fevered appearance of the tongue and mouth, and a heavy white or yellowish coating of the tongue, indicate

1 The amount of gastric juice secreted per day may be five pints or more. 
a condition of the mucous lining of the stomach and intestines unfavorable to the secretion of digestive fluids. In such cases one should eat sparingly till normal conditions are restored. Only those foods should be eaten which have been found from experience to be easily digested.

Perhaps no one condition connected with the digestion of food is followed by such a train of bodily ills as constipation, especially where it persists during infancy, childhood, and youth. The whole system becomes disordered by reason of any retention and reabsorption of bodily wastes. Ignorance of what it signifies, and of the course to be pursued permanently to relieve it, spares no one of its evil consequences. Dullness of mind, headache, dizziness, a coated tongue, and a foul breath, with more or less of a tired feeling all the time, are some of the common results of constipation. A full easy movement of the bowels daily as an established habit from childhood contributes largely toward health and efficiency for life. Insufficient activity of the muscles of the intestines, a lack in vigor of their wavelike or peristaltic movements, is the immediate cause of constipation.

To maintain the conditions favorable for a healthy activity of the bowels may require constant care. Sufficient exercise for the muscles of the trunk and abdomen, deep breathing, use of plenty of water as a drink between meals ${ }^{1}$, and enough sleep, all contribute to the general health and to a satisfactory elimination of the bodily wastes. Food which repeatedly causes indigestion is to be avoided. Regularity in action of the bowels should, under all ordinary circumstances, be maintained without recourse to medicines. Meats, eggs, milk, beans, and wheat bread are some of the

${ }^{1}$ In addition to the water taken with food at meal times, the habitual practice of drinking between meals a half dozen glasses (three pints) of water daily aids in keeping the body in a healthy condition. 
foods which have a tendency to cause constipation because of lack in bulk. Fruits and vegetables generally, together with graham flour, corn bread, bran foods, and oatmeal, are likely to stimulate the bowels to a normal activity.

The enamel of the teeth is the hardest substance in the body. It contains no blood vessels, and when once cracked or broken is not restored by nature. The dense bony material beneath it, forming the body of the tooth and known as dentine, decays when exposed to the action of bacteria. Protection of the teeth from decay, and their preservation throughout life, necessitates continuous care. Frequent examination by a competent dentist is usually advisable, especially during childhood and youth. It is better to prevent decay than to be forced to repair its ravages. There is no satisfactory substitute for a frequent use of the toothbrush. As the first of the thirty-two teeth in the permanent set may grow into place when children are but six or seven years of age, the habitual use of the brush should begin in early childhood.

It is often possible to tell much of a person's state of mind from the expression of the lips and the mouth. The passing emotions of mirth, scorn, or disgust are reflected in one's face. Discontent, brutality, and vulgarity on the one hand, or contentment and sweetness of disposition on the other, stamp themselves indelibly upon the face. Repeated impulses in the nerves distributed to the muscles of the face leave their evidences of firmness or fickleness of purpose, strength of character or weakness, in permanent lines formed about the mouth. The kind of feelings cherished, and the manner of thoughts indulged, sooner or later make or mar one's expression.

$\therefore$ By means of the nerves the varied movements of the numerous muscles of the body are directed and controlled. 
In some cases this is by direct act of the will $(\operatorname{mind})^{1}$, and in other cases such as movements of the muscles of the heart, diaphragm, and intestines, the action is largely or wholly involuntary. It is over the nerves, too, that impulses travel to the brain and other nerve centres giving rise to sensations. Education as "mind development" involves for one thing an increasing readiness in interpreting correctly the significance of sensations.

\section{Summary}

Any study of the mouth cavity must take into account that it is a part of the digestive tract, and a chief organ of speech. It is likewise the chief gateway whereby germ diseases enter the body. The senses of taste and smell may be considered as primarily for the purpose of preventing entrance of injurious and poisonous substances into the body with the food and drink, or with the air breathed.

While the tongue as an organ of speech at times may be "an unruly member," its muscles are nevertheless wholly subject to one's control. Its utterances are what we make them. In learning to speak a foreign language there is much the same difficulty experienced in getting the muscles of the tongue to give correct utterance to sounds as there is in bringing under control those of the hand when learning to play musical instruments in correct time and with suitable expression. Sustained and close attention, and much practice, may be necessary to properly co-ordinate mind, nerve, and muscular action.

${ }^{1}$ No one is likely to mistake an electric light bulb for the electricity by means of which the mechanism of the bulb produces the illumination. Nor is there any confusion in distinguishing between a dynamo as a machine, and the electrical energy sent out from it. In a similar manner a sharp distinction is to be made between the brain as the organ of the mind on the one hand, and on the other its powers (activities) in interpreting sensations, in noting relationships among these sensations, and in deciding upon a course of action in accordance with the knowledge possessed. Whatever the nature of the brain activity in the processes of thought, and however dependent mental vigor may be upon a well-nourished brain, it simplifies our discussions here to consider the mind, and the development and use of its powers, more or less apart from brain phenomena. 
Great as the value of a good set of teeth may be in the appearance of a person, their primary purpose is their use for the digestion of food. To go through life with teeth made more or less worthless by neglect in childhood is a serious handicap upon health and length of life.

\section{The Eye}

The human eyes when one stands erect command a wide range of vision without turning the head.

The eye is seldom perfect as an optical instrument. Its defects, even when serious, may often easily be remedied by glasses fitted after an examination of the eye by a competent oculist. The eyes of people whose general health is good give a lifetime of excellent service when they have not been subjected to abuse. It is the utmost folly not to give the eyes intelligent care especially during school days. When once the sight is destroyed a person is shut away from much that is in the world about him. His knowledge then becomes limited largely to what he can hear and touch.

To understand how it is that we can know of objects far distant from us, and beyond our reach, requires the study of light as given in Physics. Through the transparent interior of the eyeball light reaches the optic nerve. Its terminal fibres are spread out over the interior of the rear wall of the eyeball and form the retina.

Any transparent medium with a curved surface is a lens. Those used in telescopes and microscopes, and in spectacles, are of glass. In the eye the soft, elastic crystalline lens serves to form images on the retina just as the lens of the photographer's camera forms an image on the chemically prepared plate. The cornea (kor'-ne-ah), the vitreous humor, and the aqueous humor of the eyeball also refract light, i.e., bend it from a straight line course as it passes into and then out of them.

An ample supply of blood is furnished to the eyeball, but the humors, lens, and cornea are nourished without dimming 
their transparency. Circular musular fibres in the iris by their contraction allow less light to enter the eyeball, and as they relax the pupil of the eye is enlarged. Dust and any foreign particles lodged underneath the eyelids, or an irritation due to lack of tear-water, may cause congestion of the blood vessels in the eyeball and in its surroundings. This gives the eye a temporary blood-shot appearance.

Pain in the eyes as elsewhere in the body is nature's warning that something is wrong with the mechanism. Weariness is a signal for rest, or a demand that an abuse of the eyes be stopped. Rest for the eyes when reading, sewing,

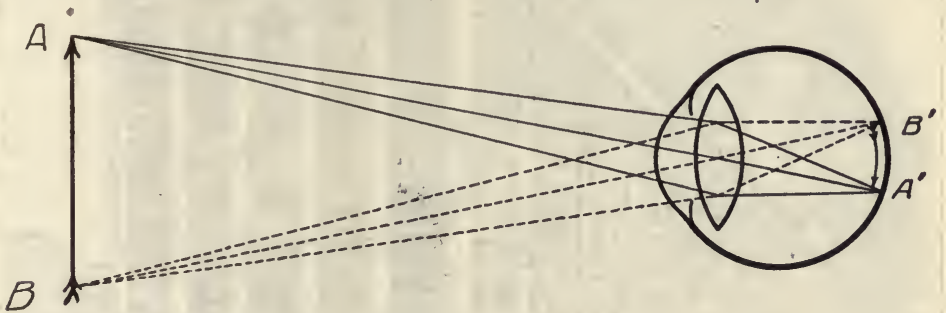

FIG. 3.-Formation of images on the retina of the eyeball. (So far as the physics of the phenomenon is concerned the images thus formed are inverted.)

2

or using the microscope, does not necessitate complete dis. use of the eyes. Any occupation that requires sustained effort to see the same object, especially if dimly lit up, soon wearies the eyes. Looking at other objects at different distances rests the eyes. The little muscles that hold the lens of the eye in a particular form in order to see any object distinctly are often kept under a strain which not only wearies but weakens them. The effect is somewhat the same as when one forces himself to hold his arm out horizontally from the body for a long time. Any serious ailment of the eyes calls for their examination and possible treatment. Glasses fitted by oculists, while commonly for the purpose of 
enabling persons to see more distinctly, are quite as often prescribed to relieve eyestrain. Changes in the eyeball itself naturally occur as a person grows older, making necessary the wearing and the refitting of glasses from time to time. That objects at different distances may be seen distinctly, changes in the form of the crystalline lens are continuously

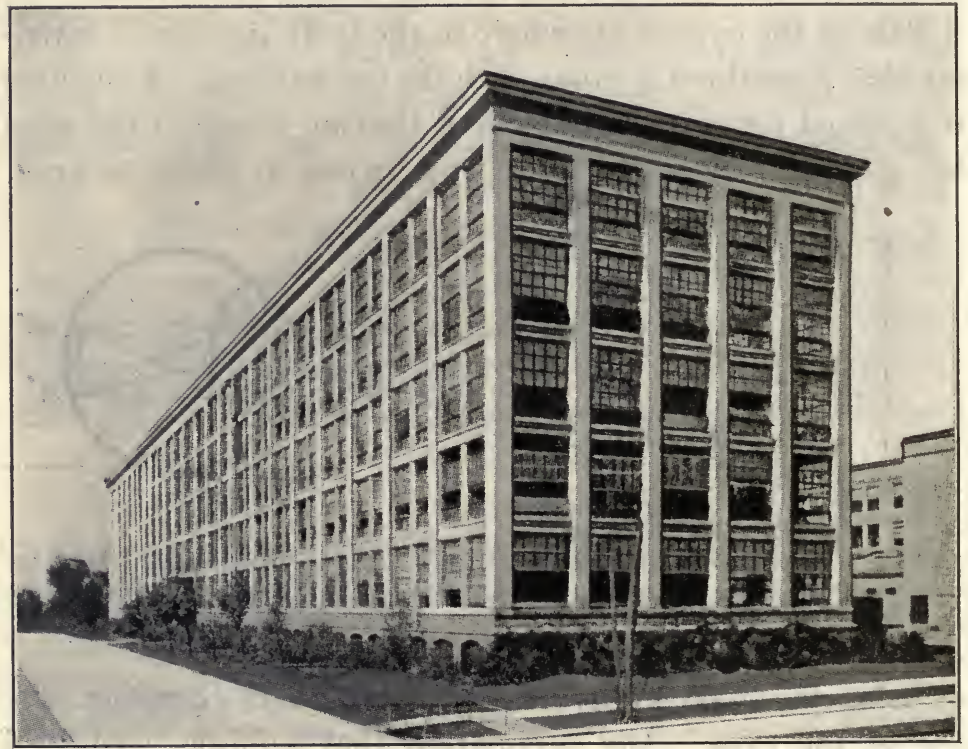

FIG. 4.-The workers here are not likely to have impaired eyesight.

taking place. This adjustment in form is known as the power of "accommodation," and it is more or less" completely lost in old age.

A whole train of bodily ailments often attend upon or are caused by eyestrain. Headaches, nervous exhaustion, and impaired digestion are often directly traceable to it. Impatience and ill-temper may arise from it. No one should be ignorant of what constitutes right conditions for continuous use of the eyes, especially any close application of them. 
Reading when weary, or when on trains, or when lying down, severely taxes the eyes and should be avoided. Large responsibilities rest upon architects and builders whose business it is to arrange both for the artificial and for the natural lighting of the rooms and buildings in which people are to live and work.

It is not especially important that objects in front of pupils in schoolrooms, and of workers in offices and shops and homes, shall be illuminated by light that "comes over the left shoulder." But the illumination must be neither too bright nor too dim, and the light must be so uniformly diffused that sharply outlined shadows do not exist in the room. Any conscious effort in excluding light from the eyes

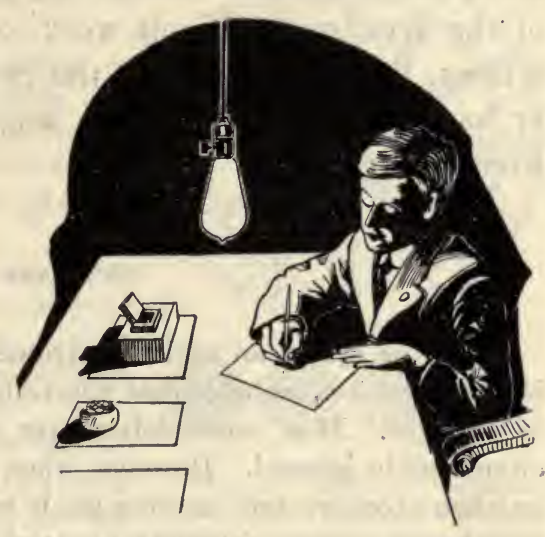

FIG. 5.-Hard on the eyes. because it is too glaring,

or in making out details of objects viewed because the light is too dim, is evidence of something wrong with the illumination of the room. No direct rays of light should be allowed to come into the eyes either from the sun or from electric bulbs. The contraction of the pupil to shut out the excess of light from an unscreened lamp shining directly into one's eyes may result in eyestrain, since too little light can then enter them from the objects upon which one is at work. The glare of the lights of an automobile blinds one to other objects near at hand that are not brightly lit up, because the size of the pupil of the eye adjusts itself to the more intense light. 
School requirements for use of the eyes are at times exacting but these requirements are never sufficient excuse for permanent impairment of vision, nor for long-continued eyestrain. Since schools do demand so much in a sustained use of the eyes, it is the more necessary that all contributing causes to weakened eyesight such as late hours, motion pictures, etc., be largely avoided. Special care should be given to maintain good health, and when necessary to be correctly fitted with glasses. Under no circumstances should use of the eyes upon difficult work, or under unfavorable conditions, be continued after the eyes have become inflamed, or have begun to ache from use, or when headache occurs from eyestrain.

\section{SUMMARY}

While the eye as an optical instrument may be conside ed perfect in its design, it is probable that relatively few people are free of defects in eyesight. Most such defects are of minor character, and may oftentimes be ignored. However, when the general health is impaired, or when excessive and exacting use is made of the eyes, these defects may become serious. Impaired eyesight is a handicap in life's activities and in its enjoyments.

Intelligent care of the eyes requi:es a knowledge of their structure, their defects, and their proper use.

Eyestrain may be caused by dim lighting, by too glaring lights, and by unequal diffusion of light. Fatigue and exhaustion of the whole nervous system may follow, upsetting the equilibrium of the body organism and resulting in a disordered state of the nerves and a loss of mental poise.

The small muscles whose office is to hold the crystalline lens in that particular form where vision is most distinct become exhausted by long-sustained close application, such as in reading fine print, in continuous use of the microscope, and in doing fine sewing. This strain is relieved if from time to time the eyes are used in looking at other and more distant objects. Many headaches from which people suffer are directly or indirectly caused by eyestrain. 
Pupils not infrequently acquire at school the bad habit of stooping or bending over their books. This strains the eyes by bringing them too close to the print. Twelve inches is about the proper distance.

\section{Exercises}

1. By what means is a wide variety in movement of hand and fingers secured?

2. Tell the location, form, manner of growth, and uses of the finger nails.

3. Name several of the structures within the hand of which something can be learned by inspection though they are hidden from view.

4. Define (a) tonsillitis; (b) adenoids.

5. What information concerning the state of one's health can be learned from the appearance of the tongue? In what sense is the tongue an organ of digestion?

6. Describe (a) the hyoid bone as to its position and use; $(b)$ the pharynx as to position and structure.

7. Why do the teeth ache? How is nourishment conveyed into a tooth?

8. How does a singer become able to produce any note desired in singing and a speaker to utter any desired sound in speech?

9. About what is the diameter of the eyeball (a) sidewise; (b) up and down? By a drawing indicate the relative size and form of the upper and lower eyelids as seen when the eye is "open."
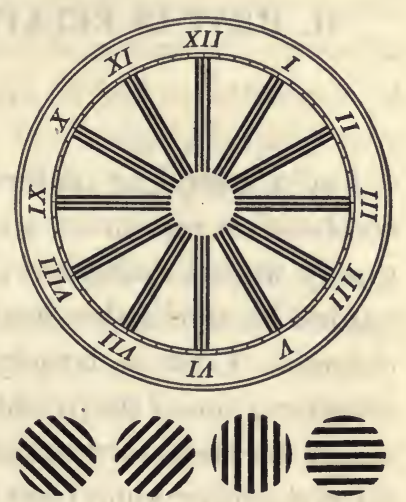

FIG. 6.-Tests for astigmatism. Hold the cut at a suitable distance from the eyes and in a good light. Note if the parallel lines in all directions appear equally distinct.

10. What usually becomes of the tear-water that drains off into the nose through the tear-duct? How are the frequent movements of the eyelids caused? What is meant by saying that these movements are commonly "involuntary?"

11. What are common defects in the eyeball' as an optical instrument?

12. What is generally true of the eyesight when it is once harmed by reckless or ignorant use of the eyes? Explain the purpose of the ciliary (sil'e-ar-e) muscles. State how they become weakened, and how this may be avoided without disuse of the eyes. 


\section{HEAT IN RELATION TO THE HUMAN BODY}

\section{Combustion}

For a complete understanding of the changes known as combustion one must study Chemistry. Combustion commonly means oxidation, i.e., union with oxygen $(\mathrm{O})$, accompanied by noticeable heat and light as result of the chemical change. Coal is largely carbon (C), and when it burns (oxidizes) one of the products is a gas known as a carbon dioxide whose chemical formula is $\mathrm{CO}_{2}$. When the gas hydrogen $(\mathrm{H})$ is burned, the product is water $\left(\mathrm{H}_{2} \mathrm{O}\right)$. Paraffine, tallow, wood, kerosene, and many other substances used for fuel and lights, contain carbon and hydrogen in their chemical composition. When burned they yield both water and carbon dioxide as the principal products of their combustion. Oxygen exists free in the air mixed with about four times its volume of nitrogen.

Oxygen as an element in water is so much heavier than hydrogen that eight-ninths by weight of all water is oxygen. It is calculated that oxygen constitutes about one-half the weight of the chemical compounds forming the rocks of the earth's crust.

One of the most important teachings of chemistry is that the same substance is always made up of the same chemical elements, and that these are always united in the same proportions by weight. The compound known as water has the 
formula $\mathrm{H}_{2} \mathrm{O}$ whether it is a liquid, or a solid such as ice and snow and frost, or the invisible vapor present at all times in the air about us. The relative weights of oxygen and hydrogen in it remain unchanged.

When coal burns with a limited supply of oxygen a poisonous gas called carbon monoxide ( $\mathrm{CO}$ ) forms. In the presence of more oxygen this gas burns with a bluish flame forming carbon dioxide. This flame is often seen above a coal fire. The illuminating gas furnished in towns and cities for fuel and lights contains more or less carbon monoxide, and any leakage of gas from burners or from stoves is dangerous because of its poisonous effects as well as its explosive nature when mixed with air.

Oxidation may go on very slowly wherever uncombined oxygen comes in contact with substances with which oxygen unites readily. This slow combustion occurs within water, and it goes on in the cells of the body. The heat liberated in the various tissues ordinarily maintains a temperature of the human body above that of the surrounding atmosphere. In some animals like the turtle and the snake this oxidation is so slow that they always feel cold when handled because their body temperature is less than that of human beings.

In the rusting of such metals as iron, oxidation takes place very slowly; in the explosive mixture of gasoline vapor or of illuminating gas with air, it may be instant and violent. Many of the high explosives used in blasting have in their composition sufficient oxygen to make it possible for combustion to occur away from the air.

The temperature to which bodies like kerosene, wood, and coal must be brought in order that combustion may occur is called the kindling temperature, or point of ignition.

A flame is a burning gas or vapor. A candle flame ceases to exist at its outer surface where combustion is complete. 
On the inside the flame begins where the kindling temperature of the supply of gas or vapor has been reached, and where oxygen is available for combustion. The candle flame has the form of a hollow cone, enclosing a cone of vapor that is not burning. The blowpipe flame is hot because the same amount of combustion occurs within a smaller space.

The color of different lights is largely due to the kind of material that is incandescent (light giving), and to the temperatures to which this material is heated. In the common electric bulb there is no combustion, the bulb having no oxygen inside of it. The temperature of the filaments caused by the electric current is sufficiently high to produce incandescence.

\section{SUMMARY}

The term combustion in opular usage means a case of oxidation where the heat liberated causes burning material to become so hot as to give off light.

The products of oxidation are known as oxides. They may be gases as carbon dioxide, or liquids as water, or solids as iron rust.

A flame is a gas or vapor that is burning. The combustion may be slow and under control, or it may be instant and explosive in violence. The size of a flame is determined by the distance outward to which the mixture of the gaseous material with air extends.

In a candle flame the inner dark cone consist of vapor not burning because of lack of oxygen, and because its temperature is below the point for ignition. The hollow luminous cone is burning vapor, the outermost limits of,which are almost colorless by reason of an almost completed combustion.

Carbon dioxide gas from the air is used by plants in the manufacture of such materials as sugar, starch, and wood fibre. But it must not be overlooked that plants, like animals, must have a supply of oxygen to maintain their life, and to provide the energy necessary for their growth. The amount of carbon dioxide given off as a product of this plant breathing is, however, insignificant in comparison with the amount converted by the plant into wood, starch, and sugar. 


\section{Pure Air and Breathing ${ }^{1}$}

In order to keep warm and dry men require shelter from the weather. The occupations of many people keep them within doors the year around. As a matter of economy and of comfort during the winter season, dwellings and places of business are guarded against the entrance of the cold outer air. This shuts away the supply of oxygen essential to health. A single gas light exhausts the oxygen of a room and produces

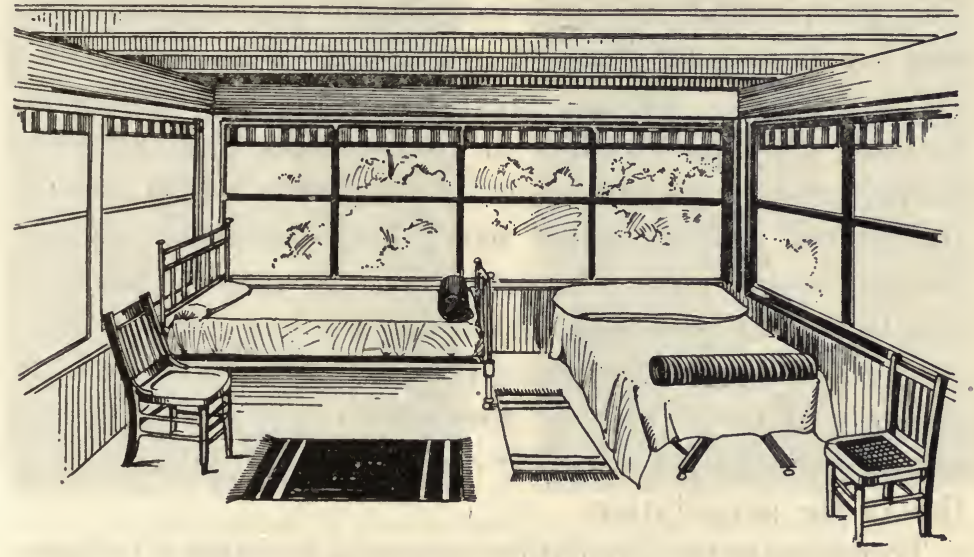

FIG. 7.-Sleeping porch, and sun parlor.

carbon dioxide as fast as the breathing of several persons. So far as need of air is concerned man is an out-of-door animal. The conditions of civilized life have shut him in so closely that health is often impaired, and life itself sometimes sacrificed.

About one-third of a person's life should be spent in. sleep. For sleep to be most refreshing and invigorating it should be in rooms or porches wide open to the out-of-doors air. Only

${ }^{1}$ Respiration as the term is used in biology involves the process of oxidation as it occurs in the cells. It is a function of living cells wherever located. On the other hand the term breathing is restricted to the exchange of gases within and without plants and animals, and is a purely physical process. 
extreme cold or dampness is excuse for sleeping temporarily shut away from an abundance of outside air. An open but well-screened sleeping porch, with a warm room to dress in when the weather is cold, makes quite an ideal condition.

During the day the ordinary activities of life render unnecessary any special attention to ventilation save where large numbers of people are together as in public halls, schools, and factories. In these places there is likelihood of oxygen starvation. The air, too, soon becomes laden with moisture from perspiration, and from water in the respired air. Disease germs may be given off into the air from any infected person present. All this makes necessary the continuous renewal of the indoors air. In cold weather air from out of doors should be warmed before it is allowed to spread through the rooms. There should never be appreciable currents (drafts) in any part of a room. The air should always be free from dust, too, and should contain considerable moisture, especially if it is furnace heated. A humidity of from 40 per cent to 50 per cent does not dry the mucous membranes of the air passages, nor does it interfere with evaporation of the perspiration.

To maintain the circulation necessary to bring a continuous supply of air into rooms, advantage is usually taken of the fact that air when heated becomes less dense (lighter). The air of a building may be kept in circulation by having one portion warmer than other parts of it. The colder and more dense air presses the warmer air onward and outward. The chapters on heat and pneumatics (nu-mat'-iks) in Physics usually include a study of air currents, and of systems of heating and of ventilating. The satisfactory ventilation of the many rooms in large buildings used for offices, stores, factories, or for schoolroom purposes, requires that air be forced into them or withdrawn from them by some mechanical means, such as fans driven by electricity. This 
air in some cases is made to pass through a room where in some one of various ways it is "washed" free of dust and other impurities, and given the desired amount of moisture. In winter it may then be warmed by passing it over steam coils before distribution in the building, and in summer it may be cooled by use of ice. Continuous stirring of air that is not changed in any other wày has been found to afford marked relief in ill-ventilated rooms. The movement of the
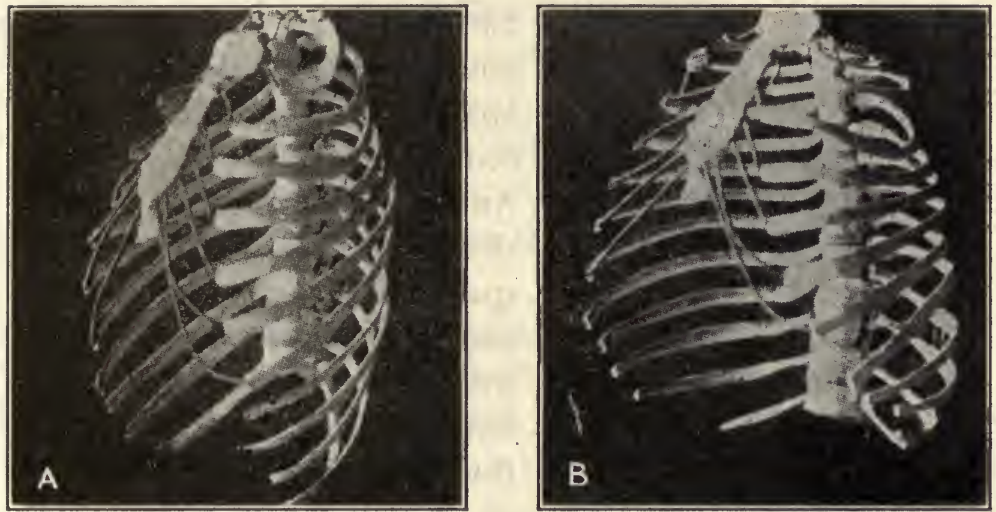

FIG. 8.-Framework of the chest walls. In $B$ the chest cavity has been cnlarged by the contraction of the muscular walls; and in $A$ decreased by the relaxation of these same muscles.

air lessens the discomfort and sense of depression occasioned by having warm moisture-laden air remain stagnant around a person.

Serving as a partition between the chest and abdominal cavities the diaphragm ( $\left.\mathrm{di}^{\prime}-\dot{\mathrm{a}}-\mathrm{frăm}\right)$ is attached at its circumference to the side walls of the chest. The framework of the chest is made up of the ribs, the spine, and the breast-bone. The muscular fibres of the diaphragm are so arranged that it is flattened downward when they contract, thus crowding the stomach, liver, and intestines outward and enlarging the chest cavity: Not least among the beneficial effects of deep 
breathing, involving as it does the full use of the diaphragm, is the rhythmic pressure exerted downward upon the stomach and liver. This promotes digestion, and tends to prevent constipation. Over the motions of this muscle which is so largely concerned in breathing a person has but slight and indirect control, making the action in large part involuntary.

The muscles of the side walls of the chest are, however, largely under control. By throwing back the shoulders,

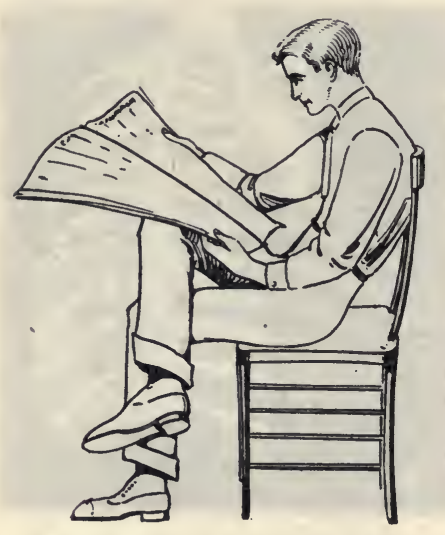

FIG. 9.-Wrong sitting position. The lungs cannot be fully inflated in breathing. and by causing the muscles between the ribs to contract and pull the ends of the lower ribs apart, the chest cavity can be considerably enlarged at will. An easy erect position, whether sitting or walking, gives larger space for the lungs than where one goes about stooped and with drooping shoulders. Persistent efforts to fully inflate the lungs in breathing is one of the ways of maintaining health. It is the unused portions of the lungs that are most likely to become diseased.

The lung capacity in use is about 200 cubic inches $(3200$ cc.). Only about one-eighth of this amount passes in and out at each breath ${ }^{1}$. The reserve supply of air not exhaled at every breath serves to prevent sudden changes of tempera-

${ }^{1}$ The following tabulation exhibits approximately the air volumes concerned in breathing:

Air passing in and out at each breath (Tidal Air)....... 20-30 cu. in. Additional air that can be but seldom is taken in (Comple-

mental Air).

I $20 \mathrm{cu}$. in.

Air that can be forced out after a full inspiration......... 150-250 cu. in. Air that cannot be driven out (Residual Air).......... $100 \mathrm{cu}$. in. 
ture in the lungs as cold air is inhaled, and to prevent death by suffocation when temporary stoppage of the air passages occurs.

Air may be rebreathed repeatedly and continue to furnish oxygen to maintain life. But it is to be remembered that exhaled air containing available oxygen may be unfit for use because of the carbon dioxide, water vapor, and waste organic matter in it. The air as inhaled commonly consists of about 2I per cent oxygen, 78 per cent nitrogen, I per cent argon, and 3/100 per cent carbon dioxide gas, along with a varialbe quantity of water vapor and dust particles. The exhaeld air is saturated with moisture, and has approximately I6 per cent oxygen and 5 per cent carbon dioxide, the argon and nitrogen gases remaining unchanged in amount. About one pint of water passes from the body daily as vapor in the breath.

The need of ventilation is often apparent to a person entering a schoolroom or public hall when those in the room are unaware of the bad condition of the air. Dullness, restlessness in body, headaches, inability to give continuous attention, and much of the feeling of irritation experienced by those shut up in schoolrooms oftentimes disappear after a few minutes of exercise indoors with windows wide open. It is to be remarked that cold air is not necessarily pure air, nor do rooms need ventilating because they are comfortably warm. Pure air, however, is no cure for late hours and insufficient sleep, or for lack of wholesome food and absence of other conditions essential to sound bodies and bright minds.

Artificial breathing in cases of drowning may, if necessary, be successfully maintained for a long period by laying the patient face down, the face turned to one side, and the mouth open to admit free passage of air to and from the lungs. Sitting astride the hips of the patient let some strong person 
alternately apply and then remove pressure upon the lungs through the walls of the chest. This may be accomplished by holding the hands against the lower ribs and throwing the

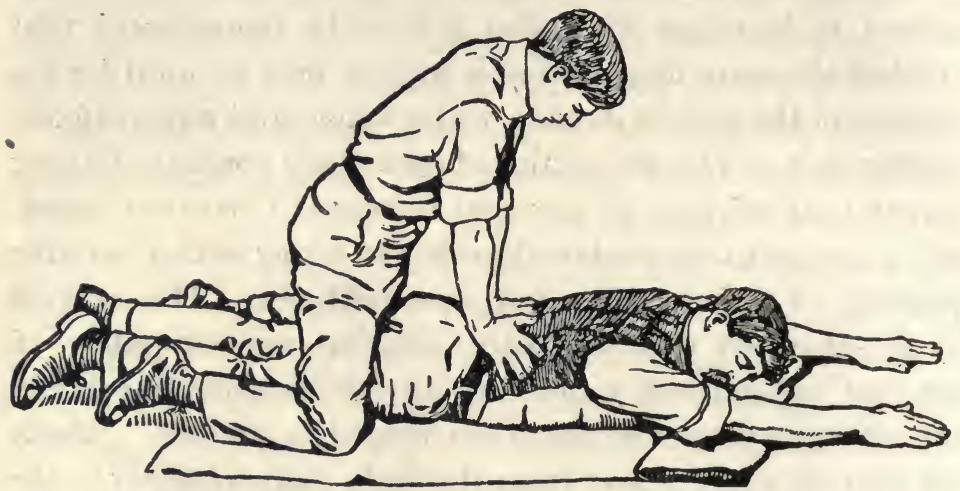

FIG. I0.-Resuscitation of the drowned-expiration in artificial breathing.

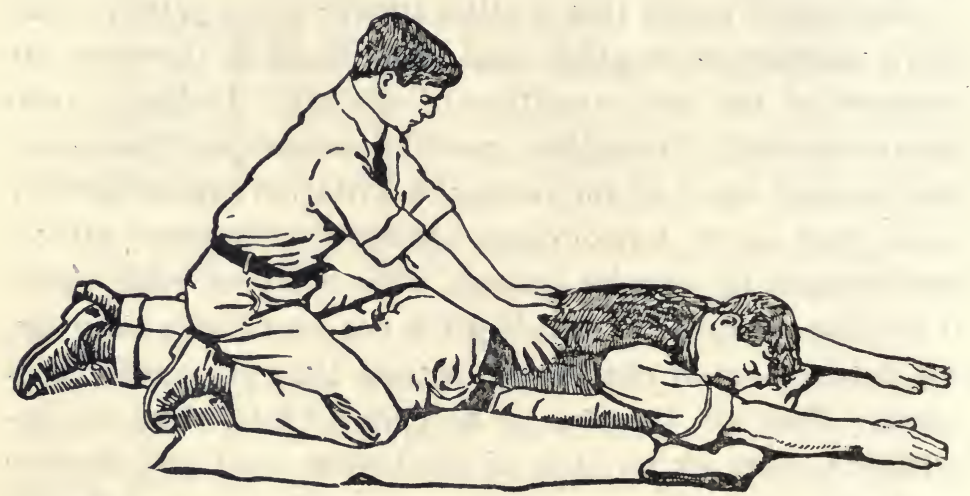

FIG. II.-Resuscitation of the drowned-inspiration in artificial breathing.

weight of the body first forward and then backward with about the same rhythm as in natural breathing.

\section{SUMMARY}

Ventilation seeks to secure an ample supply of oxygen for respiration, and at the same time to prevent the air about a person from becoming 
unduly laden with moisture, with carbon dioxide, and with organic matter thrown off from the body in the breath. A continuous renewal of the air in closed living rooms, offices, and assembly halls is necessary.

The problem of ventilation becomes a serious one only during weather when rooms are kept tightly closed on account of the cold. All unnecessary outlays for heating buildings must be avoided, and all drafts of cold air.

Particular attention should be given to securing an abundance of pure air during the hours of sleep. It is a relatively easy matter to provide sufficient bedding to protect against any danger of being chilled while asleep in a room open to out-of-doors air even in the coldest weather.

More serious than the dullness of mind and the weariness of body due to oxygen starvation when sleeping in poorly ventilated rooms is the lack of bodily vigor, and the lessened powers of resistance to germ diseases. This menace to health is the greater because the relationship is not always apparent, and because the ill consequences are often long delayed.

The development of tuberculosis in a person could often have been prevented by the same care that is exercised later in an effort to effect a cure through being 'much out-of-doors, and by having suitable employment, sufficient exercise, and nourishing food.

In the rhythmic rise and fall of the diaphragm nature has provided an important means of continuously stimulating muscular action in the digestive tract, and of preventing constipation.

Lung capacity varies much in different persons, and as a rule is considerably more in a man than in a woman. It is disuse of the lung capacity, however, that is the really serious consideration. Laziness in breathing should be overcome, but forced and intermittent efforts to do this accomplish but little. There should be enough of active daily exercise to cause a demand by the body for an increased supply of oxygen, thus necessitating deeper breathing.

The chances for life at times of choking or of drowning may depend upon the reserve air in the lungs. Everyone should know just how to proceed to resuscitate a drowned person.

The Human Body as an Engine, and the ReguLATION OF BODY TEMPERATURE

The fact that a person can do work and can move about presupposes the existence of energy by use of which these 
activities and labors are performed. Energy is often defined as that by use of which work is done. Any machine such as an engine, is only a means employed for using energy to do work. The human body comes under this definition, and this conception of the body includes brain activities as well as muscular effort.

The human body as a living organism possesses, however, the power of repairing itself under right conditions of liv-

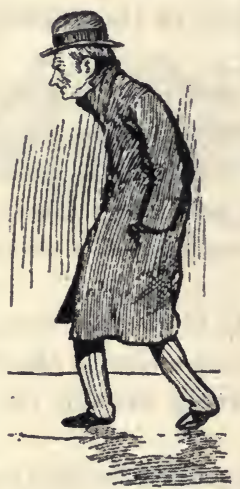

FIG. 12.-The body as a machine may break down rather than wear out. ing. If properly cared for, it should neither break down nor wear out till long past the allotted "three score years and ten." As with any other engine the character and quantity of work it can do depends in large measure upon the care it has, and the good judgment exercised in its use. Folly, ignorance, and inexperience all combine to impair its usefulness or to wreck it altogether. It is one of the purposes of schools to give instruction and training in the right uses of both body and mind. Success in living even as success in business requires the best use of all the means and machinery of life. It is necessary for the well-being of an individual that the bodily processes be under as intelligent control and as constant care as that exercised by an engineer with a locomotive, or by a chemist in laboratory experiments.

The body like the steam engine depends upon energy liberated within it by chemical changes. A considerable portion of this energy is used in keeping up the bodily processes. The activities of the heart, digestive organs, brain; and other organs require an expenditure of energy. Deficiency in its amount means imperfect performance or complete cessation in their activities. It is chiefly the starchy foods, 
sugars, and fats that are body fuels. On the other hand, oneseventh or more of the food needed by the body is required for rebuilding the various tissues. Foods that serve this special purpose are known as proteins. Starch, sugars, and fats are classed as carbohydrates. The energy from oxidation in the body maintains a temperature necessary for the various organs to perform their several functions (duties). The chemical products of this oxidation in the body, even as in the combustion of coal or oil, are largely carbon dioxide and water.

Most of the processes within the body are normally carried on without conscious effort. If it were necessary to give attention to every act in respiration, or to attend to what is now the involuntary action of the heart muscles, little else could be done. One might forget to breathe, or to keep the heart beating regularly. Freed from the necessity of directing the bodily mechanism, the mind can be employed in directing the expenditure of the excess energy of the body in those physical and mental efforts involved in earning a livelihood or in promoting culture, health, and happiness.

The living matter contained in the cells of the different body tissues cannot endure any considerable change in temperature without harm to it and possible destruction of its life. One of the functions of the skin through secretion of perspiration is to regulate the body temperature so that in health it varies but little summer or winter, regardless of whether one is indoors or out. As the perspiration evaporates from the surface of the body heat is required to vaporize the water. This heat is provided in part from the body, and the more profuse the perspiration and the more complete its vaporization, the larger is the amount of heat taken from the body. The higher the body temperature as result of muscular exercise the more active is the secretion of perspiration by the glands in the skin. It is nature's provision that 
the more heat there is in the body the more there is disposed of in this way; the lower the body temperature, the less active is the secretion of perspiration and the less the loss of heat with it.

Since the temperature of the body is commonly higher than that of the surrounding atmosphere, there is also a loss of heat direct to the air from the warm body just as in the cooling of any other heated object. By use of suitable clothing protection may be had from the dangers incident to chilling the body surface, and depriving the skin of its blood supply. If one gets chilled the internal organs become congested (overfilled) with blood that should have been distributed to the surface and extremities of the body. The regulation of body temperature by the skin is interfered with, and the disordered condition of the body known as a "cold" may result. Oftentimes this develops into dangerous ailments such as pneumonia, or into an inflamed state of organs other than the lungs.

Exposure at the throat and upper part of chest is especially dangerous when the lungs are themselves filled with cold air. There should be especial attention given to the circulation of blood in the extremities of the body. The feet and hands should be warm at all times. Wet or damp clothing not only wastes body heat by vaporization of the moisture, but clothing when damp conducts heat from the body much faster than when dry. After a bath the body should be vigorously rubbed with a dry towel till its surface is completely dry. This avoids any chill due to abstraction of heat from the body as water on the skin vaporizes. The rubbing should result in a redness of the skin. A feeling of warmth, together with a "glow" of the skin, follows an increase in the amount of blood sent to the body surface as result of the irritation produced by the rubbing. The chill experienced when leaving over-heated rooms, or crowded 
assembly halls with their moisture-laden air, may be due in part to the evaporation of perspiration from the clothing.

\section{SumMary}

The human body as an instrument for doing work may very properly be considered a machine. Its care in order to secure the largest service from it requires a degree of intelligence surpassing that needed generally in the management of machinery. Conditions must be maintained favorable to its repair through growth. Undue destruction of its parts by excessive or improper use must be avoided. Proper balance must be maintained between its waste and repair.

Any impairment of the powers of the body is a serious handicap throughout life. The harm due to ignorance is just as serious as though done by deliberate choice. Much of the ill-health of later life, and many of the limitations of the body in its usefulness as a machine, are often directly traceable to an unwise manner of living during childhood and youth.

All motion occurring in the body in the performance of work involves an expenditure of energy. All the activities of digestion, respiration, and circulation, together with those of the brain and nervous system as a whole, require a supply of energy without which the bodily processes would cease.

The temperature of the body is maintained by chemical changes within the body known as oxidation. Any considerable departure from a normal temperature of $98^{\circ} \mathrm{F}$. makes impossible, too, a continuance of the bodily processes, and death results.

One of the chief functions of the skin is the regulation of body temperature by disposing of any excess of bodily heat in the vaporization of perspiration. When by reason of old age, wasting disease, impaired digestion or assimilation, the temperature of the body runs much below normal, extra clothing must be worn and warmth from without the body must be provided.

Colds may result from a bodily state of depression due to fatigue. At such times germs lodged in the lungs and nasal passages are given opportunity for rapid development because of the lessened powers of resistance of the body. Colds may be the result of a congested and inflamed condition of the nasal passages, stomach, intestines, or kidneys, due to an excessive blood supply sent to them at a time when the surface of the body is thoroughly chilled. Whatever promotes an 
active circulation of the blood in all parts of the body, and whatever contributes to the general good health, aids in the prevention of colds.

\section{Exercises}

1. To what is the color of candle and lamp flames largely due? What is the nature of the "smoke" from chimneys?

2. What significance has the presence of carbon dioxide gas in the breath?

3. In ventilating rooms and buildings, what special attention must be given (a) to economic considerations; $(b)$ to danger to health?

4. What is meant by a flame? Why is there greater danger of accident in the use of gasoline than of kerosene?

5. State some ways of showing that the interior of a candle flame is not afire.

6. In which parts of plants is carbon dioxide gas changed chemically into material for plant structure and nourishment? What relation to this change has sunlight?

7. Why is there need to give less attention ordinarily to the ventilation of living rooms by day than by night? Why is there need of more attention in winter than in summer?

8. In tuberculosis of the lungs what at present is the only hopeful course of treatment? When only is this successful? What conditions in living are conducive to this ailment?

9. About what on an average is (a) the rate of respiration; (b) the capacity of the lungs; $(c)$ the per cent of the lung capacity employed at a breath?

10. What advantages $(a)$ in the gradual change of the air in the lungs; $(b)$ in the retention in them at all times of considerable air?

11. What good purpose is served by habitual deep breathing? What are the ill effects from habitually failing to inflate the lungs fully at every breath?

12. Describe the steps to be taken for the resuscitation of a drowned person. Give the reason for each step.

13. What is the apparent relation between vigorous exercise whether as work or play, rapidity of breathing and of heart action, and the temperature of the body?

14. In what sense does perspiration "regulate" the temperature of the body?

15. What is the meaning of the terms $(a)$ congestion; $(b)$ inflammation?

16. Why is there risk to one's health from damp feet or clothing when not exercising?

17. What relation apparently exists between temperature maintained in the body and the continuance of life activities? Explain this.

18. What is the purpose $(a)$ of the digestion of food; $(b)$ of the oxidation of portions of it? 


\section{HEALTH AND WELL-BEING}

\section{KEEPING WELL}

Our control over our health is much like that exercised by gardeners and florists over the growth of their plants. Neglect or improper care is ruinous in either case. Health and disease are essentially conditions of the cells of the body, and of the fluids about the cells. Our mastery of health lies in maintaining the right conditions.

A knowledge of "nature's laws" is of little purpose unless our manner of life is made to accord with them. Our unwillingness to do what must be done in order to promote and to maintain health will not protect us from the consequences of not working in harmony with nature's ways. ' That people who have reached manhood and womanhood in a vigorous state of health do not maintain their health and efficiency to eighty years and upward is due generally to wrong ways in living. Many of the diseases proving fatal to men and women in the prime of life could have been prevented if these persons had been examined periodically by a competent physician, and had followed his advice as to diet, sleep, and exercise.

Through the nervous system all activities of the body are directed and harmonized. Good health is impossible when the cells of the nervous system are exhausted. It is to be remembered, too, that the bodily energy is limited in quantity, and that what is expended in physical exercise is not available for mental effort. Undue expenditures for either or both of these may rob the organs of the body of the energy necessary for their activities. On an average two hours a 
day or more of suitable exercise is a minimum requisite for attaining and maintaining a high state of bodily health and vigor. Continued neglect of exercise is likely to result in an unhealthful state of the body, and a diminished efficiency. Physical exercise should be as congenial to persons living a normal life as play is to children. Persons suffering from inability to sleep often find in manual labor, in long walks before going to bed, and in active sports, a degree of physical exhaustion that is conducive to sleep.

To one who is at all thoughtful it is a marvel how lightly many people regard health, and the freedom and happiness that depend upon it. To be well born, and to have the conditions favorable for making the most of one's life, may be considered an inalienable right. To forfeit good health and well-being through lack of enlightenment, or of self control, does not lessen the irreparable loss sustained when strength and vigor have been thrown away, and life's opportunities that wait upon these have been wasted.

Sickness usually causes more or less of pain, and life itself is often put in jeopardy. A sick person in seeking to regain health must forego the usual activities of life, and be subject to losses through inability to earn and as expenditures incident to sickness. Sickness imposes more or less of a burden upon those who are called upon to care for the patient during his illness. Many times ailments supposed to have been "inherited" are but the results of the same manner of home life that caused impaired health in the parents. At any rate it is a great mistake ever to cease making intelligent efforts so to regulate one's manner of life as to overcome by hygienic living all defects and weaknesses whether inherited or not.

Disease and serious illness ought to be the exception rather than a common condition. In adults it is often an evidence of a failure to apply ordinary intelligence to the care of the 
health. To strive to maintain the highest state of health and efficiency in life is not only a wise course, but it is due recognition of an obligation to the interests of those in one's own family and in the community.

Any excessive irritation of a nerve, whether by causes within the body or outside of it, results in pain. The mind locates the cause of the trouble in that part of the body where the particular nerve affected is distributed. Pain in any part of the body may be considered as nature's warning of something wrong there, and a call of distress from that part. Without the nerve to give this warning, the mind would have no knowledge of the danger.

But so interlaced are the various nerve terminals, and so slowly is the power of interpreting sensations acquired, that oftentimes the one who is suffering may be entirely wrong as to the place and cause of the ailment. Even the trained and experienced physician is at times baffled in his attempts to diagnose a case correctly. Any intelligent treatment of one who is ill is out of question until the cause of the ailment is known. The skilled physician seeks to restore conditions in the body of the patient favorable for those bodily processes necessary to health.

A watch, however perfect it may be in its workmanship, is of little value as a time-piece when any one of its train of wheels is improperly adjusted and does not move harmoniously with the others. No one part of the body can fail in performing its function (its particular work) without harm to the body as a whole. These failures may result from causes external to the body. A cinder "in the eye," a bit of food lodged in the larynx, an infected sliver under the finger nail, may cause derangements in the workings of the body as a machine even as a bit of dust when in the wheel-work of a watch. Medicines are given as an aid in restoring natural conditions in the body. In cases where 
the suffering is extreme remedies may be administered solely to ease pain and conserve the strength of the patient.

In all muscular tissues the arteries, veins, and capillaries blende in a perfect network of blood vessels. Through them the blood must be kept moving in its round of circulation so that the tissues may be properly nourished. The blood is being continuously purified as it

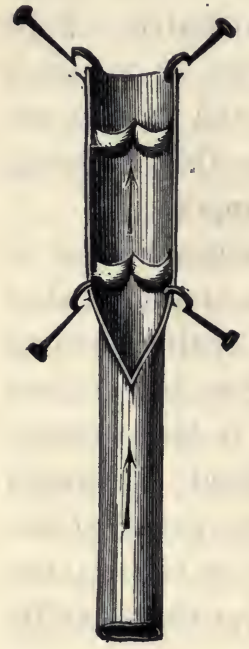

Fig. 13.-Pocketlike folds in the lining of veins serve as valves to prevent in part any backward flow of blood. (Bundy.) passes through the lungs and kidneys and other excretory organs. In the veins there is especial need to urge the blood on in order to lighten the -effort put forth by the heart in forcing along a sluggish circulation. The "blood pressure" which the heart must maintain to keep the flow of blood sufficiently rapid may overwork and weaken it. There is a constant menace of rupturing the walls of the arteries or other blood vessels under any abnormal pressure.

In the veins the lining in places is so arranged in folds as to form pockets. These allow the venous blood to pass on toward the heart freely enough, but any backward flow is prevented as the veins are compressed by muscular contractions. Thus it is that muscular activities result in a better circulation. This brings more nourishment to the muscles themselves, and maintains a better state of the whole body.

In a rush of blood to an affected part of the body to protect it from harm, and to repair any damage already done, there is occasionally a congested state of the blood vessels of that particular part. This is seen in the blood-shot appearance of the eyeball, and the feverish condition of 
the tissues about it, when a bit of dirt gets under the eyelid. One of the means commonly employed to determine whether the body as a whole is in a disturbed and unnatural state is by "taking the temperature" of the body. Any considerable departure of the body temperature from normal is cause for concern. Usually, if the temperature is approximately normal, any illness experienced is likely to prove a. temporary rather than a serious disturbance of the bodily functions.

The small tube of the clinical (klı̌n'-î-kăl) thermometer used by physicians is very much narrowed and almost closed just above the bulb. The mercury in the bulb when warmed is crowded up through this narrow opening, and can be made to return only by jarring the tube. Since the mercury reading is always the highest point (temperature) reached, the instrument is one form of a maximum thermometer.

\section{SUMMARY}

Sickness and health are conditions of the body. To regain health after having been sick necessitates the restoration of the bodily conditions upon which health depends. Medicines are only an aid in bringing this about. The bodily processes alone can restore impaired health.

Pain is nature's warning that something is wrong in the affected part of the body, and it may be considered a call not only of distress but for relief. In the body as in the care of machinery inattention to parts out of adjustment may ruin the mechanism. The removal of the cause of an ailment constitutes the only hope of keeping the body well and fit to do its work. No intelligent treatment of one who is ill is possible without knowledge of the cause of the illness.

Good health should be the rule, and sickness the exception, in well regulated living. Intelligent efforts to avoid whatever harms the body, and wisely to direct one's manner of living, is ordinarily the price that must be paid for good health and long life.

There are times when the harm from use of medicines to deaden pain and give relief from suffering is less than the exhaustion from enduring the pain. It should be fully understood, however, that such relief is temporary, and is not in any sense a cure of the ailment. So 
dangerous are the drugs used for the relief of pain, and so ruinous their long continued use, that under no conditions are they to be employed save by direction of a physician.

Exercise is indispensable to the maintenance of health and the development of the body. In order to be healthy all organs must be kept active. This is as true of the brain as of other parts of the body. Labor is the price for developing and maintaining a state of health. Work becomes a curse only when its demands on time and strength are excessive, and when one is a slave to it rather than its master.

\section{INFECTION}

Bacteriology, or the study of microscopic forms of life, is a new science. The story of its discoveries, and of the benefits which already have come to mankind through it, is as fascinating as fiction. Much of the present day knowledge of the effects of living organ:sms of microscopic size, whether one-celled animals known as protozoa or onecelled plants known as bacteria (see page 324 ), dates from the researches of Louis Pasteur (1822-I895).

In I 857 the discovery was made by Pasteur (pas'-tûr) that fermentation is due to the action of bacteria. In I 886 he was successful in his efforts to destroy the bacteria infesting the silk worms of France and Italy and threatening the destruction of the silk industry there. But it was when he turned his attention to the study of the causes of those diseases transmitted from one animal to another that the field of medical bacteriology was opened up.

Some of his first experiments were with chickens affected by cholera, and later with cattle having splenic (splěn'-1̌k) fever. He was able so to reduce the poisonous effects of a virus (poison) containing the germs of a disease that when it was administered to a healthy animal only a mild form of the disease resulted, and the animal became for a time immune to that disease. Here was the beginning of the use 
of serums and antitoxins, and an explanation of the immunity from small pox by vaccination advocated by Dr. Edward Jenner (I749-1823) and practised more or less since 1796 .

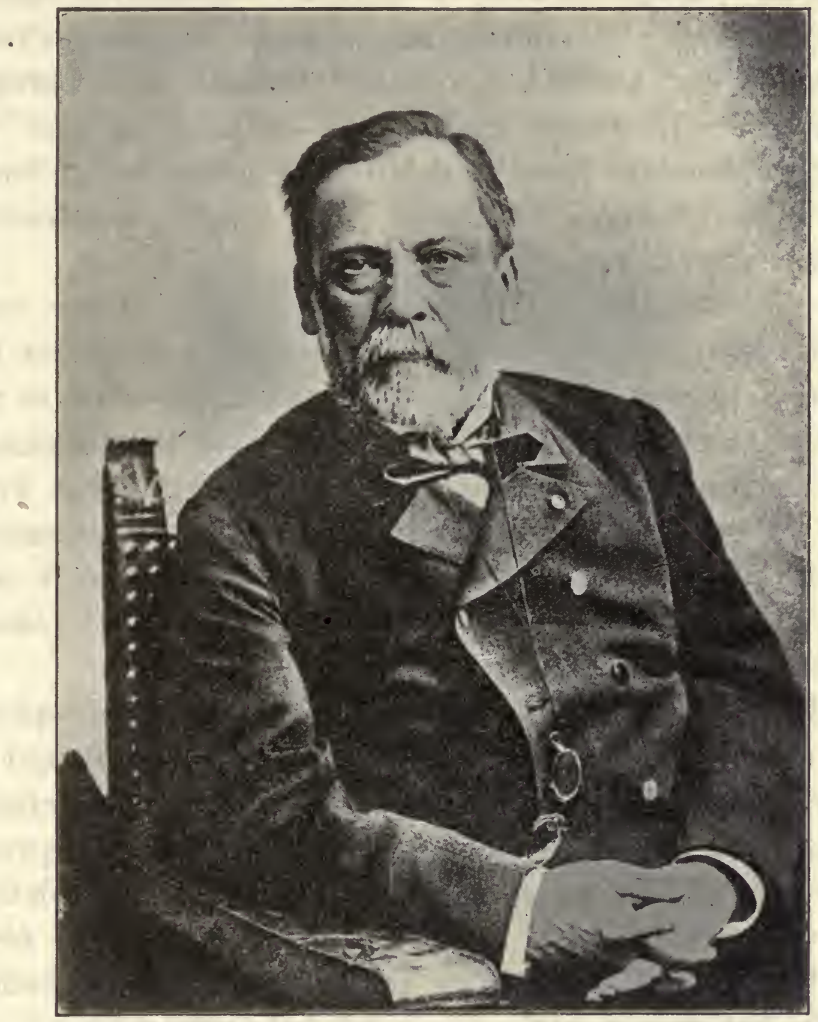

Fig. I4.-Louis Pasteur. (From Tower, Smith \& Turlon.)

Notable progress has been made in the prevention of typhoid by vaccination. It already seems probable that like small pox it is one of the dread diseases that will always be under control, and in time largely disappear. The vaccine material used contains dead typhoid germs that have been grown outside the body and then killed. Usually 
three injections are given ten days apart, and as a rule no interference with one's daily duties is experienced from the vaccination. Cases of typhoid are already rare occurrences in military camps because of enforced vaccination, and a strict observance of sanitary regulations. Discharges from the bowels and kidneys of typhoid patients should always be treated with a strong solution of "chloride of lime" for twenty minutes or more to destroy the germs before being thrown into cesspool or sewer. The danger of spreading the disease is thus greatly lessened.

An understanding of the nature of many of the most terrible germ diseases that afflict humanity is one of the notable achievements of the years just at the close of the nineteenth century and at the beginning of the twentieth. There is reason to believe that the time may come when their ravages will cease to be the scourge of humanity. Preventive measures combined with medical skill and enforced sanitation have already accomplished much toward this end.

Malaria, the sleeping sickness of Africa, and splenic fever in cattle are due to protozoa. The list attributed to bacteria includes typhoid, tuberculosis, pneumonia, tetanus (lockjaw), meningitis, influenza (grippe), diphtheria, leprosy, cholera, and bubonic plague. Measles, hydrophobia, scarlet fever, small pox, whooping-cough, and yellow fever are other infectious diseases not so positively classified. To this list may doubtless be added the dread diseases of cancer and infantile paralysis.

Many of the so-called "children's diseases," such as measles, scarlet fever, and whooping-cough, are not only to be avoided but should be regarded as highly dangerous. This is chiefly on account of possible complications with other diseases, and because of a train of serious lifelong ailments that follow them, such as weakened eyes, affected 
ears, and a condition of throat and lungs that makes them highly susceptible to germ diseases.

The extended use of antiseptics to prevent infection of wounds, is associated with the name of one of Pasteur's pupils, Sir Joseph Lister (I827-I9I2), the famous English surgeon. The Pasteur Institute in Paris, and others of its kind elsewhere in the world, have been established for the purpose of giving treatment for rabies based on the discoveries of Pasteur concerning hydrophobia (I885). In-

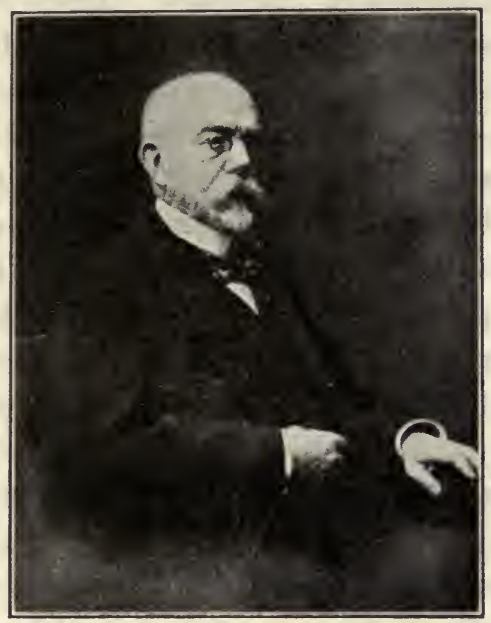

FIG. I5.-Robert Koch.

1882 the German scientist Robert Koch (kōk) discovered the germ of tuberculosis, and in $\mathrm{I}_{88}$ the germ of Asiatic cholera. Von Behring, a German bacteriologist, discovered an antitoxin for diphtheria in 1892 .

It was during the occupation of Cuba by the forces of the United States (1900) that the part played in the spread of yellow fever by one kind of mosquito (Stěg-ō'-mı̆-à) was definitely established. By reason of the preventive measures taken, that scourge of the Tropics was soon almost com- 
pletely eliminated from the death lists of Havana. So marked has the control of germ diseases become in the present generation that during the building of the Panama Canal (completed in I9I4) the health record there under American management was better than in many cities of the United States. Under French management of the canal in the earlier years, and likewise when the Panama Railroad was built, the death lists numbered thousands ${ }^{1}$.

Bacteria and protozoa that exist in or upon living plants or animals are known as parasites. Those that live upon dead or decaying organic matter are called saprophites (săp'rō-fìts). As result of the growth and multiplication of these micro-organisms the tissues upon which they feed are broken down. In the human system the waste products of their activities seem to act as poisons (toxins), destroying the protoplasm of the cells. The expenditure of bodily energy on the part of living tissues in a battle against these destructive agencies, and in the elimination of the excessive wastes of the body, is indicated in a fevered state of the patient.

The body after having become infected seems to have the power to produce products known as antitoxins. These either neutralize the effects of the toxins, or stop the multiplication of the disease germs, or both. If these antitoxins are produced rapidly enough after a person is infected, and in sufficient quantity, the patient recovers even from the most severe attacks; if not, he is likely to die. At times a patient surviving the cycle of life changes of the first of the germs has a "relapse," and a recurrence of the disease but with the original symptoms less pronounced.

1 The annual death rate of employees of the French company (1882-1890) was reported to be 23I per thousand. Under the later American control, when the agency of mosquitoes in yellow fever and malaria had become known, the death rate was reduced to 77 per thousand. There were no cases of yellow fever from rgo6 to I9ri. 
Though at such times in a much weakened state by reason of the period of sickness that has preceded, the patient may recover. The poisonous waste products of bacteria in the putrefaction of foods are known as ptomaines (tó-mā-ĭnz).

The efficacy of serums as prepared from the blood of animals known to have had an infectious disease seems to lie in the fact that such blood contains antitoxins of the disease. A person inoculated with this serum is thus furnished protection against toxins developed in his own system by the multiplication of germs. Serious illness or death is thus prevented during the time needed for his own body to produce the antitoxins in sufficient quantity.

The toxins left in the blood by a disease often prove harmful to organs that have, not been infected, and death may result from it indirectly as in case of heart failure following pneumonia.

Children often have diphtheria germs in the throat for some considerable time after their recovery from the disease. They may spread the diphtheria if allowed to return to school before a microscopic examination of discharges from the throat by a physician has shown it free of the germs. The diphtheria serum, first prepared by Von Behring, is from the blood of a horse. It contains the antitoxins of diphtheria developed in the animal during a prolonged period of infection. When diphtheria antitoxin is used at the first symptoms of the disease few deaths occur, while otherwise it is often fatal.

The simple direction that the fingers and objects generally must not be put into the mouth should be insisted upon with children after the period of infancy till its observance has become habitual. The hands should always be washed before eating as a protection against infection as well as for personal cleanliness. Fruits such as apples, peaches, grapes, berries, etc.,. and all garden stuff that is eaten uncooked, such as 
celery and cabbage, should be washed until any danger of disease germs from the soil, the air, or from dust is unlikely.

It seems wholly reasonable to believe the statements that more than one-half the sickness, and of the wretchedness caused by sickness, is produced by disease germs. Much of this terrible waste can be avoided by enlightened action on the part of individuals and communities. Many of the worst diseases that afflict mankind would speedily be brought

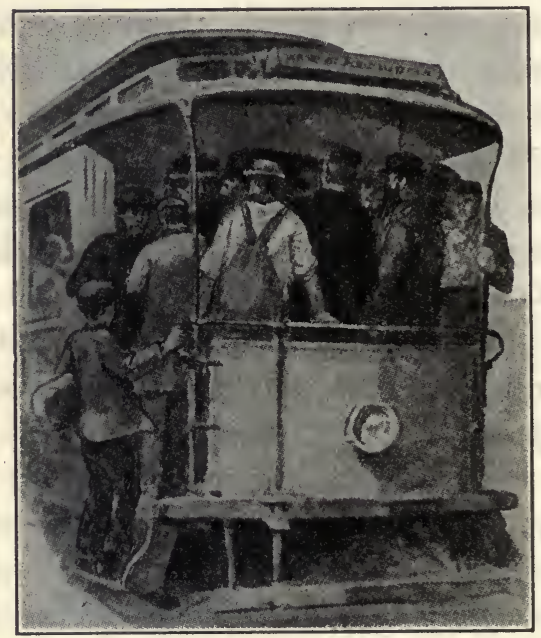

FIG. I6.-Danger of infection. Why not walk?

under control, and perhaps would disappear, if the scattering of disease germs through carelessness and ignorance could be prevented. It is to be remembered always that disease germs come from sick people or sick animals, and that to prevent the dissemination of these germs is to wipe out the disease.

Instruction in schools has an important part in this warfare upon disease. Attention to one's own health as result of studies in hygiene, and care given the health 
conditions of a community through wise sanitary regulations, are matters of utmost importance. However, even the healthiest person has times of physical weariness, depression, and weakness. At such times germs already within the body may get beyond control.

Physicians are required by law to report at once to the Board of Health all cases of contagious disease. The place where any such disease exists is at once quarantined. A placard is posted giving warning of the disease, and forbidding persons to enter or leave the building. Germs of many diseases may be carried on the person or in the clothing of those who have come in contact with an infected person. All members of a family where there is a contagious disease must be made either to remain at home or to keep away from home in order to lessen the likelihood of the spread of the disease.

The quarantine period varies according to the length of time within which serious danger of infection exists. Before the quarantine of a room or building is removed it must be thoroughly disinfected under the direction of the Board of Health. It is the duty of every person faithfully to obey the quarantine regulations, however irksome these may seem, because of the need to safeguard the health and the lives of others.

Ships coming into harbor are often held in quarantine when cases of contagious disease have occurred during the voyage, and neither people nor cargo allowed to land till properly disinfected. A quarantine is at times placed upon cattle and horses within certain districts where contagious diseases affecting them have become epidemic.

The use of formalin (formaldehyde gas in solution) proves a satisfactory disinfectant for rooms and buildings. The furniture should be left in the room, and the bedding, rugs, and all clothing should be so spread out and hung up that 
the disinfecting gas can get into every part of them. All cracks and openings of the room should be stopped gas tight. About a pint of the 40 per cent solution serves for a room of ordinary size, and the room should be kept tightly closed for twenty-four hours. Where sulphur is left burning in the closed room there is always more or less danger of

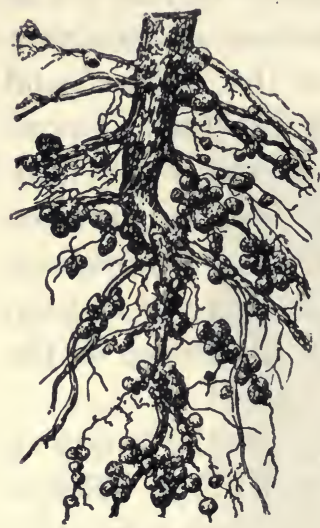

FIG. I 7.-The homes of "nitrogen - fixing" bacteria. (Conn.) fire, and the disinfection from sulphur alone is less satisfactory.

It needs to be emphasized that most kinds of bacteria are harmless to man, and many kinds are of the greatest importance to his well-being. On the roots of such plants as peas, beans, clover, and alfalfa, certain bacteria thrive that have the power to abstract nitrogen from the atmosphere and convert it into compounds. 'These nitrogen compounds later serve as plant food, thus increasing the fertility of the soil. Other bacteria give to butter and cheese their appetizing tastes and odors. By the multiplication of certain bacteria in sewage it is rendered harmless. If it were not for the action of bacteria concerned in the decay of organic matter, the collection of refuse material in thickly settled sections would constitute an ever growing problem. Carbon taken from the carbon dioxide of the air, and nitrogen from soluble material as plant food in the soil, would thus, rapidly become accumulated in dead organic bodies, and be unavailable for plant growth.

\section{SUMmaRY}

With the use of the term infection is associated the idea of disease transmitted by germs. These germs are microscopic one-celled plants known as bacteria, or are one-celled animals known as protozoa. In 
both cases they are parasites, and they are destructive of the tissues in which they lodge and multiply.

As the germs live and multiply they also produce substances known as toxins which have the effect of poisons upon the body as a whole. The human body when infected seems to have the power of forming other substances known as antitoxins which counteract the effects of the toxins. If these are in sufficient quantity in the body they lessen the severity of the illness or wholly prevent its development.

Blood withdrawn from an animal which has had an infectious disease, such as diphtheria, is supposed to contain in its watery part, or serum, antitoxins developed in the animal. This serum introduced into the blood of a human being counteracts the poisonous effects of the germ life without waiting for the slow development of antitoxins in the body of the one who is ill.

Hope of controlling infectious diseases, if not of their eradication, lies in the prevention of the scattering of the germs developed in infected persons. This involves the isolation by quarantine or otherwise of any one sick with an infectious disease. It is equally important that all discharges from the body of the patient, and all infected clothing and other articles, shall be disinfected thoroughly by use of chemicals, by sterilization, or by fumigation. The discharges from bowels and kidneys especially should be treated with a strong solution of hypochlorite ("chloride") of lime before being thrown into sewer or cesspool.

Danger of infection through foodstuffs is almost wholly removed by thorough cooking. In the laundry clothing should be boiled for fifteen or twenty minutes. Raw vegetables and fruits, and milk not pasteurized, are always possible means of infection. One argument for the use of hot drinks rather than cold water lies in the use of water that has been boiled.

\section{SANITATION}

Providing the food-supply for a family to-day in the United States is a very different matter from what it was a half century ago. Then the vegetables, fruits, and meats, together with the products of poultry yard and dairy, were home products for home consumption, or were bought direct from the producer. Home-grown animals were slaughtered at home. Some of the meat was used fresh, 
and other portions cured at home for later use by salting, pickling, smoking, and drying. Cellars and caves were piled with potatoes and other vegetables, together with apples and other orchard products. The rafters were hung with dried fruits, while pickles and preserves added variety in diet. Fresh eggs, with plenty of milk and poultry always at hand, made necessary but few food supplies from town.

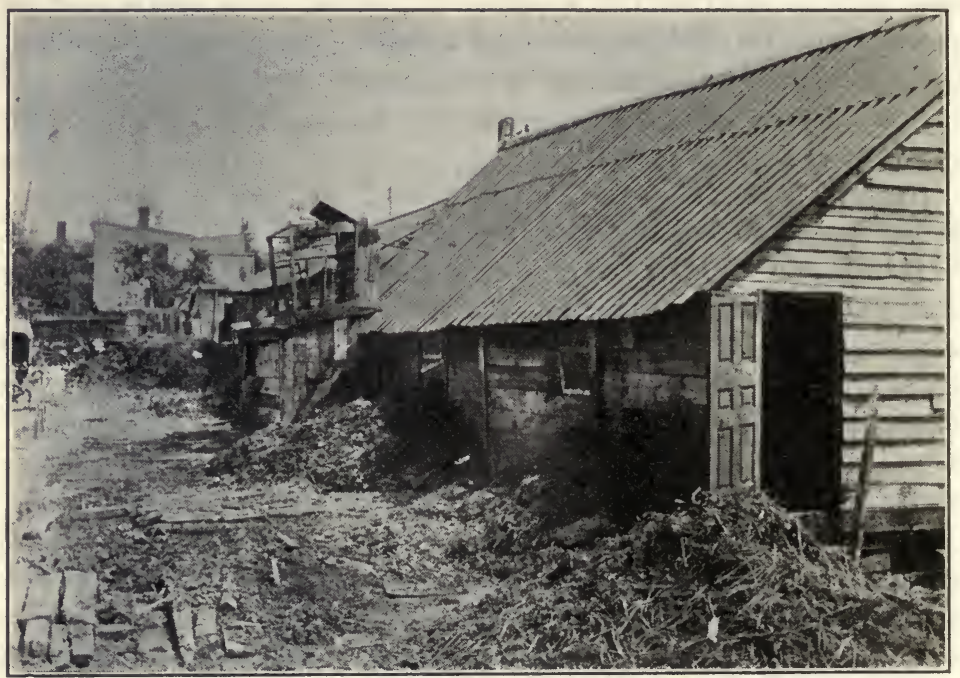

FIG. I 8.-Insanitary conditions here.

Not infrequently there was on hand enough food to last through the months of a winter season.

To-day the grocer, butcher, baker, and milkman furnish the family supplies as needed day by day. Who selects and prepares these foodstuffs, and whether or not it is done under sanitary conditions, is unknown to the purchaser. It thus becomes necessary as a matter of self-protection to enact stringent laws governing the preparation and the quality of the food supplies put on the market. Provision 
must be made for food inspectors as public officials to see to it that these laws and their penalties are enforced. An enlightened citizenship is necessary that these officials may have an active support and a hearty co-operation in law enforcement. Those desirous of carrying on business in an honest and law-abiding manner should not be compelled to meet the competition of those who by misbranding, adulteration, short weights, and other fraudulent practices seek unfair advantage at the expense of purchasers.

Preservatives are sometimes used in foodstuffs to prevent chemical changes caused by bacteria. Milk can then be kept a longer time from becoming sour, and meat from becoming tainted. Some preservatives are prohibited by law because it is believed they interfere with the chemical changes involved in the digestion of the preserved foods, or because they act injuriously upon the tissues of the body. Small amounts of preservatives are at times. used in foods put up in cans or other sealed containers when the food material as prepared for market is of an unwholesome or inferior character.

Bacteria multiply in summer much more rapidly than in winter. Fish must be kept continuously on ice in summer since it decays rapidly and soon becomes dangerous for use. Meat of all kinds, including fish, and poultry, and "shellfish," soon spoils when removed from cold storage or from cans. This is due to the rapid multiplication of bacteria in it. The refreezing of melted ice cream in which there are any poisonous secretions known as ptomaines, developed from bacteria while the cream was unfrozen, does not free it from its dangerous character however appetizing it is made to appear by use of flavors and coloring material. Poisonous products from bacteria increase rapidly in milk in summer time, causing wide spread illness and death among babies. Fresh milk and other fresh foods contain no pto- 
maines. Bacteria develop slowly or not at all at a low temperature, or in foods preserved in sugar, vinegar, salt, or by use of smoke. Meats and fruit products, such as catsup and sausage, left exposed for sale day after day without spoiling presumably contain chemicals that prevent multiplication of bacteria. These chemicals likewise make the foods less digestible if not positively harmful.

It is a part of the varied duties of Food Inspectors to see that no use is made of impure and unwholesome material in the preparation of foodstuffs, however attractive these may

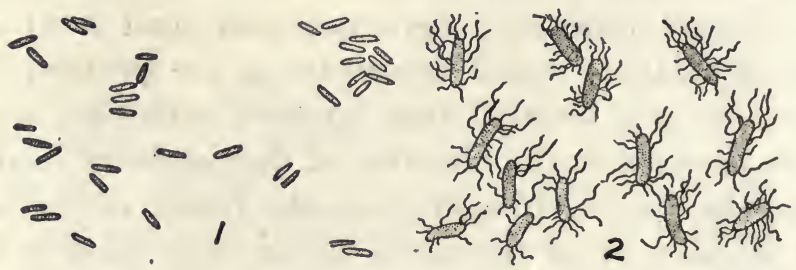

FIG. 19.-Typhoid fever germs highly magnified, and much more in 2 than in $\mathbf{I}$.

be made in appearance and price. The use of any cheaper quality of a substance, or of a cheaper substitute in the preparation of a staple foodstuff, constitutes an adulteration and is prohibited. Any dishonesty in sale of articles under a misleading brand or label is in violation of law. The general principle involved is that while the purchaser has the right to buy whatever he pleases, providing it is not an open menace to health, he needs protection in getting what he pays for so far as its nature, quality, and quantity are concerned. The various States by laws of their own, and in co-operation with the national government through its interstate commerce legislation, seek to prevent wholesale impairment of the health of the nation through its food supply. Upon a rigid enforcement of pure food legislation, and upon the skill of those who make chemical analyses of 
foodstuffs sold in the open market, the public must depend for a large measure of its protection against loss in efficiency and shortened lives due to unfit substances in the foods purchased. As a bacteriologist the sanitary expert must be able to recognize and identify any disease germs present in the water, milk, and food supply of a community.

To qualify as an expert in any one science usually requires college and university training. But so simple are the fundamentals of sanitation that the sciences of the high school give a good understanding of the conditions for personal and community health, and how these may be conserved. The relationships and applications of hygiene and sanitation are as wide and as far reaching as are human activities and interests. No one in a family circle can suffer sickness or disease without in some measure affecting the interests of all its members. The health and well-being of every individual is a matter of concern for the community and the State.

Directly or indirectly those now in the public schools need to be concerned with the safe-guarding of the health of those who work in factory, shop, mill, store, and office. In later years nearly every boy and girl now in school, either as employers of labor or as employees, will have a personal as well as an industrial and social interest in the sanitary conditions under which the indoors work of the world is being carried on. Even in school days the health of the parents, whose earnings make possible the maintenance of homes and the welfare of the family, are matters of concern to all boys and girls.

In towns having a good supply of city water, with modern plumbing conditions, there is absolutely no excuse for any lack in shops, mills, factories, and public schools of sanitary drinking fountains, and of well-kept toilet rooms. To keep the floors, walls, and fixtures of toilet rooms neat and clean requires co-operation with the care-takers of the buildings. 
Misuse of these rooms and of their furnishings by any one is evidence of unfitness to associate with those whose ways are decent and considerate.

The extended use of ice in summer time, especially when put into water or other drinks to cool them, involves risks to health from two causes. The chilling effect upon the digestive tract, due to any reduction in temperature much

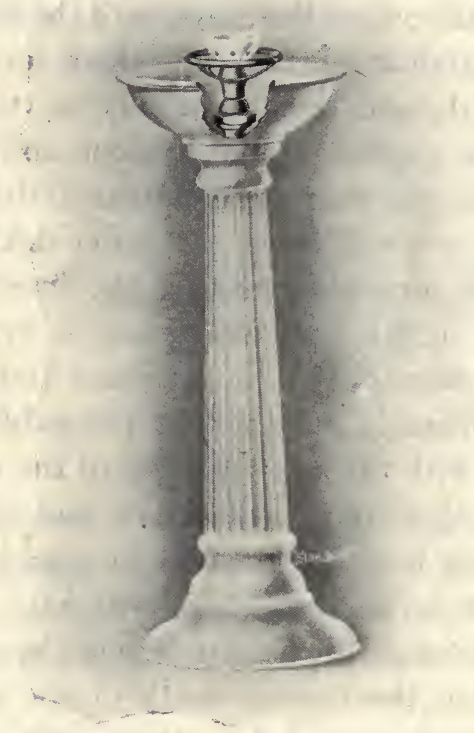

FIG. 20.-Sanitary drinking fountain.

below $99^{\circ} \mathrm{F}$. not only seriously affects the distribution of the blood supply of the body but it impairs the powers of secreting the digestive fluids. Then, too, there is the ever present danger of infection from the ice. Whether artificial or natural, it may have become contaminated either in its storage or in its distribution to the consumer. Complete protection from infection demands that ice shall never be put into drinks of any kind. 


\section{SUMMARY}

Sanitary regulations and pure food laws in late years have become more and more matters of importance. There is need of the strictest supervision over all sources of the food supply, and over the manner of preparation and sale of foods. The rigid enforcement of all regulations affecting public health has become imperative.

The food supply of a family to-day is very largely from sources outside the home, and it has been handled by persons unknown. The purchaser cannot be expected to know how it has been prepared and cared for. Wholly unfit materials may have been put up in an attractive form for sale; chemicals destructive of health may have been used; and substances of inferior quality may have been introduced as adulterants.

In order to preserve foods for long periods in condition fit for use, they are salted, smoked, preserved in sugar, or kept at or below freezing temperature. All these conditions hinder the multiplication of the germs that cause decay in organic matter. Where foodstuffs are canned the materials are sterilized at a high temperature, and are then sealed air-tight in cans to prevent the entrance of germs.

Ice cream that has been allowed to melt may be refrozen, but the refreezing does not destroy products of decay in it. Serious and even fatal results as ptomaine posioning may follow the use of foods containing the products of decay.

Instruction in the schools is concerned with whatever affects the public health as well as that of individuals. It should contribute toward an enlightened citizenship that will enforce laws and regulations for the welfare of community life.

\section{Exercises}

1. What constitutes being temperate in one's living?

2. Distinguish between bacteria and other "microbes."

3. In what ways does the multiplying of bacteria (or protozoa) within a person's body cause sickness, and bring about a diseased state?

4. Account for the certain "periods" through which different diseases run? What may be the explanation of a relapse, or a recurrence of the same ailment. with all the original symptoms?

5. Give general definitions of (a) virus; $(b)$ serum; $(c)$ vaccination; $(d)$ inoculation.

6. What is it to be immune to any disease? How is immunity explained?

7. What is an antitoxin? Explain its remedial effects. 
8. Distinguish between (a) infectious and contagious diseases; (b) antiseptic treatments and sterilization.

9. Wherein lies the great worth of formalin as a disinfectant?

10. Of the various disinfectants whose solutions are used, which is perhaps the most generally satisfactory for treatment of waste material from sick rooms?

11. What is a wise course in the matter $(a)$ of wearing other people's clothing; (b) of using public drinking cups and towels?

12. What possible dangers are there in the use of public plunge baths and swimming pools?

13. What sanitary purpose is served by cooking all meats? In the canning of perishable foodstuffs, upon what does their preservation depend?

14. How is a case of any contagious disease to be accounted for when so far as known the patient has not been "exposed?"

15. About how many years is it since Pasteur's use of the microscope laid the foundations of bacteriology? Tell something of his early discoveries. Mention other men whose researches have made notable advances in this field of science.

16. What is a necessary course to pursue with fruits and vegetables from the market which are to be served at table without being cooked? Name several fruits and vegetables eaten uncooked.

17. Under what conditions might ailments ordinarily not quarantined, such as whooping-cough, prove serious and even fatal?

18. What are the usual restrictions placed upon people when quarantined?

19. Of vaccination for the prevention of typhoid fever tell $(a)$ how it is done; (b) what the vaccine is.

\section{The Water Supply and Health}

An attempt to list the various uses of water, and to state the part that it plays in the economy of nature and the welfare of men, proves highly instructive. The extent of its uses is scarcely more striking than is the abundance of the supply needed for these uses. The round of changes in place and form undergone by water in the economy of nature is one of the marvels of the natural world. In cities provision must be made to furnish water for drinking purposes, for cooking foods, for use as steam power in mills, shops, and factories, and for heating dwellings and other buildings. An enormous supply is necessary for the disposal of sewage, for fire protection, for laundry and bathroom, for lawn and 
garden, and as ice for refrigeration. Large quantities of water are necessary in factories, gas works, dye houses, and other industries. It is indispensable for the maintenance of all plant and animal life, and for human existence.

New York City gets a portion of the enormous supply needed by its population and for its varied industries from the watershed of the Catskill Mountains ninety miles away. The expenditures of this one city alone for its supply and distributing systems represents outlays of hundreds of

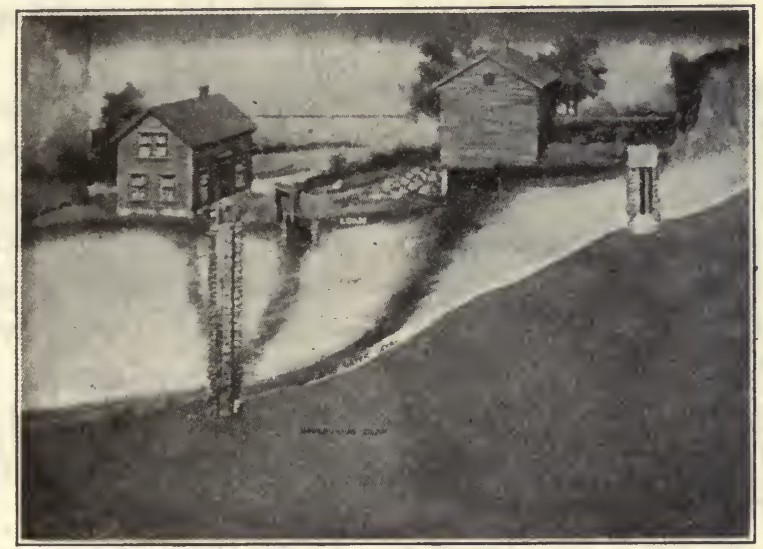

FIG. 21.-Contamination of well water. (U. S. Public Health Service.)

millions of dollars. Transportation by water has in all ages been one of the chief agencies in the promotion of manufactures, of commerce, and of civilization itself.

After surface waters from rainfall and melting snows have soaked down into the earth's crust any considerable number of feet, these waters commonly may be considered pure by reason of filtration and aeration. Slow oxidation will have freed the water of organic matter, and the material in solution will be harmless minerals. Drainage from barnyards, cesspools, privies, and house drains may, however, find its 
way into the waters that collect in surface wells. This sewage is not only poisonous to the system, but it may carry into the well water disease germs such as typhoid. In towns and cities where soils are laden with organic waste material the use of water from surface wells is prohibited. Unless one knows the conditions surrounding a surface well, and some-

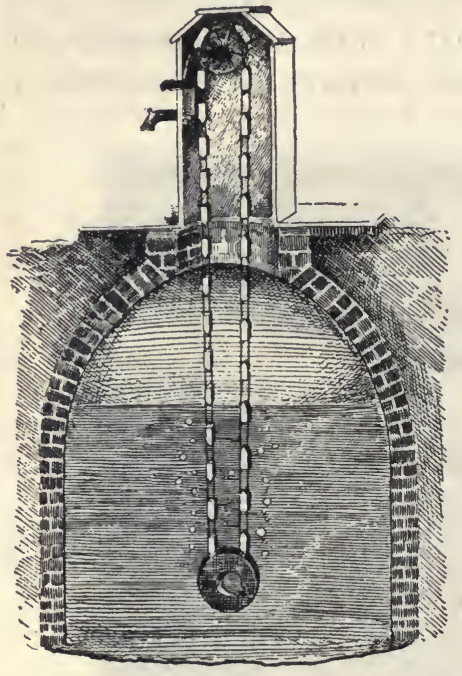

FIG. 22.-Use of chain pumps to aerate cistern water. The inverted metal cups carry air down into the water and liberate it as the cups fill with water at the bottom.

thing of the strata into which it was dug, it is always wise to regard with suspicion any water taken from it for drink or for use in preparing foods.

Surface waters sometimes find their way down between layers of rock that are separated by a porous stratum where they collect under the pressure of their own accumulation. Boring down into this water-filled layer may result in a rise of these underground waters to or above the surface of the ground. Such. waters are usually free of organic matter and disease germs by natural filtration and aeration, but may hold much mineral matter in solution.

Where rain water is caught and stored in cisterns, in spite of all precautions more or less of dust and of decaying vegetable matter will be washed from the roofs into the cisterns. The water may acquire a disagreeable odor and taste from the decay of the organic matter present, and become more or less dangerous as a drink. This organic 
matter may be destroyed by a sufficient supply of oxygen dissolved in the water. This aeration is very satisfactorily accomplished by use of a pump that carries water up on one side of an endless chain in a series of small metal cups

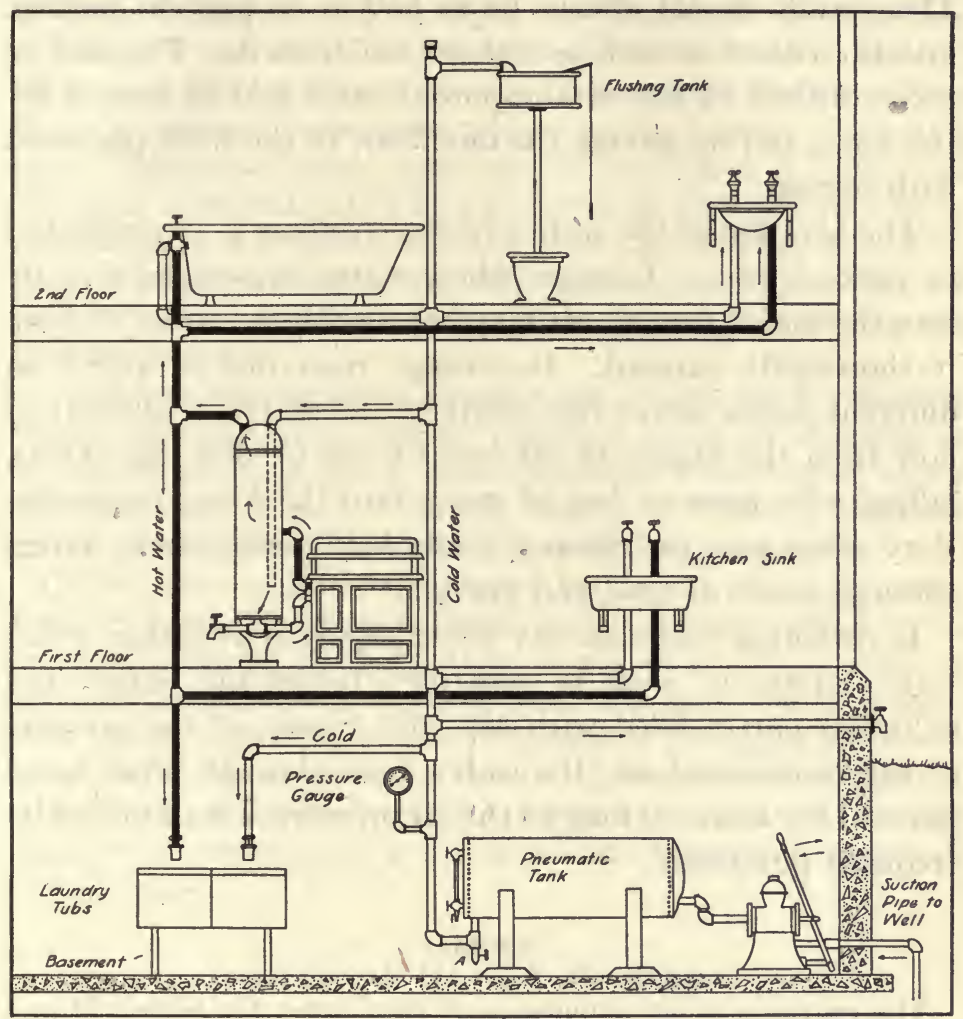

FIG. 23.-An air-pressure water system and plumbing for a house where there is no city water supply. The pumping may be done by hand, by a gasoline engine, or by a windmill.

attached to the chain. This chain runs over two wheels, one at the surface and one held suspended down in the water near the bottom of the cistern. As these cups are inverted when they pass down into the water, air is taken down and 
liberated within the cistern waters every time the pump is used.

There is always danger that surface waters and sewage may seep into a cistern through cracks in its upper walls. These walls should always be so laid as to prevent leakage into the cistern as well as leakage out from it. This can be accomplished by use of non-porous brick laid in cement for the walls, and by having the inner side of the walls plastered with cement.

The aeration of the waters of city systems is accomplished in various ways. In cases where water is pumped directly into the mains enough air may enter with the water to keep it thoroughly aerated. In storage reservoirs arranged on different levels above one another, the water is allowed to flow from the higher to the lower levels in long thin sheets, falling with more or less of spray into the lower reservoirs. Very often, too, provision is made for filtering these waters through layers of sand and gravel.

In dwellings where no city water supply is available, water from cisterns or wells is sometimes forced into large steel cylinders partly filled with air. By reason of the pressure of the compressed air, the water flows through pipes to all parts of the house so long as the air pressure is maintained by frequent pumpings.

\section{SUMMARY}

The provision of an abundance of pure water for household and general uses is indispensable to the welfare of people whether living in towns or in rural districts. Sanitary conditions require an ample supply of water for the removal as sewage of the waste matter of towns and cities. The large use of water for fire protection, for street cleaning, for homes, for public laundries, for mills and factories and various other industrial plants, makes necessary large outlays for the construction and maintenance of water systems.

The utmost vigilance is at all times necessary to safeguard the water 
supply on the farm and in the city. Disease germs in the water may cause widespread sickness and death. Water from surface wells and streams is always subject to suspicion when not safeguarded with the greatest care.

The source of the water supply for different cities, and the manner of its purification, varies according to local conditions. In some cases it is pumped from deep wells into the water mains; in other cases it is taken from rivers or lakes and stored in reservoirs where it is freed from any sediment before being allowed to flow into the distributing pipes. Sometimes certain chemicals are introduced to hasten the settling of suspended matter, and in other cases chemicals are used to free the water of organic matter and disease germs if any be present. Some definite knowledge of the water system of one's own city is a requisite for any sufficient understanding of conditions affecting the community welfare.

Apart from the presence of disease germs, the existence in drinking water of decaying organic matter, whether in a finely divided state or in solution, is a source of sickness. Oxidation is the readiest means of freeing water of organic matter, whether of animal or vegetable nature, and whether from sewage or from decaying vegetation.

Cistern water may be kept aerated by the use of a chain pump. Running water in streams is likely to have become purified by its exposure to the air, especially where its volume is not too large and where its current is more or less broken. The stored water of reservoirs may be aerated by forcing air through it from pipes laid in the bottom of the reservoir, or by the use of fountains whose spray of water falls back into the reservoir. Where water is pumped into the water mains, sufficient air for its aeration may be made to enter along with the water.

\section{General Health Problems}

The life history of flies and mosquitoes possesses great interest aside from the possibility of their becoming carriers of disease germs. A study of the structure and transformations of all insect life, and of the relations of insects to plants and to mankind, is a field of science of unsurpassed interest. Insects are of utmost economic importance to man, affecting his health, comfort, and prosperity in innumerable ways. 
The honeybee and the silk worm contribute to his well-being. But in spite of their marvelous beauty of form and coloring, and all the wonder which their structure and transformations and adaptability to changing conditions may call forth, insects are generally to be regarded as pests. They are a destructive agency against which ceaseless warfare is to be waged. There are more known species (various kinds) of insects than there are species of all other animals combined. So great is the number of insects that they are said to comprise three-fourths of the animal kingdom. Any good text on animal biology will furnish information of greatest worth concerning insects. We do not need to be scientists, however, to acquire sufficient knowledge of this group of animal life to understand how our health and comfort are affected by them.

In a general way the bodies of insects may be described as consisting of head, thorax, and abdomen. On the head are a pair of relatively large eyes, and two antennæ or "feelers." Attached to the thorax are two pairs of wings above, and three pairs of jointed legs below. The abdomen is made up of a series of rings or segments. Moths, bees, flies, butterflies, or grasshoppers may be chosen for making studies of insects. A pocket lens is a great aid in making these studies.

The feet and body of the common house fly as seen under a magnifying glass appear hairy. A sticky secretion on the feet of the fly enables it to walk on smooth surfaces, and in all manner of positions. As the common house fly revels in filth of all kinds it is a menace to health everywhere it goes. There is always the possibility of germs of typhoid, tuberculosis, or dysentery being left by flies on foodstuffs, and on the dishes used in kitchen and dining room. The female fly may lay one hundred eggs or more at a time, and under favorable conditions these may hatch within a day. The larva (grubs, or maggots) grow rapidly, especially if lodged 
in a pile of horse manure, and in about five days change to the pupa stage. In another week the full grown flies emerge, and the cycle of changes is repeated. Thus it is that in about two weeks one hundred eggs may become one hundred flies. As each female may lay four lots of eggs in a season it is possible for a single fly to be multiplied into millions between spring and fall.

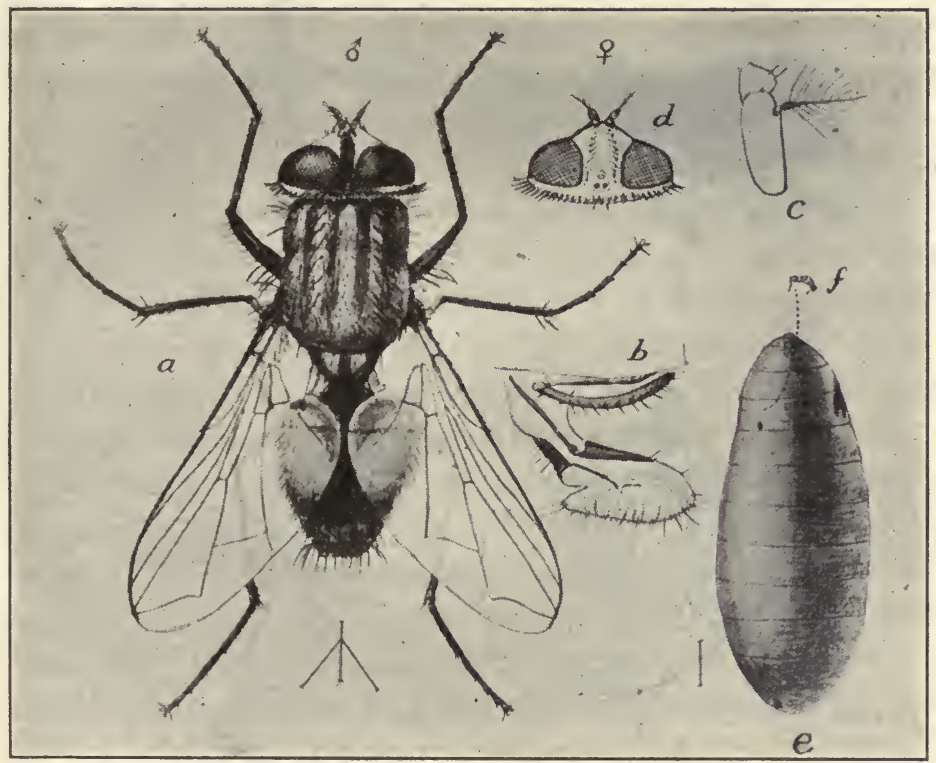

FIG. 24.-The house fly.

Control of the menace from flies lies in the fact that relatively few flies live through cold winter seasons, and that they do not go far away from their breeding places. The survivors in the spring may be trapped and the conditions for breeding may be made unfavorable throughout the season. Piles, of refuse about stables, and of decaying organic matter anywhere, are favorite breeding places. Any successful 
warfare upon flies requires preventive measures. From the earliest springtime, large outdoor flytraps should be kept about garbage cans, in stables, and near the outer doors of kitchens or wherever else food is being prepared or served.

The eggs of the common mosquito are found floating in stagnant water. Under favorable conditions these may hatch
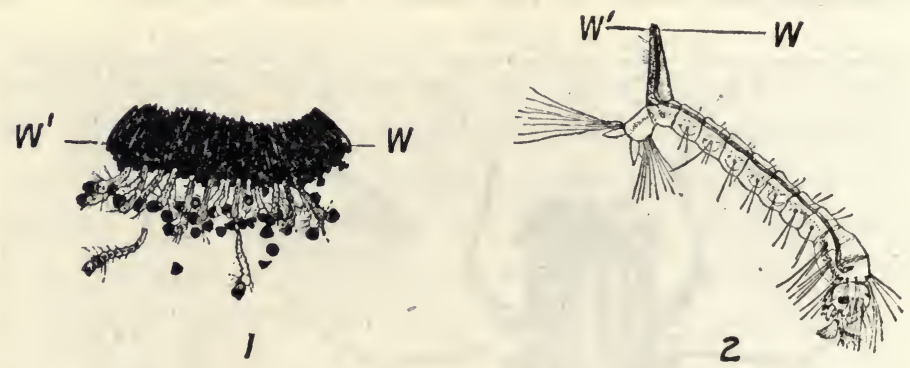

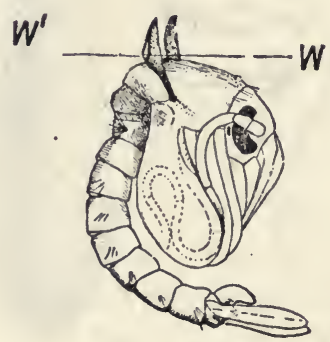

3

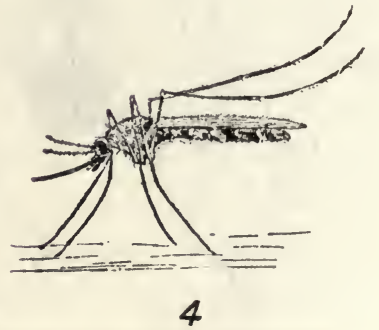

FIG. 25.--Life history of the mosquito. I, eggs; 2, larva; 3, pupa;
, the common mosquito $($ Culex). WW', water level below which larva and pupa almost wholly float. This makes possible their suffocation with a thin layer of crude petroleum spread over the water surface.

within one day. The larvæ (known as wrigglers) after about a week of rapid growth enter a pupa stage. This state continues but a few days when the change to a fully developed mosquito occurs. In waters stocked with fish, these wrigglers are devoured in large numbers. Where water surfaces of stagnant pools in marshes are covered with a 
thin film of crude petroleum, the mosquito larvæ are smothered, and the numbers of mosquitoes in any locality during a season is materially lessened.

While the common mosquito culex is a great annoyance, the malarial mosquito anopheles (ă-nŏf'-ē-lĕs) is a direct menace to health. (See page 39.) The discovery of the germ of malaria in 1880 , and of the existence of malarial germs within the body of the mosquito as its host, with , reasons for the belief that without the mosquito as an intermediary there would be no transmission of malaria from person to person, forms a wonderfully interesting story. When a malarial germ once finds entrance into the blood of a person, it lives and subdivides within some red blood corpuscle. After a period of a few days the corpuscle is broken down, and the multiplied germs are set free in the blood to enter other red corpuscles where further multiplication occurs. The characteristic chill of malaria usually follows these periodic liberations of the malarial germs in the blood.

One of the problems of a city administration is the removal of garbage economically and efficiently. The value of the waste in the garbage of a large city, including various metals, old rubber, cloth, glass, and grease, aggregates great sums annually. Destruction of garbage by fire removes the menace to health from any disease germs present in it. The sewage of a great city represents an enormous loss annually in fertilizer for soils. Sanitary conditions, however, and the cost of transportation of this material to places where it could be used, make any prevention of this economic waste largely out of question.

Rats have long been regarded as a pest, but have been tolerated. The waste caused every year by their depredations on farms, in warehouses, in dwellings, on shipboard and elsewhere is enormous. Since their agency in the spread of the dread bubonic plague has been established, active 
measures for their extermination have followed. Rats may become infected by bites of fleas that have bitten plaguestricken patients. Wherever these rats go the disease germs may in turn be transmitted from the rats to persons by agency of fleas.

In these days of cement construction there is no excuse for rat-haunted dwellings and storehouses. Hunting and destroying rats on an extensive scale is expensive. Their extermination can be accomplished in time by imposing. appropriate penalties for harboring rats upon owners of ships and buildings. It should be kept in mind that rats and mice remain only where food is available for them, and that to properly protect foodstuffs at house, barn, store, and warehouse from depredations of rats is to lessen their numbers if not entirely to be rid of them.

\section{Summary}

In agriculture the destruction wrought by insects, especially while in the larva or "worm" stage, is almost incalculable. Insects are not only a pest so far as man's comfort goes, but they are a menace to his health and to life itself.

Insects constitute the most numerous division of the animal kingdom. Between the egg when hatched, and the fully developed insect that in turn lays eggs for another generation, there are variations in the length of time required by different species to complete the "cycle." There are differences in the succession of changes that occur. However, from the eggs come the larvæ variously known as "worms," "maggots," "grubs," or "caterpillars;" then comes the pupa or "chrysalis" stage, followed by that of the grown insect.

Insects in general are characterized by having the three parts head, thorax, and abdomen. The eyes and antennæ are parts of the head; to the thorax are attached the legs and wings; and the abdomen is made up of connected ring-like parts.

While there are many kinds of flies, some of which are tormenters of both men and animals, the common house fly as a carrier of filth and disease germs should be exterminated as a sanitary measure.

The discovery of the part played by some kinds of mosquitoes in the 
spread of certain diseases, and the logical application of this knowledge to other health conditions, constitutes one of the brightest pages in the history of preventive medicine.

In the increased use of cement for building purposes lies one of the chief aids in the warfare upon rats and mice. Without access to food supplies, starvation will keep their numbers down. They are a menace to health as carriers of disease, and their destruction of foodstuffs and other property necessitates their extermination. Freedom from vermin of all kinds is an indispensable sanitary measure.

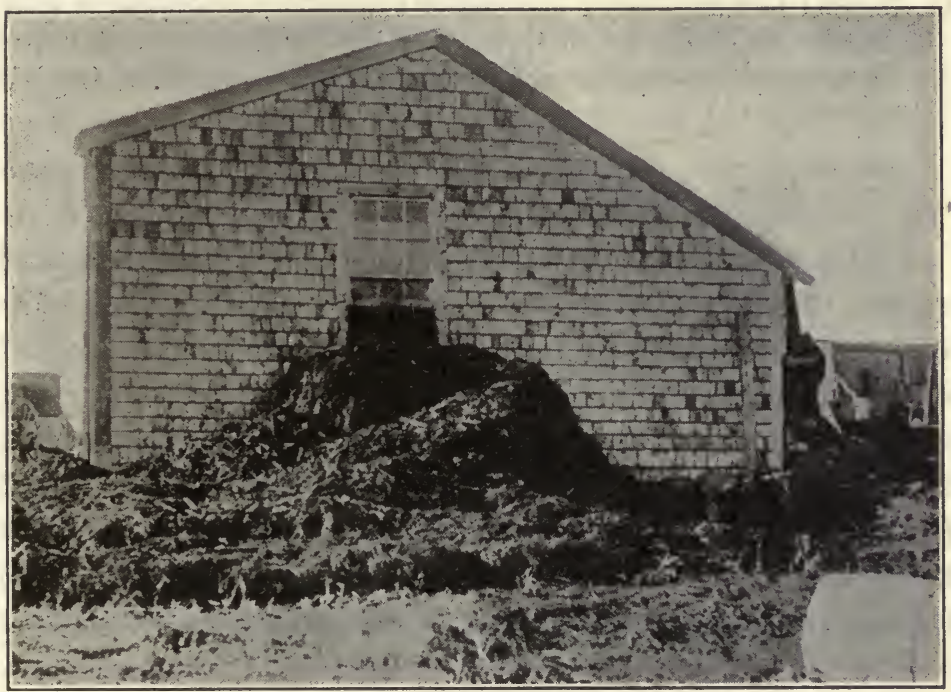

FIG. 26.-A breeding place for house flies.

\section{Exercises}

1. Name various ways in which the waters of wells near dwellings and farm buildings are likely to become contaminated.

2. How may surface drainage into wells be prevented?

3. Describe the action of "chain pumps" as means for the aeration of cistern waters.

4. Why are cisterns as sources of water for household uses in large towns and cities quite out of question?

5. How may the stored waters of large reservoirs in city water systems be aerated? 
6. How may the presence of disease germs in any sample of water be determined?

7. Why are such vigorous campaigns waged to exterminate flies and mosquitoes?

8. Why is it that the "scale" forming on the inside of boilers is so seriously objectionable?

9. Of what service is water in the nutrition of the body? Discuss how it is that the abundant use of water internally contributes to health and length of life.

10. In a general way what duties and responsibilities rest upon every individual in any community as to matters of public health?

11. In what perfectly honest way may it be possible for a dealer in foodstuffs to be able to sell at lower prices than some of his competitors? Name some dishonest forms of competition in the preparation and sale of foodstuffs.

\section{Life, Growth, Rest, and Recreation •}

Under the microscope it is found that both plant and animal tissues are made up of cells. While there is a wide variation among cells in form and arrangement, and in other respects, every living cell consists essentially of a more or less fluid content known as protoplasm. This possesses life, and it has the powers of growth and of subdivision. Food for plants and animals includes all the material required to build new cell walls, to nourish the protoplasm, and to furnish the energy required in keeping the organs of the body active.

The outer portions of the hair, skin, and nails, as well as those growths known as corns, warts, and callouses, consist largely of layers of dead cells. These are pushed outward and away from the living growing tissues underneath. A lessened blood supply to any such part of the body where unnatural cell growth is taking place may hinder and in time stop the undesirable growth.

In trees the greater part of the wood structure consists of cells largely or wholly destitute of life. So long as these are enveloped by living tissue, however, decay of the wood does 
not occur. There is an increase in the size of the tree by reason of the added annual wood formation. In animal life, on the other hand, prompt removal from the body of the dead cells of the tissue by oxidation or otherwise is necessary for the maintenance of health.

Irritation of any organ, or of any part of the body, causing an excessive blood supply there and a congestion of its blood vessels, stimulates excessive secretions and a cell-building that is likely to be unnatural in character. The high temperature of the inflamed region is likely to affect unfavorably the protoplasm of the cells. With the system unable to rid itself rapidly enough of waste matter, illness follows. Medicines may be required both to remove the cause and to stimulate the organs of the body to a more prompt removal of the waste material.

Sustained mental activity of a high order requires a wellbalanced physical development. All organs of the body, including the brain and nervous system, must be in a healthy and well-nourished state. Apparent exceptions to this rule may be explained (though not accounted for) by saying that mental activity occurs in spite of bodily infirmities, and that it is always limited more or less by them. It may be considered true generally that health and efficiency are throughout life directly dependent upon wisely ordered bodily activities. The brain and nervous system can be kept in tone and vigor only through sufficient and suitable exercise of the whole muscular system. On the other hand, the mind is largely independent of abnormal muscular development and of excessive bodily strength. A "sound mind in a sound body" has no necessary reference to physical prowess and athletic training.

Any cells of the body if kept inactive become less vigorous, and finally die as a result of disuse. The muscles unused become weak and flabby. Activity in all tissues is essential 
to their healthful state, and this is as true of the brain and nervous system as of other parts of the body. The person who maintains many interests in life, and a variety of activities both mental and manual, is not only likely to lengthen life thereby but to add to it many years of efficiency and of enjoyment in living.

Rest is essential for both body and mind that their activities may be continued. The human body as a machine at work does not provide energy rapidly enough, nor make

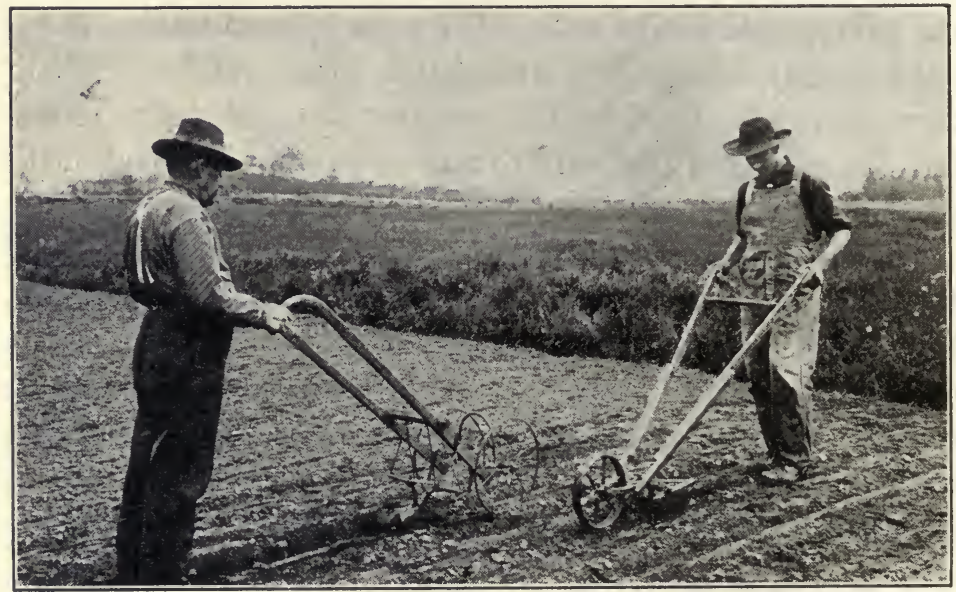

FIG. 27.-Gardening is good exercise.

tissues fast enough, to keep up with the waste. Unlike ordinary machines it is rebuilding its parts as it goes along. This requires time, and favorable conditions, and a suitable food supply. Sleep is needful to keep the body vigorous and in a healthy state. Those hours that are spent in sound refreshing sleep are not wasted. Sleep to be refreshing should be free from disturbances and interruptions, and from the ill-effects of an intemperate diet.

Eight hours per day is enough sleep for people generally. 
But excessive labor of any kind, and the wear incident to it, may require a correspondingly longer period to rebuild tissues and restore the energy of the body. Children during the years of their growth require more sleep than adults.

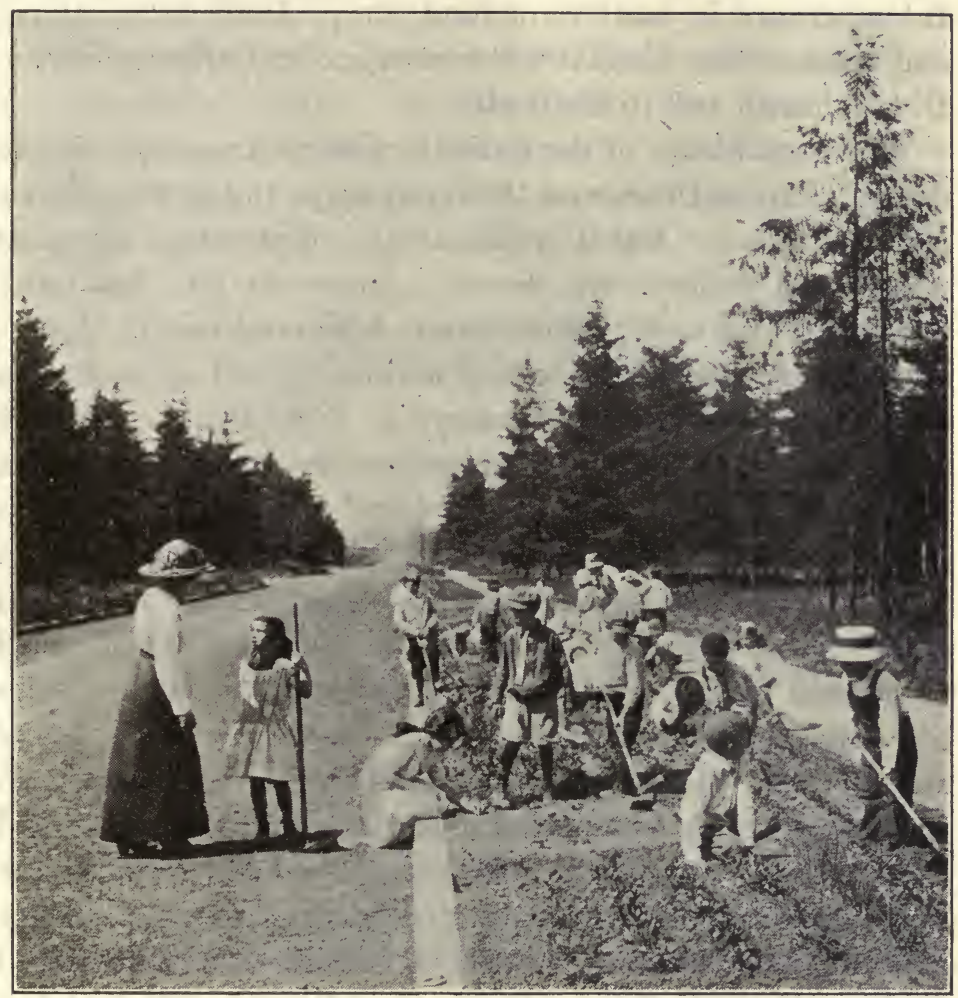

FIG. 28.-School gardens.

Sitting up late at night for study as practised by students in school is not generally advisable. Social indulgencies that carry festivities late into the night are to be wholly avoided. Physical weariness when not excessive is conducive to sleep, 
and oftentimes sleeplessness is a direct result of insufficient physical exercise.

The human body cannot manufacture something out of nothing. A healthy cell growth, and a vigorous protoplasm, is a natural result of a temperate and simple manner of life. Intemperance in matters of food, sleep, drink, occupations, and amusements dissipates the energies, and proves destructive to health and to life itself.

When machinery of the ordinary kind wears out or breaks down, it can be thrown on the scrap heap, and new machines put in its place. But it is difficult to conceive that any sane person will deliberately choose a course in life that must inevitably lead to his breakdown in body and mind. Ignorance of violations of the laws of well-being, and of the results of any departure from the ways of right living, does not change those results. Enlightenment as to the conditions for attaining and maintaining physical and mental vigor constitutes one of the most important parts of school instruction.

Recreation seeks that restoration of body and mind which makes possible the best efforts of both. There is little need to remain long, in doubt whether any particular course in life is recreation, or is instead a dissipation of one's energy and powers. While in amusements there is oftentimes no thought other than of pleasure, rest and invigoration should always result from them. Here as elsewhere, the dividing line between recreation and dissipation may be quickly discerned by one who is thoughtful of his own well-being and of the welfare of others. It is a law of human life that any right use of time and strength, and of the powers of body and of mind, brings increase in ability to do; their disuse or misuse renders one less capable. It is indispensable to health and happiness that one avoid all those pleasures that overtax the bodily energy or tend toward disease and immorality of any kind. 
The games and sports of childhood and youth furnish much of the exercise essential to the development of healthy and vigorous bodies. They make possible more enjoyment in living, and greater ability to do well the labors that devolve upon one throughout life. In rural communities a wide range of wholesome occupations and out-of-door sports is always possible; in towns and cities these opportunities are more or less restricted. So important is play considered by those who have at heart the interests of children and of society at large that special effort is made in cities to provide properly supervised sports and physical training for both boys and girls.

Aside from any outlays involved, the nature of one's employment in life should dictate very largely the forms of recreation chosen. In a general way the best results are attained from those amusements, recreations, and entertainments in which there is the most of enjoyment and of restfulness. The benefits from being an on-looker at games and plays is very generally far short of what might result from actual participation in them. This is especially the case in active out-of-doors sports and occupations. No one could reasonably think of being nourished by food eaten by another, or of growing intellectually as result of getting some one else to do his thinking for him. It is a great pity for people to deceive themselves into being content with not taking part in sports and other forms of physical exercises.

Any excessive amount of time or attention given over to amusements or to sleep constitutes intemperance in living, even as does excessive labor of muscles or brain, or overindulgence in eating and drinking.

It is the experience of the human race that besides the natural rest periods given over to sleep, the welfare of individuals throughout life requires an additional one day out of every seven, approximately if not literally, in which 
the usual routine of life is set aside ${ }^{1}$. This time should be so used as to rest the worker, and to elevate his intellectual and moral life.

Sports and games are forms of amusement in which there should be a combination of suitable physical exercise and a rational mental activity, with sometimes one and sometimes the other dominating. The greatest enjoyment and largest

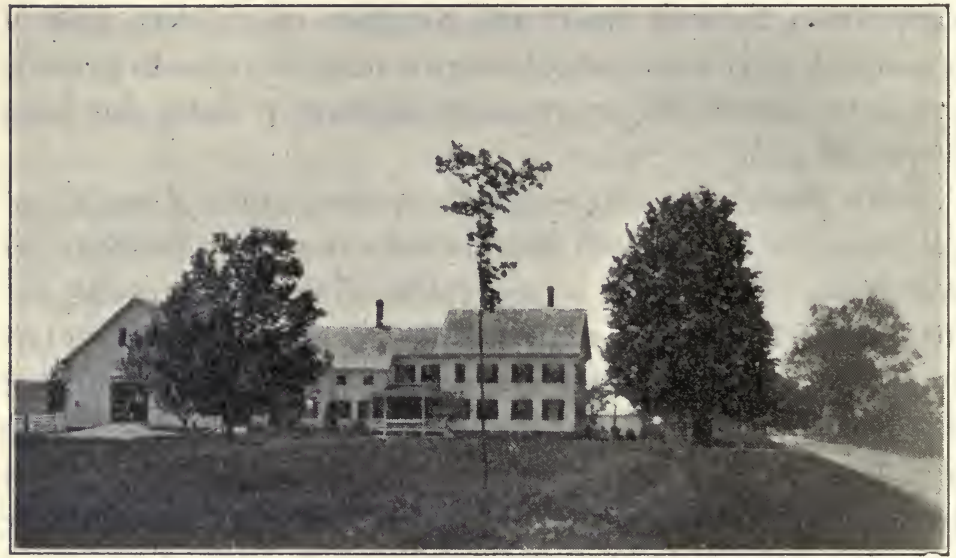

FIG. 29.-A restful scene.

benefit comes from out-of-doors sports, and from games played for the fun there is in them rather than for commercialized or competitive ends.

To permit one's self to become intensely wrought up, and to experience any long sustained excitement in witnessing professional games or plays presented upon the stage, may be exhausting in its results rather than restful and recupera-

"In this connection it is to be observed that the "Ten Commandments" delivered to the Israelites by Moses for their welfare as individuals, and for their existence as a nation, laid stress upon the requirement "Six days shalt thou labor" as well as upon setting apart the seventh day as a day of rest and religious observances. 
tive. In all cases where participation in games and sports is impossible, and where they are promoted as moneymaking schemes, it is always well to consider carefully whether indulgence in them is not likely to become dissipation rather than recreation.

It does not require any large amount of observation of effects to determine whether or not any particular form of amusement benefits or harms one physically, and whether it interferes with the discharge of one's duties; whether it refines and uplifts one's ideals of life, or tends to brutalize and degrade them. Nor does it require any large amount of ability to plan and accomplish much in the way of providing pleasurable and restful occupations about the home, and in connection with home life.

\section{SUMmary}

The human body is a structure built up of units known as cells. The same is true of other animals, and of plants. These cells are of many forms, and they have widely different uses. All living cells essentially consist of a semi-fluid content known as protoplasm. It is the "living matter" of the body. Growth in the body is the result of a subdivision of the cells due to activities of the protoplasm. ${ }^{1}$

The cells get nourishment from the watery fluid by which they are surrounded. This lymph is much like the watery part of the blood. Into it the cells discharge their waste, and this sooner or later gets into the blood. Once inside the blood vessels, it is carried in the round

${ }^{1}$ Attention is called here to a theory of biological science which is fundamental in its importance, viz., that the "life" in every living form has been transmitted from some earlier existing parent life. Each successive generation of plants and of animals has life because of cell protoplasm derived from a parent plant or animal. In other words, there is no such thing as "spontaneous generation" of life, and no creation of life energy any more than with other forms of energy. This implies that in a remote past there must have been a time when "In the beginning" there was a creation of life making possible the continuity with which the study of biological science makes us acquainted. Concerning any such time and creative act science, of course, teaches nothing. 
of circulation to the special organs by which it is eliminated from the body.

The great value to health of suitable exercise lies in an increased activity of the cells, a larger supply of nourishment brought to them, and a more complete riddance of the waste of the body from the cells and tissues.

The brain as organ of the mind requires nourishment, exercise, and freedom from exhaustive labors for its growth and activities even as other parts of the body.

The need of rest for the human body, including those periods of sleep when complete relaxation should occur, results from the fact that the human body does not rebuild its cells rapidly enough, nor provide energy sufficiently fast, to make good the waste of the body in its hours of activity.

Recreations may be considered as including all those occupations where the general results are restful. Recreation ranges in character from what is done solely as amusement to what is merely a change in form of labor. This latter is restful because it calls into use activities of the body before unused, thus freeing those parts which have become wearied.

\section{Stimulants and Narcotics}

There is a certain rate at which an engine or dynamo does its best work, and where there is the least wear. Both its efficiency as a machine and its length of life as a working agent require that it be run at its normal capacity. To overload a dynamo or a steam engine, or to speed either beyond a normal rate, means its destruction. The human body in spite of its recuperative powers suffers from the wear and waste of an unnatural strain put upon it in the use of alcoholic drinks, and sooner or later breaks down. The vital organs are affected seriously, and it is upon them that length of life and vigor of health largely depends. One may live long and be an active agent in the affairs of life after the system is incapacitated for hard muscular labor; but there is always a need for vigorous heart action, active nutritive processes, and healthy action of kidneys and lungs. The 
remedy at any time for lack of vigor and strength, whether of body or mind, is not some stimulant to further use up the scant store of energy, but hygienic living in order that the physical conditions be such as to provide the needed strength.

Only workmen with clear minds, skillful hands, and steady nerves are wanted in the railway service, in the great industries, and in all positions of trust and responsibility. Dissipation of any sort shatters the nerves, beclouds the brain, and unfits for effective service. Such workers are discriminated against in the affairs of the world everywhere and cannot hope to secure and retain its most desirable positions.

The continued use of small amounts of alcoholic liquors impairs the health, reduces the recuperative powers of the body in cases of illness, and makes one more liable to infectious diseases. Insurance companies often refuse to take life risks of even moderate drinkers because of the higher death rate among them.

The debauching effects of an excessive use of alcoholic drinks is a matter of common observation; and the use of alcohol as a beverage is a menace to human life and social welfare. The testimony of texts on human biology concerning its destructive results upon the nerve centers that are concerned in the higher intellectual processes is scarcely required. The drinker is not only made less efficient physically and mentally, but he loses in self-respect, and his powers of judgment are impaired.

Poverty, wretchedness, vice, and crime are common accompaniments of the habitual and excessive use of alcoholic drinks and narcotics. At no time does the victim of alcoholic drink plan to make a wreck of his life and manhood by becoming hopelessly enslaved. His helplessness in an attempt to regain wasted strength of body, and to reassert control over himself, calls for pity. In his home there are those who are innocent sufferers, and the com- 
munity, too, suffers loss in the worth and excellence of its citizenship.

Parents who are users of alcoholic drinks are responsible for lessened vitality in their children due to alcohol. The children of such parents are often afflicted by physical weaknesses, and are less likely to live through infancy.

So readily does one become a victim of an uncontrollable appetite for habit-forming drugs and alcoholic drinks that self-protection makes it necessary to shun the company of those who indulge themselves regardless of the risks taken.

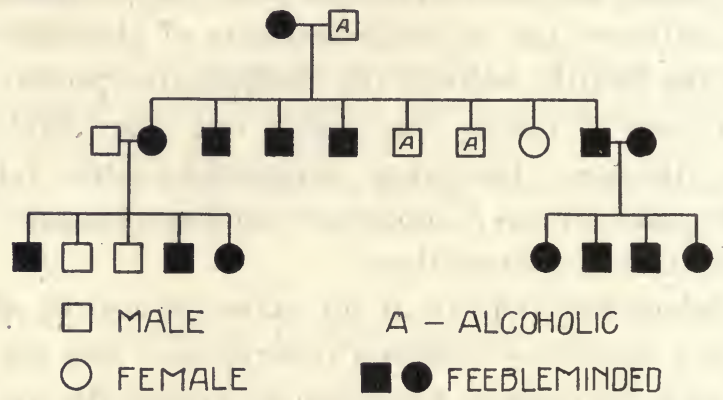

FIG. 30.-Laws of heredity are well established for both plants and animals. The diagram shows what is likely to be true of children and grandchildren where a man addicted to the use of alcoholic drinks marries a feebleminded woman. The histories of such unions confirm experimental results in the breeding of plants and of the lower animals.

It is only an exercise of good judgment to avoid any companionship and all social relationships where the price is likely to be the undermining of the health, and slavery to the use of intoxicating liquors and narcotics.

Boys beginning the use of tobacco should have knowledge of the fact that the use of it very often seems to prevent a proper development of body and mind. Only a small per cent of school boys who are confirmed smokers are able to keep their standing in school work, or later to secure and retain the most desirable positions, Alcohol and narcotic 
lrugs are never to be used in any form save as prescribed by a physician, and are always to be shunned the same as other poisons.

Perhaps one of the most notable outgrowths of the great world war of this generation has been the restrictions imposed by the warring nations upon traffic in intoxicating drinks. In Russia this at one time amounted to a prohibition of the manufacture and sale of vodka, the national drink. The government of China years ago awoke to the debauching effect upon its people of the extended use of opium. But it has been within the last few years only that conditions have become favorable for the stamping out of its unspeakable evils.

Through national legislation known as the Harrison law (I9I4), the American people have at last resorted to drastic measures to restrict the increase in a traffic in narcotics that had come to number its victims in all parts of this country by the thousands. It not only impoverishes them as individuals, but it wrecks them in body and mind, and their degeneracy constitutes a standing menace to the peace of society. This law seeks so to control the dispensing of the more powerful narcotics and habit-forming drugs (except alcohol) that their use shall be solely for medical purposes and not at all for dissipation. Society has not hesitated here to deny to the individual the right to ruin himself, becoming a burden to his family and to the community rather than a constructive factor in both. It has undertaken to punish those who seek profit in this traffic regardless of individual and public welfare.

The activities of very many of the organs of the body are maintained by impulses from nerve centres not controlled by the will, and these activities are sustained independently of any attention or thought on the part of a person. A great many of a person's voluntary acts and efforts, too, may be- 
come more or less automatic after a time. The control of them as exercised by a person in early life may be almost or wholly lost.

Where any certain sensation is received over and over again at any nerve centre, and the reaction to it results in nerve - impulses that bring about the same kind of an act, there comes a time when the mind gives these sensations no further special attention. The reaction (motor impulse) occurs when the sensation is received without any considerable thought being given to it. A "nerve-track" of sensory and motor impulses has been established through the nerve centre that may not at all involve conscious effort of will. Only by exercise of long-sustained and powerful self-restraint can these motor impulses be brought again under control of the will, and the physical condition within the nervous system changed. Physiologists thus explain "habit" as a state of the body.

Long continued use of alcohol even in srnall portions so affects the nerve centres as to destroy more or less completely the power to control acts prompted by certain sensations known as "cravings," or an abnormal appetite. Even the sight or smell of liquor may arouse desires that are not controllable by the victim of alcoholism. These cravings constitute the misery and unspeakable torture endured by those who have become slaves of "habit-forming" drugs and preparations when they are denied the ever-increasing amounts demanded by the shattered nervous system, or when they are struggling to be free of the:se habits. The knowledge that the craving is relieved by a further supply of the drug becomes sufficient incentive for any act that will furnish relief for the craving.

The users of patent medicines are always in danger from these evils. Most of such medicines depend upon narcotics in them to afford relief from pain or to bring about sleep, 
and upon their alcoholic content to arouse an entirely false hope of speedy recovery from illness. Only a trained and experienced physician may safely be trusted to determine the nature of any serious ailment ("diagnose" it), and to prescribe the treatment to remove its cause.

"Soothing syrups" for infants, and "headache powders" for adults, depend upon the presence of powerful narcotics in small quantities to deaden pain, and to induce a more or

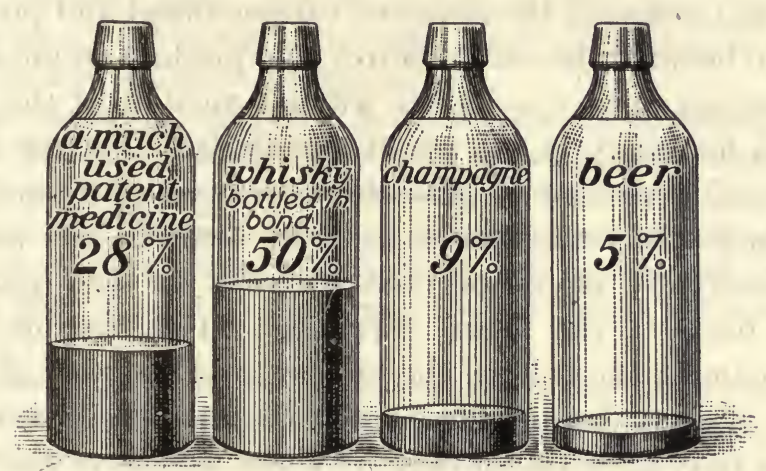

FIG. 31.-Percentage of alcohol in a patent medicine formerly having a large sale.

less unnatural sleep. Continued use of soothing syrups and "colic cures" with infants is likely to stunt their development in body and mind, and leave them sickly and unfitted to ward off the diseases of infancy and childhood. The various cough mixtures, remedies for catarrh, and "cures" for colds are likely to contain narcotics whose purpose is to deaden the sensibility of the inflamed linings of throat and air passages. While temporary relief in some cases may be experienced, the system at large is seriously deranged by use of these drugs. That the ill-effects of these drugs may not be immediately apparent does not lessen the harm wrought every time they are administered, nor avert the risks taken in 
their use. Even the reputable physician who has a full understanding of the physical condition of the patient should be exceedingly cautious in prescribing any habit-forming drugs ${ }^{1}$. The use of medicines at all times is chiefly for the purpose of bringing about conditions of the body favorable for its recuperative powers. Drugs afford at the best but a negligible amount of energy or nourishment for the body, and contribute nothing to the store of "life" as it exists in the protoplasm of the cells.

No discussion of the abuse of various drugs and preparations to benumb the nerve centres, and produce an unnatural unconscious state, is complete without mention of the blessings to humanity in the use of ancesthetics. The use of the vapors of ether and of chloroform to produce insensibility to pain in the extraction of teeth by dentists, and as used extensively by physicians and surgeons in their practice, dates back to the years $1844-1847$. The freedom from torture under the knife of the surgeon, and the relief given in times of excruciating pain by administering an anæsthetic, can be fully appreciated only by those who have had some experience. The elimination of the exhaustion from endurance of suffering, and the avoidance of the shock to the nerve centres resulting from great pain, make likely a more prompt rally and a more speedy recovery than otherwise would occur. It must not be overlooked that administering an anæsthetic is always attended by risk to life, and that preferably it should be given by an experienced physician only.

1 In the gth Revision of the U.S. Pharmacopœia (Sept., I916), an authority on medicinal preparations used in this country and recognized as a standard in all courts of law, no use of whisky, brandy, or wines as medicines is included. Alcohol has an industrial use as a solvent of various substances which have medicinal value, but such preparations are used in spite of their alcoholic content rather than because of it. 


\section{SUMMARY}

Alcohol and the narcotic drugs act powerfully upon the nerve centres of the body. The effect is to deaden them temporarily. As a result the activities of the various organs of the body are deranged, and the energies of the body are used in overcoming the ill-effects experienced. The irritated nerves in the various tissues affected by the alcohol rouse the whole system to increased activities, and this is followed by a period of depression both physical and mental.

Any continued use either of alcohol or of any narcotic is likely to produce such an irritated state of the nervous system as to demand further deadening effects upon it to satisfy the "craving" that has been aroused. The victim of the "drug habit" or of alcoholic drink finds relief only in further indulgences.

The protoplasm of the cells is harmfully affected, interfering with the growth and nourishment of the brain and of the whole body. So serious is this that the chances of recovery from sickness of any kind is found to have been lessened by even moderate use of alcoholic drinks.

The use of tobacco during youth interferes with growth as cell division, stunting more or less the development of the brain and of the rest of the body.

Powerful drugs of any kind, including alcohol and the various narcotics, should never be used save upon the written prescription of a skilled physician, and only after a personal examination by him to determine the exact nature of any ailment. It is but a remote chance that the drugs contained in a patent medicine will prove the best treatment for any one whose health is impaired.

By reason of the stimulating effect of the alcohol contained in a patent medicine, and the deadening effect of its narcotics on any pain experienced, false hopes of recovery are aroused by its use only to be cruelly disappointed. The time thus lost may make impossible any recovery later even under skilled medical treatment.

Soothing syrups and colic cures for infants, and headache powders for adults, contain narcotics in varying proportions, and should never be used save under medical advice.

The introduction of anæsthetics for use in dentistry, in surgery, and in medical practice generally, has conferred an almost priceless benefit upon suffering humanity.

Under the provisions of national legislation in the so-called Harrison Act regulating the sale of narcotics, it is sought to have a written record of sales from the importer or manufacturer to the consumer. 
Druggists, physicians, and any others licensed to dispense these drugs, are held responsible under heavy penalties for any use of them for other than medical purposes. No sales are permitted for purposes of dissipation on the part of those who have the drug habit.

Where like sensations are always followed by the same kind of responses, the brain in time gives less and less attention to either the sensations or the responses. There comes about a condition where nerve centres other than those involved in making choices and directing the acts of an individual take care of the whole matter. Indeed, so far may this loss of the will power over these acts have gone that reason and will seem to be unable to regain control over them. The person so far as that particular habit is concerned is a hopeless slave, though at times he may have the greatest desire to break from it.

\section{General Science and Right Living}

Psychology (sī-kŏl'ō-jŭ) deals with what is known of the activities of the human mind. A better understanding of the conditions for these activities should lead to a better intellectual and moral life. It is necessary that the psychologist know very definitely the structure and physiology of the brain and nervous system of the human body, and be well versed in biology. But it is:neither necessary to be a scientist, nor to have gone to college, in order to know the conditions essential for growth into the best types of manhood and womanhood.

It is to be kept in mind that those characteristics which distinguish mankind from the brutes are the result of a slow process of human development. Education through schools has to do with this development of intellectual and moral natures in individuals, and for its best results requires time and favorable conditions. While schools are maintained as one of the chief agencies to this end, it must be remembered that a large part of what any one knows and is able to do has been gained outside the schoolroom.

Influences that very largely shape one's choices and fix one's ideals of life are those of the home and its surroundings 
during childhood and youth. Habits of thought and of action formed then are likely to control in later life. Selfindulgence during early life in ways and manners harmful to the individual himself and offensive to others gives rise to social and personal limitations during the later years of manhood and womanhood. The degree of self-control and self-denial learned and practised during youth is a very satisfactory measure of any growth towards a well balanced complete manhood and womanhood. One of the chief ends of school attendance is to acquire ability in making those choices in one's manner of life, and in all matters of skill and knowledge, that contribute most to the well-being of the individual himself and of other people generally.

In acquiring information, in grasping the relationships of facts, and in making applications of knowledge, unless there is a clear discernment on the one hand between what is for the well-being of the individual and of society, and on the other of what is degrading for all, the purposes of schools may be largely defeated. The development of an intellectual and moral nature in an individual is a relatively slow process requiring a lifetime. The conditions for this development are in large part within the control of the individual himself. It is his own choice whether his educational progress shall be toward the formation of habits that experience and science have shown to be best, or toward those whose results are harmful to himself and to others. Enlightenment in hygiene and sanitation, and in the ways of right living generally, assumes that every one who is at all reasonable and sane will do what is known to be best, and avoid doing what is either questionable or absolutely harmful.

One of the fundamental facts concerning growth from childhood into self-directing manhood or womanhood is the gradual assumption of responsibility, and a manifest readiness to discharge duties without compulsion. Regardless 
of one's age and bodily growth, any one who must be made to do what he ought to do, and who must be compelled to refrain from doing what is wrong, is not yet grown. He is yet a child in the ways of right living. As persons grow older in years, and come to some degree of maturity of body, it is only reasonable that their conduct should give evidence of growth into the better types of manhood or womanhood. Knowledge gained in schools finds its chief value and most fitting expression in lives that are guided more nearly aright as result of such teachings.

People who manifest no regard for the welfare and rights of others may very properly be said to exhibit criminal tendencies. These manifestations range all the way from what is commonly called selfishness to that utter disregard which does not hesitate to destroy human life for gain. Not all practices included in such a sweeping classification are illegal by any means, i.e., prohibited by law. The liquor traffic is not only permitted in many communities but legally authorized by license. It is carried on regardless of an appalling list of evils that result from it both public and private. The adulterations of foodstuffs, the use of harmful preservatives, and the traffic in habit-forming drugs, have been made illegal. All of them involve the robbing of one person by another of health, of ability to earn a livelihood, and of possibilities for advancement in general welfare. In individual relationships in life the motto "Quid pro quo," meaning to make full return in value for whatever one gets, is conducive both to manhood and to good citizenship.

Activities that largely control the development of the body and mind occur during the years of childhood and youth. There is lack of experience then concerning the wisdom of what ought to be done. Understanding of the relationship of cause and effect in matters of health, and of the consequences of any unwise course in life, comes only through years 
of experience and of instruction. The age of discretion and of responsibility in conduct is slowly attained. The experiences and counsel of those who are older, whether written in books, listened to at home or in school, or witnessed in lives about us that are worthy of being followed as examples, make a wise course in life possible until personal experience can safely modify or replace these safeguards. Any failure to direct one's self aright does not destroy all growth previously made toward manhood or womanhood. Habits are the results of repeated efforts, and the importance of the single act as explained by the physiologist and the psychologist lies in the knowledge that another like act becomes more probable.

\section{SUMMARY}

The larger part of what any one knows is learned usually outside school. It may be considered that the chief purpose of schools is to stimulate and direct a love of knowledge, and to give efficient training in its acquisition and effective use.

What has been learned by men down through the ages in any one of the sciences has been so classified and related that it is possible in a year's study to get a good general knowledge of it.

Knowledge becomes of largest worth when it promotes our own highest welfare, both of body and of mind, and when through us it benefits others in largest degree.

Habits of any kind become fixed only through years of repetition. Both the training and the instruction given in schools should be directly concerned in fitting every one habitually to make more intelligent choices in his manner of life, and in all matters of skill and of knowledge.

The habits formed in connection with doing school work should be such as to make men and women more efficient in life, more self-reliant, and more persistent in the solution of life's problems. One's whole life should be more sane and better directed by reason of attendance upon school.

The person who must always be told what to do and when to do it, who must be made to do what he ought to do and made to refrain from doing what he ought not to do, is not yet grown up. He remains a child in development whatever his age in years may be. 
All hope of the progress of mankind, and one of the chief reasons for maintaining schools, is that each individual and each generation in turn may early become acquainted with the gains in knowledge made by the race. This renders it unnecessary for anyone to repeat the mistakes that others before him have made.

Many of the evils experienced in the lives of people are the direct results of wrong habits formed before the full significance of these habits and of their results could be understood.

\section{Exercises}

1. Explain the need of recreation and amusements. What unmistakably . distinguishes them from dissipation?

2. Upon what set ("system") of organs of the body does any narcotic (including alcohol) directly act? Explain the "stimulation" (increased activities) from the use of small portions of narcotics.

3. What is meant by the drug habit? How is it that people become slaves to it? Why is the habit unlikely to be overcome?

4. What is meant by "patent medicines?" Account for their extended sales. What constitutes sufficient argument against their use?

5. Name some of the conditions a person must observe in order to do his best and be at his best.

6. What is meant by a sound body? Name some characteristics commonly accepted as evidence of a sane mind.

7. What is understood by the term food, whether for plants or for animals?

8. Under what conditions may no harm come from being up late nights? What relationship should exist between one's kind of recreation and the nature of his employment?

9. Whence is derived the "life" of each succeeding generation of plants and of animals?

10. Why may it be well to abstain from eating when one has a cold? Why may it be well to take hot drinks and a vapor bath at such a time?

11. What constitutes (a) temperate living; (b) a "simple life"?

12. What should be the great service performed by a physician for his patients, and the chief aim of his efforts? What has been found true of the recuperative powers of those who use alcoholic drinks?

13. What only can medicine do for the restoration of wasted energies and a broken-down body?

14. In human society when must a person be prevented by others from doing as he pleases?

15. Give illustrations of the statement that those who will not deny themselves in observing nature's laws will be denied by her, as well as punished for past offenses. 


\section{WATER, AND ITS USES}

\section{Some Properties of Water}

Water is indispensable in the life of all plants and animals. In the human body it makes possible the solution (digestion) of foods. It is the means employed in the body for removal of waste through the skin, bowels, and kidneys. It keeps moist the tissues so that they can perform their several functions. In Physics a study is made of water as a type of all liquids. In Chemistry both its physical and chemical properties are studied, together with its usefulness in promoting chemical change and in carrying on the chemical processes. In the study of Physical Geography, and in Meteorology, water as an agent in the changes that occur is of first importance. In matters of hygiene and sanitation, and in the affairs of the household, the importance of water in daily life can scarcely be emphasized sufficiently. In the affairs of men and of nations water is a highway for foreign and domestic commerce, while water and steam furnish a large part of the power that turns the wheels of the world's industries. Any extended consideration of its usefulness to individuals and to mankind generally by reason of its properties and its abundance leads into every field of human activity.

All matter, including liquids and gases, is supposed to be made up of minute particles called molecules. These are too small to be seen through the most powerful microscopes. It is further supposed that these molecules as units of matter are separated by spaces relatively large as compared with the size of the molecules themselves. And it is believed that these molecules are incessantly moving back and forth in 
these intermolecular spaces (pores), and that the degree of this motion and the consequent number of collisions among the molecules is the cause of the varying temperatures of bodies. It is believed that the distinctions between solids, liquids, and gases lies largely in the different intensities of the attractions (pulls) exerted between the molecules by the intermolecular forces of cohesion and adhesion. In solids the attractive forces dominate, and the solid retains a form of its own. In gases the moving molecules drive one another apart, and gaseous matter must be confined. Left unrestricted, gases would expand indefinitely filling all space open to them. Liquids are an intermediate condition between solids and gases, and possess enough of freedom in the motion of their molecules to assume the form of a containing vessel. Molecules escape from their upper surfaces into the atmosphere more or less at all times when left uncovered. The rate of this evaporation varies with the kind of liquid, its temperature, and the capacity of the atmosphere for holding that particular vapor. Many liquids are said to be volatile because they must be kept in stoppered bottles or other containers to prevent excessive waste due to evaporation.

Water is boiling when it is changing to a vapor within the liquid mass. For pure water under one atmosphere of pressure, i.e., when the barometer reading is thirty inches (76 $\mathrm{cm}$.), the boiling temperature is $100^{\circ} \mathrm{C}$. $\left(2 \mathrm{I} 2^{\circ} \mathrm{F}\right.$.). When water is confined in a closed vessel, as in the boiler of a locomotive, and the gaseous (steam) pressure upon it becomes more and more, the water must be heated hotter and hotter to keep it boiling as the pressure upon it increases. Under two atmospheres (thirty pounds per square inch) the boiling point becomes about $120^{\circ} \mathrm{C}$, , and at fifteen atmospheres becomes about $200^{\circ} \mathrm{C}$. If at any such high temperature the pressure on the water surface be suddenly released, the heat 
contained in the water may convert the whole liquid mass instantly into steam.

By use of "vacuum pans" having air-tight covers, and with a pressure upon the liquids contained in them kept less than one atmosphere by use of an exhaust (air) pump, the boiling may go on rapidly at temperatures much below $100^{\circ} \mathrm{C}$. By reason of a lessened atmospheric pressure due to increase in altitude the boiling point of water is lowered about one degree in temperature for approximately rooo feet elevation. At Denver one mile above sea level the boiling point is approximately $95^{\circ} \mathrm{C}$.

In the use of rubber bags containing hot water as a source of warmth through a period of several hours, we have an illustration of another important property of water. Different bodies having the same weight and same temperature give off widely different amounts of heat in cooling through the same number of degrees. This is another way of saying that the same amounts of heat taken up by equal masses of different substances having the same initial temperature give widely different final temperatures to these masses.

Water has the highest specific heat of the various liquids and solids. Where equal weights of mercury and water are heated equally, the rise in temperature of the mercury is about thirty times greater ${ }^{1}$. Dry land surfaces (soils) heat much faster and get much hotter under a summer sun than bodies of water, cooling off during the night much more rapidly and to a much lower temperature.

A cubic foot of water weighs about sixty-two and one-half

${ }^{1}$ The specific heat of any substance may be defined as the number of calories of heat necessary to raise the temperature of one gram of the substance one degree centigrade. The specific heat of water is 1.00 (see page 147), and the specific heat values of the following substances are given merely for illustration:

Mercury (solid)............. 0.033

Aluminum

0.21 4

Iron .

ㅇ. I I 2

Ice

0.550 
pounds. In freezing it expands about one-tenth of its volume, and a cubic foot of the ice that is formed (not the whole of the cubic foot of water) weighs about fifty-seven pounds. The density of ice is about nine-tenths that of water. This explains why ice as it forms on the surface of water in winter does not sink to the bottom, and why ponds and streams do not become frozen solid during a winter. If large bodies of water did freeze solid, it is unlikely that this ice would ever thaw very much below the water surface. The heat of the summer's sun upon it would be used largely in vaporizing the surface layer of water. All marine life would be destroyed, and the waters would be icy cold all summer. Winds blowing over this ice cold water would check or destroy the growth of vegetation. With the density of ice so nearly that of water, it is calculated that about nine-tenths $(.92)$ of the volume of an iceberg is submerged however much it towers above water surface. Within a temperature range from $32^{\circ}$ to $212^{\circ} \mathrm{F}$. $\left(0^{\circ}\right.$ to $100^{\circ} \mathrm{C}$.) water exists as solid, liquid, and vapor. No other substance has so narrow a range in temperature for all three states.

All waters coming out of the ground are likely to contain more or less of minerals in solution. Inland lakes and seas such as the Great Salt Lake of Utah, whose waters have no outlet other than by evaporation, become increasingly saline as minerals in solution are washed in to be left there. The waters of the ocean contain nearly ' 3 per cent, of common salt. "Mineral springs" contain certain dissolved compounds that have more or less of medicinal value. Usually these waters as sold on the market are "carbonated," i.e., made to hold under pressure considerable carbon dioxide gas. When this water is poured into an open glass, and is under only the ordinary atmospheric pressure, effervescence occurs by reason of the escape of this gas into the air. 
Water itself is practically incompressible even under enormous pressure. Because of this fact the density of the water in the depths of the ocean is. approximately the same as at the surface. Bodies heavy enough to sink beneath the surface will go to the bottom. This incompressibility of water is in striking contrast with the ready compressibility of gaseous matter such as the atmosphere.

"Soda water" is carbonated drinking water sweetened and flavored by use of fruit syrups. Substances chemically prepared, and having flavors similar to those of various fruits, are sometimes used in place of the real fruit because of " cheapness. Their use may be attended with harmful results, especially for those whose digestion is at all impaired.

\section{SUMMARY}

The important uses of water are too numerous to be named here. Very many of these uses are named elsewhere in this text in different connections. In agricultural, commercial, and industrial life, and in all relations of life affecting health and well-being, water occupies a most important place.

A detailed study of water as a typical liquid is made in Physics. Brief studies of other liquids can then be made by comparison. Its composition, and its usefulness in chemical changes, are both emphasized in Chemistry, while in the other sciences the uses of water appear in manifold relationships.

The boiling and freezing temperatures vary for different liquids These temperatures are changed for any liquid by variations in atmospheric pressure, and by the presence or absence of substances in solution.

The high specific heat of water, and the excessive value of the heat involved in its vaporization, are of utmost importance in any consideration of climate.

Abundant as are the waters of earth, it is a most difficult problem to secure a supply of water sufficiently free of organic and mineral matter, and of disease germs, to warrant its use for household purposes. Oceanic waters, and those of certain inland lakes, seas, and springs, hold in solution so much salt, "lime," and other minerals as to be unfit for drink and for the preparation of foods. 
Water can hold gases as well as solids in solution. Both marine and land plants get the needed supply of oxygen for their tissues from the water. Fish are provided with special organs known as gills to get from the water that passes in and over them the oxygen they require. When water containing any gas is freed from pressure, more or less of the dissolved gas will escape. This is seen in "soda water," and in all carbonated mineral waters.

\section{VAPORIZATION AND CONDENSATION}

As elevation above the earth's surface increases it is found that the pressure exerted by the atmosphere decreases. In the study of Physics it is also found that when the pressure upon any gas is decreased the gas not only expands but its temperature falls. This result follows from the molecules being further apart. As atmospheric moisture rises in the form of invisible vapor of water it expands and cools, and the formation of clouds with or without rain or snow may follow. The air may cool, also, by reason of radiation of its heat out into space independent of any expansion.

Clouds and fogs, consist of minute droplets of water as a liquid. These cloud masses of water particles are heavier than air, and are all the time settling toward the earth's surface. Where the under surfaces of the cloud mass come in contact with warmer air, or air that is unsaturated, the liquid particles change back into the vapor form. But while the cloud is thus wasting below, it may be forming anew elsewhere, especially at the upper surfaces. Thus the form of the cloud is more or less constant.

The amount of rainfall in some of the regions of earth is a negligible quantity, while the amazing total of 500 inches or over forty feet a year is recorded for the region northeast of the Bay of Bengal. Where the annual rainfall is under twenty inches, the raising of crops without irrigation is hazardous. The distribution of the rainfall through the growing season is a factor quite as important as the matter 


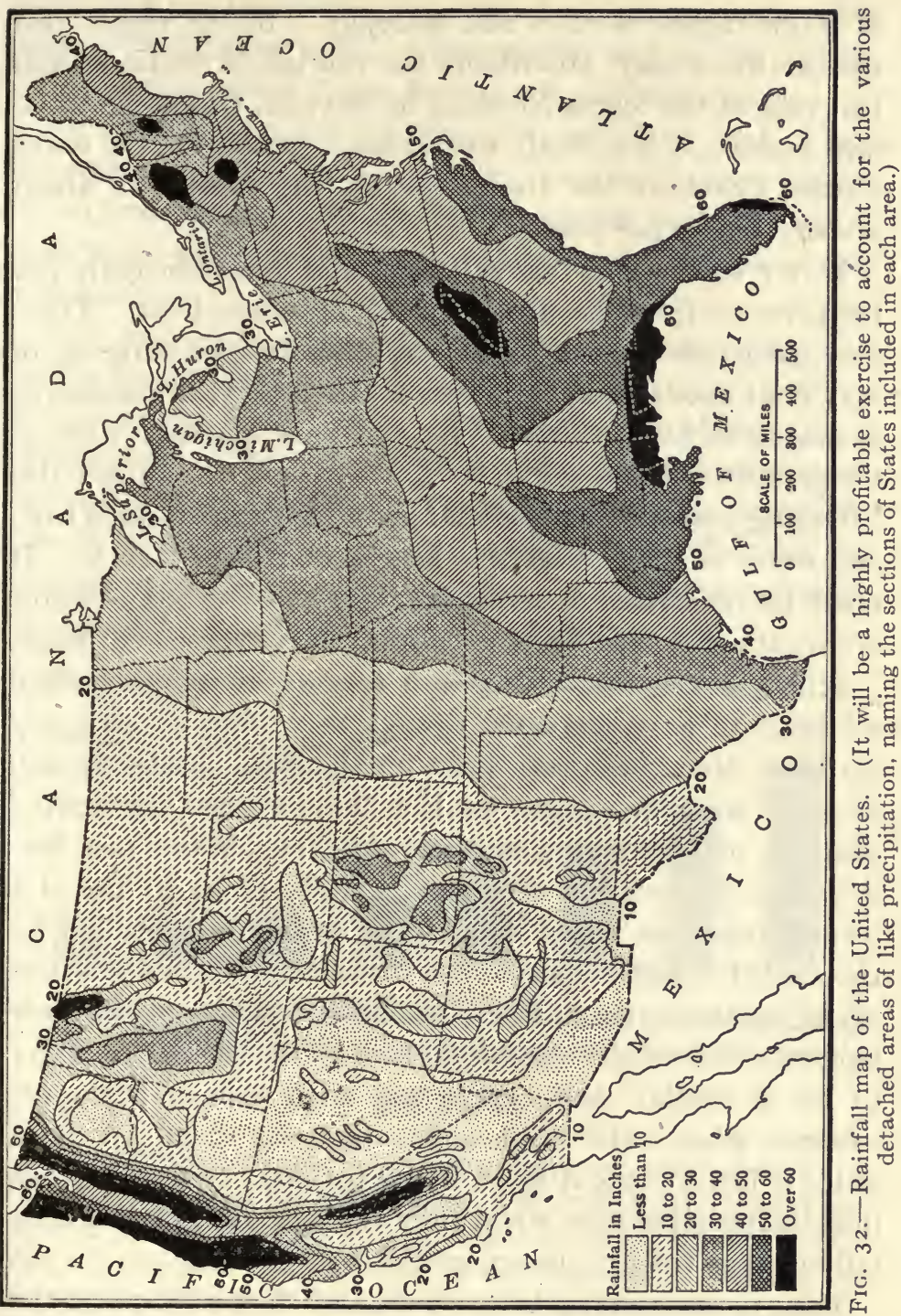


of a few inches more or less annually. In the region just east of the Rocky Mountains the rainfall is deficient, and just east of the Sierra Nevadas in Nevada, Utah, and adjacent regions, it is scarcely five inches a year. On the north Pacific Coast of the United States the rainfall is about seventy inches per year.

Water vapor when cooled rapidly and to a sufficiently low temperature forms beautiful crystals known as frost. These may gather on window panes and other exposed surfaces, or may float about in the air. Snow flakes may be considered as masses of frost crystals. Ice and snow and frost form at temperatures below $32^{\circ} \mathrm{F} .\left(0^{\circ} \mathrm{C}\right.$.), and melt when above this "freezing point." Ice melts at $32^{\circ} \mathrm{F}$. as heat is added to it, and water at $32^{\circ} \mathrm{F}$. freezes as heat is abstracted from it. It must be remembered, however, that vaporization of water occurs at any temperature even from the frozen (solid) state.

When melted iron is run into moulds, it is found when solidified to have increased enough in volume to take any markings that may have been on the sides of the mould. Iron and steel castings are made in this way, and any desired patterns may be had upon their surfaces. When cast iron is broken a crystalline structure is easily noted by use of a magnifying glass. The increase in volume is explained by the added space required for the newly formed crystals whose regular forms do not fit as closely together as did their molecules before the crystals formed. The change of water to ice is similar, and experiences with broken pipes are common when water is allowed to freeze in them. A block of ice is just a mass of more or less perfectly formed crystals indistinguishable save when they are forming or when they fall apart as the ice "honey-combs."

The process of vaporizing solids, and then condensing the vapor to the solid state once more without passing through the liquid state in either case, is called sublimation. The 
solid that has thus passed through both changes is a sublimate. Distillation is the vaporization of a liquid and the condensation of this vapor back to a liquid state again.

Air containing much moisture does not allow heat to pass through it readily. When a cloud passes between an observer and the sun on a hot day in summer the relief due to absorption of the sun's heat within the cloud mass is very noticeable.

Not only does the total amount of water per cubic foot in the air vary at different times, but the capacity of the air for holding water vapor varies widely with changes in its temperature. The ratio of the amount of water vapor present in the air at any time to the amount that the air might then hold is known as relative humidity. It tells what per cent saturated the air is at that time. Air is saturated when the humidity is roo per cent.

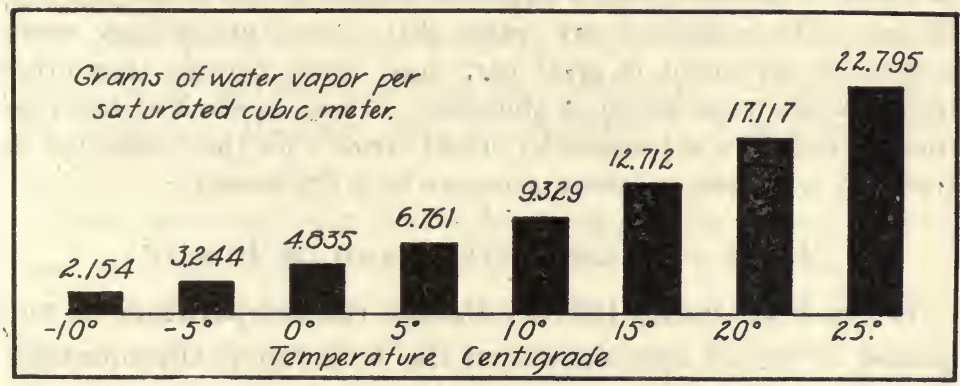

FIG. 33.-Capacity of the air for moisture at different temperatures.

\section{SUMMARY}

The invisible water vapor in the atmosphere when cooled sufficiently is changed back into the liquid state. This cooling may result from incoming cold air as a cold wind, or it may occur when the moistureladen air rises and mixes with air in the upper colder levels of the atmosphere. Then, too, cooling may be the direct result of expansion of air containing water vapor as it rises where the pressure upon it becomes less and less. 
The cloud masses consist of minute droplets of water which are continuously settling toward the earth. While in a general way their forms persist, clouds are all the time undergoing change by wasting at the lower surfaces and by reforming higher up.

When the temperature of the air falls below freezing, the water vapor it contains may be changed to frost crystals. Masses of these crystals form snowflakes. When the ground, the roofs of buildings, and other surfaces are below freezing temperature, and the air is warmer and moisture-laden, frost is likely to form upon the cold surfaces.

The presence of water in the air, whether as vapor or as cloud particles, serves more or less as a blanket, and lessens the rate of cooling of the earth's surface at night.

As the air cools at night its capacity for holding moisture decreases. With the same amount of vapor of water present in the air, its relative humidity or per cent of saturation increases. In the early evening this increase is often rapid.

Condensation is the opposite of vaporization, and both processes are involved in distillation. Natural distillation, with the sun as source of the heat, plays a large and important part in weather conditions. The rainfall of any region that is destitute of large water surfaces is dependent in great part upon winds blowing from other regions where vaporization is abundant. These winds, if unduly continued, result in a wet season for inland areas, while their deflection or cessation for causes unknown accounts for a dry season.

\section{Heat of Vaporization, and of Fusion}

It has been found that to change the temperature of one pound of water one degree on the Fahrenheit thermometer always involves the same amount of heat. It makes no difference whether the water is warmed or cooled. This quantity of heat is used as the unit in computation of heat values, and is known as the British thermal unit.- Then if water weighing twelve ounces (three-fourths pound) has its temperature raised $61 / 2{ }^{\circ} \mathrm{F}$., the water has gained $3 / 4 \times 61 / 2$, or $4 \frac{7}{8}$ British thermal units.

Most science texts make use of the metric system of weights and measures. It is much more simple to learn 
and to use, and its general adoption in business and in schools is desirable. Its heat unit is called the calorie, and its value is the heat involved in changing the temperature of one gram of water one degree of the Centigrade thermometer.

It has been found by repeated experiments, carefully conducted in physics laboratories, that when ice melts about 79 calories of heat disappear for every one gram melted. In other words the heat of fusion of ice is 79 calories per gram. In similar experiments the heat of vaporization is found to be about 536 calories per gram of water.

The meaning of these values is somewhat difficult to grasp at first. Let it be illustrated in this way. To cool boiling hot water $\left(100^{\circ} \mathrm{C}\right.$.) down to the freezing temperature $\left(0^{\circ} \mathrm{C}\right.$.) involves the liberation of 100 calories of heat per gram. If that same one gram of water at $0^{\circ} \mathrm{C}$. is changed to ice at $\circ^{\circ} \mathrm{C}$., involving a change of state from liquid to solid but no change in temperature, almost 80 calories of additional heat are liberated-the heat that was required to keep the gram of ice in the liquid state.

Even more striking is the meaning of the 536 calories of heat of vaporization of water. In the condensation of invisible water vapor ${ }^{1}$ whose temperature is $100^{\circ} \mathrm{C}$. to water that is boiling hot $\left(100^{\circ} \mathrm{C}\right.$.), involving as it does a change of state without change of thermometer readings, there is 5.36 times as much heat set free as when that same water is cooled from its boiling temperature to the freezing temperature.

A common use of the great heat value of this "latent heat" of steam is in the warming of rooms and buildings by the condensation of relatively small weights of steam in radia-

1 The so-called steam that is visible consists of a cloud of minute water particles resulting from the condensation of invisible water vapor. 
tors. These are connected by means of pipes with boilers that are often located at considerable distances away.

It is, however, in the study of Physical Geography, and of Meteorology, that one comes to have some true notion of the vast scale upon which heat is made "latent" in the vaporization of enormous quantities of water by the sun, and then later set free as this water vapor condenses. These changes are going on everywhere over the earth, but on the largest scale in the tropical regions. Our weather, and the intensity of storms, are both directly related to the heat values involved in these changes in the state of water. It will be necessary to keep in mind that other substances than water exhibit like phenomena, and that the value in calories of their heat of fusion and their heat of vaporization varies with the substance.

\section{SUMMARY}

Heat like other forms of energy can be measured. The units employed for this measurement are the calorie, and the British thermal unit.

There is a wide variation in the amounts of heat required to melt equal weights of different solids, and to vaporize equal weights of different liquids. The heat of fusion for water in the form of ice is 79 calories per gram, and for its vaporization from the liquid state is 536 calories per gram.

The heat used in changing water as a liquid into vapor, whether on the stupendous scale of natural vaporization or in steam-heating plants or elsewhere, is wholly set free when condensation of the vapor occurs.

To continue wearing damp or wet clothing, and to allow it to dry out while being worn, involves the abstraction of much heat from the body. This loss of heat ordinarily can ill be afforded.

Soils containing water will absorb large amounts of heat with small rise in their temperature. This is by reason of the high specific heat of water. Then, too, by reason of the extremely large value for the heat of vaporization of water, soils that are water soaked are likely to remain cold and unfit for plant growth late into the Spring, and after periods of wet weather. Soils with good drainage warm much more rapidly. 


\section{Exercises}

1. When persons climb mountains, or go up into the clouds in balloons, what are the clouds found to be?

2. Why does not all the water of the atmosphere fall to earth (a) when it is in vapor (gaseous) form; $(b)$ when in minute droplets as in fog?

3. Why is it that in winter we sometimes can "see our breath?"

4. Explain the thinning out and disappearance of the clouds of early morning as the sun rises higher and higher. Why is it that at other times as rain continues the clouds break away giving place to clear skies?

5. Whenever there is an inch of rainfall, $(a)$ what is the number of cubic feet of water that falls per acre of land; $(b)$ how many gallons (23I cubic inches $=$ one gallon); $(c)$ how many tons (one cubic foot $=62.4$ pounds)?

6. Name and describe several forms of clouds.

7. Aside from rainfall, what important part in nature is served by clouds?

8. How may an ample supply of water for drink and for cooking purposes be provided on long journeys by ship? In what way may a supply of ice be provided?

9. What is meant by "humidity" of the atmosphere? What is the exact significance of the term "relative humidity?"

10. Whence comes the heat, directly or indirectly, for natural distillation?

11. Be ready to quote and interpret the last stanzas of Longfellow's Rain In Summer.

12. What may explain in part the refreshing coolness that frequently follows a summer shower? What relation is there between the temperature of soil under a summer sun and the abundance of water in it? Why is this so?

13. Explain the heating of rooms and buildings by steam as a phenomenon of heat of vaporization. What is true of the temperature of water boiling freely in a tea-kettle as it is heated more and more? Explain.

14. Explain how the melting of ice and snow, and of the frost in the ground, delays the coming of warm weather in spring time.

15. What is meant by the heat of fusion? Describe an experiment to explain it.

16. What is a calorie? What is the value in calories of the latent heat $(a)$ of steam; (b) of ice?

17. What is the part played by moisture in the atmosphere in equalizing throughout the year the temperatures of coast regions? Account for the extremes of temperature of inland arid districts by day and by night.

\section{Solution, Diffusion, Absorption, and Osmosis}

The phenomena of absorption, diffusion, solution, and osmosis are easily understood on the hypothesis that a chief 
difference between the solid, liquid, and gaseous forms of a body is in their rate of molecular movements, and in the size of the spaces ("pores") between the molecules. An hypothesis in science $i s$ a supposition used as an explanation of phenomena. Systematic advance in scientific knowledge makes large use of hypotheses. It must always be remembered, however, that these hypotheses are based upon what is known to be true, and that they are always subject to change to accord with any newly discovered facts.

A belief found to have wide application, and always found

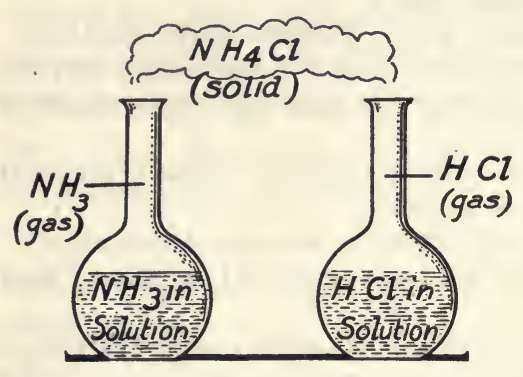

FrG. 34--Diffusion of gases. true to the facts of the natural world wherever it is applicable, is known as a "law" in science. It may be noted here that civil and military laws on the other hand are requirements that certain named things shall be done or shall not be done.

The penalty for disregard of any of nature's laws is not imposed by any court or judge. It follows as a natural consequence of failure to observe them. This is just as true when ignorance occasions the offense as when done wilfully and by design.

When like states of matter intermingle by reason of their own molecular activities, the change (phenomenon) is called diffusion. Owing to the relatively strong attraction between the molecules of solids scarcely any diffusion takes place between them at ordinary temperatures even when in close contact. When molecules of unlike states of matter intermingle the phenomenon is called absorption. If as result of either absorption or diffusion a homogeneous (hōmō-gè'nē-ŭs) liquid results, the term solution is preferred 
to either of the others. When diffusion of liquids or diffusion of gases occurs through a porous (permeable) partition, the phenomenon is called osmosis.

To change a solid to the liquid state requires an expenditure of heat. This is manifestly the case in the melting of ice, and of such substances as sulphur or lead. As salt dissolves in water there may be a noticeable fall in the temperature of the liquid. Heat is abstracted from the water to aid in changing the salt to a solution. When salt has been scattered over ice that has been broken into small lumps the surfaces of which are water covered, the lumps may become frozen together. This is because the heat abstracted from the ice cold water as the salt dissolves is sufficient to convert the water into ice. In the freezing of ice cream the heat lost by the cream is partly used in the solution of the salt to form a brine, but more largely in the melting of the ice packed around the can that contains the cream.

The boiling temperature of the solution of any solid in water is higher, and its freezing temperature is lower, than with pure water. A saturated solution of common salt, for example, does not freeze until the temperature reaches $-22^{\circ} \mathrm{C}$. Advantage is taken of this fact in making ice cream, and in the use of solutions of calcium chloride or of common salt (sodium chloride) for the brine into which the cans of pure water are set in making artificial ice. The waters of sheltered inlets of the ocean may remain open in winter, when near by fresh waters in rivers and lakes become ice covered.

Osmosis in plants and animals is a phenomenon of utmost importance. The circulating fluid in both cases, containing as it does the dissolved food material, must penetrate all parts of the tissues and make available to every living cell the nourishment it needs.

The less dense any solution or gas is the more likely it is 
to pass rapidly through a porous partition. Where liquids or gases upon opposite sides of a partition are of different densities, the more rapid inflow of the less dense fluid causes a pressure within. Though the rise of water through the stems of plants, even to the very tops of the giants of the

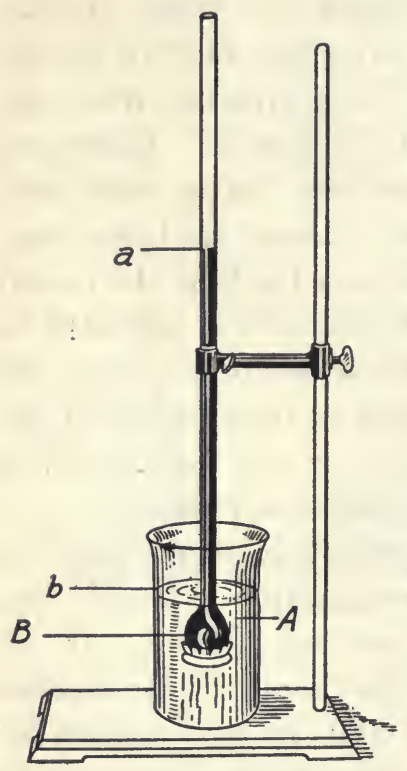

FIG. 35.-Osmosis. The more rapid inflow of liquid from $A$ to $B$ has elevated the liquid surface within from $b$ to $a$. redwood groves of the Pacific Coast, may not be wholly understood, this osmotic pressure is in part an explanation of it. The height of the liquid column in an experiment with a diffusion bulb measures the large pressure developed there. Plants at times do not have a sufficient supply of water in hot summer days to make good their loss through the leaves. If the inflow of sap into the cells of a plant is insufficient to keep them filled, the plant wilts until such time as these conditions change. The term osmosis implies interchange of like fluid states through a porous partition, as liquid mixing with liquid or gas mixing with gas. However, some liquids osmose so very slowly that their passage through the membrane becomes a negligible quantity, and the flow becomes practically a mass movement of one of the fluids in one direction only.

\section{SUMMARY}

Where like states of matter intermingle by reason of their molecular movements alone, as in the mixing of two free gases, the change is known as diffusion. Where the states of matter are unlike, as ink into 
a blotter or air into water, the phenomenon is called absorption. If the result of the diffusion or absorption is a homogeneous liquid, the phenomenon is preferably called solution. Freedom of the molecules to intermingle is common in all these phenomena.

In science a formal statement of a general truth of wide application is known as a law. To the extent to which a law is applicable its statements must always be in accord with the facts of any particular case.

An hypothesis is a supposition advanced to give a clearer understanding of any phenomenon, or any group of closely related phenomena. It is always subject to change as additional information concerning these phenomena is acquired, but it is always based upon what is known to be true.

Where the diffusion of like states of matter takes place through a porous partition, as when the liquids within and without the cells in plants and in animals intermingle, the phenomenon is known as osmosis. The less dense a gas is, or the less dense a liquid is, the more rapidly it gets through. By reason of an unequal rate of diffusion through porous partitions there is developed what is called an osmotic pressure of varying value.

Some substances such as white of egg, glue, and cooked starch, osmose very slowly if at all even as thin liquids. They are known as colloids.

\section{Exercises}

1. Give several illustrations of the phenomena $(a)$ of diffusion; $(b)$ of absorption. In wlich of these cases, if any, is there also a solution? Why so?

2. What length of time can man go without water and $(a)$ not suffer; $(b)$ not die? With abundance of water all about them why do men die of thirst at sea?

3. Why is the "lime" in waters used as drink and in cooking likely to be harmful to the body? Name some of the grains which as foodstuffs are chief sources of supply of bone material.

4. What is meant by the phenomenon of osmosis? How is it to be accounted for? Explain osmotic pressure.

5. That osmosis may go on freely throughout the body what must be true of the condition of the tissues? What is meant by (a) the lymph; $(b)$ the lymphatic (limm-făt'-rk) system of the body?

6. Since the starchy foods from plants, and albuminous foods like white of egg, do not when in solution osmose readily, what change is necessary during digestion besides just dissolving them? 
Streams, Valley Formation, and Surface Erosion

Into the lives of those whose childhood days are spent near beautiful rivers or smaller streams there comes much of pleasure and of education denied to others less happily situated. Aside from the sports of fishing, rowing, skating, and swimming, the variations in surface forms that are an

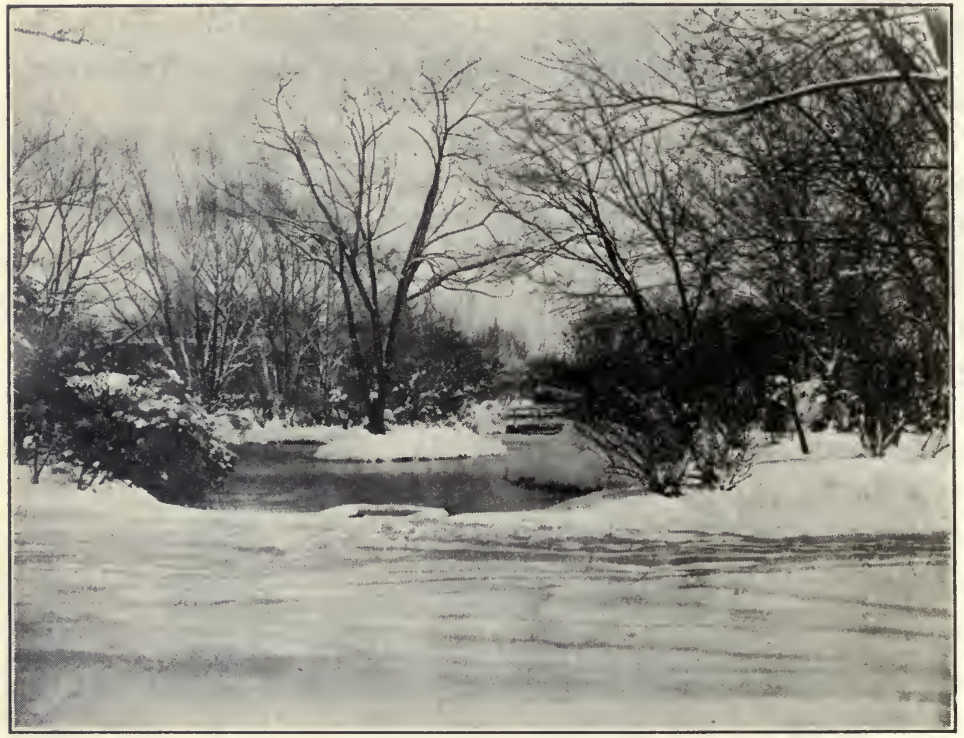

FIG. 36.-A stream in mid-winter.

accompaniment of such streams enrich the experiences of life, and make possible a clearer understanding of the geographic and economic conditions of other regions of the earth. There will be a variety in the landscape due to differences in land elevations, and the occupations of the people will be varied because of the different natural conditions existing in a region of irregular surfaces.

Any study of the history of the United States goes hand 
in hand with a knowledge of its geography. Its navigable streams have affected in large measure the trade and industries of the country, and the location of its large cities. Until the advent of railways, these streams were the chief factors in determining the directions of development of the country. By reason of a full knowledge of the streams of one's own locality, and of their relationship to local affairs, there is made possible a better understanding of the geography and history of the state and nation, and of the more distant parts of the earth.

From a careful study of any good map of one's own county or township ${ }^{1}$, it becomes possible by noting the direction of flow of its streams, to determine among other things $(a)$ where the highest lands are located; $(b)$ what apparently influenced the location of the older settlements known to have been made; $(c)$ how railroads have affected the growth of towns in the region studied; $(d)$ what becomes of the waters flowing out from that region; $(e)$ the probable use made of the streams for trade and industry.

A study of the streams of any section, including their rate of current and volume of flow, the character of 'the banks and the beds of these streams, contributes much to an accurate knowledge of the region in which one lives. Closely associated with this should be a knowledge of the character of the soils, of the natural and industrial resources of that section, and of how its prosperity is related to all these.

One of the most extensive wastes of natural wealth and resources in the United States during the last half of the nineteenth century was that of fertile soil from the surface layers of its landed areas. Extensive forests covering a large portion of the country were cut away, and as a direct result of deforestation enormous waste by erosion went on year after year. Following the breaking up of the sod covering of the

${ }^{1}$ If neither is at hand make use of the largest available map of the State. 


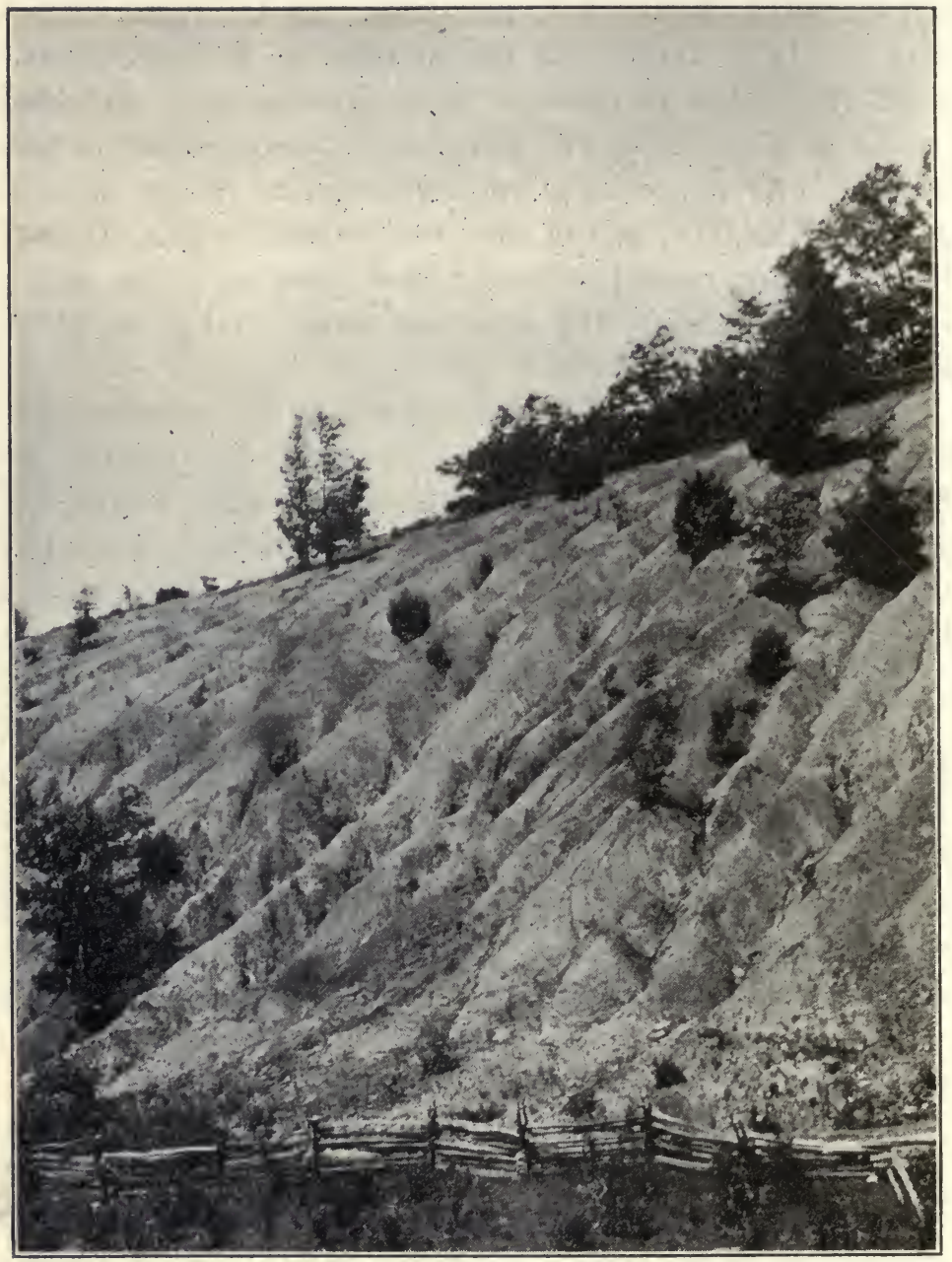

Fig. 37.-An eroded surface. (Courtesy U. S. Forest Service.) 
fertile loam soils of the central portions of the country, products of the decay of vegetation through long periods of time were washed away from the surface slopes.

As direct result of ill-advised methods of cultivation of these slopes, not only were they denuded of their best soil but they became gullied and worthless as tillable land. Proper conservation through tillage and general management might have kept these lands productive for all time. Rivers like the Missouri and the Mississippi have their waters laden with soil washed from the land surfaces within their basins, and this earth material is almost wholly lost as available productive soil ${ }^{1}$. A similar process continued through longer periods has resulted in some parts of the world, such as northern China, in large areas unfit for tillage and for all agricultural pursuits. Though large areas of productive lands are being brought into use by irrigation in the arid sections of the country, the annual losses by erosion of tillable lands, and the washing away of their most fertile parts, represents a deplorable waste of the wealth of the nation. So dependent is the present prosperity and the future greatness of any people or nation upon the productiveness of the soil that its impoverishment rather than its betterment is a national calamity. In I 902 the Reclamation Act was passed by Congress authorizing large outlays for irrigation systems in the arid regions of the United States. These undertakings have involved the building of great dams for storage of waters and the construction of water channels. In Colorado, water from the Gunnison River is made to flow through a long tunnel to irrigate the adjoining valley. The sale of "water rights" on irrigated lands is expected in time to return to the government all the outlays made.

${ }^{1}$ It has been estimated (Salisbury) that the amount of sediment carried daily into the Gulf of Mexico by the Mississippi River is equal to dumping mud and sand into the waters of the gulf at the rate of over thirty car loads of twenty-five tons each every minute continuously day and night. 
In Physical Geography the relation of erosion to valley formation is discussed at length, together with the wonderful results accomplished by streams in making broad and deep ways for themselves. When one looks upon channels that have been worn down through solid rock hundreds of

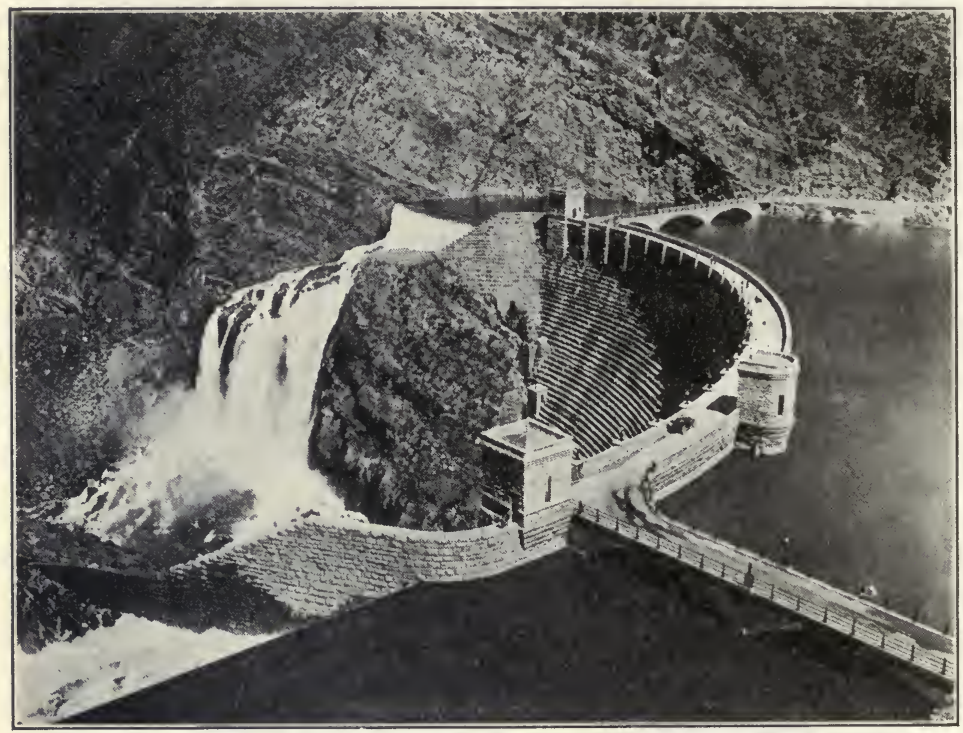

FIg. 38. - The Roosevelt Dam on Salt River, Arizona, is 280 feet high. It has a storage capacity sufficient to cover with water $1,367,000$ acres one foot deep. Below the dam, and out of sight in the picture, is a power-house capable of developing 7,500 horsepower.

feet in depth, and miles in length, the power of running water to do work almost passes belief. And the wonder does not grow less as one considers that this continuous flow of the waters toward sea-level is made possible by their continuous return as atmospheric moisture to elevated regions. As result of solar heating and the vaporization of oceanic waters and the precipitation of this moisture inland on the higher levels, the flow of streams is continuous, and the work of 
leveling down continents goes on ceaselessly. Wherever the bedrock of the earth's crust appears at the surface without any covering of soil, it may be supposed that erosion by the agencies of wind and water has occurred, and that the disintegrated rock particles resulting from weathering have been carried elsewhere.

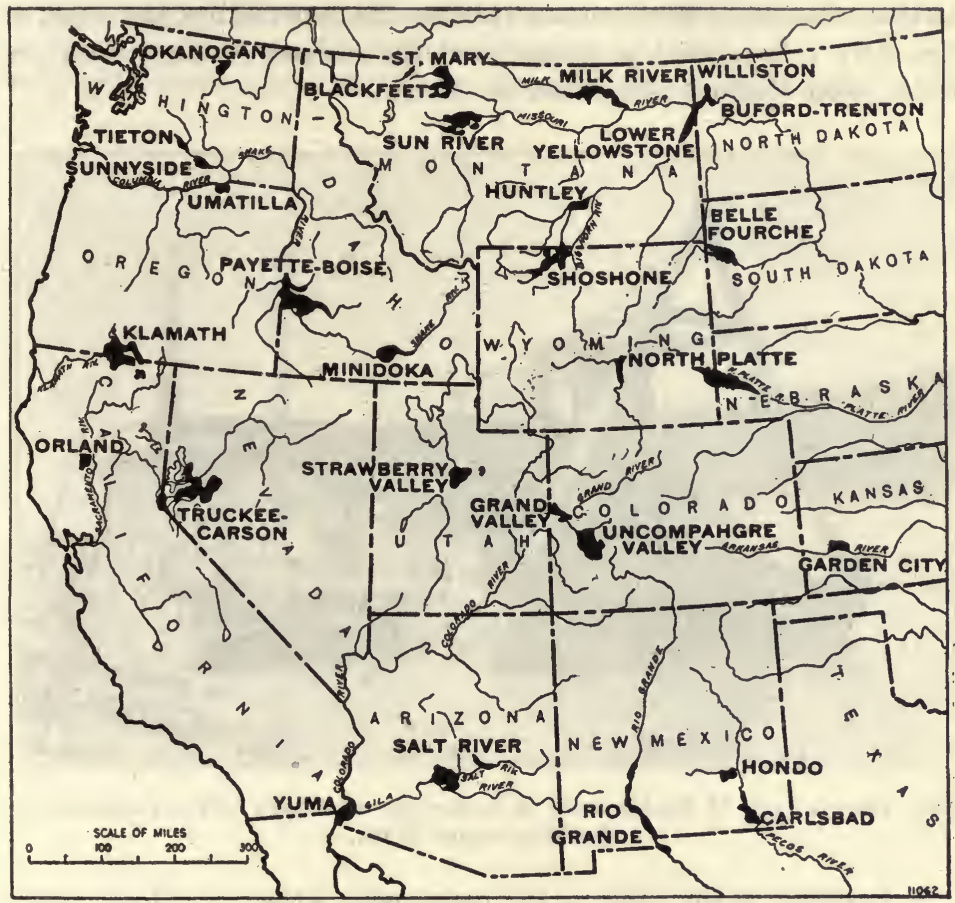

FIG. 39.-Principal irrigation projects in western United States.

\section{SUMMARY}

The navigable streams of the United States figure largely in the history of its exploration and settlement.

Water power is a resource fundamental to the nation's industrial life. Agricultural enterprise on the largest scale is possible only in broad and fertile valleys where the slopes are gentle, and the soil is deep. 
Continued erosion of hillsides and valley slopes is a menace to the wealth of the nation. There is need for intelligent cultivation of the soil on the steeper slopes to conserve its productiveness.

Irrigation has brought under cultivation large tracts of land highly productive when well watered. Many of these irrigation projects are government enterprises not only in this country but in Egypt, India, and elsewhere.

Hills very generally represent relatively hard formations of the earth's crust which have resisted erosion. In general, too, the slopes of the older valleys are less abrupt, and the streams through them are wider, more shallow, and slower in current.

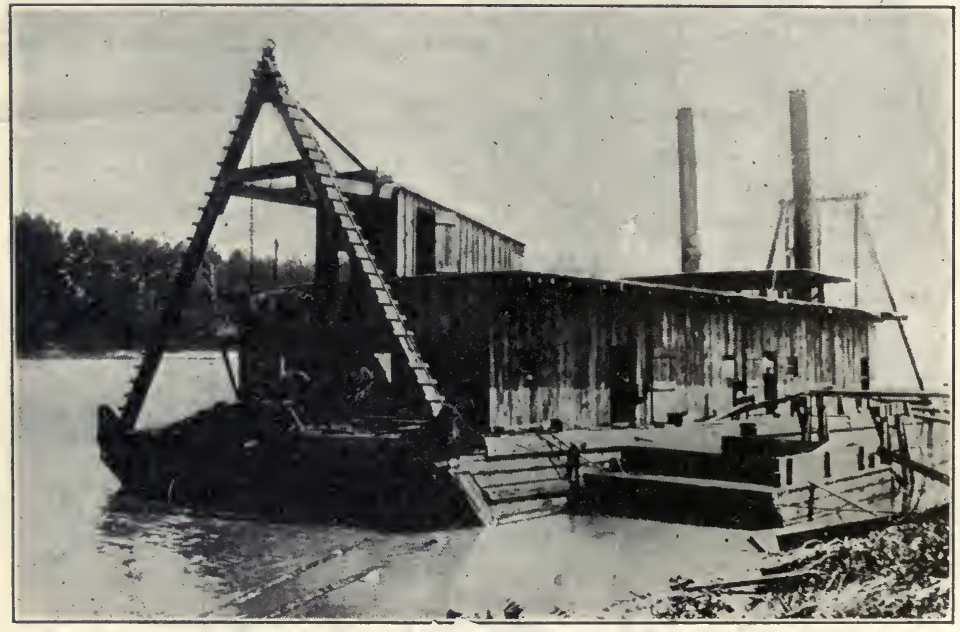

FIG. 40.-A type of dredge used in removing sand bars and silt deposits in the Mississippi River.

A "divide" is the crest at the upper edge where two slopes meet, and where the waters from rainfall and snowfall drain off in different directions. A river system consists of a main stream and all its tributaries. A river basin is the land area whose run-off contributes water to a river system.

\section{Exercises}

1. Name sections of this country where water power is abundant and cheap. Why is it not so in other well-watered regions? 
2. In what respects is electric power preferable to water power? What relation has the existence of water power to cheap and abundant electric power? Mention notable illustrations of this in the United States.

3. What advantages are there in transportation by inland water ways over transportation by railroads? What limitations are there for the former?

4. What notable illustrations recorded in history of the rise of nations as they have engaged in foreign commerce?

5. Name ways in which water is changing the surface forms of earth (a) under man's direction; $(b)$ without any part taken by man.

6. Tell of efforts by man to control the destructive effects of surface waters.

7. Explain valley formation through the agency of water.

8. Why is running water more likely to be pure than stagnant water? 


\section{THE ATMOSPHERE}

\section{Properties AND Uses of AIr}

We are accustomed to think of fish and other marine life as living in the waters of the ocean. But we are less likely to speak of an atmospheric ocean in the bottom of which birds and human beings live and move. It is calculated

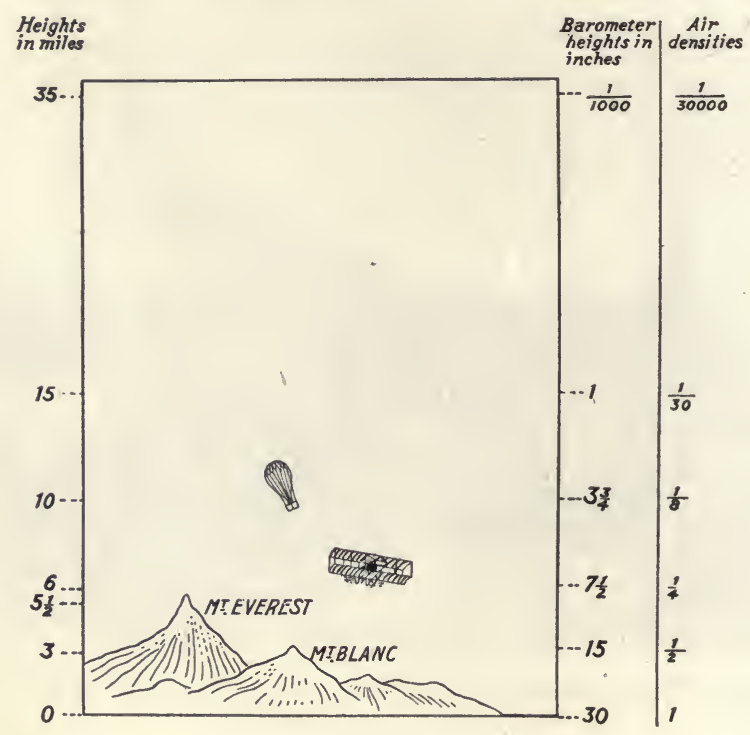

FIg. 41.-Depth and density of the atmosphere. (Tower, Smith \& Turton.)

that one-half of the atmosphere is within four miles of the earth's surface, and twenty-nine thirtieths of it within fifteen miles of sea-level. While probably all of it is inside two hundred miles of the surface, there is no means of knowing positively how far upward it may extend. The highest altitude reached by man is about seven miles. By reason of 
their molecular activities the gases composing the atmosphere expand outward away from the surface until the earth's attraction overcomes their expansive power. This prevents complete loss of these air particles into the vast spaces surrounding the earth.

By reason of the readiness with which air is compressed, the lowermost layers in which man lives are the most dense. As a person ascends a mountain or goes up in a balloon, there is less and less of air (and of oxygen) in any one breath even when the lungs are filled to their utmost capacity. As the air grows more and more rarefied, in order to provide the needed supply of oxygen the breathing is quickened and becomes labored. In time distress is experienced, and a person may become unconscious. In balloon ascensions resort is sometimes made to artificial respiration, pure oxygen gas compressed into tanks being taken along and breathed as needed.

The notions of the ancients concerning the natural agencies against which man has to contend, and whose nature was but dimly comprehended if at all, is illustrated in the myth of Aeolus $^{1}$ and his bag of winds. Disregarding any moral that may be implied, there is no suggestion in it of any conception of whence winds come and whither they go. Literature is filled with references to the winds. Poetry and song abound in allusions to them in terms more or less true to nature. It would be a great pity if, in coming to know better the causes of natural phenomena, this age of scientific thought and achievement should lose any part of the rich inheritance of poetic fancy, though at times it does take strange liberties with scientific fact. References of this character range from the loftiest heights of prophetic vision ${ }^{2}$ to the simple rhymes of the nursery ${ }^{3}$.

1 See story of homeward journey of Ulysses and his companions.

${ }^{2}$ See Psalms I47, I48.

${ }^{3}$ See "The Wind" by Robert Louis Stevenson. 
The atmosphere is washed free of various gases and of suspended solid matter by the rains, and kept constantly agitated and uniformly mixed by diffusion and by air currents. Sunlight kills many bacteria floating in it, and oxidation disposes of much matter in the air of plant and animal origin. Growing plants in sunlight are all the time withdrawing carbon dioxide from the air and returning approximately the same volume of oxygen gas to it. Air has weight just as does all other matter whether solid, liquid, or gaseous. Although this weight varies under different conditions of temperature and pressure, it is approximately one and one-fourth ounces per cubic foot.

The lower layers of the atmosphere at all times contain more or less of water particles as clouds, and water in the form of vapor, and varying quantities of dust and smoke particles. Of the heat received from the sun it is calculated that 60 per cent does not get through to the earth's surface, being arrested in the atmosphere. However, that which does get through to the land and water surfaces is hindered even more by this same blanket of the lower atmosphere from escaping into space by radiation. A frost is much less likely when the sky is beclouded, or the air is filled with smoke.

About 78 per cent of the air is nitrogen gas. This nitrogen is of course breathed in and out of the lungs along with the oxygen. It is non-poisonous and harmless, and it does not support life. It is characterized by its negative qualities, and is tasteless, colorless, odorless, and chemically inert (inactive). It so dilutes the oxygen of the air that the oxidation in the body is kept within bounds. If the air contained a larger per cent of oxygen, fires once started might easily become uncontrollable.

Compounds of nitrogen in the soil in soluble form are indispensable in plant growth, and in this way contribute 
directly to man's supply of foodstuffs. The supply of nitrogen in the atmosphere is inexhaustible. None of man's efforts, however, to form food materials for plants direct from atmospheric nitrogen in large quantities and at relatively low cost have been successful to the extent desired. To maintain and to increase the content of the soil in its nitrogen compounds suitable for plant growth is a problem of science directly concerned with the feeding of the world's population.

\section{SUMMARY}

The atmosphere as a mixture of gases has the properties common to all matter in a gaseous form. Its composition is approximately 78 per cent nitrogen, about $2 \mathrm{I}$ per cent oxygen, $x$ per cent argon, and 3/100 per cent carbon dioxide. Water vapor and dust are present in varying proportions.

It is believed that the atmosphere may extend outward from the earth's surface two hundred miles more or less, but by reason of its compressibility one-half of it is within four miles of sea-level, and twenty-nine thirtieths of it within fifteen miles of the earth's surface. These calculations are based upon readings of barometers that have been carried upward to different altitudes, and upon calculations of the height of meteors when first seen.

So completely is the atmosphere mixed by its own diffusion and by winds that, aside from its content of water and dust, very little variation in its composition is found at different places and at different times. The withdrawal of oxygen from the air by animals, and the increase in its per cent of carbon dioxide due to respiration and combustion, is counterbalanced by the action of plants in abstracting carbon dioxide from the air and setting oxygen free.

Winds are named according to the directions from which they blow. It is likely that the directions of ocean currents in some cases is largely shaped by the direction of prevailing winds.

Atmospheric conditions directly affect health. A cold damp air chills the body surface causing, it may be, colds and other more serious ailments. Very dry air is injurious to the mucous lining of the airpassages, and by its irritating effects may upset the nervous equilibrium of the body. The air-passages and lungs are not only irritated by dust blown about, but disease germs become widely scattered by the air: 
Pressure Exerted by the Atmosphere, and Effect of Pressure on Gases

When masses of air have a velocity of many miles an hour as winds we have evidence of the great pressure exerted by the air. We can feel it push against us as we are hurried along by it in its course, or as we struggle against it when breasting a gale. It is calculated that when a wind is blowing at the rate of twenty miles an hour its pressure upon any surface, such as the side of a building, is approximately two pounds per square foot. At sixty miles per hour this pressure becomes eighteen pounds, and at one hundred miles per hour fifty pounds per square foot. The pressure increases as the square of the increase in velocity. Winds approaching this greatest velocity are known as hurricanes, and their destructive violence can readily be understood.

When the atmosphere is calm, however, we do not ordinarily appreciate the fact that it exerts any pressure upon exposed surfaces. This pressure may be thought of as the weight of a column of air reaching downward from the uppermost level of the atmosphere, and having a cross-section the same as that of the body pressed upon. The weight of the mercury contained in a barometer tube is used to measure the value of atmospheric pressure. At sea-level the height of the mercury column averages about thirty inches (or $76 \mathrm{~cm}$.), and this height is taken as the standard for atmospheric pressure. As the weight of a column of mercury thirty inches high and one square inch cross-section is about fourteen and one-half pounds, the pressure of the atmosphere at sealevel must be fourteen and one-half pounds per square inch. This amount of pressure by any gas is often spoken of as "one atmosphere." In making bárometers great care is exercised that the space above the mercury in the tube shall be free of air. 
Air penetrating the tissues of our bodies maintains a pressure within equal and opposite to the pressure from without. We are unconscious of the existence of any such air pressure until in some way an inequality is brought about in it.

For changes in altitude on or near the earth's surface the barometer falls about one inch for every rooo feet elevation. In balloon ascensions where the rise is rapid, the aeronaut

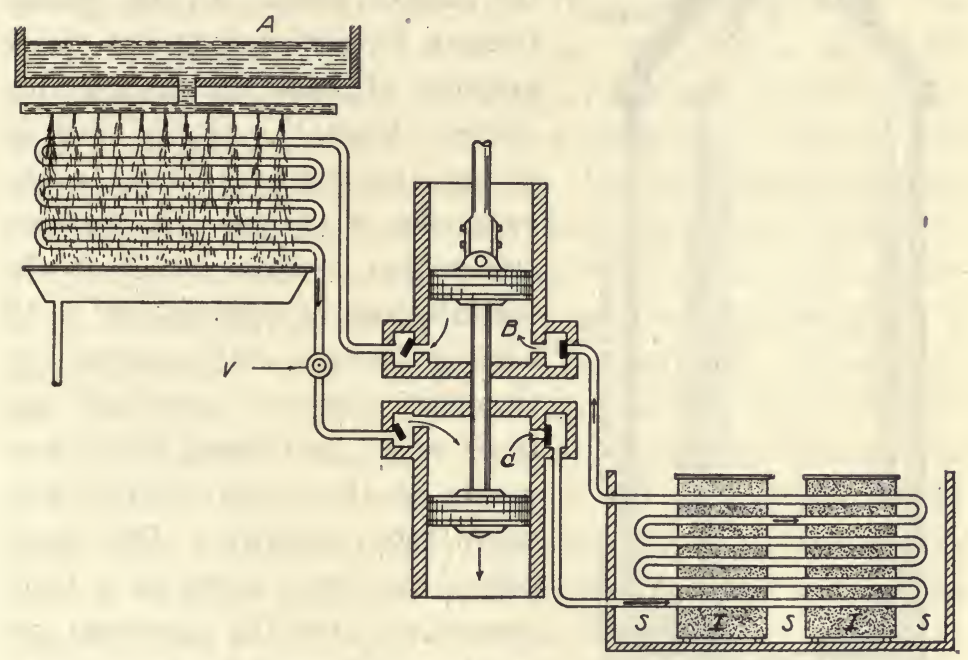

FIG. 42.- The manufacture of artificial ice. $\quad V$, Valve regulating pressure; $A$, water supply, and drip, to carry off heat from compression of the ammonia gas; $I$, containers of distilled water to be frozen; $S$, brine (solution of low freezing temperature); $B$, compression chamber; $C$, expansion chamber.

sometimes bleeds at the nose and mouth because of the rupture of the walls of blood vessels. This is due to the fact that the gaseous pressure within the blood soon becomes greater than the outer air pressure, the latter being rapidly reduced because of the ascent.

It is customary not to fill balloons full of gas before they are sent up owing to the expansion of the gas as the balloon rises into the less dense upper atmosphere. The heat of the 
direct rays of the sun may intensify this increase in volume, and there is great risk of bursting the gas envelope.

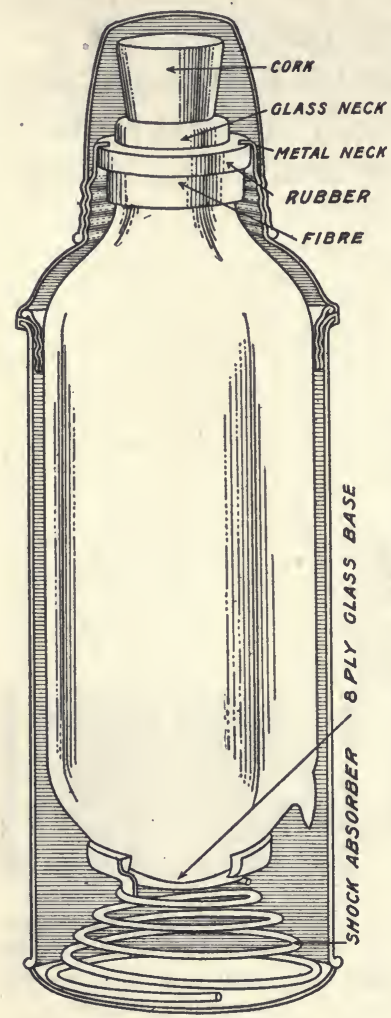

FIG. 43.-A thermos bottle. The air was withdrawn from between the double glass walls, and the opening then sealed by melting off the tube as shown at the lower right side of the bottle. The metal case is for protection only. (Tower, Smith \& Turton.)

By compressing gases sufficiently it is possible to cause a change in them from the gaseous to a liquid state. When this pressure is released the liquid changes back to the gaseous form. In the change from a liquid to a gas a large amount of heat disappears (becomes "latent"). It is used in giving increased velocity to the molecules of the gas. A common application of this fact is in the manufacture of artificial ice ${ }^{1}$. An exhaust pump is employed to continuously remove ammonia gas from pipes containing liquid ammonia so that vaporization goes on in them rapidly. This same pump may also serve as a compressor to force the ammonia gas much compressed (perhaps liquefied) back into the pipes of the cooling tank. The same ammonia is thus used repeatedly to cool the salt solution (see page 99) in which the pipes are submerged. The energy required to run the pump and compressor is furnished by an engine.

${ }^{1}$ A discussion of the steps involved usually may be found in texts in Physics in connection with the subject of heat, and in Chemistry in connection with the topic ammonia. 
With powerful pumps it is possible to so compress air in pipes capable of withstanding great strain that when the compressed air is cooled to a very low temperature it changes to a liquid state, and becomes liquid air. It then looks very much like water. As the air is being compressed its temperature is raised by reason of the crowding together of its molecules. The pipes containing it can be kept cool, however, by allowing water to run over them to carry away the "heat of compression." When stop cocks in the pipes are now opened a very little, allowing an outrush of some of the highly compressed air into an enclosed space around the pipes, its expansion is so excessive that its temperature and that of the compressed air within the pipes is greatly lowered. While there is loss of much of the compressed air in its return to its normal density, other portions of it will be changed to a liquid form by reason of the low temperature. Liquid air must be kept in containers that are like "thermos" bottles in having double walls from between which the air has been withdrawn. These containers must not be kept stoppered other than with a plug of cotton since the enormous expansion in volume of this air as it slowly changes back to the gaseous form would cause destructive explosions.

Among the many things that are fascinating in the story of liquid air, mention can be made here only of its use as a source of nearly pure oxygen gas at a relatively low cost of production. The atmosphere is largely composed of oxygen and nitrogen gases in the proportion of about four volumes of nitrogen to one of oxygen. When air is liquefied it consists of a mixture of liquid oxygen and liquid nitrogen. Any water vapor and any carbon dioxide gas present in the air at first will have been eliminated by having been solidified (frozen). At ordinary temperatures and pressures this liquefied air changes back to the gaseous condition rapidly, and in this vaporization the liquid nitrogen changes to a gas 
first leaving an almost pure liquid oxygen. This oxygen as a much compressed gas in strong steel cylinders can be transported for use anywhere.

\section{SUMMARY}

Differences in atmospheric pressure are due to differences in density. This change in density results from changes in temperature and from variations in the amount of water vapor present in the air. The higher the temperature and the greater the amount of water vapor the less the density.

The rise and fall of the mercury column in the barometer measures the varying pressure of the atmosphere whatever the occasion of its change in density. Any considerable fall of the barometer within a short time usually indicates a marked increase in the amount of water vapor in the atmosphere, making more probable the precipitation of some of it as rain or snow.

The volume of any gas is inversely proportional to the pressure upon it.

Gases may be changed to liquids by subjecting them to high pressure and low temperature. The heat resulting from their compression is easily disposed of by allowing cold water to flow over the pipes in which the gas is confined.

Compressed gases when allowed to expand abstract from surrounding bodies an amount of heat equal to what was freed in compressing them. The cooling effect of compressed gases when allowed to expand is extensively used in maintaining low temperatures in cold storage houses, in the manufacture of artificial ice, and in keeping large buildings cool in summer.

Ammonia gas is a by-product of the plants where illuminating gas is made. This gas is easily liquefied, and it can be purchased in the liquid form confined in heavy steel cylinders. It is to be remembered that the ammonia water of the laboratory and the laundry is merely water containing ammonia gas in solution.

The temperatures at which different gases change to liquids when under the same pressure vary widely. For the same gas it is always the same.

\section{Applications of Atmospheric Pressure}

That man can live and move about far below the surface of water, that he can build foundations for bridges out in 
mid-stream from bedrock upward, and that he can carry on warfare beneath the waves of the ocean, seems marvelous. These achievements rank with man's mastery of the atmosphere in which he makes the air a highway for travel and for sport, and a place for carrying on warfare. But at all times and everywhere man must be provided with an abundance of air to breathe, or death from lack of oxygen speedily follows.

By use of powerful compression pumps large volumes of air may be made to occupy little space within a submarine. By its withdrawal from one side of an air-tight movable partition water can push its way into the boat, causing it to sink. By allowing the compressed air to expand this water is again driven out, and the boat is so lightened that it will come to the surface. By use of electric motors, the boat is rapidly

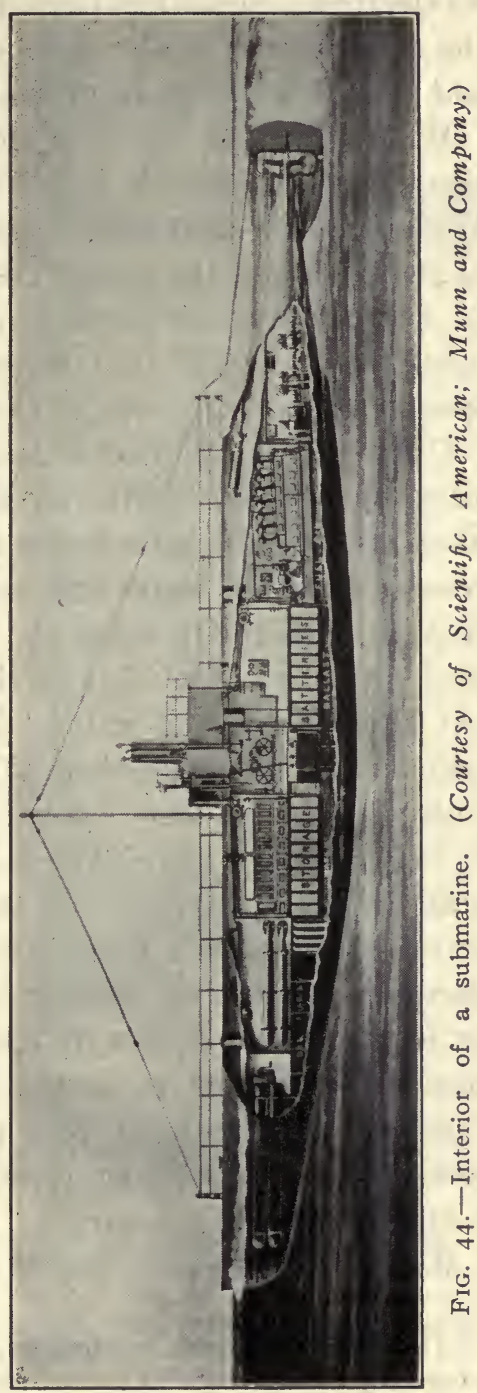
propelled through the water beneath the surface, and its 
rise to surface or its descent into the depths greatly accelerated. Small but powerful gas engines are used when the submarine is at the surface. Electricity from dynamos and storage batteries furnishes light for the boat.

While provision can be made to keep up artificial respiration for a considerable length of time, any accident to the machinery of a submarine when submerged is likely to result in its becoming the burial casket for its imprisoned crew. So enormous is the pressure of the water outside at any considerable depth ${ }^{1}$ that attempts to escape through any opening made in the side of the craft may be futile.

Caissons ( $\left(\bar{a}^{\prime}\right.$-sŏnz) are usually large hollow steel cylinders made up of short lengths riveted together. These sections when taken to the place where a bridge pier is to be built are lowered into the water one at a time, and on top of one another, till the lowermost one reaches bottom. Each section in turn is riveted to the upper edge of the section last lowered into the water. While this is being done the cylinder hangs suspended. It is weighted by masonry built within it to keep it down in the water, and to prevent its being swept away. The lowermost part of the cylinder is an air-tight chamber, and compressed air forced into this chamber from above keeps out the water. Excavation can then go on inside the bottom of the cylinder, allowing it to settle deeper and deeper by reason of its own weight. The material excavated is hoisted out through shafts having "air-locks" (partitions) that prevent escape of the compressed air. In due time from the bedrock up the cylinder is filled with solid masonry.

When workmen pass into or out of the working chambers

1 The pressure of water in pounds per square foot upon a submerged body is found by multiplying 62.4 pounds (the weight of one cubic foot of water) by the depth of the body below surface. In sea water the weight per cubic foot is about $2 \frac{1}{2}$ per cent greater. 


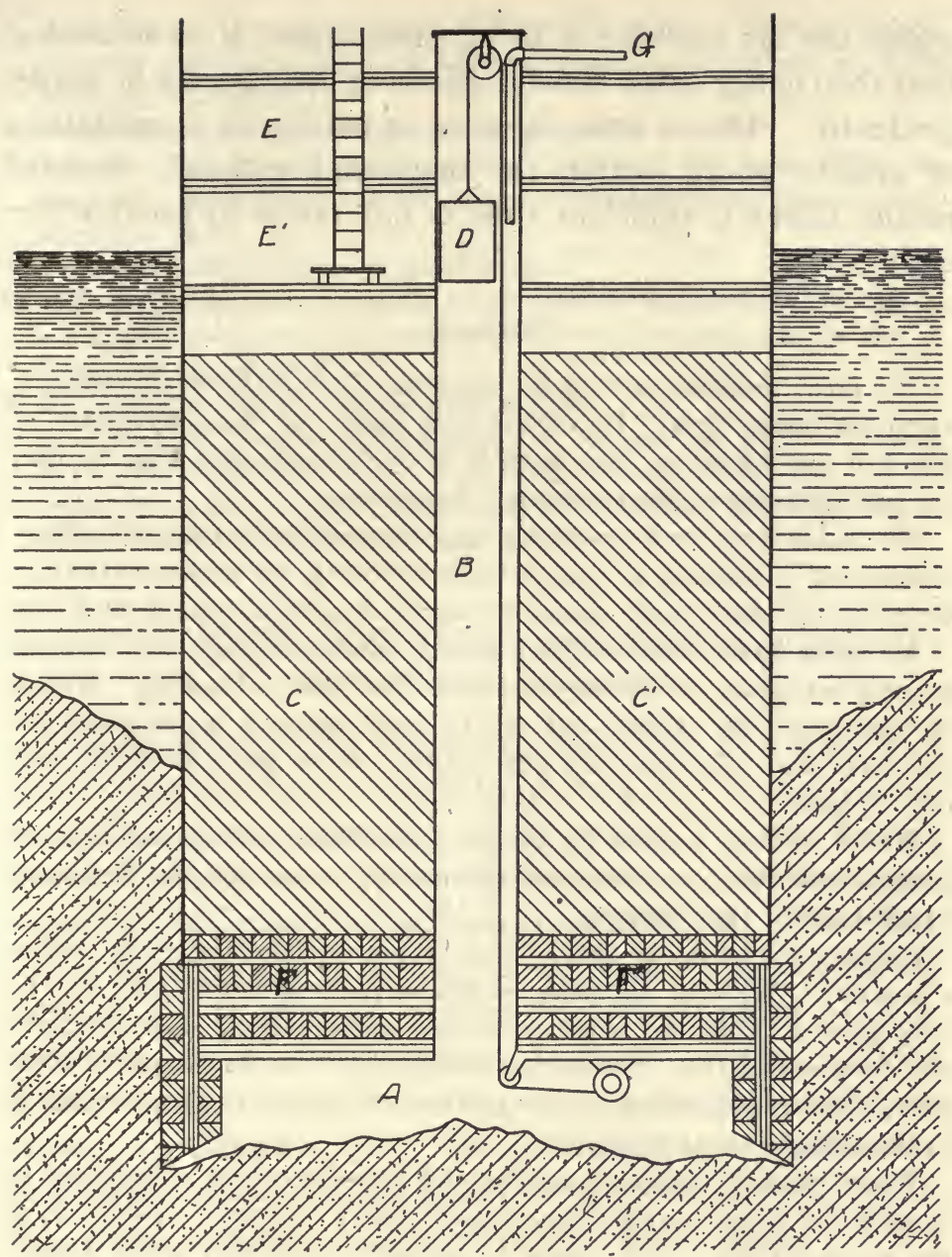

FIG. 45.-Caissons. $A$, the working chamber where excavation goes on in an atmosphere of such density (and pressure) that water from without is kept from entering; $B$, air-tight shaft through which workmen and material pass up and down; $E, E^{\prime}$, chambers through which workmen pass to and fro from the cage, and where the atmospheric pressure to which they are subjected is gradually changed. $F, F^{\prime}$, ballast of masonry to keep caisson in place; $G$, pipe conveying air under great pressure into the caisson chambers. 
where the air pressure is being maintained, it is necessary that the change in air density affecting their bodies be made gradually. This is done in order to permit an equalization of density of air within the body and without. Serious results follow if sufficient time is not taken to provide for this.

\section{SUMMARY}

The great pressure exerted by compressed air makes it an effective agent for doing work. Its escape from pipes and hose, by means of which it can be taken anywhere, is so easily controlled that its uses are manifold and of great economic importance.

Air-brakes have made possible a large increase in the speed of railway trains, and a decrease in danger from accidents, by reason of the fact that the engineer is given complete control of a train through their use.

Air drills have revolutionized mining, tunnel building, and all engineering enterprises involving the removal of rock by blasting. By aid of compressed air excavations can be made beneath water when not too deep, and solid masonry put in place under water from the bedrock upward.

Where drilling is done by use of compressed air in mines and in tunnel headings, the escaping air serves to provide the necessary ventilation for the workmen.

Compressed air in the tires of bicycles and automobiles makes riding a comfort. Without spraying outfits employing compressed air the fruit grower could not wage profitable warfare upon insect enemies and fungus growths. Submarine navigation involves the use of compressed air in controlling submergence of the boats, and for air supply to the persons aboard the boats.

Water pumps commonly employ the pressure of the atmosphere to raise water above a valve placed some thirty feet more or less above the water surface. This height varies with the density of the atmosphere, and its consequent pressure. The flow of water through siphons where it runs "up-hill" part of the way is due to atmospheric pressure.

\section{Exercises}

Get information from all sources at hand upon some or all of the topics named below. Describe the construction and operation of these appliances. Use drawings wherever helpful to clearness. Be concise in the descriptions. 
1. Air drills, and their uses in mines and tunnel building. Their advantages over the old hand drills $(a)$ in amount of work accomplished; $(b)$ in the health of the workmen.

2. Pneumatic tubes, and their uses as change carriers in stores.

3. Vacuum cleaners, and their uses for household purposes. The care necessarily given them, and the causes of their failure to give satisfactory service at times.

4. Air-brakes, and their uses on railway trains.

5. The construction and operation of an artificial ice plant. Make use of a diagram, and be sure to make very clear the part played in the process by heat of vaporization.

6. The sand blast, and the uses to which it is put.

7. Spraying outfits used by fruit growers, and for painting large structures, or surfaces where hand work is too difficult or too expensive.

8. Pneumatic hammers used in riveting together the steel frames of bridges, large buildings, and other structural work.

Currents in the Atmosphere, and Their Relation to Atmospheric Pressure

It is not infrequently noted that when a great fire occurs a wind begins blowing, fanning the flames and driving on the fire. The great masses of air heated by the fire have a lessened density as result of expansion due to the heat, and a pressure less than that of the surrounding air. The result of this is an inrush of the denser air from all sides, and the warmed air is crowded upward as the direction of least resistance. The usual statement concerning this condition is that when the air is warmed it rises, and the cooler air rushes in to take its place. This mistakes cause and effect. The less its density the greater the ease with which the air is crowded upward, and the more rapid its ascent.

The presence of water vapor in the atmosphere lessens its density. If water vapor is added to any certain amount of dry air, the combined weight must of course be greater than the weight of the air alone. But moisture-laden air weighs less per cubic foot than dry air. If now from the weight of a cubic foot of saturated air is taken the weight of 
the water in it, the weight of the dried air remaining is found to be less than what the weight of a cubic foot of dry air at that temperature should be. Evidently the decrease in density of air to which water vapor is added results from the replacement of some air by water vapor whose density is only about five-eighths (.62) as great as that of dry air. In its change from the liquid to the gaseous state water increases in volume about sixteen hundred fold.

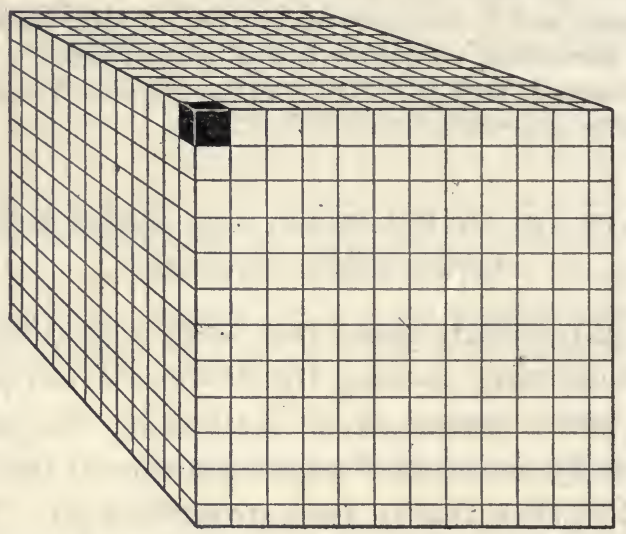

FIG. 46.- In changing from a liquid to a vapor water expands about sixteen hundred fold. (Tower, Smith \& Turton.)

As a rule the winds that spring up at times of great conflagrations blow in one direction only, becoming oftentimes a gale in violence. To account for this it may be supposed that the atmospheric pressure is greater at a place in some one direction from the ascending warmed air, and that the inrush from that side is more marked. Gradually the air current or wind from that direction becomes dominant, supplying the volume of air of the ascending current so completely that any movement of air inward from other directions is not noticeable.

This condition of atmospheric movement as a result of 
the fire may be likened to a high chimney or smoke stack through which is maintained a violent uprush or draft hundreds of feet in height. This will be continued as long as sufficient heat is supplied from the fire below. In some respects this condition resembles that existing in and about the funnel of a tornado whose passage across a country leaves a trail of destruction. Fortunately the width of the

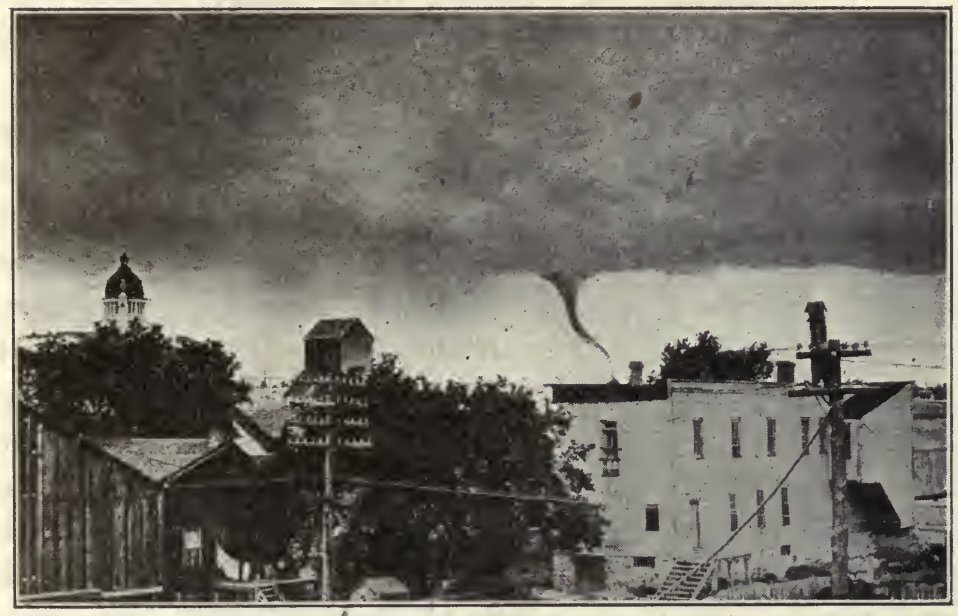

FIG. 47.-The tornado is a storehouse of energy.

track of the tornado is often scarcely more than fifty or one hundred feet and rarely more than one-half mile. While the velocity of the air whirl about the funnel may at times approach two hundred miles or more an hour, the progress across country may be only forty or fifty miles per hour.

In the case of the tornado the heat required to maintain the updraft is largely the latent heat (heat of vaporization) which is set free as a result of the condensation of atmospheric moisture. (See page 96.) When moisture-laden air feeds into the upward moving air current, it expands very rapidly, with an accompanying fall in temperature and 
the condensation of much moisture. It is to this excessive condensation and consequent heavy rainfall that the inky black cloud accompanying the tornado is usually due. At times more or less of dust and soil is carried up by the rising air currents. The more moisture there may be in the air the more of condensation there will be. The more latent heat there is liberated the greater will be the upward rush within the funnel of the tornado. As the supply of moistureladen air lessens, the violence of the storm subsides, and the tornado may thus die out because of lack of heat energy.

The air that constitutes a tornado has a violent whirling motion. As a result of this the interior of the whirl is likely to be very much rarefied, approaching more or less the condition in a vacuum. As the warmed air rises, its ascent becomes a spiral, and in the northern hemisphere the direction of the whirl $i$ s to the right around the centre of motion. In dusty roadways on hot days in summer there are often seen illustrations of this air movement in the dust whirls that spring up apparently without any disturbance whatever from passing air currents. In such cases the highly heated air would seem to have broken its way through and upward, and to rise with sufficient energy to carry with it in its whirling motion some of the finer dust particles.

\section{SUMMARY}

Wind is a term that very properly may be restricted to air currents along the earth's surface of sufficient velocity to be noticeable. Winds are the direct result of inequality of pressure in different parts of the atmosphere, the result of unequal heating and of varying amounts of moisture.

All air currents, including winds, may be considered as efforts to restore equilibrium in an atmospheric pressure that is all the time being disturbed by solar heating, and by the processes of vaporization and condensation.

Somewhere off in the general direction toward which the wind is blowing the air of lighter density and lesser pressure is being forced 
upward away from the earth's surface as an ascending air current, thus ceasing to be a wind. And somewhere off in the general direction from which the wind comes we may suppose that there is a region where cool, dry, and therefore dense air is settling down from the upper atmosphere.

In tornadoes not only is there an uprush of air having great velocity, but at the same.time this ascending air may have a far swifter whirling motion that causes it to rise with a spiral movement, and to have a twisting effect on objects.

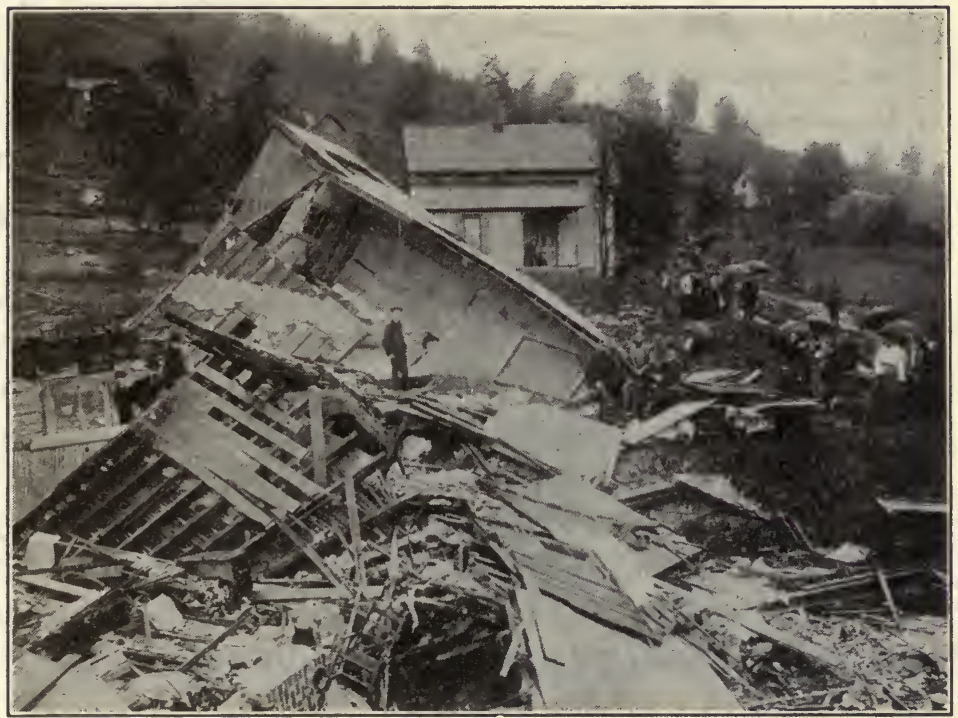

FIG. 48.-The effects of a tornado.

The central portions of the funnel of the tornado may be considered as more or less a vacuum. This results from the whirling motion which throws the air outward away from the centre of the rising column.

Buildings more or less tightly closed, and caught in the centre of the track of a tornado, are sometimes found with their walls pushed outward by the air which was confined within them. The air outside them must have been almost instantly and completely withdrawn upward and away from them. 


\section{Areas of High and Low Pressure}

The rotation of the earth is one of the great factors in establishing the direction of the air currents of the earth as a whole. At the equator the velocity eastward of the earth's surface is about seventeen miles per minute $(25,000$ miles in 24 hours). The atmosphere resting on the land and water surfaces shares in this eastward velocity. It is a rate much greater than the drift of the upper air currents from the equatorial region toward the poles.

As a resultant of these two motions (velocities) northward and eastward, the upper air currents of the northern hemisphere instead of following a meridian due northward drift toward the northeast, and perhaps somewhat more easterly than northerly.

By reason of the earth's rotation, too, the winds (surface currents) in the northern hemisphere blowing toward the equator pass over regions of greater and greater eastward velocity as they approach the equator. This southward moving air does not acquire this eastward motion of the earth's surface readily enough to maintain a southerly direction along a meridian, but is all the time being left behind (deflected) to the westward. Its direction across the earth's surface instead of being due south is southwesterly, i.e., it becomes a northeast wind.

As the causes which accomplish these results are continuously operative, the trade winds of the northern hemisphere as well as like winds in the southern hemisphere are quite constant both in direction and in velocity. This movement is especially marked on the oceans where disturbing factors do not enter in to overcome or divert them.

In the middle latitudes, as in the United States, this planetary circulation (air currents of the earth as a whole) controls wind direction only in part. The course taken by the 
wind in these regions is almost wholly a matter of the direction of an inrush of surface air into areas of low pressure, or of an outrush from areas of high pressure. In other words

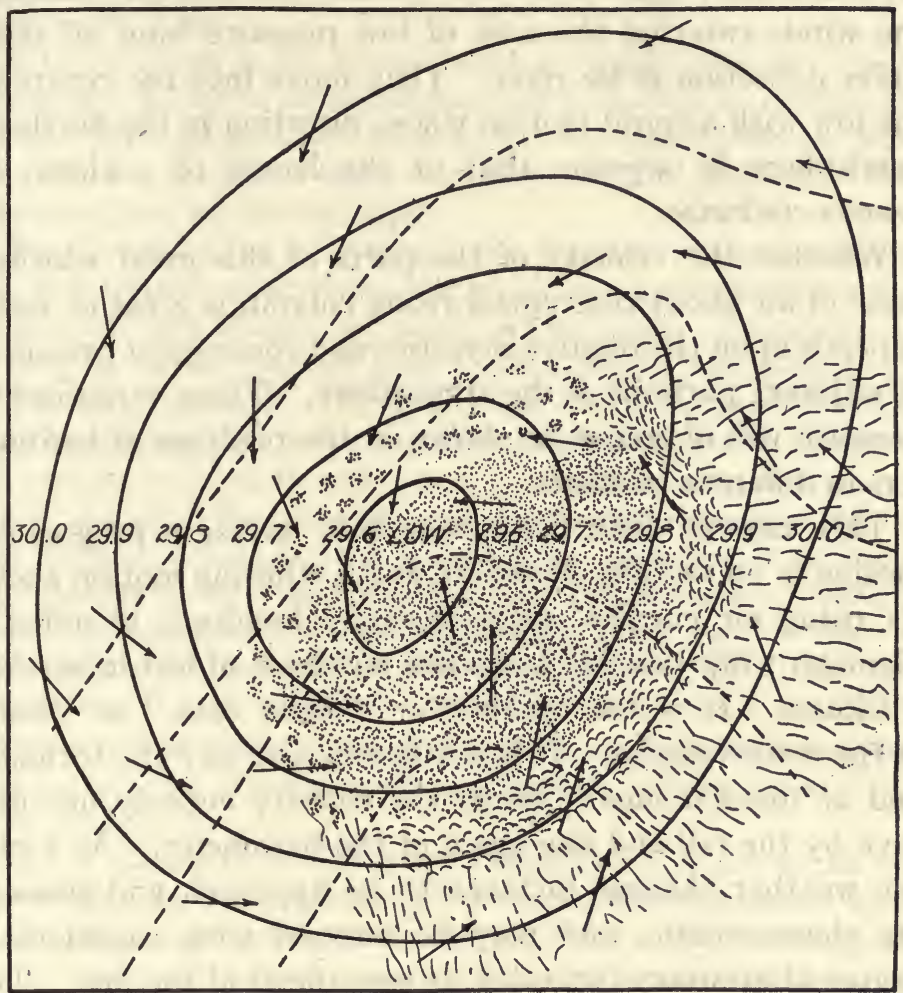

FIG. 49.-The direction of winds into a low. The solid lines are isobars, and the shaded areas in the east and southeast quadrants show. where precipitation commonly occurs. The whole storm area may be thought of as an inverted funnel with its centre of least pressure the place for escape of.air upward.

this is a region of variable winds controlled almost wholly by the successive passages across country of areas of high and low pressure.

The conditions that have been discussed above cause the 
flow of air into a low from the south to be deflected toward the right (east). The flow into a low from the north is likewise deflected towards the right (now the west). As the inflow from the other sides of the low are affected in a like manner, the winds entering the area of low pressure from all sides suffer deflection to the right. They move into the centre of the low with a spiral motion whose direction in the northern hemisphere is opposite that of the hands of a clock, or counter-clockwise.

Whether the velocity of the parts of this great whirling mass of air about the central rising column is great or small depends upon the relative densities and consequent pressures of adjacent portions of the atmosphere. These variations in pressure will of course be shown in the readings of barometers in different localities.

This mass of disturbed atmosphere having a progressive motion in an easterly direction, and a whirling motion about its rising air current, may be many hundreds of miles in diameter while possibly but a few hundreds of feet in vertical thickness. It is the cyclone, or "storm area," or "low" of the meteorologist. It is not destructive like the tornado, and at times it moves across the country entirely unnoted save by the fall and rise again of the barometer. As a rule the weather changes incident to its approach and passage are characteristic, and may be foretold with considerable degree of accuracy for a day or two ahead of the low. The average eastern progress of the cyclonic movement is about thirty miles per hour.

\section{SUMmary}

As moisture-laden air feeds into the rising air current at the centre of a "low," the lessened density and pressure there allows its expansion. The lowered temperature that results from this expansion may at times result in cloud formation only, while at other times there will be more or less of precipitation. 
The spiral movement of air upward around the centre of a "low" may be accounted for as the result of differences in the rate of eastward motion of portions of the earth's surface in different latitudes. This velocity varies from seventeen miles a minute at the equator to a zero value at the poles.

Wind directions in the United States are largely controlled by the changing positions of the atmospheric conditions known as highs and lows in their passage across the country. In a general way the winds at any point are from a high toward a low, and the positions of these highs and lows are ever changing.

The cyclone of the meteorologist is a condition of the atmosphere, not a destructive storm. The weather changes accompanying it may at times be very marked, and again scarcely noted. Its average rate of progress eastward is about seven hundred miles in twenty-four hours.

The heat equator is an imaginary line that for sake of simplicity may be considered as connecting all those places where the sun's rays are vertical as the earth makes each day's rotation. Such a line continued day after day would be a spiral, extending as far northward as the Tropic of Cancer on June 2I, and as far southward as the Tropic of Capricorn on or about December $2 \mathrm{x}$. This involves a shifting of over three thousand miles north and south in six month's time. It practically coincides with the earth's equator on or about the dates September 2I and March 2I. Owing to differences in altitude of places along the course of the heat equator, and because of local conditions, any line connecting places of highest temperature would be very irregular.

As the northward moving upper atmosphere gradually settles over the North American continent and comes to the earth's surface in the Rocky Mountain plateau, it may be considered as still retaining more or less of its eastward motion acquired in the equatorial regions. As dry cold air, and therefore dense air, its eastward passage across country will be accompanied by relatively high barometer readings, clear skies, and cooler temperatures. Its advancing eastern edge may so chill the atmosphere of any section to which it comes as to cause cloudiness, with possible precipitation in the form of snow.

\section{Exercises}

1. What determines the height at which a column of mercury in a barometer tube is sustained? Why would a water column be sustained at a greater height? 
2. What are the twa common causes of change in atmospheric pressure? What is the reason for forecasting rain when there is a marked fall in the mercury of the barometer?

3. What is true $(a)$ of the relative weights of dry and moisture-laden air; (b) of the capacity of air to hold moisture as its temperature rises? What are the relative densities of water vapor and of air?

4. What is meant by the heat equalor? What is its location relative to the earth's equator? Account for its shifting position.

5. Discuss the conditions that give rise to a more or less constant "low pressure" along the heat equator.

6. What is an explanation of the heavy rainfall accompanying the migration of the heat equator north and south, and the recurrence of the rainy seasons in the Tropics? Under what conditions may there be only cloud formation as moisture-laden air rises?

7. Give a possible explanation (a) for the origin of the highs; $(b)$ for their generally eastward motion across the United States.

8. Account for the fact that any wind moving northward in the northern hemisphere is deflected east of north, becoming a southwest rather than a south wind. In what direction do winds in the northern hemisphere move about a low as regards the direction in motion of clock hands?

9. How is the cooling of air as it rises largely to be accounted for?

10. What condition of atmosphere is supposed to exist within the funnel of a tornado? Why is this?

11. What is a plausible explanation for the increase (or decrease) in violence of a tornado? Why does a tornado after a time cease to exist as a destructive storm?

12. Distinguish between a cyclone and a tornado. 


\section{WEATHER AND CLIMATE}

\section{Weather in the Affairs of Men}

It is not at all strange that comments upon the weather should be prominent as people exchange greetings in the affairs of life. The advance of mankind from savagery to civilization is intimately related to man's mastery of the forces of nature. Not the least of these triumphs have been achieved in efforts to secure protection from the weather. Among civilized peoples dwellings are planned, built, and furnished at relatively large expense in time, labor, and materials. The cost of a modern dwelling of the average type of American houses represents years of the savings of a wage-earner. The annual outlay for necessary clothing for the individual members of a family is a large drain upon the average income.

The tiller of the soil especially meets success or failure as he is favored by weather conditions or experiences losses on account of them. The complex machinery of modern life becomes seriously disordered when snow blockades or floods stop railway traffic for a time, and when communications by telegraph and telephone are interrupted by storms. The total of losses in great disasters due directly or indirectly to the weather is, however, small in comparison with the extent of suffering, impaired health, and shortened lives on the part of those who by their own incompetency, or by force of circumstances which they cannot control, lack sufficient protection from the weather. 
Failure to take precautions, and to make preparations against conditions of weather and climate that are inevitable, is an evidence of lack of thrift and foresight, and must result in hardships. It is the part of wisdom for everyone to avoid all unnecessary exposure, and to take all reasonable precautions against danger to health, life, and property. In the struggles of men for life and comfort and prosperity in spite

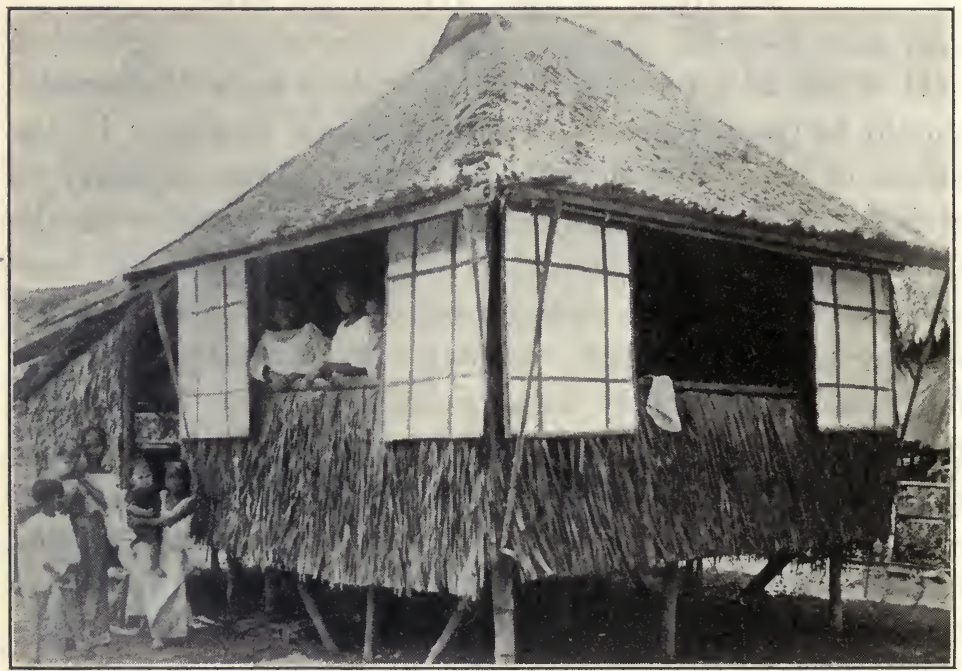

FIG. 50.-A house in the Philippines. (Courtesy of the Smithsonian Institution.)

of adverse conditions of climate, both resourcefulness and capability are developed. The intelligence and industry of a people are very closely associated with these efforts, as are their advances in civilization and the stability of their governments.

Energy employed to battle against unfavorable weather conditions cannot be turned to other uses. The efficiency of one's physical and mental efforts is reduced to the extent that his energy is exhausted or impaired by them. 
The benumbing effects of the cold of the higher latitudes, and the enervating effects of heat and moisture in tropical countries, may be named as sufficient cause for the failure of the peoples of these regions to keep pace with the other parts of the world in the arts and activities of civilized life. However, the enterprise of the present day has been able to master adverse climatic conditions. This is strikingly exhibited in the Panama Zone, Cuba, and the Philippines, as controlled by the United States, and in portions of tropical Africa under the enlightened rule of European nations.

Aside from the discomforts of extreme heat or cold, excessive moisture or dryness, and dangers from exposure to weather changes, it is not easy to establish definite relationships between weather conditions and the health of people generally. A breeze, springing up in a hot day in summer when there has been no air stirring, does for large numbers of people what starting an electric fan does for the persons in a room whose hot stagnant air has become oppressive and benumbing. Though the temperature of the air may remain the same, perspiration vaporizes more rapidly, there is a lower body temperature, a lessened sense of discomfort and of nervous irritation, and an invigoration that bespeaks less waste of nerve energy. Certain diseases have been prevalent and often are epidemic at certain seasons of the year. But knowledge of the nature of infectious diseases, and of the ways of their prevention, lessens the likelihood of any such relationship being maintained.

It is a common experience, however, that the presence of too much moisture in the air on a hot summer day so interferes with the rapid vaporization of the perspiration from the body that great discomfort follows. Heat prostrations, especially in sea board cities, are frequently the direct result of the body being unable to get rid of its own heat sufficiently fast through vaporization of perspiration. Overcrowded and poorly venti- 
lated assembly halls and schoolrooms may give to persons in them a feeling of discomfort and illness due to the same cause.

On the other hand too small an amount of moisture in the air dries the air passages and skin, causing an irritation that disturbs the nervous equilibrium. In our furnace-heated houses in winter time it is possible by evaporation of water at the furnace to control the amount of moisture in the air., The humidity should range from 40 to 50 per cent of saturation $^{1}$. Too great humidity is enervating, and no sustained physical or mental effort is possible. If the air is too dry furniture shrinks, and the mucous linings of the air passages are irritated and rendered more susceptible to infection.

Usually the high following a period of clouds and rainfall -brings air that is clear, cool, and bracing. One is invigorated and stimulated by it. But for unknown reasons the round of weather change in the United States incident to the passage of highs and lows across the country is sometimes interrupted. A high may remain stationary over any section for upwards of a week, especially in summertime, bringing to that section an unbroken period of clear skies, drying air, and pitiless sunshine. From this nerve-racking condition the advent of moisture in the atmosphere brings relief and refreshment. Changes in diet and in mode of life are even more important than changes in clothing to withstand the "hot spells" in summer without prostration and suffering.

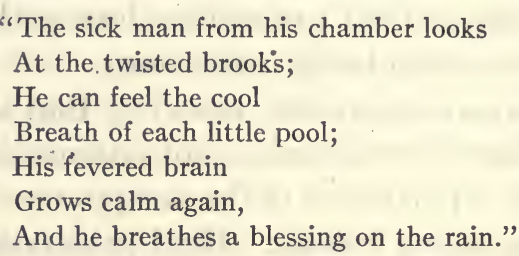

Longfellow's Rain in Summer.

1 A humidity of 60 to 70 per cent, as commonly stated in text-books, would be likely in cold weather to result in condensation of vapor on window panes, and on walls of rooms. 


\section{SUMMARY}

Any discussion of the weather takes account of temperature, humidity, winds, precipitation, and the state of the sky as to cloudiness. While the weather at any place may vary from day to day, even from hour to hour, the climate of any region on the other hand is an average of the weather conditions through long periods of time, and it changes but little.

Personal well-being and self preservation alike demand that the weather be taken into account in the affairs of life. Making provision against weather changes, and any unfavorable conditions incident to these changes, constitutes one of the chief incentives for thrift and resourcefulness in individuals. It is a large factor in making and maintaining the enlightenment and progress of nations.

Suitable changes in diet, clothing, and activities should accompany changes in weather in order to adjust the manner of life to prevailing conditions. Failure to do this is likely to involve waste, lack of efficiency, and risks to health and to life itself.

It is likely that nervous temperaments may at times be seriously affected by weather conditions unusually prolonged, resulting in some cases in depression of spirits and at other times in undue exhilaration.

Where the humidity of the air is high in summer there is enough of interference with the vaporization of perspiration to cause discomfort. If extreme, this condition may imperil life by an unduly high temperature in the body. Heat prostrations do not necessarily imply exposure to the direct rays of the sun.

Weather forecasts to be of value must take into account existing conditions over relatively large areas. They demand a skilled interpretation of these conditions. The forecasts are based upon "laws" of the weather, or general statements concerning weather changes. These laws have been verified from weather records extending over long periods of observation.

\section{Weather as Affected by Highs and Lows}

In the central west of the United States where typical weather conditions due to highs and lows are the rule, the moisture-laden winds may be considered as coming from the Gulf of Mexico. They commonly enter the southeast 
quadrant of a low. By reason of the lessened pressure experienced in these areas as the air currents rapidly ascend there is an expansion of the air and a consequent cooling of it. The skies are beclouded and some of the moisture may be precipitated as snow or rain. On the other hand the cool dry air from the north and northwest brings clear skies and bright sunshine.

As an easterly moving area of low pressure, or cyclone, approaches and passes an observer so that successively he is in its eastern edge, then in its central portions, and then in its western edge, a certain succession of weather changes is likely to occur. Regardless of the rate of the eastward movement of the storm area and the length of time required for the round of changes, the order in which these changes occur, and their characteristics, will be somewhat as follows:

I. While in the eastern edge, an increasing cloudiness culminating in more or less of precipitation; a rising temperature; winds from the southeast, and south.

2. While in the central portion, cloudiness and rain (or snow) continued; little or no wind; relatively high temperature.

3. While in the western portion, cloudiness gives way to clear skies; winds from northwest, and west; lower temperatures (cooler).

When the area of low pressure passes to the northward, there is a typical succession of changes experienced by the observer while enveloped in turn by the southeast, south, and southwest portions of the storm area. These changes are commonly (a) an increasing cloudiness, more or less of precipitation, and a rising temperature; (b) a change of wind direction from southeast through the south to the west, with the skies clearing, and a lower temperature.

When the storm area passes to the south of an observer the wind directions change from easterly through the north 
to northwesterly winds, and there is a succession of cloudiness and possible precipitation followed by clearing skies, the winds from the north being cool. The rate at which the changes occur, and the intensity of the storm, is forecasted by the rapidity and extent of fall of the mercury in the barometer.

During the summer the paths of the lows across the United States are likely to be farther to the north, and in winter farther to the south. For an observer in any one place there is likelihood of a repetition in summer of warm winds from a southerly direction, and in winter of cold winds from a northerly direction.

Some or many of these features of weather changes may be absent in the passing eastward of any cyclonic area, and the intensity of these features may vary widely. But so largely are they characteristic of cyclones that without recourse to weather maps and barometers close observers of changes in the appearance of the sky, in the directions of the wind, and in thermometer readings, are able to foretell weather changes somewhat accurately. The direction of the centre of any area of low pressure from an observer will in general be somewhat to the left of the direction toward which the wind is blowing.

\section{SUMMARY}

The advancing edge of a low commonly brings to each region over which it passes more or less of cloudiness and of precipitation. Where this occurs it may be explained as due to an expansion of the moistureladen air passing into the low. By reason of this expansion the temperature of the air is lowered sufficiently to condense more or less completely the moisture it contains.

When the low has passed on eastward across the United States the westerly winds blowing toward it are relatively cool and dry, coming as they do over the central continental areas northward into Canada. As these winds become warmed from the regions over which they pass 
their capacity for moisture increases, and clouds disappear as result of the vaporization of the water particles forming the clouds.

The paths traversed by the centres of these areas of low pressure on their eastward journeys across country generally range farther north in summer, and much to the southward in winter. This results in weather changes far more varied than would be true if dependent only upon the approach of storm areas from the west and their passing on eastward.

The isotherms on weather maps connect places reporting the same temperatures. Isobars connect places having the same atmospheric pressure as shown by barometer readings.

So numerous are variations from the general rules of weather that no brief summarization of weather conditions is at all adequate. Local conditions are often large factors in the weather of any particular section. "As fickle as the weather" does not, however, signify that the great controlling causes of the weather may not in a general way be understood by those who have made no extended study of Meteorology.

\section{Exercises}

1. What distinction is made in the use of the terms weather and climate?

2. What besides total annual amount is important in the relation of rainfall to the raising of crops?

3. What geographic conditions make winds from the north and northwest in the interior of this continent of lower humidity?

4. Name several ways in which men protect themselves from unfavorable weather conditions.

5. Contrast the exposure incident to occupations and travel now and in earlier generations.

6. To what extent can man control the weather?

7. Explain the clearing of the sky and the cooler weather when a low moves on eastward, and northwesterly winds spring up.

8. In what ways do winds affect the well-being of mankind?

9. Trace any apparent relationship between climate and the civilization of any people.

\section{The Thermometer, and Heat Transmission}

Changes in the volume of a body by reason of its being heated or cooled are proportional to the changes in its tem- 
perature $^{1}$. So generally is it true that heating a body causes it to increase in size, and cooling it causes shrinkage in volume, that any exception might be wholly disregarded. But the peculiar behavior of water must not pass unnoticed. As water is cooled more and more it shrinks in its volume, as might be expected, till a temperature of about $4^{\circ} \mathrm{C}$. is reached. Further cooling results in its expanding till it changes to ice. As previously noted there are many instances of increase in volume where change from liquid state to solid occurs, but water when cooled begins to expand while yet several degrees above the freezing temperature. This makes $4^{\circ} \mathrm{C}$. the temperature of maximum density for water, and any change from that temperature, whether rise or fall, involves increase in its volume.

The amount of expansion (and of contraction) is relatively small in solids, is more in liquids, and is relatively large in gases. Every substance has its own so-called coefficient of. expansion. This fractional number is found by dividing the increase (or decrease) in size for one degree temperature change by the size before the change in temperature was made. In dealing with gases the pressure under which they are confined must be kept constant, and the volume of the gas at the freezing temperature of water $\left(0^{\circ} \mathrm{C}\right.$.) is the basis for comparison (division).

The coefficient of expansion for mercury is sufficiently small so that in the large tubes of barometers any rise and fall of the mercury column by reason of temperature changes of several degrees may be considered a negligible value for all general purposes. Thermometer tubes, however, have an exceedingly small bore. The difference in levels of the

${ }^{1}$ For the heat of vaporization and of fusion, where changes of solids and liquids and gases from one state to another are considered, see page 95 . Neither change in volume by reason uf change of state, nor consideration of any heat liberated or made latent in any such changes, is involved in studies of the thermometer. 
mercury in them at the boiling and freezing temperatures of water, even when divided into Ioo (or 180) equal parts, gives spaces (degrees) sufficiently long to be easily read. Fractional portions of these spaces may be estimated to the tenths of a degree.

Mercury has other advantages for use in thermometers. It does not cling to the glass as does water and other liquids. Hence its rise and fall is not interfered with by adhesive force. Its boiling point of $350^{\circ} \mathrm{C}$., and its freezing temperature of $-39^{\circ} \mathrm{C}$., make it serve for all ordinary temperature changes. For temperatures either very high or very low special forms of thermometers are employed, descriptions of some of which are commonly given in Physics. Then, too, the coefficient of expansion of mercury is very nearly constant, the mercury not expanding appreciably more per degree temperature change in one part of the scale than in another part.

When a confined gas at $0^{\circ} \mathrm{C}$. has its temperature raised or lowered one degree, and the pressure to which it is subjected is kept the same all the time, it is found that the increase or decrease in its volume is always $1 / 273$ of the volume at $0^{\circ} \mathrm{C}$. If the temperature is changed $20^{\circ}$ then the expansion or contraction is $2 \% 273$ of that volume. - If then a gas could be cooled to a temperature of $-273^{\circ} \mathrm{C}$., and it still remained a gas, its volume theoretically would become zero. Such a temperature is assumed to exist, and it is called absolute zero. Temperatures in the centigrade scale are changed to absolute readings by adding 273 to their centigrade values.

To the scientist this possible temperature has the greatest interest. Within recent years temperatures approximating absolute zero have been attained in physical laboratories. The story of how this has been done, and of the changes that take place in the nature of substances subjected to these temperatures, adds an interesting chapter to the study of Physics. 
When coal or wood is burned in a stove; the warmth (heat) liberated as a result of combustion is disseminated in three different ways. The stove itself becomes heated largely by conduction. In such cases the heat travels from molecule to molecule till distributed throughout the body that is heated. It is believed that in the conduction of heat in a body a quickening of molecular motion is passed on through it, and the degree of this molecular activity manifests itself in the rising temperature at different places outward from where the liberation or application of heat occurs. This belief is in accordance with the molecular theory of the structure of matter, and makes possible the definition that heat is molecular energy.

From a stove as a center convection currents are set up as the air next the hot surface is warmed and expanded, and a circulation of air is maintained. (See pages 20 and 123.) A hot-air furnace is essentially a large stove located commonly in the basement and surrounded by a metal jacket from which large sheet-metal pipes convey heated air as convection currents direct to the rooms to be warmed. Into the space between jacket and furnace cold air is conveyed directly from out-of-doors, or more commonly through cold-air pipes from the various rooms to which the heated air rises, thus completing a round of circulation of air in these rooms. In part at least this air may be warmed many times over.

Unequal heating of the rooms of a house from use of a hotair furnace sometimes results by reason of the fact that heated air cannot rise through the hot-air pipes into any room from which the cold air is unable to escape freely through openings of sufficient size. Distribution of the heated air to different rooms in a house may be controlled by use of dampers in the hot-air pipes.

In hot-water heating plants the heat liberated at a furnace 
in the basement sets up convection currents in water that fills pipes within the furnace, and radiators in the rooms to be heated, and the connecting pipes. The heated water goes from furnace to radiator, and then as cooled water from the radiators back to the furnace to be warmed anew. In steam-heating plants and in vapor systems the essential difference from the hot-water system is in having the pipes filled with steam or water vapor, the heat liberated at the radiators being largely heat of vaporization (latent heat) from the steam as it condenses to water in the radiators. Where there are pipes to carry the steam to the radiators, and other pipes to carry away the water of condensation, there is little or none of the disagreeable "bumping" that often occurs when steam is entering a radiator from which water is draining back to the boiler through the same pipe.

Conduction and convection are modes of transmission of heat by reason of molecular activity in matter. But heat can pass through space destitute of matter, even through a vacuum. Heat from the sun reaches the earth through vast spaces supposed to be lacking in any material medium for its transmission. Scientists assume that heat requires some medium in which it can pass through space. It is assumed to be the case that heat, light, and other forms of energy (see pages 162 and 343) are transmitted through space as pulsations (wave motions) in a so-called "ether" medium, and that these pulses move outward or radiate in every direction and always in straight lines. Such a supposition has sufficient experimental evidence supporting it to make it the most reasonable of all explanations of heat radiation.

However, this "radiant energy" is not heat until the ether waves fall upon some body whose molecules acquire a quickened motion by reason of the absorption of the motion of the ether medium. In this way the temperature of the body is raised as ether energy is transformed into molecular motion 
or heat. The warmed body in turn may lose this energy of its molecules by conduction to other bodies, by convection currents, and by radiations from itself as an original source.

Some substances are much better conductors of heat than others. Some conduct heat so slowly as to be called nonconductors. In fireless cookers the space between the double walls is filled in with asbestos, felt, or some like nonconducting material, thus preventing the loss outward of the heat (molecular motion) of the material put into the inner receptacle. This permits the softening process, or "cooking" of any foodstuff to continue for a long time after the heated material has been properly packed away in the cooker. The fireless cooker may likewise be used to keep things cool in summer by keeping out the heat of the surrounding air. Icehouses are constructed on the same principle, the space between their double walls being packed with some cheap non-conducting material such as saw-dust, thus preventing heat from without reaching and melting the ice.

Refrigerators for household use, fire-proof safes, and vaults for storage of business papers and other valuables are built with double walls filled with non-conducting material of some kind. In "thermos bottles" air was withdrawn from between the double walls of glass, and that space was then sealed air-tight by melting off the tubular outlet of glass. Transmission of heat either inward or outward through this vacuum is thus made impossible by either conduction or convection. The jacket of hot-air furnaces, and the pipes carrying heated air from the furnace to the rooms to be warmed, are covered commonly with thin sheets of asbestos to lessen wastage of heat in its transmission. Steam and hot-water pipes are protected "from the cold" in some like manner.

It is to be remembered that the rise of heated air through the smoke pipe and chimney, constituting the "draft" of a 
stove or furnace, represents a waste of heat liberated in the combustion of the fuel used. While much of this waste is incident to the maintenance of an oxygen supply for keeping up combustion, it is possible to so regulate the dampers of a heating outfit by frequent adjustments as to keep the waste of heat and of its fuel equivalent at a minimum. The heat in the water drawn from reservoir or boiler at a kitchen range may be heat saved rather than lost up the chimney. In the use of gas ranges, too, a careful regulation of the flow of gas will save much unnecessary expense. After water that is being heated has begun boiling it cannot be made any hotter when in an open dish. To keep it boiling thereafter, only enough heat is needed to replace what is being carried off in the escaping vapor.

\section{SUMMARY}

Temperature means degree of heat. It is entirely independent of the quantity of matter in the body, but is proportional to the rate of motion of the molecules of the body. Heat in a body is the energy it possesses by reason of its molecular motions.

The measurement of temperature is based upon the principle that changes in volume of a body are proportional to temperature changes. It is assumed that expansion takes place at the same rate as the rise in temperature. As the molecular motion decreases shrinkage in volume and lowering of temperature occur at the same rate.

The coefficient of expansion is the fraction showing what part of an original length, surface, or volume a body increases per degree rise in temperature. For solids and liquids, it varies with the substance; for all gases, when based upon the gaseous volume at $0^{\circ} \mathrm{C}$., it is $1 / 273$ of that volume per degree centigrade, or $1 / 491$ per degree Fahrenheit.

Mercury has many properties adapting it for use in temperature measurements. Enclosed within a sealed glass tube it is readily seen through the glass. Its rise and fall is not interfered with by any adhesion to the glass. The wide range in temperature between the freezing and boiling points of mercury covers all ordinary uses of thermometers. Its specific heat, i.e., the amount of heat necessary to change its tem- 
perature one degree, is so small that its change in volume when confined in a small tube is apparent when the total quantity of heat involved is relatively small. At the same time the coefficient of expansion is so small that a short tube only is needed for its increase in volume from the freezing to the boiling temperature of water.

From the coefficient of $1 / 273$ for the expansion (or contraction) of gases, a thermometer scale has been devised having degrees of the same value as those of the centigrade scale, but a zero 273 centigrade degrees below the zero of the centigrade scale. Much use of this "absolute" scale is made by scientists.

Heat passes outward from any place where it is set. free either by conduction or convection in a material medium (solid, liquid, or gaseous bodies), or by means of waves radiating outward through an ether medium.

Where bodies cool (lose heat) other than by conduction or convection, it may be supposed their molecular energy or heat is used up in originating ether impulses or wave motions that pass off into surrounding space. These in their turn may fall upon some body whose molecular motion is quickened by the "absorption" of the ether motion, the body thus becoming warmed. This transformation of ether motion into molecular motion, or heat, is involved in the absorption by bodies of light and other forms of radiant energy.

Bodies may be kept hot, or "kept cold", by enclosing them in spaces more or less free of air, or by filling confined air spaces with material that neither conducts nor conveys heat readily.

\section{Solar Heating}

The angular difference in direction of two lines from an observer at any time, one directly upward (vertical) and one toward the sun, may be considered as the obliquity of the sun's rays at that particular time. This value is expressed in degrees. If the sun at the time is halfway down from the zenith (point directly overhead) to the horizon, the obliquity of the sun's rays is $45^{\circ}$. When the sun is at the horizon, the angle is $90^{\circ}$. Heat and light from the sun then may be considered as passing across the surface of the earth where the observer is without being stopped by the earth's surface. 
The obliquity of the sun's rays from its rising to setting changes from $90^{\circ}$ in the morning to a minimum value when on meridian (solar noon), and then to $90^{\circ}$ again when it sets. It will be found by continued observations that this daily path varies in points of rising and setting, and in meridian altitude (number of degrees up from the south point of horizon at noontime). Changes in the diurnal circles of the sun relative to our horizon are the result of the revolution of the earth about the sun. Any complete understanding of these changes requires the study of Astronomy.

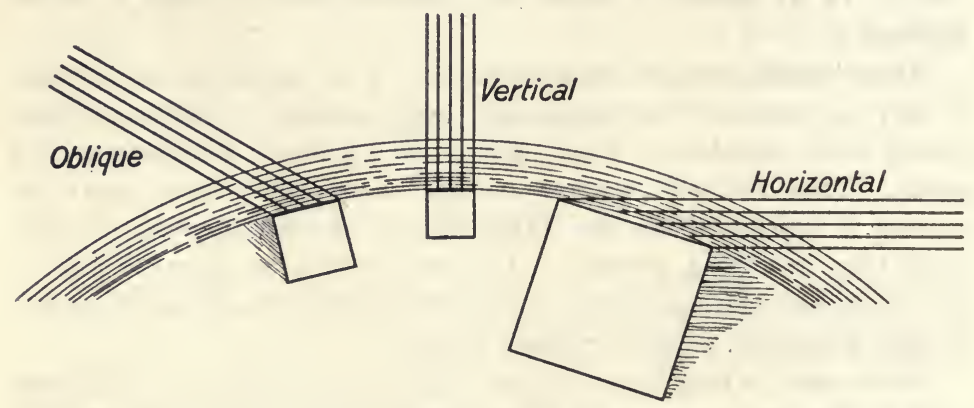

FIG. 51.-Relation of solar heating to altitude of the sun. An illustration of the teaching that the more nearly vertical the sun's rays the more restricted the area heated by a solar beam of any given cross-section, and the more intense the heating effect.

It is not at all difficult to imagine, especially during the month of June every year, that if the sun continued after June $2 \mathrm{I}$ to rise farther and farther north of east, and to set farther and farther north of west, there would come a time when the sun neither set nor rose. Its diurnal circles would remain continuously above the horizon. We are taught in astronomical geography that an observer within $231 / 2^{\circ}$ of the poles of the earth (inside the Polar Circles) may witness the sun continuously above the horizon for days at a time; that at the poles this time of continuous sunlight (absence of nighttime) must be somewhat more than six months in duration. 
What days of continuous sunlight would mean for us in our latitudes, especially in summer with the sun high up in the heavens at noon, is easily imagined. With the sun shining down steadily, even though clouds might at times give some relief, the heat would be intolerable and destructive.

However, in the polar regions the elevation of the sun above horizon cannot at any time exceed $23 \frac{1}{2}^{\circ}$. As a result of this low altitude the heat intensity is small, the area covered by a sunbeam of any cross-section being relatively very large. In a similar manner in our latitude the increasing obliquity of the sun's rays from about September 2 I each year through the three succeeding months results in decreased insolation (solar heating), and the coming on of winter. For a long time after March 2I the increasing amount of heat received does not become sufficient to maintain plant growth. It is to be mentioned in this connection, too, that the more obliquely heat and light fall upon any surface the larger is the portion of both reflected. Such reflected heat is lost so far as warming the earth's surface is concerned.

\section{SUMMARY}

By the obliquity of the sun's rays is meant their slant, or departure from being directly overhead. This obliquity is measured in degrees.

The periods of continuous sunshine within the Polar Circles range from twenty-four hours to six months according to nearness to the Poles. But these periods of unbroken sunlight, and of entire lack of darkness save for clouds and storms, does not result in temperatures sufficiently high to banish the cold of either of the Frigid Zones. So low down upon the horizon is the sun during the long polar day that the intensity of the solar heat is small. Then, too, of this heat the larger portion is reflected because of the great obliquity of the rays, leaving but little to be absorbed to warm the earth.

\section{Exercises}

1. What causes the rise and fall of the mercury in (a) thermometers; $(b)$ barometers? 
2. Calculate the values in centigrade readings of $(a) 77^{\circ} \mathrm{F}$; (b) $59^{\circ} \mathrm{F}$; $(c)$ $2 \mathrm{I} 2^{\circ} \mathrm{F}$.; $(d) 140^{\circ} \mathrm{F}$.

3. Calculate the values in Fahrenheit degrees of $(a) 100^{\circ} \mathrm{C}$; $(b) 30^{\circ} \mathrm{C}$.

4. At what temperature does mercury $(a)$ boil; $(b)$ freeze? For very low temperatures, as in the polar regions, what liquid is used in place of mercury for thermometers?

5. State what scientists believe true concerning $(a)$ the nature of heat in bodies; $(b)$ the cause of differences in the temperature of bodies:

6. Distinguish between conduction and convection of heat in matter.

7. Where heat passes through space destitute of matter, what is the accepted teaching concerning its manner of transmission? What is the name given the supposed medium that transmits the motion?

8. What is the distinction in meanings of the terms reflection, transmission, and absorption of heat.

9. Where light or heat waves fall very obliquely upon a land or water surface, what becomes of the larger portion that evidently is not absorbed since it does not warm them? What is true of the amounts absorbed by land surfaces as compared with water surfaces? 


\section{MATTER AND FORCE}

Some Properties of Matter, and Changes in Matter Due to Force

To spend time watching the flames of a bonfire, or the disappearance of burning material in a stove or furnace, is a common experience. Wherever matter disappears in flame before our eyes, the thoughtful mind wonders at the evidence of some mysterious agency actively at work. There is something fascinating in watching even the burning of a match stick, something awe-inspiring in witnessing a great conflagration when a city is fire-swept. It is little wonder that the ancients regarded fire as one of the natural elements, and we sometimes speak now of destruction by fire and flood as work of "the elements."

Only an elementary knowledge of Chemistry is needed to understand that the burning of substances, as we commonly witness it, is but the process of their oxidation, or union with oxygen. The products of this combustion are largely gases and vapors which ordinarily pass off into the air unobserved. To explain the changes that occur before our eyes, we rest satisfied with the statement that they result from the action of chemical force, but what this "force" is we do not undertake to say. The most that can be taught of it has to do with the conditions under which it manifests itself, and the products of its action. With these the study of Chemistry is largely concerned.

Living matter has the distinguishing characteristics of 
spontaneous motion, of grow th by cell division, and of reproduction. These activities are seen in plants and animals. Lacking these manifestations, matter is lifeless. The biological sciences are those largely concerned with studies of living bodies, while the physical sciences deal with the phenomena of matter apart from manifestations of life in it. This distinction, however, is an arbitrary one for the purpose of grouping scientific knowledge into convenient fields for study. In General Science no regard need be paid to these distinctions.

Whatever the changes through which matter may pass, two characteristics are maintained-it always occupies space, and its mass (quantity of matter) remains unchanged. While no one knows how matter originated, it is fully believed that there is no destruction of matter in the many changes to which it is subject. It is believed, too, that there is no creation of any matter, though newly formed substances (kinds of matter) take the places of those that have disappeared. And it is through these changes occurring in matter that we learn about force.

The study of Physics is concerned with the innumerable changes occurring everywhere about us as result of so-called physical forces. In these changes the nature of the matter involved remains the same. Any "explanation" of these changes consists very largely of statements of what these results are, and what conditions affect the changes. That these statements be clear and exact, it is necessary to use terms with some degree of scientific accuracy. Indeed, in learning the elementary and fundamental facts concerning the physical forces and their phenomena ${ }^{1}$, there is the best of opportunity to acquire accuracy of statement together with

${ }^{1}$ Any change in matter, however simple and familiar, is a phenomenon. In popular language the use of the term often implies that which is unusual and striking. 
clearness and conciseness of expression ${ }^{1}$. This is necessary in formulating definitions of the properties of matter such as these:

Density of matter refers to the compactness of its molecules, or the amount of matter in a given space.

Size, or volume, refers to the amount of space occupied by a body.

Impenetrability is the property that does not permit two bodies to occupy the same space at the same time.

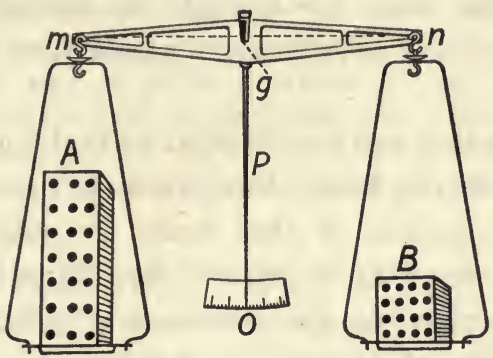

FIG. 52.-Masses the same as shown by the position at $O$ of the movable $\operatorname{arm} P$, but densities different.

Extension is the property manifest in the fact that a body does occupy space.

Form results from a limitation of the extension of a body in different directions. If matter extended outward indefinitely it would be without form. There would then be no separated portions of matter, or bodies.

Mobility refers to the fact that bodies are movable, i.e., they can be made to change positions.

${ }^{1}$ From simple experiments performed in Physics it is possible to acquire groups of facts which call for discrimination in the use of words to express what has been learned. Loose use of language, and the incomplete indefinite grasp of facts usually accompanying any such use, defeat one of the most important purposes in the study of high school sciences. On the other hand, an ability to repeat the carefully chosen words of a text-book in science is no proof of a full understanding of their meaning. Wrong notions, or imperfect ones, obtained from a misinterpretation of the readings of a text are not easily corrected when once acquired. Special effort should be made in all studies in elementary science for a right choice and use of terms, and for a definiteness in knowledge concerning what is expressed in these words. One of the valuable results of wisely chosen laboratory exercises is the acquisition of a vocabulary of exact scientific terms expressive of what has been learned through experimental effort. 
Inertia as another of the properties of matter refers to the fact that bodies at rest cannot set themselves in motion, and that when in motion they cannot stop themselves. A body in motion presupposes some force having acted upon the body to cause the motion. On the other hand it is a matter of common experience to note that moving bodies come to rest. Whatever their tendency to keep moving, i.e., their inertia as moving bodies, they are brought to rest after a time by reason of some form of resistance experienced by them when moving.

Only as sufficient force is applied to make good the loss of energy as a moving body does work in overcoming resistance will the motion of that body be maintained. This resistance may be that of friction developed as one surface slides upon another; or the resistance of medium as when a body moves through the air, or through a liquid or a solid; or it may be due to the opposing action of some other force.

That the earth in its revolution about the sun not only continues its journey by reason of the action of some initial force long since spent, but at a rate which makes the years as periods of its revolution of a uniform length, argues that with its enveloping atmosphere the earth sweeps through spaces destitute of any matter, even of the most rarefied gaseous nature, and so meets no resistance to its motion.

When a body is acted upon in any such way as to cause a change in its form without a change in its position, it is said to be under a strain. The body is more or less deformed. The force causing a strain, whatever the force may be, is called a stress. The two terms are correlative, i.e., the use of one of them implies the other.

The properties defined above are characteristics of all matter whether in solid, liquid, or gaseous state. They are the so-called general properties. There are also specific properties of matter characterizing certain bodies only. 
These are dependent upon molecular forces acting within the body, and are attributes more especially of solids. Of these only the following are defined:

Tenacity refers to that property manifested by a body in the resistance it offers to being pulled, bent, or twisted apart. A dry dead twig may easily be broken, but the toughness of the fibres of flax and of other textiles makes possible their incalculable value to mankind in fabrics and cordage.

Elasticity manifests itself in a tendency in bodies when released from a strain to return to an original form or volume. Bodies may be flexible or compressible, they may be pulled or twisted into new forms, but it in the tendency to recover from any such strain that their elasticity is manifest. Bodies such as wet clay which may be shaped into desired forms that are retained by reason of lack of elasticity in them are said to be plastic.

When a body falls we "explain" it by saying that it is caused by the attractive force of the earth known as gravity. This pull of the earth is exerted not only upon bodies at or near its surface but it reaches outward through all space, attracting all other bodies in the universe. Sir Isaac Newton $\left(\mathrm{I} 64^{2-} \mathrm{I} 727\right)$ formulated the belief now accepted as statement of a great general truth that every particle of matter in the universe attracts every other particle in the same manner as the falling body is attracted by the earth. This universal pull of bodies upon one another is called the force of gravitation. Little more is known about it than in Newton's day, and what causes it no one knows. When the attraction is between the earth and bodies at or near its surface, the term gravity is more commonly employed. The molecular forces of cohesion and adhesion, acting between the particles of bodies at insensibly small distances, are likewise attractive forces binding matter together into masses. Gravitation acts, however, through measurable (sensible) distances and throughout the extent of the universe.

It was part of Newton's statement ("law") concerning gravitation that its value was affected both by the masses of 
the bodies involved, and by their distances apart. With the mass of the earth considered constant, and the value of its attraction directly proportional to the amount of matter in the body attracted, it becomes easily possible by means of the spring balance to determine the relative pull of the earth for different bodies. The weight of a body is the value of the earth's attraction for it. Weighing it is finding out how many times greater this attraction is than that for some other body whose mass is taken as a unit. The close association of our ideas of matter and of force is noted in the fact that the name pound is in use both for the standard unit of mass carefully safe-guarded at Washington, D. C., and for the

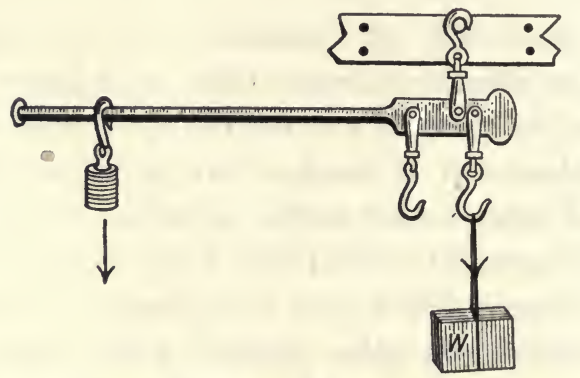

FIG. 53.-Weighing is a comparison of earth pulls.

value of the earth-pull upon this mass, or any duplicate of it, anywhere in the world. A like confusion exists in the use of the terms gram of force and gram of mass.

One thing must be noted in this connection, however, marking a sharp distinction between a pound of matter and a pound of force. The pound mass is an unchangeable quantity regardless of the place to which it may be taken. 'On the other hand, the earth's attraction for this pound mass varies in value, and this variation depends largely upon altitude (distance above or below sea-level), and upon latitude. This dependence upon latitude is due to the fact 
that the earth is not perfectly spherical, being flattened at the poles. A body taken towards the equator is at the same time being taken farther from the earth's center. At the equator it is calculated that a body is about thirteen miles farther from the center than when at one of the poles.

The astronomer explains that gravitation is the great controlling force by means of which the moon is made to move in a circular path about the earth. All bodies when moving tend to move in straight lines by reason of their inertia. It is gravitation that holds the earth itself in a circular path about the sun as a center', preventing it from rushing off into space. The calculated value of this pull of the sun upon the earth in order to hold it to its circular path (orbit) is a value so great as to pass comprehension. When a body is whirled about the hand at the end of a string, it is only necessary to increase the mass of the body and its rate of motion (velocity) to overcome quickly the strength of the string. So great is the mass of the earth, and so enormous is its velocity in its orbit (about eighteen miles per second), that any cable we can conceive fastening earth to sun and replacing gravitation would be as the strands of a spider's web for strength.

\section{SUMMARY}

When we say that matter is anything that occupies space, it does not follow that we have any considerable knowledge of its real nature. We have merely named one of the readiest ways of identifying matter. The properties of matter are those characteristics by means of which bodies may be recognized and identified.

Little is known, too, of the real nature of force, but information is available concerning the conditions under which it becomes manifest.

Force is the cause of all changes occurring in matter. The different ways in which force manifests itself, and the difference in conditions for its manifestation, give rise to a long list of so-called forces, such as heat, light, magnetism, electricity, gravity, cohesion, etc.

We have been familiar from childhood with the effects of the force 
of gravity. The pull of the earth gives weight to bodies, and causes the familiar phenomenon of falling bodies. There is sufficient reason for believing that every particle of matter, regardless of where it may be, exerts a pull upon all other matter everywhere. Why it does this is unknown. The value of the force of gravitation depends upon the amount of matter in the bodies attracting each other, and upon the distances separating them.

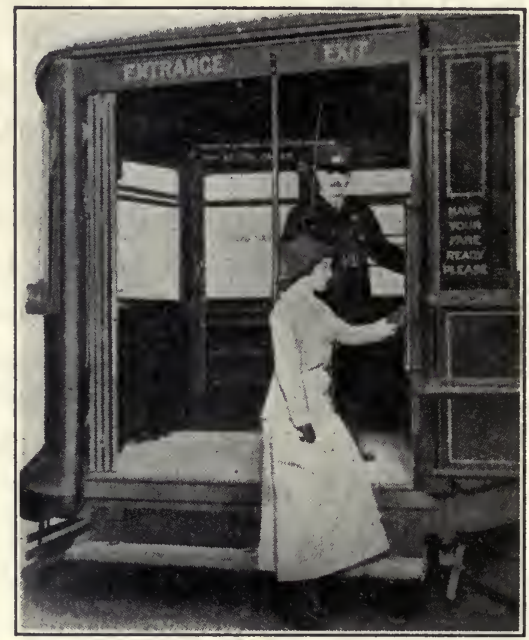

Fig. 54.-Alighting from a street car. When facing forward one is less likely to be thrown if the car suddenly starts.

A similar attraction exists between the minute particles known as molecules of which matter is supposed to be made up. The distance through which this molecular force is exerted, however, is too small for any actual measurement.

\section{Exercises}

1. Distinguish between mass and density of bodies.

2. What is meant by the properties of bodies?

3. Name four forms of strain. Of these, which are involved in testing the tenacity of a piece of wire?

4. When mercury is spilled and breaks up into globules, why do they retain a spherical form as they roll about?

5. What is meant by the ductility of metals? Mention several uses of iron when in the form of wires. 
6. What property of matter is involved where one is thrown when stepping off a moving car? Why should one face toward the front end of a street car in alighting from it?

7. Is the earth's pull upon a person (his weight) affected by having another body come in between him and the earth? Is there any way in which to screen a person from the pull of the earth, i.e., of preventing the force of gravity from acting upon him? What then is true of a person when he is "losing weight"?

8. What is a pound $(a)$ of force; $(b)$ of matter? 


\section{WORK AND MACHINES}

\section{Meaning of the Terms Work and Energy}

When a magnet picks up bits of iron, when heat causes water particles to separate into steam as in the locomotive, when the force of gravity causes the falling of bodies, just as when muscular force moves a book from one position to another, work is done. And when work is done by causing motion in matter, energy has been used in doing the work.

All changes in matter-changes in size, temperature, state, form, position - are the results of the action of forces. But when it is desired to lay emphasis upon changes in position, whether of the body as a whole or of the particles within it and of which it is composed, "energy" is said to have been used, and "work" to have been done. Wherever work is done there is expenditure of energy, and the amount of one is a measure of the other.

It is an accepted belief or "theory" held by scientists that there is no such thing as the destruction of energy, and that it is impossible to create energy. It should be remembered in this connection that the theories of science are based upon what is known to be true, and that likewise they are in accord with known facts insofar as their verification is possible. Theories are thus more than mere opinions.

The utmost that man can do is either to transfer energy from one body to another, or to transform one kind of energy into some other kind as when electrical energy is converted into heat and light energy. In all such transformations and transferences there is waste in the amount of energy available for man's use, often a large waste, but it is believed that there 
is no destruction of energy. When energy is expended upon bodies without causing any apparent motion in them, or not enough motion to account for all the energy expended, these bodies become heated, i.e., molecular motion in them is increased and their temperature rises.

Rubbing a match head on a rough surface raises its temperature sufficiently to cause ignition. The muscular energy expended is much in excess of what is needed to move the match through the air from its one position to the other. The excess energy that is used in moving the match overcomes the resistance to motion offered by friction. It appears as heat, and ignition occurs. Electricity in passing through the filaments in electric light bulbs produces heat, or molecular motion, instead of causing any motion from place to place in the lamp parts. When one attempts to break a piece of iron or copper wire by bending it back and forth rapidly, the wire may become so hot as to burn the fingers. Part of the muscular energy used appears as heat in the wire. A piece of metal subjected to a vigorous pounding becomes too hot to hold in the hand. The use of oil and other lubricants in machinery is to lessen the waste of mechanical energy through its conversion into heat.

The sun is considered the primary source of the energy that causes all changes in the material, world about us. Upon this solar energy all life upon the earth is dependent. It is a matter of great interest to learn by readings in Astronomy how scientists account for the tremendous annual output of energy from the sun, and what beliefs are entertained as to the period through which this may continue. Some of the ways in which plant life appropriates it, and how in turn it becomes available for animal life, will be discussed làter. (Pages 226 and 268.)

To account for the transmission of this energy from the sun to the earth it is necessary to believe in the existence of a 
means for its transmission. There must be a medium by which it can pass through that vast extent of space between earth and sun which is supposed to be destitute of matter. It is quite impossible to conceive energy transmitted from one place to another without a medium for its transmission. It is supposed, and it is just a supposition, that such a medium does exist. It is, however, wholly unknown to us through the senses, and so cannot be matter. By supposing it to exist, and attributing to it certain properties, all phenomena of the transmission through space of heat, light, and electricity can be accounted for. Their transmission occurs just as if such a medium did exist, and belief in its existence is as assured as though it were a material medium that could be weighed and handled. As a belief this is much the same as when we assert that a person has a mind, or that he possesses the sense of sight, because he acts just as if such were the case. By making this supposition the behavior of the individual can be explained and interpreted in a way wholly impossible otherwise.

Somewhat as sound waves are transmitted outward from any source by the air or other material medium so we may conceive a succession of pulsations in the medium known as ether. Whether these wave motions manifest themselves to us as heat, light, or electricity depends upon their number per second reaching us, i.e., upon their wave frequency. It is to be remembered, too, that not only may bodies upon which these ether waves fall absorb the motions and become heated thereby, but these waves may be reflected, or they may be transmitted into the spaces beyond.

\section{SUMMARY}

Work is done when bodies are moved, and when any change in motion occurs in the body as a whole or in its molecules. Both the work accomplished and the effort expended in doing the work are measured in the same units and theoretically are equal in amount. 
However, there is a difference, sometimes a great difference, between the energy expended and the amount of useful work done: The ratio of useful work done to the energy used in doing it constitutes the efficiency of the machine employed.

The terms work and energy are correlative. The use of one implies the other. A distinction which may be made in use of the terms force and energy is that while all changes in matter are the results of forces acting, the term energy is to be employed only when it is desired to emphasize the fact that a change due to any force involves motion in a body or in its parts. Work has been done upon the body.

While theories are only suppositions, they are always based upon facts, and in their applications must always accord with the facts.

For the transmission of energy from place to place some means or medium is necessary. To account for the transmission of solar energy through space destitute of all matter it is believed that an ether medium exists. Only by supposing the existence of such a medium can the transmission of light, heat, and other forms of energy outward through space be accounted for. Assuming that it does exist makes possible an understanding of phenomena otherwise inexplicable.

\section{Exercises}

1. What sharp distinctions are made in the use of the correlated terms force, energy, and work?

2. What is the literal meaning of the terms $(a)$ transfer; $(b)$ transform?

3. In the realm of science does believing a thing so make it so? When only does supposition become worthy of being entertained as a belief or an opinion?

4. Distinguish between theory and mere speculation. Of what service is theory in the study of any science?

5. What meaning has the statement that only in beliefs well-founded are the great achievements of men wrought out?

6. State the argument for the existence of an ether medium.

\section{Levers AND PUlleys}

However simple or however complicated any device for doing work may be it is called a machine. Through the use of machines men employ to advantage their own strength as muscular force, and what is of far greater importance 
they are able to make use of the various and exhaustless forces of nature. Among the simple machines employed in a wide range of usefulness is the pulley which is a modified form of a lever. Any full understanding of pulleys involves a discussion of levers.

When a force $(P)$ is employed to overcome a resistance or lift a weight $(W)$ by use of a lever, it may be considered that the lever is essentially a rigid bar turning about a pivot or an

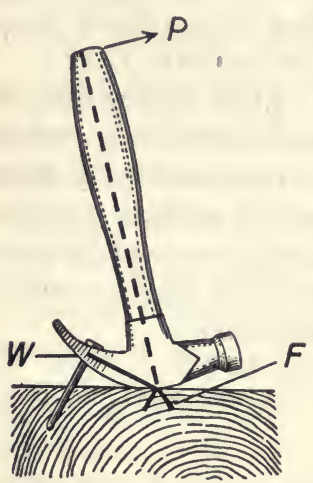
axis. This point of support is known as the fulcrum $(F)$. It is not necessary that levers be straight, although they are usually represented in books by straight lines.

$P$ may be on the side of the fulcrum opposite $W$ as in first class levers, or $W$ may be between $F$ and $P$ as in second class levers, or $P$ may be between $F$ and $W$ as in third class levers ${ }^{1}$.

The power arm $(\mathrm{Pa})$ may be conFIG. 55.-A bent lever. sidered as a radius of the arc traversed $P F$, Power arm; $W F$, by $P$ around $F$ as a centre. This
weight arm. means that the straight line representing the actual length of the power arm of a bent lever may be largely outside the body. The weight arm ( $W a)$, too, may lie outside the lever.

It is worth while to represent these three kinds of levers as described, using straight lines upon which lettered positions are assigned for the effort, the resistance, and the fulcrum. The correctness of these constructions should then be verified by reference to drawings in some text in Physics.

In all cases the movement of a lever is one around the

${ }^{1}$ Archimedes, the Greek philosopher $(287-2$ I 2 B.C. $)$ is said to have asserted that he could lift (overturn) the earth if he but had a place for a fulcrum somewhere out in space off the earth's surface. 
fulcrum as a centre. The lever is supposed to remain fixed so far as motion from one place to another is concerned. No rotary motion occurs when the value of the effort balances that of the resistance, and the lever then is in a state of equilibrium. It is wholly free to move, and is acted upon by forces capable of moving it, but the effects of $P$ and $W$ are so counter-balanced that no motion occurs.

The effect of $P$ is calculated by multiplying together the value of $P$ and the length of $P a$. This product is called the moment of $P$, and the use of this term may properly be confined to forces acting on bodies to produce rotary motion. The moment of $W$ is calculated in a similar manner, and $P$ and $W$ are in equilibrium when their moments are equal regardless of the kind of lever employed. The term applies equally well in the use of pulleys.

It becomes evident from any such discussion of moments that to maintain equilibrium, or to have the moment of $P$ sufficiently large to cause $W$ to be moved, it is possible to employ a small value for $P$ if $P a$ be correspondingly long. If $P a$ be made shorter and shorter then $P$ must become larger and larger, and will exceed the value of $\dot{W}$ when the power arm is shorter than the weight arm as in third class levers.

The farther out from $F$ either $P$ or $W$ is placed the longer will be the arc of the circle described by them in any movement of the lever. The lengths of these arcs covered by $P$ and $W$ in any one turn of the lever bear the same relation to each other as do the lengths of the arms. It is thus possible to state that $P$ times the distance through which $P$ moves $(P d)=W$ times the distance through which $W$ moves $(W d)$.

As the time taken for $P$ and $W$ to move through these different distances is the same for both, it follows that whichever is the farther from $F$ and passes over the longer arc will move at a correspondingly greater velocity. Thus it is 
that $P \times P v$ (power velocity) $=W \times W v$ (weight velocity). A great many problems of interest present themselves in everyday life which involve the use of levers and pulleys for applying force advantageously. In some cases the overcoming of great resistance is accomplished with a small effort. In other cases a high rate of speed in doing work is secured, as when the forearm is bent at the elbow. As result of the contraction of the muscles of the upper arm, a rapid movement of the hand and of whatever it may grasp results.

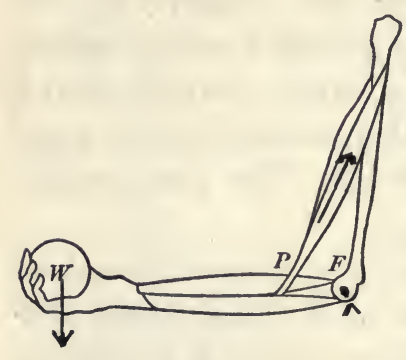

FIG. 56. The forearm is a lever of the third class. The relationship then of $P, W$, and $F$ is that of a third class lever.

The term momentum as used in Physics has to do with motion also. But in this case the product that is known as the momentum of the body involves a motion of translation, i.e., a change from one position to another rather than a rotary motion. Its value is calculated by multiplying the quantity of matter in the body (its mass, or more commonly its weight) by its velocity. Momentum presupposes a body in motion in order to be able to speak of its velocity. Moment is a term as applicable when a body is in a balanced state about some centre as when it is in motion, and it involves the conditions for rotary motion.

\section{SUMMARY}

A machine is any device for doing work, and its purpose is the employment of forces of all kinds to the greatest advantage. This advantage may in some cases be a rapidity with which the work is done, in others the small expense for the power used, and in others ease and convenience in doing the work.

While animals may be considered machines, ordinarily the term is 
restricted to any more or less complicated and lifeless mechanism devised and made by man.

By means of machines man can employ not only the strength of himself and of other animals to advantage, but he harnesses the different forms of energy of inanimate nature to do his bidding. The force of gravitation in the energy of winds and of running waters, the heat energy in steam, and electrical energy from the dynamo and from batteries, are familiar sources.

There is always waste of energy (not destruction of it) in the running of any machine. The larger this waste the less efficient is the machine. The efficiency of a machine is expressed by stating what per cent the useful work done by the machine is of the energy expended in doing it.

A study of the so-called simple machines such as levers, pulleys, and the inclined plane, aids in an understanding of the mechanism of those that are more complicated and whose parts may be modified almost beyond recognition. The screw and wedge may be considered forms of the inclined plane, and the wheel and axle a form of pulley.

A lever is free to move only about a fixed point as a fulcrum, and does not travel from place to place. In the use of a set of pulleys, those that are known as the movable pulleys are attached to the body that is being moved, and travel with it.

Disregarding all waste of energy in any machine, the product of the effort put forth as a power into the distance through which it acts equals the product of the resistance overcome into the distance through which the resistance is offered. As commonly stated, power times power distance equals weight times weight distance. This is a "law" or general statement concerning machines.

Since the time involved in the motion of both the power and the weight is the same, this law of machines may likewise be stated as power times power velocity equals weight times weight velocity.

Whatever effort is required to overcome resistance beyond this calculated value may be considered as used in overcoming the resistance of the machine. So far as useful work is concerned it is energy wasted.

The term momentum is applied to the product of the mass (or weight) of a body into its velocity. This makes the term applicable only in cases when bodies are moved from place to place.

The moment of a force has no reference to velocity. It is applicable in cases of levers where the motion is about a fixed point as a fulcrum. A body is in equilibrium when the moment of the effort ex- 
pended upon it equals the moment of the resistance offered to its motion:

In the case of levers the ratio between the distances through which power and weight move is just the same as that of their lever arms which are radii of the arcs described.

\section{Electromagnets}

So common is the use of electricity in modern life that in one form or another its phenomena are familiar to all. The uses of electricity are so important that some knowledge of its development within recent years becomes necessary. It is not complimentary to one's understanding of the times in which he lives, and of the conditions affecting the affairs of his day, not to possess this knowledge. Because of the widespread use of electricity, and its ever growing importance in the affairs of men, this may be called an "electrical age".

The scientist sees in the water-fall of some mountain stream a vast amount of stored-up solar energy previously expended on the water in its evaporation, and in its transportation to the higher altitudes where condensation took place. The man of affairs in the world sees the possibility of converting into electrical energy the power for doing work possessed by this running water, and of transferring this energy over wires to distant towns and cities where it may contribute to man's comfort and serve him in manifold ways.

A coil of wire of many turns, and whose ends are joined to make a "closed circuit," has an electric "current" developed in it when it is made to rotate very rapidly within the influence of a powerful magnet. The discovery of this fact by the English scientist Faraday in $183 \mathrm{I}^{1}$ was a wonderful step forward in the mastery of man over the forces of

${ }^{1}$ And by Joseph Henry, an American, at a somewhat earlier date. However, it was about forty years later before the dynamo became an industrial reality. 
nature. As a result of the painstaking researches of scientists from the days of Michael Faraday down, and of the genius of many inventors, the dynamo uses solar energy stored in the water-fall, or in the coal that was formed long ages ago, and places at man's disposal in the most convenient form an increase in power for doing the work of the world that is amazing. Through the study of Physics one's knowledge of electricity which otherwise might be more or less fragmentary, becomes more comprehensive and better organized. This grouping and organizing of knowledge characterizes the study of science.

As a machine the dynamo cannot create any energy. It can only return in the form of electricity a portion of the energy used in its operation. The fact that it does yield as a product a very large per cent ( 90 per cent and upwards) of what is transformed makes the dynamo highly efficient as a machine. The steam engine on the other hand is highly wasteful of the heat energy it consumes, its efficiency often being less than ${ }_{5} 5$ per cent. Essentially the dynamo consists of a number of closed circuits each having many turns of wire that is very carefully insulated. These coils are made to rotate at an exceedingly high rate of speed into and out of a succession of powerful electromagnetic "fields" arranged around the circumference of the rotating group of coils (armatures). So long as these conditions are maintained there exists within these closed coils an electric pressure. Special devices have been invented whereby connection is maintained between the wires of these coils and an outside or external circuit so that a continuous outflow of electricity from the dynamo when in operation becomes available to furnish. light, power, and heat.

It is scarcely more than a generation since schools were giving much time to teaching the phenomena of frictional electricity typified in the experiment where a dry glass rod 
is rubbed with dry silk. In the apparatus case of the physics room there was likely to be a static machine with various pieces of apparatus to use with the machine. Interesting as these experiments were, and valuable as the instruction accompanying them may have been, they receive far less attention now.

The study of the flow of an electrified condition along conductors (wires) as current electricity, and the maintenance of this electrified condition by means of cells and batteries of various kinds, is still an important part of courses in

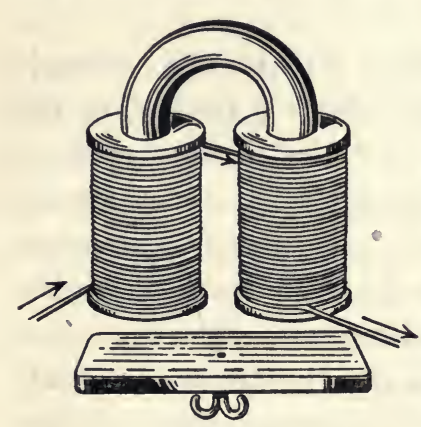

FIG. 57.-An electromagnet. high school physics. But more and more time is being given to the study of electrical currents, electrical devices, and electrical changes in those cases where the electricity is produced by dynamos. The problem of transmission of electrical energy without wires has been solved. But other achievements and further advances in human knowledge concerning electricity are probable. Even sluggish minds may well be stimulated in efforts to master what has already been accomplished in order to be prepared to comprehend and to make use of what is yet to be learned and applied.

The production of electrical energy is closely associated with magnetism in the dynamo, and with chemical changes in cells. The existence of electricity in a circuit produces magnetic, chemical, and heating effects. These may be seen, for example, in the electromagnet, the electric lamp, and in electroplating. An excellent illustration is afforded in these relationships of the significance of the phrase "correlation of forces"-such a relationship that through the action of one force another force manifests itself. 


\section{SUMMARY}

The close connection between magnetism and electricity is manifest in the fact that pieces of iron and steel are best magnetized by passing a current of electricity through a wire wound many times around the body to be magnetized. When the steel is removed from the coil of wire it is found permanently magnetized. No manifestation of the occurrence of any change has been apparent in the process. A piece

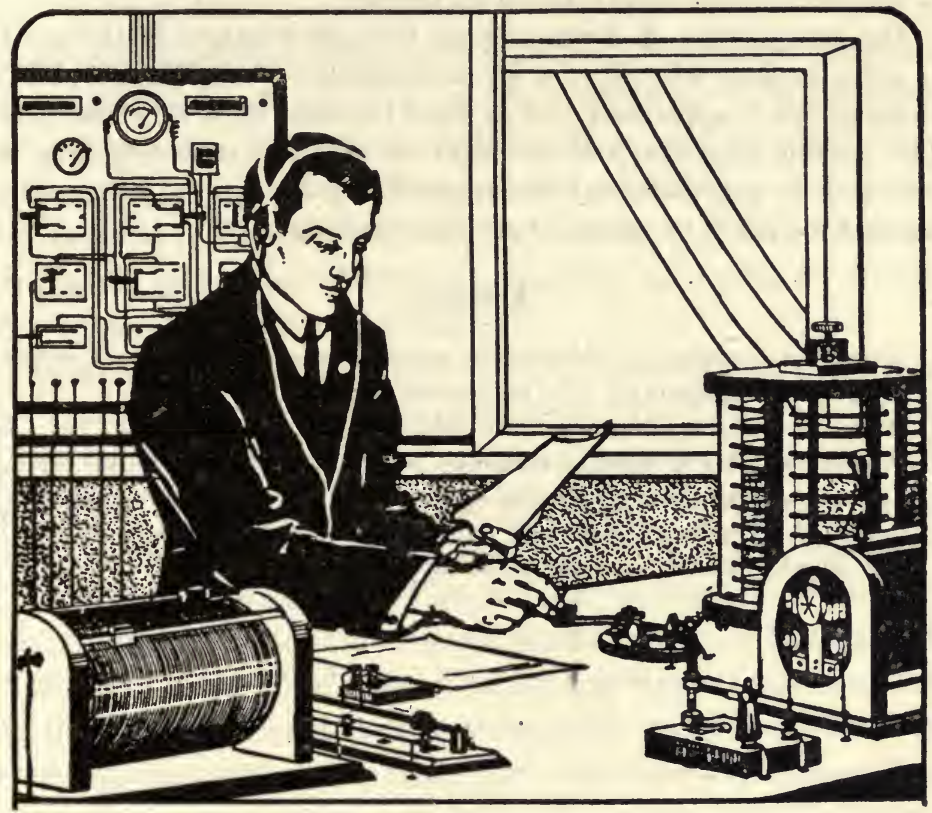

FIG. 58.-Wireless telegraphy.

of soft iron loses its magnetism when the current ceases, however powerful as a magnet it may have been while the current was passing around it.

The employment of electromagnets in door bells and in telegraph instruments illustrates their usefulness in causing motion back and forth through. short spaces. The electrical impulses causing this motion may originate at far distant places. As the soft iron bar (armature) is alternately drawn to the magnet and then released, its 
motion may not only be used to ring bells and give signals but to open and close other electrical circuits. This is seen in the telegraph instrument known as the relay.

Another manifestation of the relationship of electricity and magnetism is seen in the production of electric energy in coils of many turns of wire each made to rotate rapidly into and out of the field of a powerful magnet. The dynamo has become one of the most important of the machines employed in the service of man, rivaling the steam engine in the number and importance of its services.

The transmission of electric signals through distances of thousands of miles without wires is now an accomplished fact. The possibility of doing this is apparently due to wave impulses in an ether medium. The notable magnetic and electrical disturbances occurring here on the earth at times of great disturbances in the sun probably have reached the earth by means of an ether medium.

\section{Exercises}

1. Name an advantage $(a)$ of horseshoe magnets over bar magnets; $(b)$ of electromagnets (temporary) over permanent magnets.

2. How is it that a magnet can affect objects of iron at a distance?

3. Where the relay is used in telegraph work, and a short "local circuit" and battery wholly independent of the main line is employed, in which line is the key put for sending out signals to other stations? Where is the sounder placed for making the signals received audible? Why so? 


\section{SOME CHEMISTRY OF EVERYDAY LIFE}

\section{A Review of Some Chemical Changes}

Every substance has some distinguishing characteristics, or properties, by which it is known as different from all other substances, and by means of which when once known it may always be recognized. Physics and Chemistry are sometimes spoken of as "fundamental" sciences because they are so largely concerned with the properties of bodies by means of which the bodies are identified.

When a chemical change occurs in a body the properties by which it was before known disappear and other properties, often widely different ones, become manifest. It is in this way that a chemical change is known to have taken place. The original substance has ceased to exist, and new substances take its place. The matter continues to occupy space, however, and its mass remains the same. The amount of the new material as determined by weight is exactly the same as that from which the new substances were formed. The chemical properties of a body may be considered those that are made apparent through chemical changes, while physical properties involve no change in the nature of the substance.

To understand better chemical changes in matter it is assumed to be true that the molecules of a body have physical properties the same as those of the body as a whole, and that the molecules themselves are made up of still smaller particles called atoms. These atoms have their own characteristic weight values. - Atoms of the same kind are believed to have the same weights, while different kinds of atoms have 
different atomic weights. When like atoms unite to make molecules the substance is known as an element in chemistry, and when the molecules of any substance are made up of different kinds of atoms the substance is a chemical compound. The molecules of some compounds, small as molecules are conceived to be, contain large numbers of atoms of different kinds. Other molecules, as in common salt (sodium chloride), are believed to contain but two atoms each.

Many chemical changes occur when a sufficiently high temperature is reached, as when a little gun-powder is heated. In the chemical laboratory it is a common practice to dissolve substances and use their solutions in bringing about chemical changes. In such cases heat is often employed to hasten and make complete the changes. In the natural world about us heat and light from the sun, and the presence of moisture in the soil and in the air, are all agencies in aiding chemical changes.

In the decay of organic matter the micro-organisms known as bacteria are active as agents in the chemical changes that occur. In the processes of digestion not only is chemical change in the foodstuffs promoted by solution and warmth, but the digestive secretions contain substances known as enzymes whose uses are to bring about chemical changes in the food materials. These enzymes seem to cause chemical changes by reason of their presence, and without themselves undergoing change. Diastase ( $\mathrm{d}_{\overline{1}}^{\prime}-\mathrm{a}-\mathrm{s}$-sās) produced in plants, ptyalin (tī'-á-lĭn) in the saliva, pepsin in the gastric juice of the stomach, and pancreatin are examples of enzymes.

The term metabolism (́mē -tăb'-ō-lizm) is used to include all chemical changes occurring in the body whether for its nourishment or for removal of the waste due to life activities. The maintenance of bodily conditions favorable to these chemical changes constitutes to a large degree the problem of health and length of life. Impaired metabolism 
means loss in efficiency, even when serious illness does not occur. A physician in times of illness seeks through right hygienic conditions and the use of medicines to restore in his patient those bodily conditions favorable for normal chemical activities. The work done by the cells of the body, and by its various organs, is through chemical changes brought about in them and by them. One value of exercise lies in its direct stimulation of these chemical changes, and in the maintenance of conditions favorable to their accomplishment. Lack of wisely chosen exercise results in an impaired metabolism, and a decrease in bodily vigor and efficiency.

Fermentation as a common chemical change may be the result of the growth of yeasts as in bread, or of bacteria as in the "mother" of vinegar. In all cases the action of any enzyme or the development of bacteria ceases when unfavorable conditions arise. Oftentimes the life activities of the bacteria themselves produce these unfavorable conditions as in the case of the souring of milk and of vinegar. When a certain degree of acidity is reached the action ceases. The acid in the gastric fluid of the stomach is unfavorable for any continued action of the ptyalin of the saliva.

When the chemical element chlorine $(\mathrm{Cl})$ is liberated from its compounds in the presence of water $\left(\mathrm{H}_{2} \mathrm{O}\right)$, so great is the attraction, or affinity, of chlorine for hydrogen that a chemical change is likely to occur between these two elements to form the compound hydrogen chloride, or hydrochloric acid $(\mathrm{HCl})$, with the liberation of the element oxygen $(\mathrm{O})$.

Under such conditions the free oxygen by reason of its great chemical affinity is likely to unite with whatever may be at hand that is readily oxidized, thus "burning it up" and completely changing its nature. Organic matter in solution in drinking waters is likely to cause sickness, and disease germs are sometimes present in water for household uses. 
Both may be disposed of by treating the water with small amounts of substances that give off chlorine. when in water. One such compound is known as calcium hypochlorite, and in an impure form it is sold in cans as "bleaching powder." Its uses as a disinfectant, for destroying offensive odors from decaying organic matter, and for bleaching cotton goods, all are the result of this oxidizing process that follows the chemical change between the chlorine and water.

Among the items of household supplies there are few where greater inconvenience would be caused in doing ' without them than in the case of friction matches. People camping out are at times painfully aware of this. Yet it is less than a hundred years since they have been used. The heads of safety matches consist of some substance rich in oxygen, such as potassium chlorate, mixed with antimony sulphide and glue. The surface on which the safety match heads are to be rubbed is a mixture of glue, red phosphorus, and some material such as powdered glass to largely increase the friction. Aside from the danger of fire from the accidental ignition of yellow phosphorus when used in matches, its deadly effects upon the workmen in match factories are such as to condemn its use.

\section{SUMMARY}

Where chemical changes occur it is believed that the quantity of matter involved in the change remains the same. However, the appearance of entirely different characteristics in the matter after the change warrants the statement that new substances have been formed, and that the original substances have wholly or in part ceased to exist.

Elements in chemistry are believed to be made up of atoms of like kind, while compounds contain unlike atoms.

Both heat and solution are aids to chemical action, and in many cases are necessary to bring it about. Plants of microscopic size are agents in bringing about decay in dead organic matter, and in causing other chemical changes. Lifeless substances known as enzymes promote chemical changes in the digestion of foods and elsewhere. 
Metabolism has reference to those chemical changes occurring in the body concerned with its nourishment, and with the removal from its cells of all waste material.

\section{The Chemistry of Cleaning}

No matter how thoroughly oil and water may be shaken together they soon separate. There is less of adhesive force between oil and water than of cohesion between water and water, or between oil and oil. If, however, there be shaken up with them' some such substance as the white of egg (albumen), it is possible to cause the oil to remain mixed with the water. A liquid mixture containing suspended (not dissolved) oil or fat particles is called an emulsion. It generally has a milk-like appearance.

The value of soap as a cleansing agent depends in part upon the fact that when dissolved in water it serves to form an emulsion with oily or greasy matter. The use of soap is commonly accompanied by chemical changes of importance, too, especially in the case of laundry soaps.

Gasoline when applied to a grease spot on clothing simply dissolves the grease, and the cloth may then be freed of the grease by a thorough rinsing. If a strip of absorbent cloth is put underneath, and gasoline is applied to the spot, any washing of the garment may be unnecessary. The garment can be dried with a hot flat-iron, using a blotter or other absorbent body under the place where the spot was.

If a strong ammonia solution be applied to a grease spot $a$ chemical union occurs, and the new substance formed is soluble in water and may be washed out. If, however, the cloth is allowed to dry without a thorough rinsing, the new compound (which is of the nature of a soap) undergoes change, and the grease spot reappears in the cloth much enlarged by capillary action.

If instead of ammonia water a laundry soap is used, a similar chemical change occurs between the grease and a 
substance in the soap known as an alkali, the amount of which if excessive may act destructively upon the skin and possibly upon the fibre of the cloth. The soapy compound made with the grease should be removed by thorough rinsing.

Water used for cleaning purposes is said to be "hard" where it has in solution compounds of calcium and of magnesium commonly spoken of as "lime." A chemical change occurs between these compounds and the soap so long as the supply of them in the water lasts, preventing any cleansing action by the soap. One product of such reaction (chemical change) between the soap and the lime in the water is the insoluble dirty scum that is such an annoyance in the use of hard waters. This "lime soap" becomes lodged within the fibre of clothing washed in hard water, injuring the fabric and giving the clothing a dirty appearance. The hardness of water may be measured by its soap-consuming power.

The waste of soap thus indicated has led to a general use of washing powders. These essentially are strongly alkaline substances in powdered form that dissolve quite readily in warm water. As a rule they consist very largely of some substance such as sodium carbonate $\left(\mathrm{Na}_{2} \mathrm{CO}_{3}\right)$, commonly known as "sal-soda" or "washing soda", which may be purchased in bulk at a few cents a pound. Great care must be exercised in the use of all washing-powders to secure complete solution of them before their use with clothing, and to be certain that the solution is not so strong as to injure the fabric.

A laundry bluing in common use is a compound of iron, and garments must be thoroughly rinsed to free them of all alkali before using it. Otherwise there will be left on the clothing spots of iron rust (oxide of iron) as the result of chemical changes in the bluing due to the action of the alkali, or blue streaks may appear where soap was left in the cloth. There should be bluing enough left in the cloth to destroy the slight natural yellow of cotton and linen fibre. 
The chemical changes which occur in the use of sodium carbonate to soften waters containing in solution small quantities of calcium suphate $\left(\mathrm{CaSO}_{4}\right)$ are thus expressed:

$\mathrm{CaSO}_{4}$ (soluble) $+\mathrm{Na}_{2} \mathrm{CO}_{3}$ (soluble) $=\mathrm{Na}_{2} \mathrm{SO}_{4}$ (soluble) $+\mathrm{CaCO}_{3}$ (insoluble). The sodium sulphate which remains in solution does not interfere with the action of the soap, and the calcium carbonate as a finely divided white solid may be ignored in the further stages of the washing. Soap can then be used without waste. Magnesium sulphate $\left(\mathrm{MgSO}_{4}\right)$ present in the water is disposed of at the same time, magnesium carbonate $\left(\mathrm{MgCO}_{3}\right)$ being precipitated. Any carbonates of calcium and magnesium in the water at first are precipitated as the water is heated. Hardness, due to these carbonates is said to be temporary, while that from the presence of the sulphates of calcium and magnesium is said to be permanent. In laundries where thousands of gallons of water are used daily extensive plants for softening the water are installed at large outlays.

\section{SUMMARY}

In an emulsion of oil or fat the finely divided particles are held in a suspended rather than a dissolved state. The milk-like appearance of the liquid is due to the diffusion of light from the suspended particles just as fog, and the steam escaping from locomotives, commonly appear white by reason of diffusion of light from the minute water particles composing them.

The cleansing power of water in laundry uses necessitates the freeing of all adhering dirt and greasy matter from the fabric. This is accomplished by both mechanical and chemical means. In both cases there must be the least possible injury to the fabric itself.

The carbonates and the sulphates of calcium and magnesium are soluble to some small extent in water, and constitute the "lime" in water. The carbonates largely separate out when the water is heated. They are said to make the water temporarily hard. The sulphates must be gotten rid of by chemical means. 
The hardness of water is sometimes calculated from the amount of soap consumed in ridding a measured amount of water of its lime by chemical action. This is considered accomplished when lather from the soap remains for some time after it has been formed.

\section{Exercises}

1. Explain the use of borax in toilet and bath waters.

2. When only will soap added to dish-water or wash-water give a suds? How determine in either case when enough washing powder has been added before making free use of soap?

3. Why use bluing in the rinse water only in laundry work, and never in the wash water?

4. Account for any lessened wearing qualities in garments by reason of frequent laundering.

5. How proceed to rid a garment of a grease spot by use of gasoline without leaving the spot much enlarged? What is meant by "dry cleaning"?

6. Explain the cleansing power of soap.

\section{Acids, Bases, And Salts}

Any accurate use of the terms acid, base, and salt requires a more extended knowledge of Chemistry than can be taught in the study of General Science. Their very common use in general science readings, however, almost necessitates some knowledge of the distinctions to be observed in their use, and something of what these terms imply. The use of litmus paper is only an aid in testing for acids and bases, indicating as it does acid, alkaline, or neutral effects. Some salts show acid effects on litmus paper, and others turn red litmus paper blue, i.e., they are alkaline.

Vinegar contains from 3 to 4 per cent of acetic acid, and sour milk has in it lactic acid; the juices of oranges, lemons, and grape fruit have citric acid; rhubarb and grapes have tartaric acid ${ }^{1}$. But there are acids lacking any sour

${ }^{3}$ In the gastric juice of the stomach there is a small amount of free hydrochloric acid whose presence neutralizes the alkaline saliva, and tends to prevent fermentation of food in the stomach by its destructive effect on bacteria. The digestive ferment pepsin requires the presence of an acid, too, for its action. 
taste, even as there are bases without the characteristic effects of ammonia and lime water on litmus paper. The chemist resorts to other means of classification than taste, or effect on litmus, to establish the distinctions between these important classes of chemical compounds.

To aid in making somewhat clear the distinctions that are fundamental in this classification, let us make use of the formula employed by chemists to express what is known of the chemical composition of some of the substances listed as acids, bases, and salts. Only a few of these can be given here. Through the use of formulæ the chemist employs a short-hand expression of his knowledge of the composition of substances, naming the chemical elements that enter into their composition. He likewise reads into a chemical formula the weight proportions of the elements, and many other facts that are not apparent to one who has not studied Chemistry. It is possible to tell from the formula whether a substance is an acid, a base, or a salt.

In the formulæ of the chemical compounds given below, note what is common in those $(a)$ of the acids; $(b)$ of the bases; $(c)$ of the salts ${ }^{1}$.

Acids

Bases

Salts

hydrochloric, $\mathrm{HCl}$ sodium hydroxide, $\mathrm{NaOH}$ sodium chloride, $\mathrm{NaCl}$ nitric, $\mathrm{HNO}_{3}$ sulphuric, $\mathrm{H}_{2} \mathrm{SO}_{4} \quad$ calcium hydroxide, $\mathrm{Ca}(\mathrm{OH})_{2}$ calcium sulphate, $\mathrm{CaSO}_{4}$ hydrosulphuric, $\mathrm{H}_{2} \mathrm{~S}$ copper hydroxide, $\mathrm{Cu}(\mathrm{OH})_{2}$ copper sulphide, $\mathrm{CuS}$

The chemist makes large use of the theory that when any one of these substances is put into water some of its molecules break up. This dissociation fo molecules always yields two parts, and each consists of an atom or a group of atoms that is electrified. One of these electrified parts of a molecule (an ion) has electricity of one kind (positive), and the

${ }^{1}$ It is to be remembered that all these are used as illustrations only, and that any complete discussion of this topic belongs in Chemistry. 
other part has the opposite kind of charge (negative). When these ions reunite, this electrification disappears, the one kind neutralizing the other. A substance which thus breaks up into ions is called an electrolyte.

He explains that the acid effect of liquids on litmus paper is due to the existence of free hydrogen $(\mathrm{H})$ ions, and the basic effect is due to free hydroxyl $(\mathrm{OH})$ ions. The neutralization of an acid by a base then becomes simply a chemical union of these ions to form $\mathrm{H}_{2} \mathrm{O}$ (water), and the withdrawal from solution of both acid and basic ions.

Such conceptions as these make possible an understanding of chemical changes otherwise unsatisfactorily explained.

It must be noted, too, that the salt whose formula is given in every one of the cases exhibits in its formula a relationship to both the acid and the base. A salt in chemistry is defined as a compound considered as having been formed in the reaction between an acid and a base. These changes as they are supposed to occur may be expressed in the form of equations. The formulæ before the sign of equality represent the substances that as factors enter into the chemical change; those after it represent the substances that are products of the change. While these equations are often employed to express what we think may happen, it is to be remembered that their use by the chemist is supposed to express what is known to have happened.

It will be noted in the formulæ of all salts that the hydrogen of the acid has been replaced by atoms of the metallic element of the base. This illustrates one of the best of definitions of acids, i.e., a substance whose molecules contain hydrogen atoms that are replaceable by a metal. A base appears to be a substance whose molecules consist of metallic atoms combined with the hydroxyl group (hydroxyl radical). These definitions will come to have a much greater significance with a better knowledge of Chemistry. The term 
radical applies to any group of atoms such as $\mathrm{OH}$ which in chemical changes appears to behave as a single atom, changing from molecule to molecule of different substances apparently as a group rather than as separated atoms.

When the formula for any salt is given, it is possible to find the formula for the acid from which it may be considered the the salt was formed. This can be done by replacing the metallic atoms of the salt by a number of hydrogen atoms chemically equivalent to them. The number of hydrogen atoms replaceable by a single atom of another element measures the valency of that atom. Thus the valency of sodium in $\mathrm{NaCl}$ (formed from $\mathrm{HCl}$ ) is one, and of copper in $\mathrm{CuS}$ (formed from $\mathrm{H}_{2} \mathrm{~S}$ ) is two. The valency of an atom or radical is likewise determined by the number of hydrogen atoms with which it will unite. 'Thus the valency of $\mathrm{Cl}$ in $\mathrm{HCl}$ is one, and that of the radical $\mathrm{SO}_{4}$ in $\mathrm{H}_{2} \mathrm{SO}_{4}$ is two.

In the study of Chemistry one must become able to determine the valency of elements in compounds. As formulæ of the simpler chemical compounds are met in this text and elsewhere it is worth while to notice what seems to be the valency of different elements and of any radicals. For example, it will be noted that the valency of $\mathrm{Ca}$ and of $\mathrm{S}$ is two in the compounds $\mathrm{CuS}$ and $\mathrm{Ca}(\mathrm{OH})_{2}$, and that of the radical $\mathrm{OH}$ is one.

\section{SuMmary}

A base is a compound of hydroxyl $(\mathrm{OH})$ and any metallic atom or radical. An acid is a compound containing hydrogen atoms replaceable by metallic atoms or radicals. A salt is a chemical compound that may be considered as formed when any of the hydrogen of an acid is replaced by a metal.

In the break-up (dissociation) of molecules when certain substances dissolve, the metallic atom or group of atoms is conceived to be positively electrified, and the negatively electrified atom or group is nonmetallic in character. The behavior of hydrogen ions is the same as that of the metallic ions. 
The chemist explains the acid effect of solutions upon litmus or other test papers ("indicators") as due to the presence of free hydrogen ions, while the alkaline effect is due to the presence of free hydroxyl ions.

The formula used in place of the name of any chemical compound not only is a shortened way of writing its name, but it also states at a glance what elements enter into the compound, their grouping, and their weight proportions. All this must be known by the chemist before the formula can be written.

An equation sets forth what substances enter into a chemical change as factors, and what are the products of the change. The combined weights of factors and of products must be equal, as must the number of atoms on the two sides of the sign of equality.

Any use of equation writing to express what is thought to have occurred, or what may occur in a chemical change, is liable to lead to wrong conclusions. Its proper use is to set forth what is known to have occurred. It is a means for stating facts that have been verified by exacting tests.

The valency of any atom or radical is simply a number. It tells how many hydrogen atoms will replace the atom or radical, or with how many hydrogen atoms it will unite.

A radical is a group of atoms which in chemical changes behaves like a single atom.

\section{Electricity and Chemical Changes}

In the study of electricity from cells there is reason to believe that the electrified condition passing along a circuit and constituting the current is being maintained by chemical changes occurring in these cells. It is also assumed that this outward passage of the electrified condition is by way of the carbon plate in the dry cell, or copper plate in the simple cell.

Where the terminals of a broken circuit are put down into an electrolyte, that electrode by way of which the current enters the electrolyte is called the anode (way in), while the one from which the current leaves the electrolyte is known as the cathode (way out). When a current sufficiently strong is passed through dilute sulphuric acid as the electrolyte, 
gases appear at both electrodes. By collecting a sufficient amount of them for testing, the gas at the cathode is found always to be hydrogen, and the gas at the anode is always oxygen. These gases are apparently from the decomposition of some of the water $\left(\mathrm{H}_{2} \mathrm{O}\right)$ of the solution. The process of breaking up chemical compounds by passing an electric

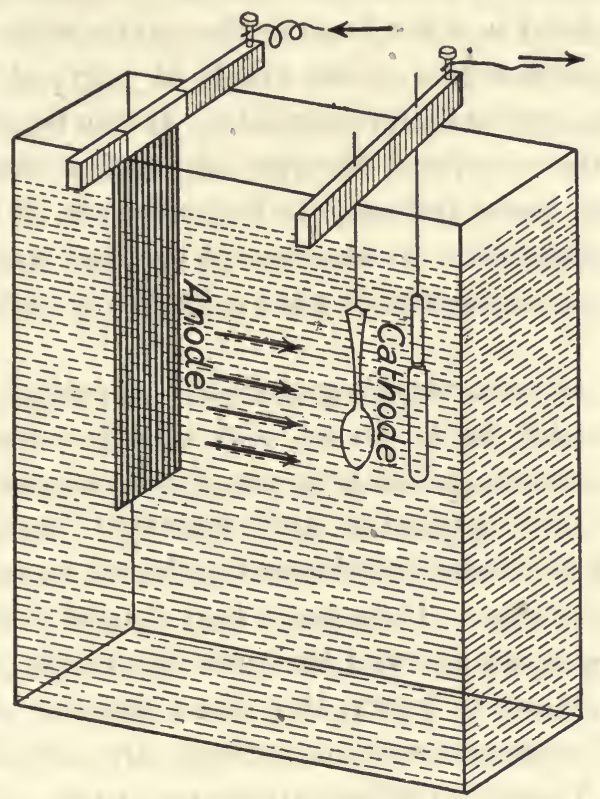

FIG. 59.--Silver plating. The passage of the electric current through the solution of a silver compound results in the deposition of a thin coating of silver over the exposed surfaces of articles serving as the cathode (-electrode).

current through their solutions is called electrolysis (electrical analysis).

Instead of the sulphuric acid in dilute solution as electrolyte there could be used a solution of some compound of silver. With a current sufficiently strong, silver as a metal in the pure state would then be deposited on the cathode, forming a thin even layer or "plate" over any suitable 
object employed as the cathode. Extra thick deposits would constitute "double-plate" or "quadruple-plate." In a similar manner nickel plating uses a solution of a compound of nickel for the electrolyte, and copper plating uses a solution of a copper compound.

In Electricity as in other science subjects, theory aids in an understanding of phenomena. By use of theories students can comprehend in a few lessons the significance of phenomena whose explanation is the result of years of patient research on the part of many scientists. It is to be remembered, too, that the accepted theories of science rest upon an experimental basis, and seem to be verified in all cases where they are applicable. At the same time they must never be considered as statements of what is known to be true beyond question.

To aid in an understanding of electrolysis what is stated on page I8I under Acids, Bases, and Salts is conceived to be true. When some substances are dissolved, not only are their molecules separated and scattered throughout the solvent, but the molecules themselves break up into two parts each known as ions. These parts may consist of single atoms or of groups of atoms, and the more dilute the solution the larger the extent to which this dissociation is carried. In the case of sulphuric acid, the groups are considered as $\mathrm{H}_{2}$ and $\mathrm{SO}_{4}$. These electrified atoms or groups of atoms act as carriers of electricity and serve to complete the circuit of the current used in electrolysis.

In the case of solutions of compounds of metals the metallic ions pass from the solution to the cathode where they give up their charge of electricity, and as atoms free of electrification they collect on the cathode as pure metal. It is found that if the anode in such cases consists of the same kind of metal as that which is being deposited, or of any impure form of it, this anode wastes as result of the electrolytic 
action. The electrolyte will then remain at the same strength of solution all the time, and the metal from the anode will gradually accumulate at the cathode in a pure state. Chemically pure metals, such as copper, are prepared or "refined" in great quantity for the industries by electrolytic action.

When the binding posts of the piece of apparatus known as a "simple cell" are connected by a wire, and the two metal strips as terminals of this wire are put down into the acid solution of the cell as an electrolyte, the two plates of the cell may be considered as electrodes. This is true of other kinds of cells. The current set up in such a closed circuit is supposed to enter the cell from the external circuit by the zinc plate as anode, and to leave the cell from the copper plate as cathode.

It is interesting to note that storage batteries such as are used in electric motor cars are "charged" by electrolytic action. Chemical changes are made upon the plates of the storage cells by the hydrogen and oxygen set free by the passing current. During the charging process these plates are the electrodes of the "primary current." When these chemical changes have been completed, the storage battery is "charged." The connections with the primary circuit may then be broken, and the storage battery is now in its turn capable of sustaining a current to run the car so long as a reversed chemical action continues. When the plates have been restored to their original condition chemically, the storage battery must be charged anew. The "gassing" of the storage cells at the completion of the charging process is but the escape of oxygen and hydrogen gases formed by electrolysis, and not longer used in chemical changes on the plates of the cells.

The marvelous changes that have been wrought by the application of electricity in the industries is well illustrated 
in the present-day production of aluminum metal by electrolysis. Bauxite, an ore of aluminum, contains 50 per cent or more of alumina $\left(\mathrm{Al}_{2} \mathrm{O}_{3}\right)$. This is separated from the other material in the ore by a series of chemical changes relatively inexpensive. Alumina is insoluble in water, and its melting point is too high for practical purposes. However, a mineral known as cryolite and imported in large quantities from

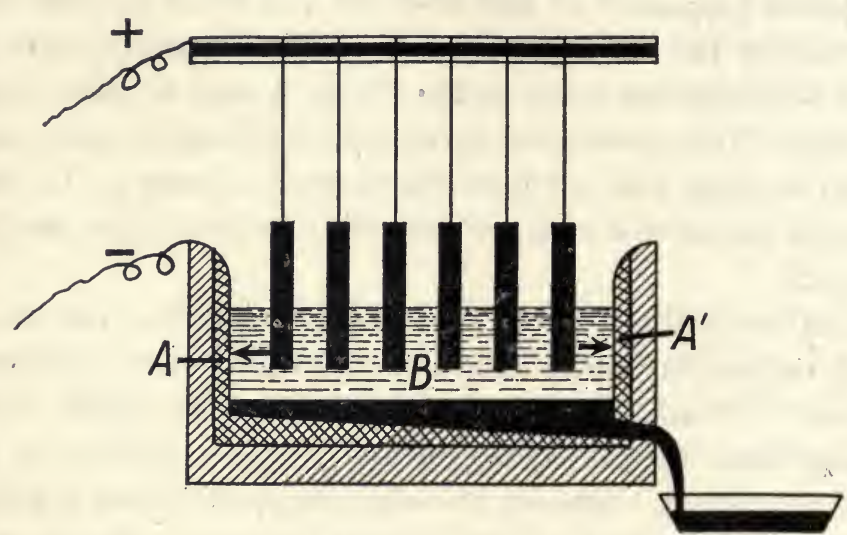

FIG. 60.-Manufacture of aluminum. $A, A^{\prime}$, a lining of carbon which serves as the cathode in the electrolytic action. $B$, melted cryolite which dissolves the oxide of aluminum as it is added from time to time. The temperature of the "bath" is kept so high by the passage of the electric current that the aluminum metal as liberated collects in a molten state.

Greenland not only melts at a relatively low temperature, but when in a molten state it readily dissolves alumina. When a powerful electric current is sent through such a solution, the alumina is decomposed. Oxygen is given off at the anode and pure aluminum metal at the cathode. The heat developed in the passage of the current through the electrolyte keeps the material in the bath molten, and the aluminum metal is drawn off from time to time in a liquid form. 
It is a matter of interest to note that the process at present employed for the enormous output of this metal is essentially the same as that invented by Charles M. Hall ${ }^{1}$ in 1886 . The price of aluminum metal on the market dropped from four dollars per pound to twenty cents per pound as soon as the new process could supply the demand.

Aluminum ware and utensils are light, durable, and attractive. The density of aluminum is only 2.7 while that of iron is about 7.8. The metal neither rusts nor corrodes. The tarnish which dulls the appearance of aluminum kitchen ware should not be scoured off. It is largely an oxide of the metal, and serves as a protective coating. Strong alkalies, such as soda, should not be used in aluminum vessels except to clean them. The metal is acted upon chemically by alkalies, especially in hot strong solutions. Aluminum in a powdered form when mixed with oil serves as a paint for iron surfaces, giving them a cheerful neat appearance as well as protecting them from rust.

\section{SUMMARY}

In the production of electrical energy in cells by chemical changes, the value of the energy output from a cell depends upon the difference in the degree of chemical change at the two plates. To increase this difference to a maximum one of the plates usually is so chosen that no action at all takes place upon it.

The plates of a cell must be immersed, or embedded, in an electrolyte whose ions serve as carriers of electrical energy from one plate across to the other thus closing the circuit. The separation of the plates by any considerable thickness of liquid, or by a porous wall such as a cup of earthenware, hinders this action and increases the internal resistance of the cell to the passing of a current.

Whatever this electrical energy passing along the wire may be, its presence may be detected by its effect upon a suspended magnetic needle such as a magnetic compass. Enough heat may be developed

${ }^{1}$ Hall was then but twenty-two years of age, having graduated the year before from college. 
in the conducting wire to be noticeable, too, and at times the wire may become incandescent.

In the process of electroplating we have a good illustration of electrolysis. When the terminals of a broken circuit are immersed in the plating solution as an electrolyte, and a current of electricity is sent through it, the positively charged metallic ions in the liquid pass to the cathode. Here, upon losing their electrification, they are deposited as a metallic coating upon whatever serves as cathode.

On the other hand the negatively charged ions pass to the anode, lose their electrification, and unite with the anode when it is of suitable material. At other times they unite with the water surrounding the anode, and again at other times escape as gaseous products into the atmosphere.

It must be remembered that in this theory of the dissociation of electrolytes in solution into ions there is the most satisfactory explanation of what actually occurs - a phenomenon that otherwise remains complex and not understood.

\section{Limestone, AND Other Carbonates}

One of the chief chemical industries is the manufacture of sodium carbonate from common salt $(\mathrm{NaCl})$. The importance of it, and of its related and dependent industries, requires that every well-informed person have some knowledge of it, at least as much as may be gained from a high school text in Chemistry. The extent of industries such as this is in no small degree an index of the industrial activities of a nation.

In the Solvay process of manufacture saturated solutions of common salt are treated with ammonia $\left(\mathrm{NH}_{3}\right)$. This with water forms ammonium hydroxide or "ammonia water" $\left(\mathrm{NH}_{4} \mathrm{OH}\right)$. Carbon dioxide $\left(\mathrm{CO}_{2}\right)$ passed into the solution may be supposed to form carbonic acid $\left(\mathrm{H}_{2} \mathrm{CO}_{3}\right)$ with the water. As a final result of chemical changes that occur, sodium bicarbonate $\left(\mathrm{HNaCO}_{3}\right)$ or "baking soda" separates out as a finely divided solid. These chemical changes for 
sake of simplicity are represented as occurring in a series thus:

(I) $\mathrm{NH}_{3}+\mathrm{H}_{2} \mathrm{O}=\mathrm{NH}_{4} \mathrm{OH}$

(2) $\mathrm{CO}_{2}+\mathrm{H}_{2} \mathrm{O}=\mathrm{H}_{2} \mathrm{CO}_{3}$

(3) $\mathrm{NH}_{4} \mathrm{OH}+\mathrm{H}_{2} \mathrm{CO}_{3}=\mathrm{H}_{2} \mathrm{O}+\mathrm{H}\left(\mathrm{NH}_{4}\right) \mathrm{CO}_{3}$, or ammonium bicarbonate

(4) $\mathrm{H}\left(\mathrm{NH}_{4}\right) \mathrm{CO}_{3}+\mathrm{NaCl}=\mathrm{NH}_{4} \mathrm{Cl}$, or ammonium chloride, which remains in solution $+\mathrm{HNaCO}_{3}$, or sodium bicarbonate, which is precipitated. Hundreds of tons of salt are worked up daily in making sodium bicarbonate at the Solvay Works, Syracuse, N. Y.

Upon heating the sodium bicarbonate sufficiently it is converted into sodium carbonate $\left(\mathrm{Na}_{2} \mathrm{CO}_{3}\right)$, the well-known "washing soda," one of the most extensively used of alkalies in the arts and industries. The nature of the chemical change that occurs is shown in the equation

$$
{ }_{2} \mathrm{HNaCO}_{3}=\mathrm{H}_{2} \mathrm{O}+\mathrm{CO}_{2}+\mathrm{Na}_{2} \mathrm{CO}_{3} \text {. }
$$

Enormous quantities of sodium carbonate are used in glassmaking, in soap-making, for washing powders, and in the manufacture of the important compound known as "caustic soda" or sodium hydroxide $(\mathrm{NaOH})$. The wide range of uses of sodium carbonate is due chiefly to the fact that it is a cheap and effective agent to neutralize acids.

It is to be noted in this connection, too, that sulphuric acid occupies the same first rank in industrial importance among acids that sodium carbonate does among alkalies. The amazing total amount of this acid ${ }^{1}$ used in the United States, England, and Germany is expressive of the manufacturing and commercial enterprise of these nations.

A description of the making of lime from the rock known

${ }^{1}$ According to the U. S. Census Report (19I4) one hundred ninety-four establishments reported the manufacture of over four million tons of sulphuric acid. 
as limestone, and of the manner of use of this lime in building operations, may be found in Chemistry texts and other reference books. It has much of interest in itself, and its discussion may well lead to further readings on many related topics. One such topic is the nature of concrete and of cement, both of which are used in enormous quantities

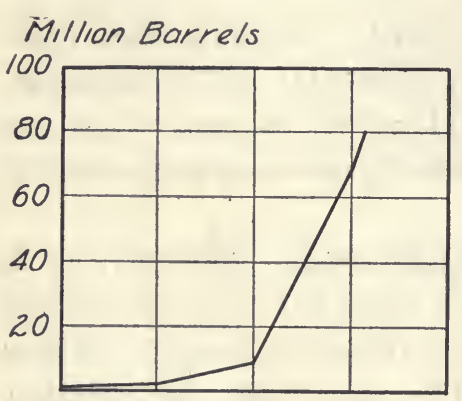

$1880 \quad 1890 \quad 1900 \quad 1910$

FIG. 61.-Growth of the cement industry in the United States. annually for construction purposes. The growth of the cement industry in this country from 42,000 barrels in 1880 to $80,000,000$ barrels in I9I 2 was especially rapid from I900 on, marking a period of intense industrial activity. It made possible the completion of great engineering enterprises and other construction works previously out of question. One of the chief ends in those study of General Science is arousing an interest in those activities of men that are applications of science, and to learn where to go to get information concerning them which is both definite and sufficiently elementary.

In the abundant limestone layers of the earth's crust the geologist reads an intensely interesting chapter of the world's history. In the rock he finds the "fossils" of shells. He recalls that shells of clams, oysters, and other marine life belonging to the division of animals known as the Mollusks, are all very largely carbonate of lime. So is the material of the great reefs and islands built by the little coral animals out of mineral matter in solution in sea-water. The chalk deposits of the southern English coast and elsewhere are of the same chemical nature, and under the magnifying glass these exhibit the remains of minute shells. The extensive 
deposits known as marl are an admixture of clay and carbonate of lime. They all give evidences of an origin in common with the material brought up by dredges from the bottom of the ocean and found to be rich in shells.

It would seem that carbonate of lime in solution in sea water is appropriated by varied forms of marine life in the building of shells as external skeletons. These shells more or less broken are in time deposited along with other material on the ocean floor. As result of pressure from the material

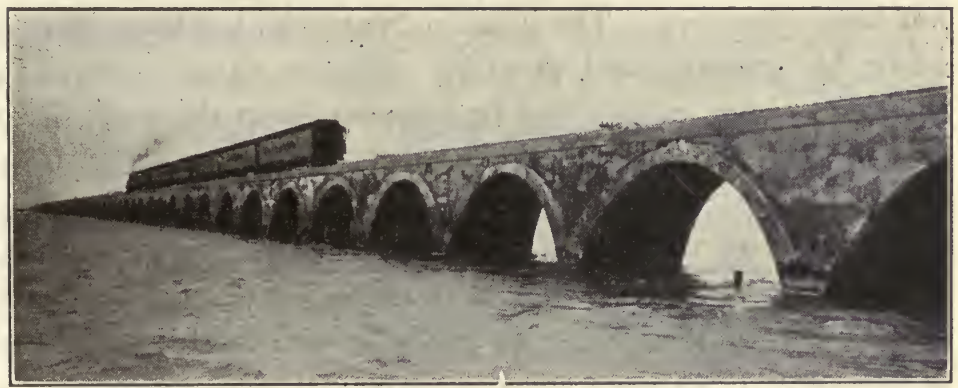

Fig. 62.-Concrete construction. (Courtesy of the East Florida Railway Company.)

accumulating above, aided by the cementing effect of material from the water, the whole becomes a compact mass in the course of time. By reason of changes in the earth's crust these sedimentary rocks, more or less distinctly arranged in layers, may become elevated from the ocean depths even as we now find them as limestone strata of enormous extent and of great thickness.

Marble is limestone rock which is somewhat crystalline, and sufficiently compact to take and retain a high polish. It is valued highly for building purposes, and in art. Marble varies greatly in color, grain, and durability by reason, possibly, of other earthy material with which the calcium carbonate is often mixed, and because of a variation in the 
heat and pressure to which it has been subjected. Some of the marble quarried in Italy and Greece has been famed for centuries in art because of its snowy whiteness. It has a texture well suited to the chisel of the sculptor.

Great caverns are not infrequently met in the limestone strata of the earth's crust, with miles of underground passages, and with vaulted chambers having huge masses of stone in the form of icicles hanging from the roof. Here on a large scale, and through long periods of time, the solvent action upon limestone of water containing carbon dioxide has been operative. The dissolved material has been carried away by underground streams. Where water containing the "lime" has evaporated in dripping from the roof, limestone has been left in place either as stalactites above or as stalagmites rising from the floor. These may have become joined into an ever enlarging mass that serves as a pillar to support the roof. The Mammoth Cave in Kentucky, and the Wyandotte Cave in Indiana, are notable examples in the United States of these caverns in limestone rock.

Some sandstones wet with hydrochloric acid effervesce freely. If acted upon sufficiently long they are reduced to a mass of separated grains of sand by reason of the removal by the acid of the limestone cement. Such sandstone, as well as limestone itself, when used for building purposes is likely to "weather" more or less. It crumbles enough to become unsightly and a menace to the strength of walls.

Carbonates of copper, of iron, of zinc, and of other metals are valuable ores. From them the respective metals are generally obtained:-

I. By roasting the ore which changes it to an oxide just as limestone $\left(\mathrm{CaCO}_{3}\right)$ when heated yields calcium oxide ("quick-lime") and carbon dioxide as shown in the equation $\mathrm{CaCO}_{3}=\mathrm{CaO}+\mathrm{CO}_{2}$.

2. By a "reduction" of these oxides of the metals to a 
more or less pure metallic state by heating them to a high temperature along with carbon (coal, or coke) with the formation of the gases $\mathrm{CO}_{2}$ and $\mathrm{CO}$.

However, the steps taken in extraction of the different metals from their ores, whether as carbonates or other compounds, vary widely owing to the character of the earthy material mixed with the metallic compound, the physical condition of the ores, and the relative expense of material and labor involved in the processes.

The term limestone is often loosely used to include not only the sulphate of calcium $\left(\mathrm{CaSO}_{4}\right)$ as well as the carbonate; but the carbonates and sulphates of the element magnesium $\left(\mathrm{MgSO}_{4}\right.$, and $\left.\mathrm{MgCO}_{3}\right)$. These latter are sometimes spoken of as magnesium limestone. The rock $\mathrm{CaSO}_{4} \cdot 2 \mathrm{H}_{2} \mathrm{O}$ with more or less of earthy admixture is known as gypsum. When relatively pure it can be heated to drive off part of the water of crystallization, and then ground to form "plaster of Paris" whose uses for making plaster casts and stucco work are so well known.

\section{SUMMARY}

In the industrial world the varied uses of sodium carbonate, and of the numerous compounds prepared from it, make its production in enormous quantities and at a relatively low cost of utmost importance. In the Solvay process of soda manufacture, the raw material is salt, ammonia, and carbon dioxide-all cheap materials. The chemical process involved is relatively a simple one, and the market price of both the carbonate and the bicarbonate in large quantities is low.

When the limestone rock $\mathrm{CaCO}_{3}$ is quarried and heated intensely hot in kilns (kils), the valuable building material known as lump or "quick" lime $(\mathrm{CaO})$ is produced. This is "slaked" by the addition of sufficient water, and the chemical change yields the finely powdered white solid $\mathrm{CaO}_{2} \mathrm{H}_{2}$. This when mixed with sand and water makes mortar such as used in laying walls of brick and stone.

The calcium carbonate of the enormous deposits of limestone rock may be considered as once having been in solution in sea water. It 
was abstracted and built into shells by animals in the ocean. In due time these shells, mixed with more or less of earthy sediment from the waters, accumulated at the ocean bottom, and became compact. Marble as calcium carbonate seems to have been subjected to much heat caused, probably, by great pressure.

Many of the ores of the metals are carbonates, and when these are roasted in furnaces, just as when limestone is heated in kilns, great quantities of carbon dioxide gas pass off into the air. Oxides are left.

$\mathrm{CaCO}_{3}$ is nearly insoluble in water. If there be $\mathrm{CO}_{2}$ in the water, forming with the water carbonic acid $\left(\mathrm{H}_{2} \mathrm{CO}_{3}\right)$, the solution occurs much more freely. This is probably due to a change of the carbonate into the bicarbonate of calcium whose formula is $\mathrm{H}_{2} \mathrm{Ca}\left(\mathrm{CO}_{3}\right)_{2}$. This dissolves much more readily than the carbonate.

\section{The Chief Among Metals}

Without coal as a fuel the machinery of modern industrial life would largely stand idle. It becomes equally apparent upon reflection that without metals there would be few machines to operate, and these necessarily of the simplest type. Millions of the world's workers are engaged in operating machinery in mills, factories, shops, and foundries, or in occupations dependent upon providing the raw material for this machinery and in the transportation of its finished products. Transportation by land and sea, the transaction of business, the discharge of household affairs, and the carrying on of agricultural pursuits without the aid of machinery would mean a return to a semi-civilized state.

Something of an idea of the importance of metals in everyday life is gained through an attempt to list the articles and conveniences made impossible by a prohibition of the use of all metals. There would be no steam or gas engines, no steamships or steam and electric railways, no printing presses, no telegraph and telephone service, no suitable tools for the artisan and builder, only the rudest and most primitive of implements for farming and of conveyances in travel, no airplanes and auto trucks, no heating plants and plumbing, 
no utensils of metal in our homes, and no builder's hardware such as screws and nails and bolts for the construction of our houses. An index of the industrial activity, enlightenment, and advance of a nation in civilization, is the extent of its metal products. It was the mineral resources of AlsaceLorraine wrung from a defeated France in 187 I that has made this territory so valuable to Germany, and the coal and iron mines of northern France and of Belgium were an immediate objective of Germany's forces at the outbreak of the World

\begin{tabular}{|c|c|}
\hline COUNTRY & $\underset{10}{\underset{20}{2} \text { Production of Iron Ore in Million Tons }}{ }_{30}$ \\
\hline United States & \\
\hline German Empire & \\
\hline France & \\
\hline Great Britain & \\
\hline Sweden & \\
\hline Austria-Hung & \\
\hline
\end{tabular}

FIG. 63.- Iron ore mined in different countries in I9I3.

War in I9I4. An enormous output in metals, together with the fuel required for their production and for marketing them as finished products, is required for industrial and commercial supremacy in world affairs.

In its wide range of usefulness iron may be counted chief among the metals. In the production of iron ores the United States leads the world, and in I9I3 it reached the enormous total output of sixty-two millions of tons. Its chief iron ore deposits are in the districts west and south of Lake Superior, and in northern Alabama about Birmingham.

Chemically considered the metals are elements, but they commonly occur as compounds of definite chemical composition, usually as oxides, sulphides, and carbonates. These compounds are mixed with rock and earthy materials, and 
when present in sufficient quantity to warrant profitable extraction of the metal the mixture is called an ore. Compounds of iron are widely distributed in soils often giving them a yellow, brown, or reddish appearance. The characteristic red of brick and tile is due to oxides of iron. Bricks made from clays free of iron compounds are light yellow in color.

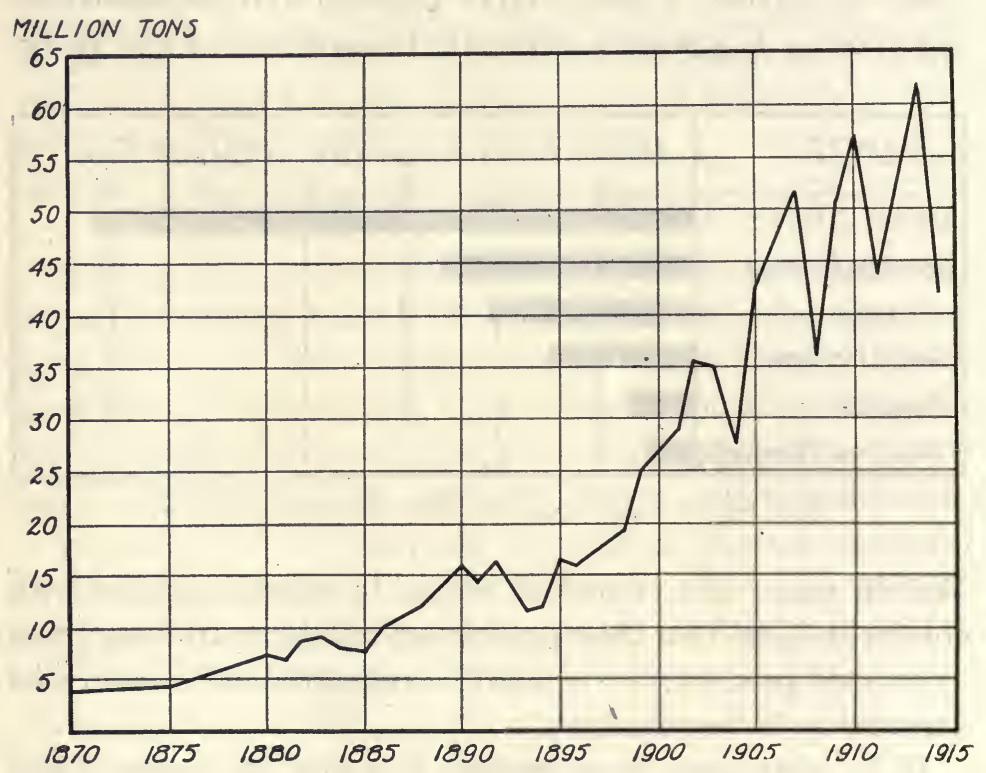

, Fig. 64.-Production of iron ore in the United States I870 to I9r4.

The sulphides are perhaps the most abundant of the iron compounds but are nearly worthless as ores owing to the difficulty in completely ridding the iron from them of all sulphur, a small amount of which makes the iron brittle. Coal mined in certain districts contains iron sulphide, and when burned it gives off very offensive gases as sulphur compounds. Iron disulphide $\left(\mathrm{FeS}_{2}\right)$ as glittering yellow particles 
scattered through sand and rocks has often been mistaken for gold, and is frequently referred to as "fool's gold."

The tonnage passing through the "Soo" Canal connecting Lake Superior and Lake Huron far exceeds that through the Suez Canal, or any other of the great water ways of the world. Much of this traffic is ore from the northern Minne-

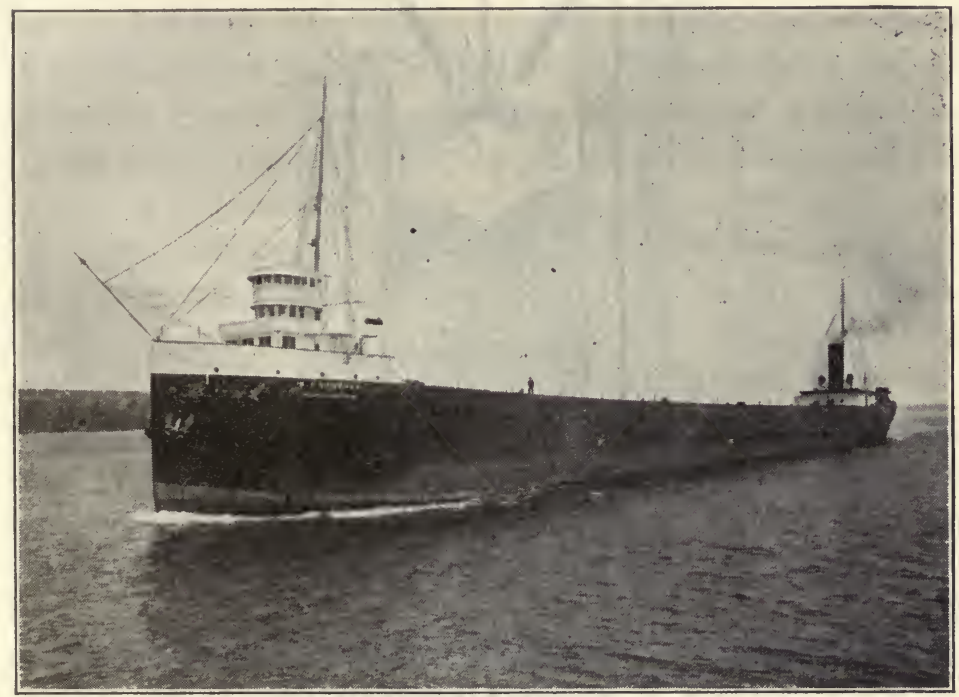

FIG. 65.-A freight carrier on the Great Lakes. (Courtesy of Duluth Chamber of Commerce.)

sota region en route to the blast furnaces of the lake ports of Milwaukee, South Chicago, Detroit, and Cleveland, and (by rail) to Pittsburgh one of the world's greatest centres of iron and steel manufacture. Return cargoes of coal for the upper lake region swells the tonnage volume of this enormous. lake traffic.

The manufacture of iron and steel is so vitally connected with national life and prosperity, and a general understanding of operations involved in producing commercial iron is so readily acquired, that information concerning its sources and 


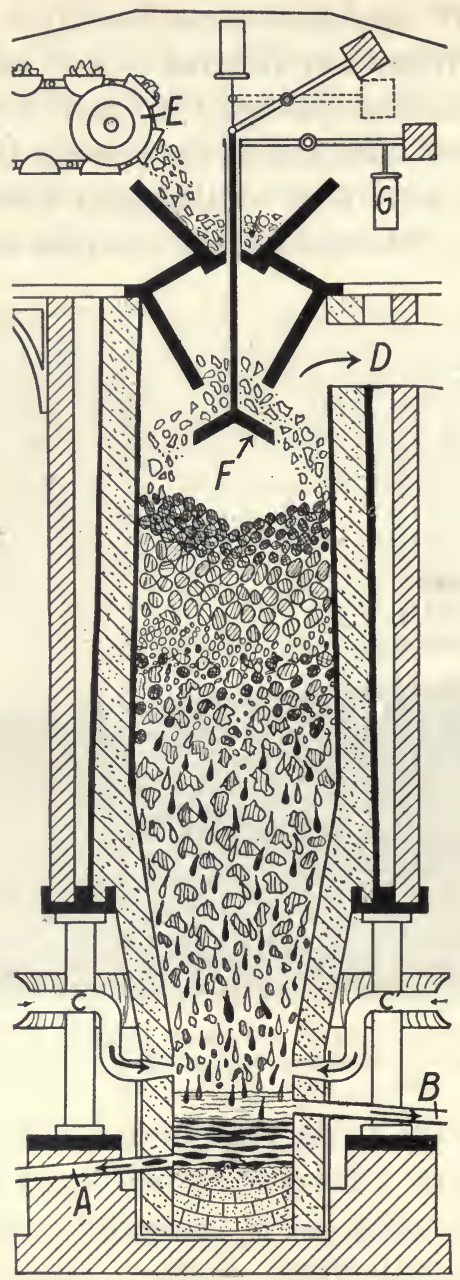

FIG. 66.-Cross-section of a blast or "reduction" furnace for the making of pig iron. $A$, Outlet for molten iron; $B$, outlet for slag; $C, C^{\prime}$, inlets for hot air blast; $D$, outlet which conducts escaping gaseous products to ovens for heating the "blast"; $E$, conveyor which feeds into the furnace coke, ore, and limestone; $F$, floor to lower hopper which when filled automatically dumps itself; $G$, counter-balance for floor of upper hopper. 
manner of preparation for market need not wait upon a study of Chemistry.

Iron is obtained from its oxides by an intense heating in "blast" furnaces of a mixture of ore, fuel (usually coke), and limestone. A reduction of the ore is accomplished by reason of the chemical combination of oxygen from the iron compound with carbon and carbon monoxide gas $(\mathrm{CO})$ from the fuel at the high temperatures maintained day and night in the furnaces for months at a time. The supply of air required to furnish the oxygen necessary for the combustion of the fuel is forced through pipes into the bottom of the furnace as a "hot blast." This air has been heated by passing it through ovens kept intensely hot by burning under them gases conducted through great pipes leading out from the top of the covered furnace stack. A considerable part of these gases is $\mathrm{CO}$ the same gas which forms a large percentage of illuminating gases furnished for household uses. Iron set free in a liquid form in the furnace settles to the bottom, and from time to time it is allowed to flow out into moulds made in a bed of sand, forming when solidified the "pig iron" of commerce. It contains about 5 per cent of carbon together with small amounts of sulphur, phosphorus, silicon, and other substances.

When remelted this iron can be made to take the form of any mould into which it is run, and any markings on the sides of the mould. (See page 92.) These castings when quickly cooled are brittle, but when the cooling is continued through many hours the iron becomes more or less malleable.

Wrought iron is nearly pure iron, and results from burning out of molten cast iron the carbon, sulphur, phosphorus, silicon, and other substances it contains. It is tough, ductile, flexible, and malleable. Steel may be made from wrought iron by combining with it a certain small carefully calculated per cent of carbon. This amount is varied somewhat accord- 
ing to the uses to be made of the steel, and the qualities desired in it. Various small proportions of nickel or of other metals are sometimes combined in steel to give it desired properties fitting it for certain uses in parts of machinery where great powers of endurance are required, or in the armor of battle ships where impenetrability without brittleness is necessary.

The separation from the iron of the earthy material of the ore along with the ash and clinkers from the fuel is facilitated by the use of limestone as a "flux." In combination with sand present in the ore the calcium carbonate at the high temperature of the furnace forms a molten glass-like mass which floats as a viscid liquid above the molten iron, and when withdrawn as "slag" from the furnace from time to time it carries with it the refuse material of the furnace. The alternate layers of fuel, flux, and ore are fed at frequent intervals in at the top of the furnace stack where they are hoisted by machinery continuously in operation so long as the furnace is "in blast."

The material mixed in the furnace with the fuel and ore as a flux varies in chemical nature and in amount according to the earthy constituents of the ore. Indeed, throughout the whole series of operations from the raw ores to the finished metal product exact chemical knowledge of the material used and of the changes occurring in it must be maintained. This makes possible an output of metal of any desired quality. No "guessing" at results is permissible in the industries. The exactness attained in quality of manufactured products by reason of applied chemical knowledge is strikingly seen in the fact that steel of any certain quality is sold under contract for delivery a year or more later, and before the ores or the coal for reducing them have been mined. The makers of various fabrics contract for the delivery of goods of certain desired colors before the chemicals to be used as dyes 
have been prepared, or the cotton for the cloth has been grown, or the wool to be used has been clipped from the backs of sheep.

Iron when heated softens long before it melts, and while hot can be drawn into wire or be rolled into sheets and other desired forms. In the big rolling mills steel rails for railroads, and the great pieces of structural iron for bridges and for the framework of big office buildings in cities, are rapidly handled and given the forms desired by means of powerful machinery in use there. The shaping of iron on the anvil of the blacksmith when hot, and the welding of iron whereby two pieces become one, is made possible by the fact that iron softens without melting as it is heated.

Exposed to air and moisture iron surfaces become corroded with "rust" (iron oxide). This can be prevented by keeping the iron painted, or by means of a thin coating of some metal not readily affected by the atmosphere. The "tinplate" of dealers in metals used for roofing, kitchen utensils, and dairy articles, is sheet iron which has been dipped into molten tin, a very thin coat of which adheres to the iron. The "galvanized" iron ware is sheet iron, wire, etc., which has been similarly dipped into molten zinc which forms a protective coating on the iron.

By heating iron and steel to certain temperatures determined by experiment and recognized by the skilled worker in metals by the color, and then cooled at a rate and in a manner likewise learned by experience, certain desired degrees of hardness, elasticity, flexibility, and tenacity may be given these metals in a process known as tempering. Edged tools of all kinds, as swords, razors, knife blades, chisels and axes must be made of tempered steel. The metal must be sufficiently hard to hold an edge when ground, but not so brittle as to break easily when hard objects are cut. It must be flexible enough to bend without breaking, 
but so elastic as to spring back at once into the original form. The hairsprings of watches are good illustrations of steel painstakingly tempered, their cost representing largely the labor expended upon them. Spring balances of tempered metal are used for weighing, and comfort in travel is made greater by the steel springs under the wagon or auto body and underneath the railway car. The character of the work of "The Village Blacksmith" has materially changed during the past fifty years, machine work in metals having now largely replaced hand labor. However, the increase in dependence of mankind upon the use of metals in that time for comfort and well-being has been little short of marvelous. In extent of use, and in the changes wrought by such uses in the affairs of men and of the world at large, iron and steel rank chief among the metals.

\section{SUMMARY}

The industrial activity and commercial supremacy of an enlightened nation is intimately related to its national resources in metals, and in coal supplies for the development of these resources.

By reason of the enormous quantities of iron employed in the arts and industries, and because of properties which adapt it to innumerable uses, iron ranks first among the metals in usefulness.

The metals are chemical elements. An ore is a mixture of rock or other earthy material with some compound of a metal present in suffcient quantity to make its extraction profitable.

The "pig iron" of commerce is a product of the "blast" or "reduction" furnace where the iron ore as an oxide gives up its oxygen to combine with the intensely heated carbon of coke or coal.

Castings of iron and steel of excellent design are possible by reason of their expansion as they solidify. Metals very generally shrink in volume as they change from the molten to the solid state. Gold and silver coins have designs and lettering stamped upon their surfaces under pressure of powerful machinery. Mixtures of various metals in a molten state and in certain proportions are known as alloys. Some of these, such as type-metal and various kinds of "bronze", are successfully moulded due to their expansion when solidifying. 
Steel in general is iron containing somewhat more carbon than wrought iron but less than cast iron, the per cent varying according to the uses to be made of the steel and the properties it necessarily must have.

The "tempering" of steel by workmen skilled in the art through experience consists primarily in securing a desired degree of flexibility, elasticity, tenacity, and hardness. These properties are varied by the extent and rate of temperature changes to which the metal, and the cohesive force acting between its molecules, is subjected. 


\section{AT OUR HOMES}

Rooms of the House, Their Furnishings, and the Cost of Living

A good home, together with all the comforts and influences and associations that should centre in it, is essential to the largest degree of happiness in life. However costly the dwelling that shelters a family, it may be anything but a true home by reason of the manner of life of the people who inhabit it. On the other hand the best of human affections and influences may centre in the rudest of structures. Yet it remains true that comfortable and well-appointed dwellings constitute a large factor in having good homes. To possess a good home and good home surroundings, though these be moderate in cost, is worthy the ambition and sustained effort of any American citizen, man or woman.

It is the testimony of close observers that people of limited means and scant resources are very commonly the ones who fail to get the full worth from every dollar spent for home comforts and for family support. Lack of understanding of what to get as appointments for the home, and of what should constitute a suitable original outlay for them and a reasonable period of service from them, results oftentimes in deplorable waste and unnecessary deprivation.

There is ample opportunity for the exercise of individual tastes and preferences after standards have been established concerning what is desirable for the comforts and conveniences of modern family life. These standards may be upon any scale desired for the persons whose interests are to be served. 
Public schools are maintained to make possible higher ideals and larger attainments to those who avail themselves of school advantages. Discussion of whatever contributes in any large degree to better living has an important place"in the school curriculum. Courses in Home Economics can and should give instruction in schools calculated to lessen waste in American home life, and to increase its comforts and

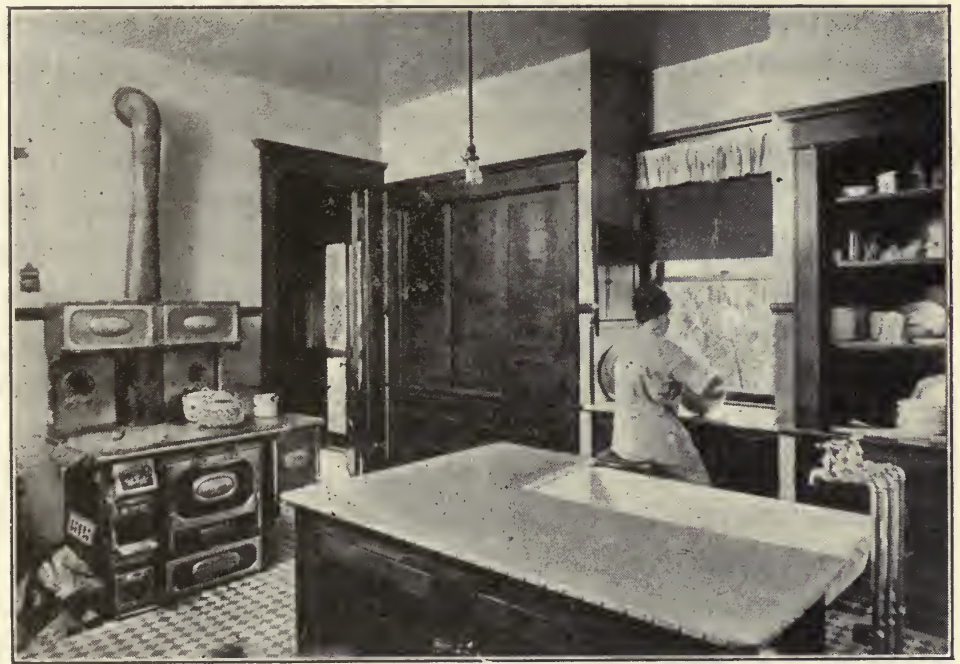

Fig. 67.-A modern farm kitchen.

general welfare. Here as in other school activities advantage should be taken of the knowledge gained through home experiences. These, along with the instruction given in schools, may be so organized as to uplift and improve life in the home.

Wise expenditure of a family income, and an efficient household management, requires scarcely less of business and administrative ability than does the conduct of enterprises outside the home. Efficiency counts not less here than in 
the business world, and to this end both husband and wife contribute in the discharge of all duties assumed by them or naturally devolving upon them as individuals. The arrangement of rooms in the house, and the furnishings that best contribute to the conduct of household affairs, together with all matters connected with the cost of living, are of joint concern to all members of the family.

So great have been the changes within the last half century in conditions of family life, and in the kind of work necessary in household affairs, that plans of houses built to-day differ widely from those of two generations ago.

This is true in many respects other than "modern conveniences". Then the kitchen was the centre of all the manifold activities of the home life. As a veritable "living room" it was made sufficiently large for use as dining room, laundry, and sitting room, and for the preparation of foodstuffs for both immediate and later family use. Nowadays it is often a model in its compact arrangements and conveniences for work. It is so planned as to economize both time and energy in the discharge of the fewer household duties that centre in the kitchen.

Before moving into any dwelling it is a matter of wise precaution to gain some knowledge of its history with regard to infectious diseases. The possibilities of disease germs remaining lodged on its walls and woodwork, or in corners and cracks where dirt has accumulated, is sufficient reason for care in this respect. Paint and varnish and new wall paper have values other than for cleanliness and improved appearances.

Since sunlight and fresh air are destructive of disease germs, and dampness is conducive to their development, all rooms in a dwelling should be light, airy, and dry. Windows are to let in sunlight and air as well as to keep out dust and cold. From time to time the furnishings of rooms 
should not only be dusted out of doors, but be exposed as well to wind and sun. The basement should be dry and well lighted, and thoroughly ventilated. Its floors and walls and foundations should be so constructed as not to harbor rats, mice, or vermin of any sort. The experiences of the human race long ago established the fact that cleanliness in person and in the home not only contributes to comfort and civilization, but is essential to health and well-being. Boiling hot water for laundry uses, for washing dishes, and for general household affairs, is a most effective disinfectant, and the free use of soap contributes to the same end.

Any consideration of the cost of living naturally has much to do with food and clothing. Discussions in school of food values and prices, supplementing home experiences, very properly may emphasize the fact that there is often great waste in the purchase of food supplies both in their quality and in the quantity secured for the outlay made. The choice of a wholesome and balanced diet is an important topic of instruction in schools. Ignorance in this respect usually results both in malnutrition and in thriftless living. The wide variation in food values secured by different people in return for the same outlay makes necessary some elementary instruction in schools concerning the purchase and preparation of foods. It is a matter of general good health and well-being. Cheap cuts of meat, for instance, may contain when properly cooked as much nourishment as those more expensive. To substitute less expensive foods for the more expensive ones, when the former furnish just as much food value, is not only thrift but good common sense. The practice of doing without tea and coffee is not only a matter of economy, but it has the greater purpose of promoting health. Neither tea nor coffee has any food value, and other drinks may be provided that are free from the harmful effects of caffeine. 
To choose habitually what really ministers in largest measure to one's welfare in matters of food, clothing, amusements, and self-indulgence necessitates a knowledge of the experiences and teachings of others. This knowledge may be gained at home and at school, from books and from people. In general it is a reasonable statement that any girl's edu-

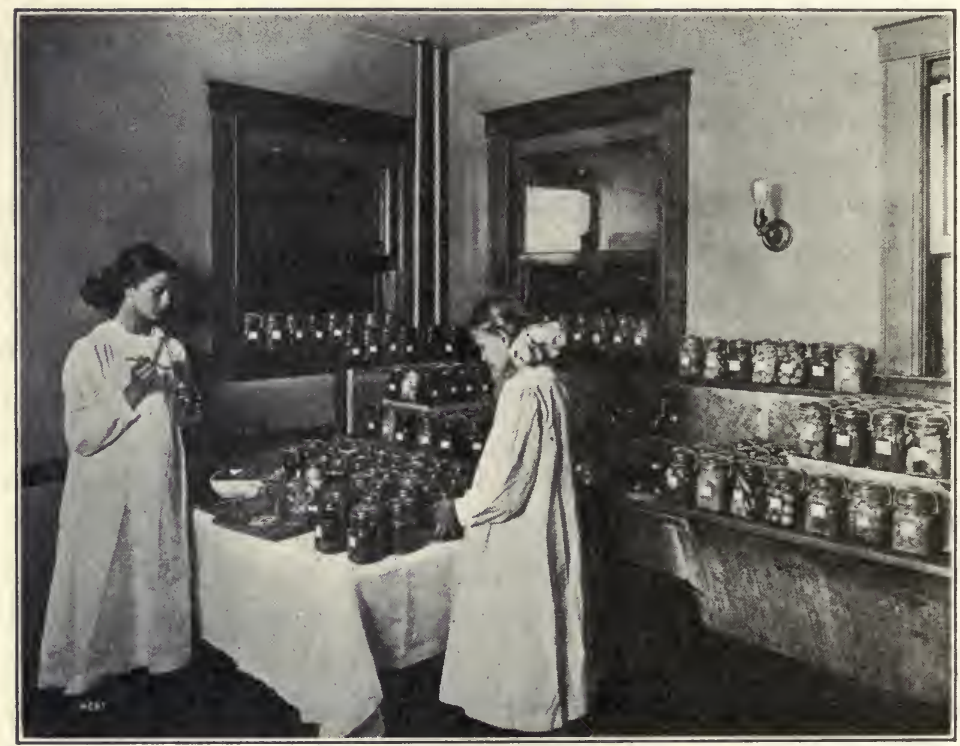

FIG. 68.-Canning as a home occupation.

cation is incomplete without some definite personal acquaintance with the affairs of a household, and some degree of proficiency in their management. And in no less degree, though in different relationships, every boy's education should include an intimate knowledge of the needs of a household, and how these can be supplied within the limits of a moderate income.

Fortunately the cost of a simple rational manner of living is relatively low under normal conditions. It is not only 
relatively inexpensive as a rule, but it contributes largely to the very best things in life. To learn this by experience only may be to repeat the mistakes of others rather than profit by them. Thriftlessness leads to poverty with all its limitations upon comfort and well-being. To become capable of earning a sufficient income, and to be intelligent in its expenditure, usually involves long-continued and well-directed effort and much self-denial.

Without the advantages of attendance upon school the wage earner is always at a great disadvantage, and the most desirable positions of service, power, and profit are often unattainable to those lacking in education. The personal characteristics of thrift, industry, business integrity, and right conduct in all things are, however, not dependent upon schooling. The cost of right living demands both a knowledge of what is best for one, and a willingness to do what is best. Self-restraint is necessary in one's life to assure its efficiency, and to avoid wasting life's opportunities and possibilities.

There is always a sharp line of distinction to be drawn between outlays in life that are necessary because of the better conditions of living that result from them, and those other outlays which though desirable are not in any sense indispensable. No community can afford to be content with a contaminated water supply whatever the cost involved in safe-guarding it. No individual or family can afford to inhabit a dwelling in the basement of which water always stands, whatever may be the expense of drains and waterproof foundations. On the other hand outlays for what merely gratifies expensive tastes and habits are always questionable. The use of tobacco may very properly be challenged on the ground of its being a useless expenditure, as well as on the more serious charge of its being a menace to the physical and mental development of boys and young men. 
Generally speaking nothing in life costs too much if there is ample return in well-being for the individual himself or for others. To attain the best things in the lives of individuals requires as a rule long-sustained efforts and sacrifices. There is doubtful value in any lesson that has required no effort, and in any education or in any fortune for which labor and sacrifice have not been given.

There is no other one item in the nation's bill of expenditures so appalling in its economic waste as that for alcoholic drink. Increased taxation is necessary to care for those whose lives have been wrecked by it directly and indirectly. The consumer gets nothing in exchange for his outlays that ministers to his well-being, and it lessens his efficiency as a worker and undermines his thrift.

\section{SUMmary}

Unwise expenditures in living expenses are a common accompaniment of poverty, and often a direct cause for it. Lack of intelligence in buying largely increases the cost of living for those who have abundant means; for those of limited resources, it usually results in getting far less for their outlays than they should.

Any proper valuation of articles purchased takes into account not only the original outlay for them as cost price, but their probable length of service, and whether or not they are well suited for their intended uses. This is especially true in the purchase of clothing, and when buying a house and household furnishings.

Business ability, and an executive skill of high order, is required for an efficient household administration. In spending wisely the part of a family income set aside for family expenses, the wife and mother becomes as truly a supporter of the family as the husband and father.

Instruction at school in household management, based upon home experiences and applied to the betterment of the home life, constitutes an important service rendered by the public schools. Public school instruction in the elements of home economics is a means for bettering individual welfare and improving social conditions.

Health and self-respect alike demand that families be well housed. In congested centres of population the high cost of dwelling places, 
whether to own or to rent, constitutes an increasingly difficult problem in living.

Ignorance in the choice of a suitable diet for a family, and for an individual, is not only thriftless but it commonly results in malnutrition, ill health, and shortened lives. The well-to-do are perhaps as often victims of this failure to regulate diet as are those handicapped by poverty.

Any rational manner of life takes account of whatever ministers to the comfort, happiness, and welfare of individuals and of communities. It seeks the highest efficiency in right living, and avoids whatever is merely self-indulgence. A simple life is quite consistent with a high order of living and in a measure is indispensable to it.

It is to be remembered that in changes of styles in clothing there is involved the financial gain of those who seek to market a new stock of goods. It is not fundamental to well-ordered living to discard clothing of any sort while it is yet suitable and serviceable merely for the sake of changing to something new.

\section{Exercises}

1. Who usually determines the selection of things needed in a household, both as regards their quality and the prices paid for them?

2. In what sense is the wife in a home, though not a wage-earner, as truly a supporter of the family as the husband?

3. Distinguish between. $(a)$ waste and thrift; $(b)$ necessities of life and its luxuries; $(c)$ comforts in living and extravagances. What factor very largely determines in which of these classes an outlay by any person or family shall be put?

4. What advantages may there be in cooking breakfast cereals the day before rather than on the morning of their use?

5. Where gas is used in cooking, or for laundry purposes, why is it wasteful not to turn the gas low as soon as the wash water or food begins to boil?

6. What precautions should be observed in the purchase of fruits other than securing honest measure and fair prices? What further precautions are necessary before use of these fruits as food?

7. Aside from a garden, name various ways of reducing expenditures for foods without sacrifice of proper quantity and wholesome quality.

8. In what ways is there relation between the high cost of living and following the fashions in dress?

9. To what extent are "styles" in clothing properly followed?

10. Give some arguments for the outlay involved in the maintenance $(a)$ of free public schools; $(b)$ of churches as places of public worship.

11. What is a wise rule to follow in the matter of outlays for amusements? 
12. As an important item in the cost of living, what are some of the arguments advanced to warrant a system of insurance against fire, accidents, death, and disabilities from old age?

13. What may be used to clean sinks and bath-tubs of the "scum" from hard water?

14. What is the nature $(a)$ of paint; $(b)$ of varnish? Aside from any improvement in appearance, why should woodwork be painted if it is to be exposed to the weather? Why have furniture and woodwork indoors varnished?

15. What in general should characterize the furnishings of a home?

16. State the value of a basement for a house aside from the extra room it affords.

\section{Fuel ANd Lights for Modern Homes}

Possibly in no one respect are the comforts of modern life more fully manifest than in the heating and lighting of American homes. Whittier in "Snow Bound" pictures for us a winter's evening in a New England home of the first half of the nineteenth century:
"Shut in from all the world without, We sat the clean-winged hearth about, Content to let the north wind roar In baffled rage at pane and door, While the red logs before us beat The frost line back with tropic heat; And ever when a louder blast Shook beam and rafter as it passed, The merrier up its roaring draught
The great throat of the chimney laughed."

However, we should not overlook the fact that all other rooms in this typical farm home were probably icy cold, and that with all the lavish use of wood as fuel in the big-throated fireplace, costing as it did little more than the labor incident to cutting and hauling it, there was none of the comfort enjoyed by us in the even temperatures so easily maintained in all parts of our present-day homes. 
The poet in his later years could well forget that in the big living room of his boyhood days, with face burning from the heat of the open fire, there was scarcely a place where his feet at the same time were not chilled in the rush along the floor of cold air from every doorway crack to feed the chimney's draft. In memories of the "Dear home faces whereupon the fitful firelight paled and shone" the hardships incident to a winter's cold in the homes of those early days were doubtless forgotten.

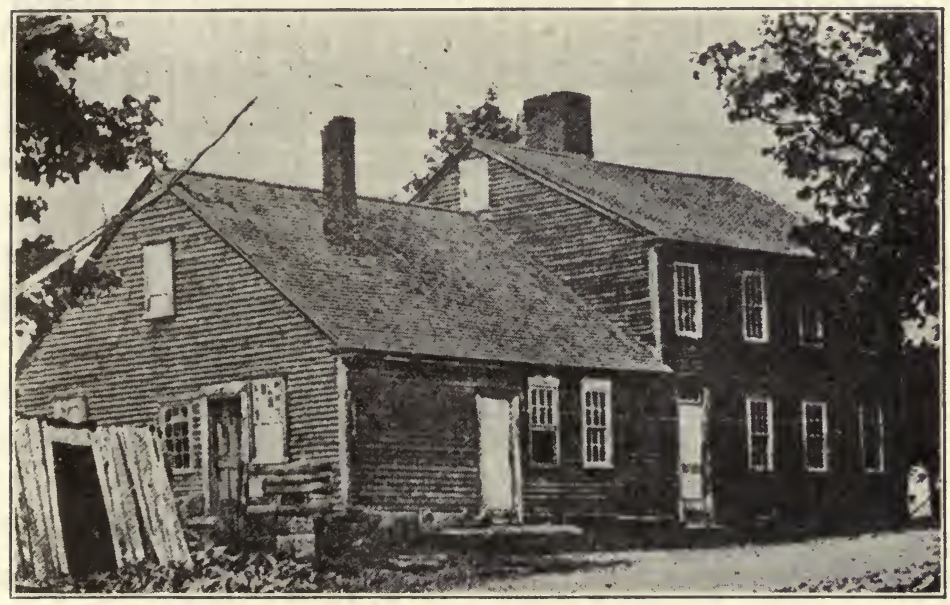

FIG. 69.-Birthplace of Elias Howe, inventor of the sewing machine.

In time the woodlands were largely cleared for cultivation, the trees it may be having been burned just to get rid of them. The old-fashioned fireplace was closed. More and more generally from about 1830 onward stoves began to come into use as heaters and for cooking purposes. Coal as a fuel was discovered in Pennsylvania about 1820 . The rapid increase in amounts used for industrial purposes, however, dates from about 1880 .

The production and distribution of the enormous amounts 
of coal now required in the United States at prices which on the one hand shall not affect disastrously the varied industries of the country dependent upon steam power, and on the other the comfort of the people in their home life, constitutes a "fuel problem" likely to continue till the natural resources of the country in its coal deposits shall have become exhausted.

\section{Million Tons}

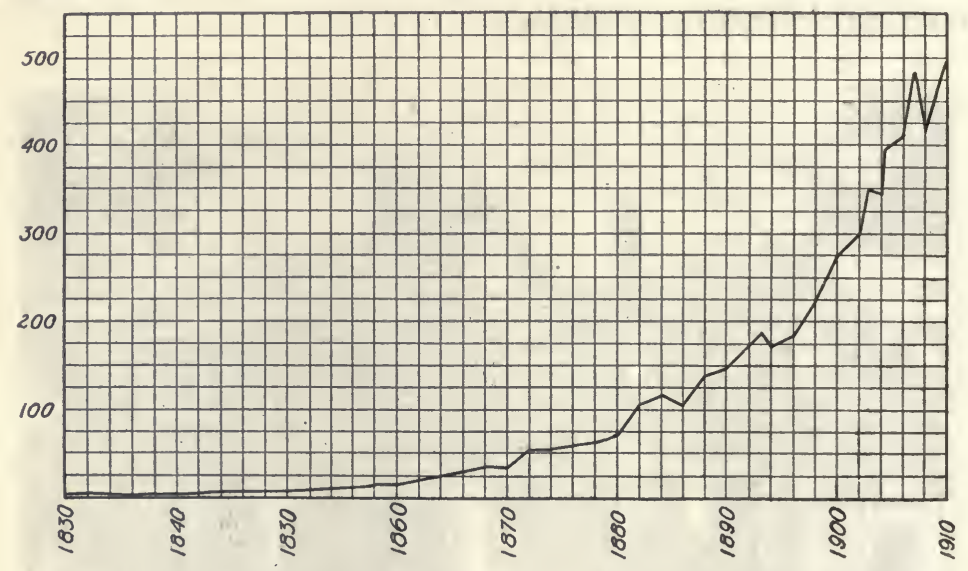

FIG. 70.-Production of coal in the United States 1830 to I9ro.

Without coal as a fuel, and without any available substitute for it in ample quantity, practically all the machinery of modern life must come to a standstill. Factories, shops, mills, furnaces, together with railway and steamship lines, cannot be operated on the same scale as now. Commerce, transportation, and manufactures will return to the lower volume of an earlier age, and present-day standards of living will likewise be lowered. That this may not come to pass other motive power than steam more and more must come into use.

Coal as dug from the earth is carbon in varying per cent of purity. Its structure gives ample evidence of its being the 
remains of plant growths. The coal age in the earth's history as given in Geology must have been a time when climatic conditions were unlike those of the present day. Vegetation grew rank in an atmosphere warm, and laden with moisture and carbon dioxide. During long periods of time accumulations of woody material of great thickness must have been kept from decay by submergence in the waters of marshy regions. Under the pressure of layers of earthy material washed in upon it, this vegetable matter largely shut away from the air became changed in course of time into the varied forms with which we are familiar as coal. The several layers ("veins") of coal, separated by layers of slate or other rock material, represent successive periods of accumulation and of submergence. Through later periods, and probably when vegetation did not flourish so luxuriantly, these thicknesses of vegetable matter became buried in the depths where as coal they are now found.

It should be mentioned here that all this carbon represents "stored solar energy" used by plants in the separation of the carbon from the carbon dioxide of the air. Enormously long periods of time must have been involved in this formation of the coal layers so nearly indispensable to the welfare of mankind. It is calculated that at the present rate of increase in the production and use of coal the world's supply will become exhausted in somewhat more than a hundred years. Long before then, however, unless other forms of energy are employed for doing the world's work, the rise in prices due to a limited supply is likely to make them prohibitive for most people.

All means for illumination in common use in homes depend upon the fact that when the temperature of a substance has been raised sufficiently high it becomes incandescent, i.e., it gives out light. In candle, kerosene lamp, and illuminating gas flames the carbon particles present in the gas or vapor 
are made incandescent by the heat of combustion as the vapors and gases burn. In the incandescent and arc electric lights the incandescence is caused by electrical energy being transformed into heat. Much resistance is offered to the passage of the electricity in the filaments of one, and through the air gap separating the carbon pencils of the other. The intimate relationship believed to exist between heat and light as forms of energy is shown in the explanation that as the temperature of a body rises by reason of increase of its molecular activity there comes a time when the ether disturbances originating in the quickened movements of its molecules, and radiating outward from the body in straight lines in every direction, become sufficiently frequent per second to affect the optic nerves in our eyes, resulting in a sensation of light and enabling us "to see." Bodies from which these light waves originate are said to be luminous. Most bodies about us are non-luminous, and we see them only because light coming to them is reflected to us and into our eyes. Much of the expense of artificial lighting systems lies in the fact that there is large waste involved in production of the heat necessary to incandescence. Illumination by "cold light," i.e., at temperatures as low as that of the light emitted by fireflies, would greatly increase the comfort and cheapen the cost of household illumination.

\section{SUMmary}

The plumbing, heating, and lighting of modern American homes exhibits in a striking way the contributions of scientific achievement and inventive genius to the comfort and well-being of this generation. The homes of our grandparents, and the palaces of kings a century ago, lacked these things. What we now consider necessary to our well-being they had not dreamed of.

Coal like the other natural resources of timber, ores, petroleum, and natural gas, is not exhaustless in quantity. As a source of power by reason of the heat liberated when it is burned, coal is at present indis- 
pensable in the industries and in commerce. The heat liberated from it may be considered solar energy stored during the centuries of a remote past.

It was not till about 1880 that the "incandescent" light with its carbon filaments within an exhausted glass bulb, perfected by Thomas A. Edison ( $1847-$ ), became a commercial success. The extended use of the powerful arc lights for out-of-door illumination waited upon the development of the dynamo to maintain sufficient strength of current through long periods of time at relatively low cost.

\section{Some Foodstuffs}

There is much more to any consideration of what one shall eat and what one shall drink than is involved in its market price as part of the cost of living, and its purity and wholesomeness as these affect one's health. How much to eat (or how little), and the relative amounts of the different foods ${ }^{1}$ in order to give a balanced ration, are too often given scant attention till ill-health and its limitations make orders from the physician imperative.

A person's appetite naturally is not only nature's warning of need for food by the body, but under normal conditions it should serve as a guide in choice of the foods best suited to meet these body needs. That which is appetizing, and for which one has great relish, is in general good for one. Unfortunately the appetite may become perverted or dulled, and its guidance alone is always unsafe. The use of any fond or drink that creates a craving, and which demands more and more use of it (any "habit-forming" substance), is always to be shunned. One should never eat beyond his ability to fully digest what is eaten. Any meal is sufficient

${ }^{1}$ The term foôd as used here and later is to be distinguished from "foodstuffs" as sold in the market, and the various "dishes" served at table for our meals. It has reference to the groups of chemical compounds named on page 222. 
where one can work to the next meal time without becoming exhausted in strength or ravenous in appetite. When people are well any lack of appetite should generally mean absence of bodily need for food. As a rule it is better to stop eating, especially when the meal has been at all hurried, before being quite fully satisfied in hunger.

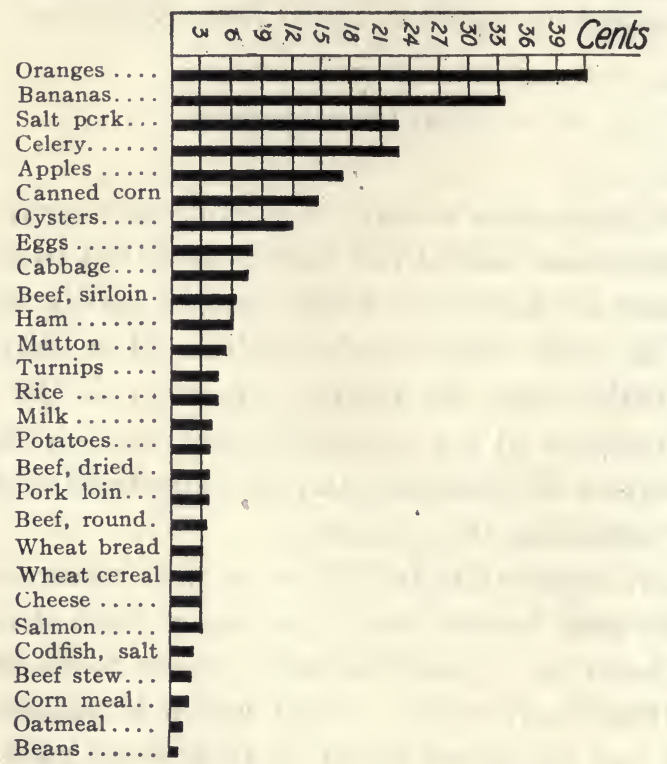

FIG. 7I.-Comparative cost of the same amount of protein from different foodstuffs ${ }^{1}$. (After Weed.)

Poor cooking, improper combinations of foodstuffs; and use of substances unfit for food because indigestible, are all responsible for much ill-health. It is very likely, however, that even more human wretchedness and sacrifice of lives comes from over-eating. The very poor often suffer greatly

${ }^{1}$ The prices of foodstuffs both in general and in relation to one another have been wholly changed as result of the world war. This, however, does not impair the worth of this exhibit of relative values under normal conditions. 
from lack of nutrition because of inability to purchase food. But very often it is ignorance of what is most nutritious and best to get with the money available that is responsible for the suffering.

Where well-to-do and ordinarily intelligent people are not normal in health, and not free from disorders and ailments

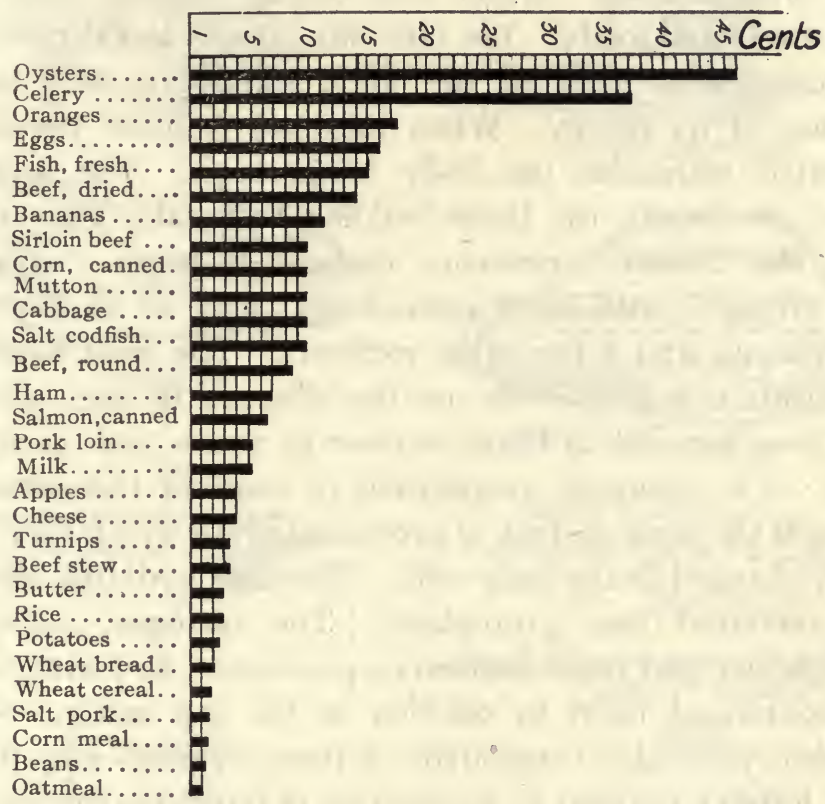

FIG. 72.-Comparative cost of the same amount of energy from different foodstuffs. (After Weed.)

directly traceable to over-indulgence in foods, it is a reflection upon their judgment and.self-restraint. Foods may be unsuited to an individual in their quality and quantity, or because of conditions under which they are eaten. In many cases of ill-health the mischief was done during the years of childhood and infancy, and before the years of discretion had been reached. During youth, as well as in later years, 
simple living as to foods and drink is commonly a sensible manner of life. In these respects as with amusements and recreations the course of life in general should be to reject whatever harms or leads to injury.

The foods may be grouped sufficiently for our purposes into fats and oils, carbohydrates (such as starch and sugar), and protein foods. Water and certain mineral salts are also considered foods. The fats, oils, starch, and sugar may be regarded as fuels for the body, and source of a large portion of its energy. When they are oxidized the heat liberated maintains the body temperature. The protein foods are largely the tissue-building material. They contain the chemical elements carbon, hydrogen, oxygen, and nitrogen, with small quantities it may be of sulphur, phosphorus, and a few other elements. The most familiar foodstuffs rich in proteins are the albumen in eggs, gluten in grains, legumen in beans, myosin in meats, and casein in milk. The chemical composition of some of the proteins is much the same as that of protoplasm into which they are easily changed in the body cells. The carbohydrates cannot be converted into protoplasm. The nitrogen, sulphur, phosphorus, and other elements are obtained by plants from compounds of them in solution in the sap water. Soils deficient in soluble compounds of these elements may have their fertility restored by application of fertilizers containing the necessary chemical compounds.

A "balanced ration" takes into account the needs of the body for repair and growth, for warmth and energy, and for maintenance of a state of health. It seeks to approximate the relative proportions of the foodstuffs needed by the body at all times, and to vary the proportions to suit the conditions of season and employment as these change from time to time. It is impractical to undertake to do more than approximate any exact balance in the foods of which we 
make choice at different times. However, it is not only possible but it is indispensable for the maintenance of good health to observe in a general way the required proportions,
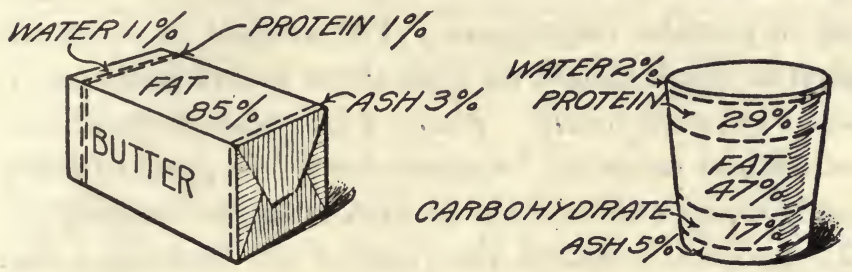

NUT BUTTEP

\section{PROTEIN}
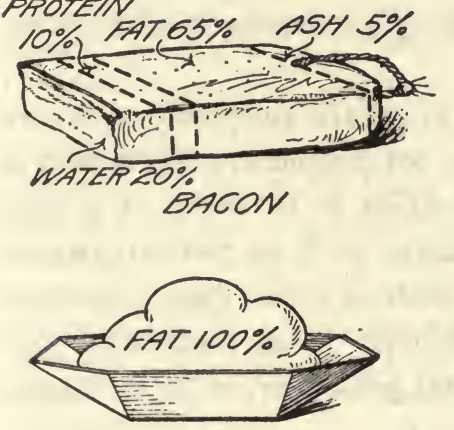

$\angle A P D$
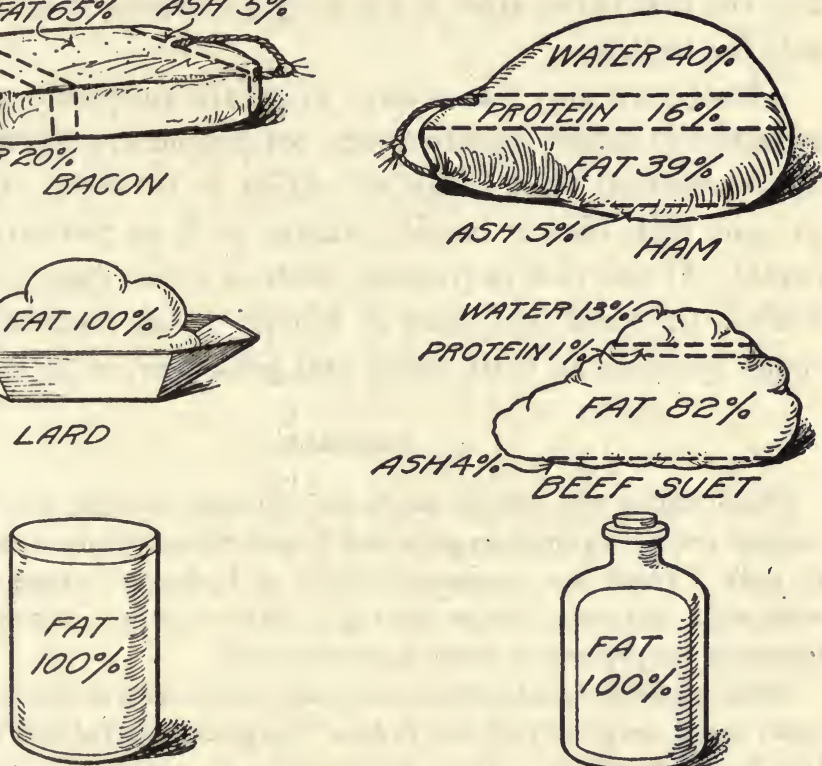

VEGETABLE FATS
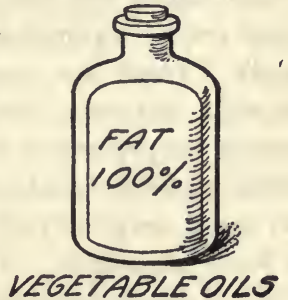

FIG. 73.-Composition of some common fatty foods.

especially when the diet suffers little change from day to day. The proportion of the foods as classified above may be stated in a most general way, and subject to changes due to age and 
other reasons, as five-sevenths carbohydrates, one-seventh fats and oils, one-seventh proteins. In cases of illness, and of convalescence afterward, the maintenance of this balance, or a departure from it under direction of a physician, becomes a matter of greatest importance. The amount of water per day taken as drink should be from three to five pints and is best taken between meals. Water with meals is beneficial, but food should never be "washed down" in place of being thoroughly masticated and mixed with saliva before swallowing. To habitually follow the practice of drinking a half pint of water or more the last thing before retiring at night and the first thing after rising in the morning is an excellent rule for health.

Though we may not always know the proportions of food required to supply bodily needs, for people in good health an approximation to a balanced ration is to serve at a meal (a) one dish that is largely starch, such as potato, rice, or cereal; $(b)$ one rich in protein, such as meat, eggs, cheese, or beans; $(c)$ some fats, such as butter; or fat meat, and some sugar (perhaps in fruit jellies and preserves, or as molasses).

\section{SUMMARY}

Chief. among the protein foods are albumen in eggs, gluten in the various grains, legumen in peas and beans, myosin in meat, and casein in milk. These are composed chiefly of hydrogen, oxygen, carbon, with some nitrogen, and in the egg a little sulphur. Other chemical elements are present in small quantities only.

Some minerals in solution in drinking waters, and in the cereals and other foods, serve to keep the organs of digestion active and the digestive fluids abundant. Three to five pints of water daily contributes toward maintaining a normal condition of digestion and circulation, and the elimination of waste from the body.

The introduction into milk of some acid coagulates the casein. The rennet used in cheese-making is a dried portion of the stomach from a calf, and it contains some of the acid secreted there for use in digestion. The gastric fluid in the human stomach contains a little 
From such a table as that below suggestions of choices may be had, as well as a knowledge of the relative food values of different foodstuffs.

Approximate Composition of Foodstuffs

\begin{tabular}{|c|c|c|c|c|c|c|}
\hline $\begin{array}{c}\text { Food Materials } \\
\text { (edible parts) }\end{array}$ & $\begin{array}{l}\text { Water } \\
\text { per } \\
\text { cent }\end{array}$ & $\begin{array}{c}\text { Protein } \\
\text { per } \\
\text { cent }\end{array}$ & $\begin{array}{l}\text { Fat } \\
\text { per } \\
\text { cent }\end{array}$ & $\begin{array}{c}\text { Carbo- } \\
\text { hydrate } \\
\text { per } \\
\text { cent }\end{array}$ & $\begin{array}{c}\text { Ash } \\
\text { per } \\
\text { cent }\end{array}$ & $\begin{array}{l}\text { Heat value of } \\
\text { one pound } \\
\text { (in calories) }\end{array}$ \\
\hline Apples................ & 83.2 & 0.4 & 0.5 & 14.2 & 0.3 & 285 \\
\hline 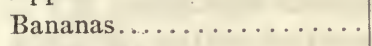 & $75 \cdot 3$ & I. 3 & 0.6 & 22.0 & 0.8 & 447 \\
\hline Beans, dry.............. & r 2.6 & $22 \cdot 5$ & I. 8 & 59.6 & 3.1 & I 565 \\
\hline Beef, sirloin ............ & 60.0 & I8.9 & 18.5 & $\cdots \cdots$ & I.O & I099 \\
\hline Beef, round............. & 68.2 & $2 I \cdot 3$ & $7 \cdot 9$ & $\cdots \cdots$ & I. 2 & 709 \\
\hline Beets, cooked. .......... & 88.6 & $2 \cdot 3$ & 0.1 & $7 \cdot 4$ & I. 6 & I 80 \\
\hline Butter.................. & 10.5 & I. O & 85.0 & I. 0 & 0.3 & 3491 \\
\hline Cabbage................ & $9 \mathrm{I} \cdot 5$ & I. 6 & 0.3 & 5.6 & I.O & I 43 \\
\hline Celery ................. & $94 \cdot 5$ & I. I & 0.1 & $3 \cdot 3$ & I.0 & 84 \\
\hline Cheese, cream.......... & 30.2 & $25 \cdot 9$ & $33 \cdot 7$ & $2 \cdot 4$ & 4.2 & I 890 \\
\hline Cherries................. & 80.9 & $\mathbf{I}: \mathbf{0}$ & 0.8 & I6.7 & 0.6 & 354 \\
\hline Chicken................ & $72 \cdot 7$ & $21 \cdot 5$ & $2 \cdot 5$ & $\cdots \cdots$ & I. 3 & 493 \\
\hline Cornmeal.............. & 15.0 & $9 \cdot 2$ & I.9 & $75 \cdot 4$ & I. 4 & 1620 \\
\hline 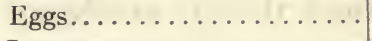 & 73.8 & $13 \cdot 4$ & 10.5 & $\cdots$ & I.O & 672 \\
\hline Lettuce................ & $94 \cdot 7$ & I. 2 & 0.3 & 2.9 & 0.9 & 87 \\
\hline Macaroni................ & 10.3 & I3. 4 & 0.9 & $74 \cdot \mathrm{I}$ & I. 3 & I625 \\
\hline 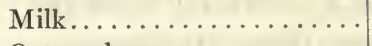 & 87.0 & $3 \cdot 3$ & 4.0 & $5 \cdot 0$ & 0.7 & $3 I$ \\
\hline 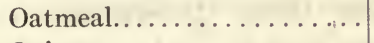 & $7 \cdot 6$ & I6. I & $7 \cdot 2$ & $67 \cdot 5$ & 2.0 & I $8 \mathrm{Ir}$ \\
\hline 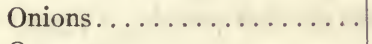 & 88.0 & I. 6 & 0.3 & $9 \cdot 9$ & $\cdots$ & 22 \\
\hline gges............... & $87 \cdot \mathrm{I}$ & 0.8 & 0.2 & I I. 6 & $\cdots \cdots$ & 233 \\
\hline ters............... & $87 \cdot \mathrm{I}$ & 6.2 & I. 2 & $3 \cdot 7$ & 2.0 & 228 \\
\hline uts.............. & 9.0 & 25.8 & 38.6 & $24 \cdot 4$ & 2.0 & 2490 \\
\hline Pork, shoulder.......... & 50.3 & I $7 \cdot 3$ & $3 I . I$ & $\cdots \cdots$ & 0.9 & 1585 \\
\hline Pork, salt............... & I $2 . \mathrm{I}$ & 0.9 & 82.8 & $\cdots \cdots$ & $4 \cdot 2$ & 3555 \\
\hline Potatoes......... & 78.9 & 2.2 & O. I & I 8.4 & I.O & 378 \\
\hline Rice....... & I 2.4 & 8.0 & 0.3 & 79.0 & 0.4 & I 59 I \\
\hline Strawberries.......... & 90.0 & I.O & 0.6 & $7 \cdot 4$ & ... & I69 \\
\hline String beans............ & 89.0 & $2 \cdot 3$ & 0.3 & $7 \cdot 4$ & $\cdots$ & I 84 \\
\hline Sugar. . . . . . . . . . . & 2.0 & $\cdots$ & $\cdots \cdots$ & $97 \cdot 8$ & 0.3 & I 8 r 5 \\
\hline Tomatoes, fresh. . . . & $95 \cdot 3$ & 0.9 & 0.4 & $3 \cdot 9$ & 0.3 & 104 \\
\hline Wheat, flour........ & I $2 \cdot 5$ & I0. 8 & I. I & 74.8 & 0.5 & I608 \\
\hline Wheat, graham........ & I3. I & $13 \cdot 3$ & 2.2 & 71.4 & I. 8 & $\quad 1628$ \\
\hline
\end{tabular}


free hydrochloric acid. The casein in curdling gathers up much of the butter-fat present in the milk.

Milik should contain about 4 per cent of butter-fat, and 86 per cent water. There is considerable sugar of milk in it, a matter of importance in preparing foods for infants.

In preparing sausage for sale it is a common practice to mix in with the lean and fat meat as ground together more or less of starchy material. As a "filler" this increases the weight of the product, and at the same time by absorption of the moisture contributes to the keeping quality of the sausage. It is a cheaper material than meat, and so may be regarded as an adulterant. The use of preservatives in meats interferes with their digestion when eaten, and they may be positively harmful in the system.

\section{The Carbohydrates}

The botanist notes in the green coloring of vegetation the presence of chlorophyll. The little bodies containing this chlorophyll as found in the protoplasm of the cells of the plant are known as chloroplasts. In them the water from the ground and the carbon dioxide from the air are being manufactured directly or indirectly into sugar, starch, and cellulose (wood fibre) by use of the energy derived from sunlight. Animals appropriate and use these products of chemical change in plants, but only plants can produce them from the raw materials.

It has been found by botanists that plants as well as animals must have oxygen to live, i.e., to maintain the life of the protoplasm. A product of the processes of plant "life as a whole is a relatively small quantity of carbon dioxide gas. This shows that the process of oxidation goes on in plants even as in animals, though much more slowly. During the daytime, and under the influence of sunlight, this action may be completely masked by the fact that carbon dioxide obtained from the air is at the same time being chemically combined with water in the plant. A product of this change is a relatively large amount of oxygen 
given back into the air. It is in this way that the large amounts of oxygen gas withdrawn from the air by respiration, by decay of vegetation, "and by the combustion of wood and coal, are returned to it, and the per cent of oxygen in the air maintained practically unchanged.

Neither botanists nor chemists undertake to say definitely just how the changes occur in the chloroplasts, nor the exact nature of the chemical products at successive stages of these changes. It is, however, an aid to an understanding of the chemical relationship between the products of chlorophyll activity by assuming that it can be expressed in this way:

$$
\mathrm{CO}_{2}+\mathrm{H}_{2} \mathrm{O}=\mathrm{O}_{2}+\mathrm{CH}_{2} \mathrm{O}
$$

The $\mathrm{CH}_{2} \mathrm{O}$ may be considered a compound of carbon and water, and is type of the compounds known as carbohydrates, of which starch, sugar, and cellulose are familiar examples.

Assuming this change to have taken place, the chemical relationship of these carbohydrates becomes more apparent by a comparison of their chemical formulæ, rewritten with reference to the $\mathrm{CH}_{2} \mathrm{O}$ group of atoms:

$$
\begin{aligned}
& \text { Starch............... }\left(\mathrm{C}_{6} \mathrm{H}_{10} \mathrm{O}_{5}\right) x^{1}=\left(6 \mathrm{CH}_{2} \mathrm{O}-\mathrm{H}_{2} \mathrm{O}\right) x^{1} \\
& \text { Grape sugar............ } \mathrm{C}_{6} \mathrm{H}_{12} \mathrm{O}_{6} \quad=6 \mathrm{CH}_{2} \mathrm{O} \\
& \text { Cane sugar............ } \mathrm{C}_{12} \mathrm{H}_{22} \mathrm{O}_{11}={ }_{12} \mathrm{CH}_{2} \mathrm{O}-\mathrm{H}_{2} \mathrm{O} \\
& \text { Cellulose............. }\left(\mathrm{C}_{6} \mathrm{H}_{10} \mathrm{O}_{5}\right) y^{1}=\left(6 \mathrm{CH}_{2} \mathrm{O}-\mathrm{H}_{2} \mathrm{O}\right) y^{1}
\end{aligned}
$$

These hypotheses conform quite closely to what is known about these substances.

1 The subscripts $x$ and $y$ are some unknown but definite numbers of these groups. By conceiving the molecules of starch and of cellulose to be made up of different numbers of groups, and these groups arranged in different combinations (even as the same kind of bricks may be built together to form entirely different structures), it is possible to account for such different substances as starch and cellulose even when made up of the same chemical elements united in the same proportions by weight. 
Starch is lacking in solubility in cold water, while the sugars are easily dissolved. It would seem probable that whichever carbohydrate may be the direct product of the building-up process under the influence of light, photosynthesis as it is called, the distribution of this product through the tissues of the plant for use as food or for storage involves changes from starch to sugar and then again to starch. These changes, apparently, are easily accomplished in the plant economy.
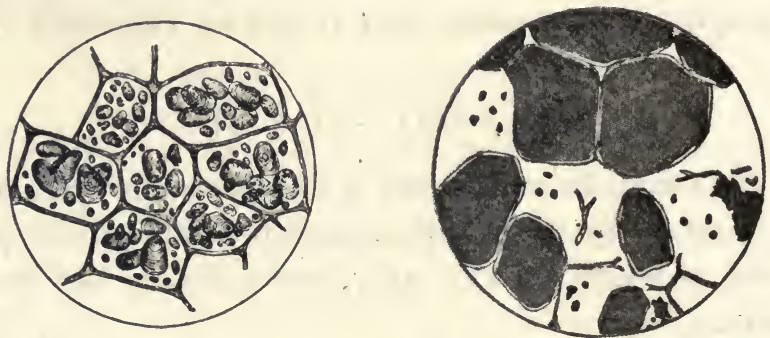

Fig. 74.-Starch cells of potato showing granules within cellulose. When cooked these granules swell and burst open, a condition favorable for digestion.

There are very many examples in Chemistry of substances entirely unlike one another, but having the same elements in them united in the same proportion by weight. The most satisfactory explanation of their differences in properties is a supposed difference in the arrangement of atoms in the make-up of their molecules.

In the processes of digestion, too, while starch and sugar are foods of greatest value and readily digested ordinarily, the cellulose is very largely indigestible. Long-continued cooking softens and to some extent makes available small portions of the cellulose of vegetables and grains. A certain amount of cellulose in our foods is of great value, however, in giving bulk to it, i.e., in making it less concentrated. 
This stimulates a desirable activity of the muscles of the digestive tract.

In the starch of potato, rice, corn (maize), and the various small grains used by man as foods, there is appropriated by him what the parent plant had stored for the use of the young plants of a succeeding generation. In the development of a young plant in the process of germination, this stored starch becomes changed into soluble grape sugar. The chemist and the botanist are baffled in their understanding of just how these changes are accomplished.

The common potato is largely starch and water. Unlike the grains, which are seeds containing the embryos of new plants, the potato is considered an underground stem very much shortened and thickened. In it there is a storage of starch to start out the new growths of potato. The "eyes" of the potato are buds from which are developed roots and stems. These as new plants depend for their first growth upon the stored food of the tuber (thickened stem).

The beet is type of a class of plants which store a food supply for the next season's growth in their roots. These are much thickened as a result of this storage. These beet roots when set out a second season grow, blossom, and produce seeds for the perpetuation of their species. This growth of stalk and flower and seeds makes use of the stored food of the past season's growth. In the case of the sugar beet the stored sugar is chemically like that in the stems of sugar cane and sorghum. There is enough of it to make its extraction from the sliced beet roots profitable. Enormous quantities of beet sugar are produced in Germany, France, and the United States.

In the seeds of corn and cotton and flax, as well as in certain fruits such as olives and various kinds of nuts, a supply of food in the form of oil is stored for the young plant when germination shall occur. In other cases as in peas, 


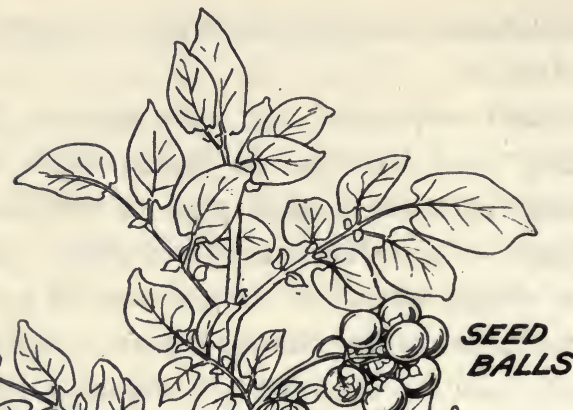

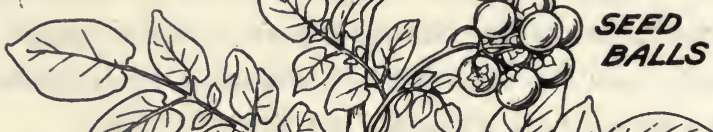
तir $\rightarrow$ (E)

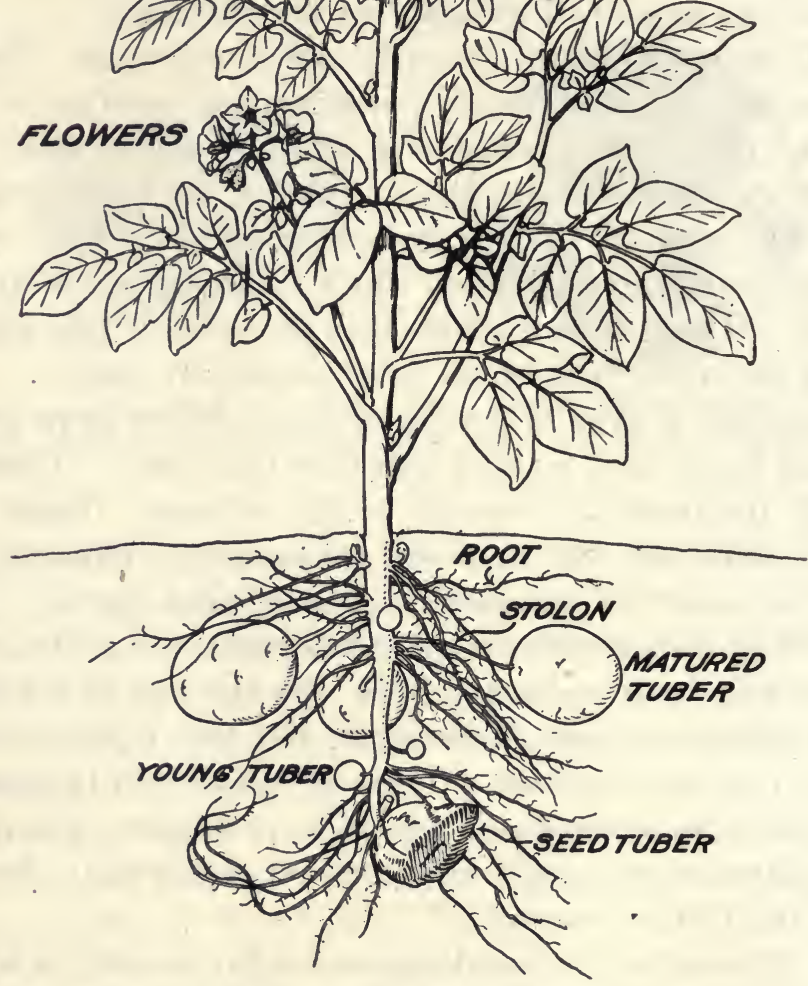

FIG. 75.-The common potato. 
beans, and the gluten of grains, there is formed the complex compound known as protein.

\section{SUMMary}

Starch and cellulose are made up of the elements carbon, hydrogen, and oxygen, and these are in the same proportions by weight in both substances. Ordinarily this would mean that any two bodies of which this is true are one and the same substance. But starch and cellulose have entirely different properties and are recognized as entirely separate substances. While starch is one of the chief foods of mankind, cellulose is indigestible and is familiar to us in such forms as cotton and linen (flax) fibre, wood, paper, etc.

The most reasonable explanation of the production of different substances from the same proportions by weight of the same elements is that the ways in which the atoms have been put together must be unlike. In the studies of chemical compounds of plant or animal origin cases of this kind are not uncommon.

Plants under the influence of sunlight can manufacture their own food as starch and sugar out of the raw materials of water and carbon dioxide gas. They may store any excess of it in root, stem, leaf, seed, or fruit. Probably it is in the form of sugar only that it is conveyed in the sap of the plant from where it is made to where it is stored, and then again to where it is needed later for the growth of the plant and the maturing of its seeds.

The accomplishment of this change back and forth of starch and sugar, and their change into cellulose in the woody part of the plant structure, is not well understood by either botanists or chemists. The substance made by the plant known as diastase is probably concerned in these chemical changes in the life processes of the plant.

In some plants along with the starch stored as food for the plant is more or less of vegetable oils. Olive, cocoanut, cottonseed, and linseed (flaxseed) oils are good illustrations. Many different kinds of nuts contain oil enough to be very noticeable when the pulp is crushed.

The presence of starch, especially after having been boiled in a little water, is made known by a characteristic blue coloration when treated with a little weak iodine solution. (See page $30 \mathrm{I}$ for test for proteins.)

When a few drops of Fehling's solution, whose blue color is due to the presence in it of a compound of copper, is added to a solution containing any grape sugar or glucose and heated, the blue color disappears 
and a yellowish (and perhaps reddish) precipitate forms. Cane sugar does not give this result with the Fehling solution, although some few other less common sugars do.

\section{Exercises}

1. Name various grains having extensive use as foodstuffs. What others are less commonly used?

2. Name the two food elements constituting the larger part of the grains. Wherein does the food value of wheat exceed that of an equal weight of corn?

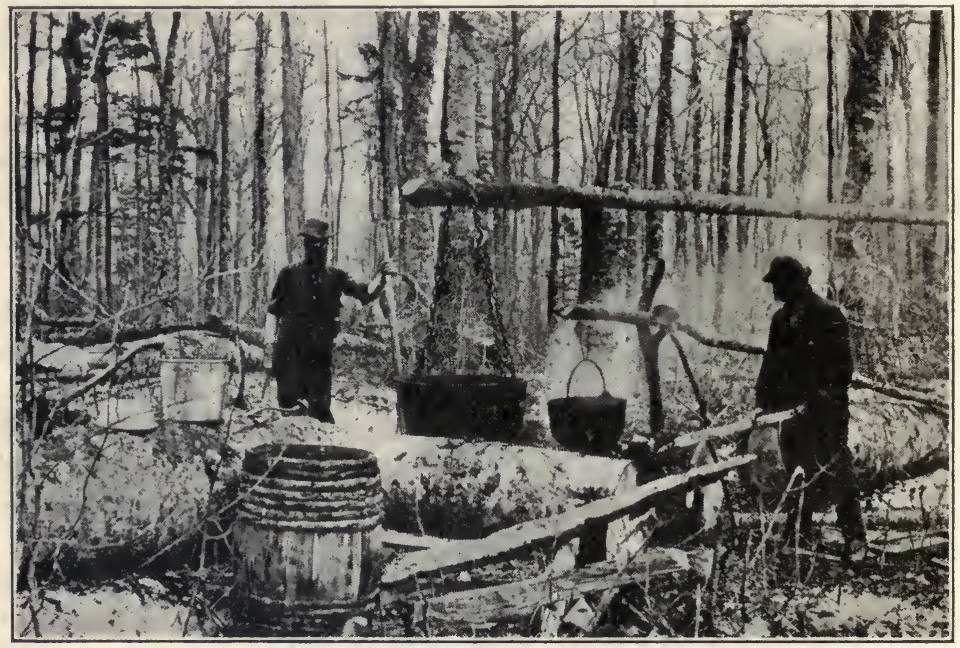

Fig. 76.-Boiling maple sap. The old way of making maple syrup.

3. Name several foods other than the grains that are rich in starch. What is the chemical test $(a)$ for starch; $(b)$ for gluten; $(c)$ for sugar?

4. What purpose is served by the gluten of wheat flour in the making of loaves of bread? Wherein lies the difficulty experienced in making bread from corn or rice flour?

5. What is the purpose of yeast in bread making? What advantage in its use over baking powder? Why is the flour for bread moistened with water, and the dough "raised" in a warm place? What causes sour bread?

6. What is the purpose of kneading several times the dough from which bread is to be made? Name four important ends accomplished in the baking of a loaf of bread. 
7. What constitutes the cooking of starch in foods? What is the nature of the popping of corn, and the baking of potato?

8. Discuss the chemistry of starch formation in plants. What is the chemical formula for starch?

9. What is the chemistry of the digestion of starch? What need is there for any such change? In the similar change which occurs in seeds whereby the stored starch is made available for the young and growing plant as food, what is the ferment whereby this change is brought about?

10. What is malt? Explain its use in prepared foods for infants.

11. Describe the steps in the manufacture either of cane or of beet sugar. Why are "vacuum pans" used in boiling the syrups?

12. Name two important uses of starch in baking powder.

13. Explain the rising of a loaf of cake. Why does it retain its form when baked? What explanation is there for "fallen" cake?

14. About what per cent of wheat flour is starch?

15. Explain the ill-effects of eating unripe fruit. What changes occur in the ripening process?

16. What uses have (a) grape sugar (as a solid); (b) glucose (as a liquid)? What is true of the relative sweetness of cane and grape sugars?

17. Learn from some text in Chemistry, or any other source, the names of the several kinds of sugar, and the source of each kind.

18. What deleterious materials are sometimes used in making candy? What constitutes excess in the use of candy?

19. What ways are employed other than drying and canning to keep fruits for long periods in a condition fit for use as foods?

20. What "preservatives" are sometimes found in jellies and canned goods? What purpose is served in the use of coloring materials, such as coal tar dyes, in ketchup? What effect upon the digestibility of foodstuffs have most of the chemicals used as preservatives? Why is this so?

21. Make a list of the various foods represented in the table service of one day. Then underscore all those that are from plants.

22. What dietary conditions are met in the use of bread and milk as a simple food?

\section{Fires, Burns, and Various Accidents}

Perhaps nowhere does the competency or incompetency of an individual, his practical knowledge or lack of it, manifest itself so notably as in times of emergency. While it may not be worth while always to be getting ready for the unusual to occur, and for what is unlikely to happen, yet the unexpected often occurs, and accidents are common. Avoid- 
ance of lifelong suffering and disability, even the preservation of life itself, may depend in emergencies upon the prompt and intelligent course of action of some individual upon whom responsibility is thrust without warning.

In the most urgent cases there is no time and often no opportunity to consult other persons or to read from books. One must know exactly what to do and how it is to be done, and must act without loss of time. A fairly good substitute, however, for this skill and knowledge, and a much better course than to act inadvisedly just for the sake of doing something, is to have some reliable book of directions always at hand for times of emergency. With its contents one should be sufficiently familiar to be able to turn immediately to the needed detailed directions which one cannot be expected to remember. The book should give this information so briefly and so clearly that it can be read and understood at a glance. An inexpensive booklet, containing information much condensed, printed in good type and with ample spacings, is more serviceable for general use than a lengthy medical treatise.

Instruction should be given at home and at school upon what to do before the doctor arrives, and what course to pursue in times of accident or panic. This teaching should not wait upon some deplorable occurrence or some great disaster. Such instruction may very properly include such matters of common knowledge as these:

I. To free the stomach of poison, or of undigested food, a simple household emetic easily administered is a teaspoonful of ground mustard well stirred in a cup of lukewarm water. Then after a little by thrusting the fore-finger far back in the throat vomiting may be brought about. Repeat the treatment if deemed necessary.

2. A good sterilizing liquid into which to place spoon, thermometer, or other small articles in use by patients sick with an infectious disease, or the instruments used by dentists and surgeons in their practice, or by teachers in examining the throats of pupils, is a 4 per cent solution of carbolic acid (one ounce to a quart of water). 
3. A solution of a pound of chloride of lime from a freshly opened can in three gallons of water is perhaps the cheapest and most effective disinfectant with which to treat for twenty minutes or more all excreta before it is thrown out into sewer, privy, or cesspool.

4. One of the best ways of freeing formaldehyde gas from formalin for disinfecting purposes is to add crystals of permanganate of potash to the formalin in the proportion of one-half pound per pint of the liquid. The dish containing the formalin should be set in another and larger dish in case there should be any overflow or spattering.

The enormous losses annually by fires in the United States constitutes a standing reflection upon the course of the American people in the conservation of their resources, and upon their intelligence in not more effectively preventing these wastes. From the long list of reported causes of fires it is possible to ascribe an appalling number to heedlessness, and to an indifference to life and property that well may be considered criminal. Closely akin to these is dishonesty and incompetency in the construction and in the care of buildings. Painstaking efforts to avoid fires, and intelligent precautions against them, are elements of an enlightened citizenship. The insurance rates necessarily charged to repay losses by fire in the United States are a sad comment on the thrift of people, and constitute no small burden upon the occupants of buildings whether as owners or as tenants.

While texts on human biology, and various books on what to do in case of emergency, give information about burns and their treatment, and how to alleviate suffering and to prevent infection, no books or schools can insure persons against the results of foolhardiness on their own part or on the part of others.

When kerosene is poured upon smoldering coals a large amount of vapor is likely to form. This vapor mixed with air is explosive, and requires only an ignition temperature to result in flames that reach outward as far as the vapor has diffused. The spread of the combustion throughout the mixture is almost instantaneous. To use gasoline, benzine, 
or naphtha in rooms closed or not thoroughly ventilated is to invite a like result from ignition of its vapor.

When one's clothing is on fire, and when one is enveloped in smoke or flame, a safe course to pursue is to throw one's self to the floor where there may be some air to breathe, and where the flames will pass upward and away from the body. Wrapping one's self closely from neck down in several thicknesses of blanket by quickly rolling over and over in it may smother the flames of burning clothing. Putting a wet handkerchief over the mouth and nose lessens the danger of strangulation from smoke.

Where the skin is not broken, relief from the pain of a burn may be had by putting the burned surface into cold water thick with baking soda, or by keeping the burned area covered with a paste of the soda. Later, soft cloths with some soft ointment may be applied to keep the skin soft and moist. Where blisters form, the watery liquid may be removed by use of a sharp needle that has first been sterilized by holding it a moment in a flame, or dipping it into some sterilizing liquid. Where the skin is burned off medical attention is necessary as infection of the wound must be prevented. In binding up the wound, cotton should not be put next the wound because the removal of the threads later may occasion intense suffering.

Burns seriously affecting one-third or more of the surface of the body are likely to prove fatal. This result is not so much from the destruction of tissue, or from infection when the skin has been broken, as it is from an excessive irritation of the nerve terminals and a destructive shock to the cells of the nerve centres. The centres that stimulate and control the organs concerned in respiration, circulation, nutrition, etc., may be so affected by the shock as to fail to maintain their activities.

Many people who have suffered accident of one kind or 
another are able, in spite of suffering and limitations, to do well their duties in life. Then, too, the hardships from the accidents of life oftentimes reach beyond the sufferer to others more or less dependent upon him. The losses to individuals and to society in general by preventable accidents, where persons are killed or maimed for life, astound those who know of their extent. It is difficult to estimate how much apparently unnecessary human loss and human woe is represented by these accidents.

The terrible sacrifices of life and health on the soldiery in times of war, and the sufferings and wretchedness endured as a result of war by the innocent and helpless, even of generations unborn, have been endured by mankind through all the ages. Though excused at times, only in rare cases are they justified. On the other hand, there has been a growing demand in the United States of late years for better protection to the lives and health of the vast army of industrial workers engaged in peaceful production rather than the devastation caused by war. These efforts have gone to great lengths in the exercise by society at large of care to safeguard workers against accident. The liability of employers of labor for any negligence in this respect is coming to be generally recognized.

There are many occupations in which men are engaged in order to earn a livelihood where their health is imperiled despite all precautions taken both by the workmen and by their employers. The lungs of the coal heaver, and of workmen in cement factories, flour mills, and stone cutting establishments, are likely to become irritated by the solid particles that pass the guards established by nature along the nasal passages. In match factories, in the manufacture of illuminating gas, and elsewhere, men may be harmed by foul and poisonous gases. Devices to protect life and health lessen these risks and may wholly eliminate danger. 
Perhaps the greatest obstacle to any full measure of success in these efforts is the culpable negligence and indifference of workers themselves, and a lack of the forethought that makes accidents unlikely. The "safety first" crusade in the industrial world has sought to impress upon employees having to do with travel, transportation, and industrial life generally, the demand that human life under no circumstances shall be put in peril. No risks are to be countenanced under any conditions, and the efficiency of any employee depends upon whether he is trustworthy as well as capable.

A man who drinks, whose brain is not clear and whose judgment is warped, whose nerves are unsteady and senses dulled, is not wanted anywhere in the trades, shops, factories, railway or steamship service, in business houses or the professions, nor in any place where property and life are in any measure dependent upon his discharge of duties. The drinking man, however brilliant in his attainments, is not considered reliable, and the financial loss in making good his mistakes sooner or later costs him his position. Employers of labor cannot afford the risk involved where any man wilfully imperils his own life or that of others in any way.

Railway corporations have long insisted upon the highest degree of efficiency in locomotive engineers. Prepared for service by long training, steady of nerve and of good judgment, unwilling to take risks and mindful of the responsibilities resting upon them, these men as a class have won and have retained the confidence of the traveling public. Men in charge of expensive steam and electric plants are of necessity competent men, and their license is supposed to be evidence of their fitness to discharge the responsibilities of their positions. Incompetency manifests itself sooner or later, and causes loss of license to operate power machinery.

One of the features of the introduction and general use of 
automobiles as power machinery, operating at high rates of speed on public highways, has been the distressing list of fatalities annually, amounting the country over to an enormous total in killed and maimed. "Safety first" needs to be learned by each new generation of automobile drivers. Protection should be assured to people on the public highways as elsewhere against incompetency, recklessness, and an indifference to human life and suffering. Only those of proved competency in the handling of machines should be licensed to use the highways of public travel.

\section{SUMMARY}

In times of accident and of danger it is important to keep from becoming unduly excited. Definite information of the procedure to be followed in times of emergency, whether in the home or elsewhere, is knowledge upon which life itself may at times depend. What to do till the doctor comes is knowledge worth having.

Many fires are undoubtedly accidental. It is extremely probable, however, that enormous annual losses by fire in the United States are wholly unnecessary, and chargeable to carelessness, shiftlessness, or incompetency. This waste puts a heavy tax upon property holders generally, for they must pay higher fire insurance premiums to cover these unnecessary fire losses.

Death from burns follows at times because of the shock to the nerve centres as result of the pain from the irritated nerve ends. Especially is this the case when the centres affected are those from which originate the impulses maintaining action of the heart and other vital organs. Where the skin is broken in case of a burn, antiseptic dressings must be used for the wound to prevent its becoming infected.

In all places in life, and under all circumstances, due precautions to prevent accident are to be insisted upon. Indifference to the welfare of others is selfishness, and foolhardiness in conduct shows lack in good judgment and in ordinary good sense. Forethought and painstaking measures are obligations resting on all persons alike.

\section{Exercises}

1. In view of possible fires in a factory building, what advantage is there in having the elevator shaft far removed from the stairways? Under what circumstances have fire-escapes many times failed to provide means of escape from burning buildings? 
3. To what special dangers are workmen exposed $(a)$ in mines; $(b)$ in bridge building, and in the erection of great office buildings; $(c)$ in railroad shops; $(d)$ in foundries?

4. Name at least four extra-hazardous occupations for men employed indoors.

5. Upon what day of the week have most accidents been found to occur? What interpretation is placed upon this? What relation to this has the lesson on Rest, Recreation, and Amusements?

6. Make a list of devices that very suitably may be headed "For Safety First". Make a list of short rules and regulations for the public designed to accomplish this same end. 


\title{
XI. SURROUNDINGS OF THE HOME
}

\author{
The Garden, and Its Care
}

A home garden for the dweller in town may have a greater worth to its possessor than any mere savings in garden produce. A healthful diet is very likely to include for most people plenty of vegetables in season, whether from a garden on the farm or in town, whether raised by the consumer or purchased in market. But wholly aside from this fact, and from the pleasures that come through the care and cultivation of growing plants, the physical exercise involved in garden work is unexcelled in its benefits. Out-of-door work in the garden and on the home premises, together with an hour's walk a day, is an amount of exercise that is not only desirable for the ayerage town-dweller, but is usually possible to anyone in connection with the ordinary round of life. The value of a garden as a place in which to get physical invigoration and mental clearness, especially during the morning hours, is too commonly underrated. Regular hours for labor that have in them as an incentive something that is worth while furnish an assurance of continued good health and of a life that is efficient to the last. In the commonplace affairs of everyday life, especially in connection with a wellkept home and its surroundings, are to be found pleasures and contentment not possible elsewhere.

A liking for plants, and an apprecration of their important part in the enjoyments of life, comes in large measure through care for them and from the responsibilities that this care involves. The boy or girl who grows up in town or city with- 
out having had the care of plants in yard and garden, and who has not learned to be successful in the cultivation of vegetables and flowers, of vines and shrubs, has missed one of the humanizing influences of life. The care of plants and of domestic animals at home teaches much that is of great value in the studies of Botany and Zoology. But its greatest

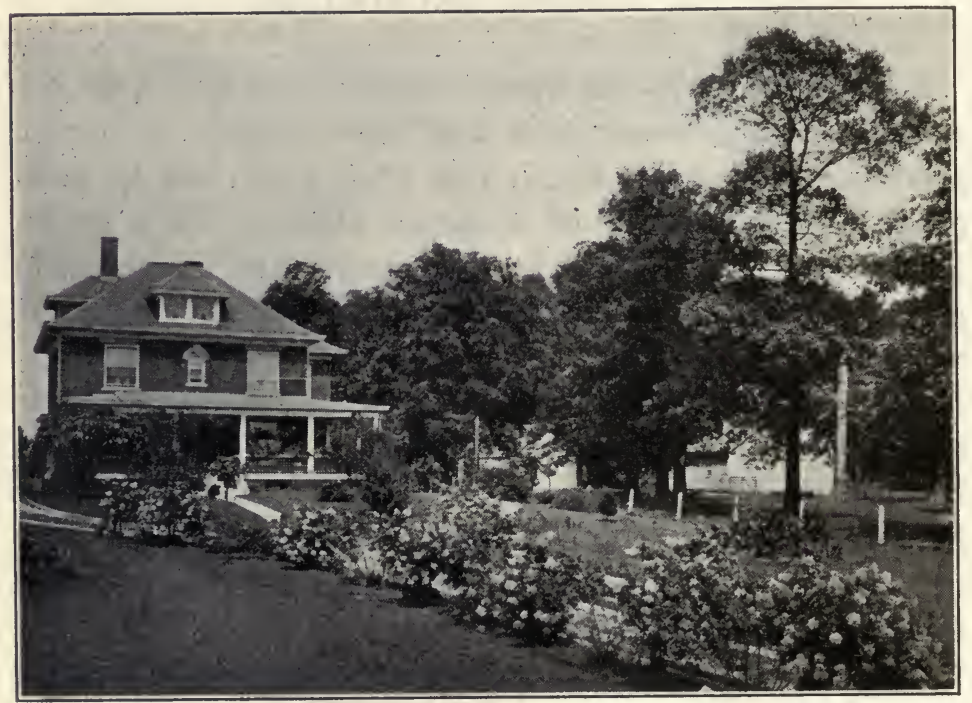

FIG. 77.-Lawn, shrubbery, and trees as surroundings of a home.

educational value lies in the sense of obligations assumed, and in a regard for living things that it develops.

Where the sciences of Botany and Zoology are taught to pupils whose only knowledge of plants and animals is from the courses in the classrooms and laboratories of high schools, the results are likely to fall far short of the possibilities of these branches of study. Very much in literature remains a closed book to those who during childhood and youth have been denied the birthright of a personal knowledge of plants and of domestic animals gained through care of them. 
In the care of a garden as in the affairs of life generally initiative is accounted an indispensable trait in any one who would succeed. The power of initiative is sometimes said to be an ability to see what needs to be done, a readiness to undertake it, and an industry and perseverance that accomplishes what is undertaken. No success is achieved without it in any of the pursuits of life whether professional, financial, social, or political.

Much of the farmer's success with crops is secured by doing on a larger scale what must be done in the care of a garden. The soil must be in suitable condition as a seed bed that the young and growing plants may thrive from the time the seeds germinate. It must contain the needed food material in available soluble form. There must be the necessary cultivation of the surface soil so that the supply of moisture in the ground is sufficiently conserved to provide for the needs of the growing plants. Weeds that appropriate the supply of food material,

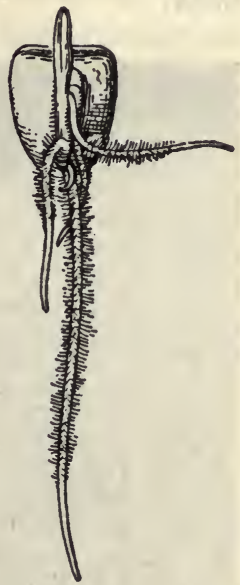

F IG. 78 . - Roothairs on corn seedling magnified. and that rob the crop of available soil water during the growing season, must be kept down. Then, too, failure is sure to follow the use of seeds of poor quality and of impaired powers of germination.

Any cultivation of the soil must be so suited to the crop and to changing weather conditions as to preserve a texture in which the rootlets and root-hairs may everywhere penetrate it with ease. The root system of a tree is likely to be more wide-spreading than its branches, with innumerable rootlets penetrating in every direction all the soil round about the tree. There is reason to believe that when a plant is uprooted even with considerable care a very large part 
of its root system breaks off and is left in the ground. The root-hairs are found just back of the growing ends of the roots. They are it may be but an eighth of an inch or less in length, and are merely elongated cells of the outer covering of the rootlets. They never become roots but disappear as the rootlet grows older and forms a thicker outer coat or bark.

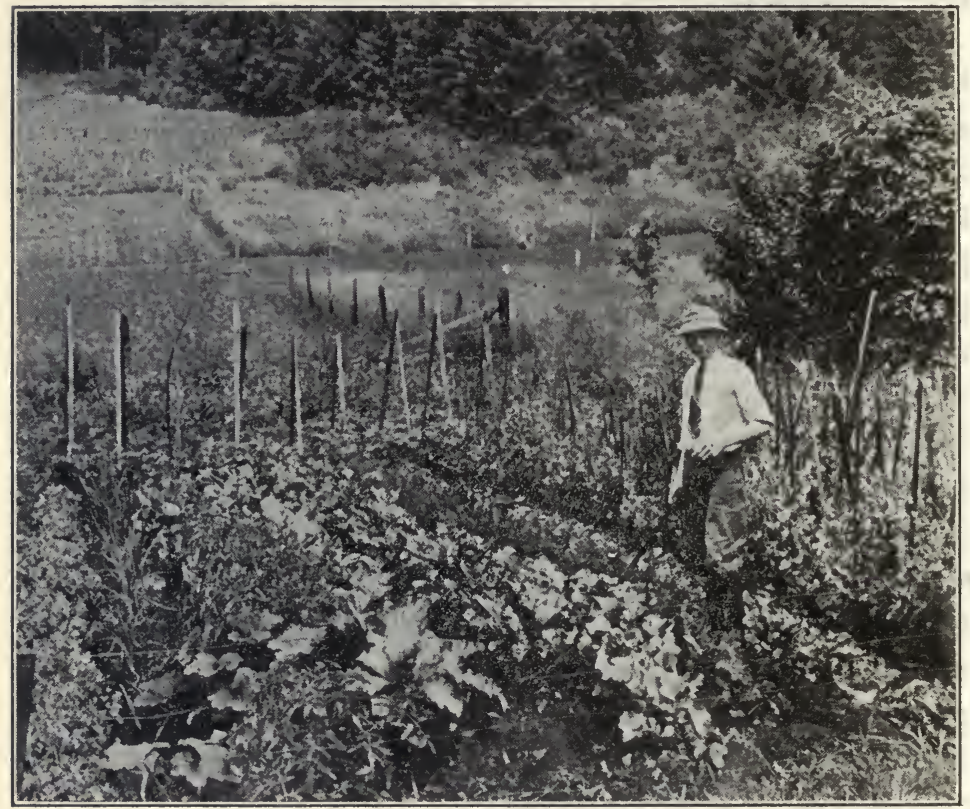

FIG. 79.-The young gardener.

All labor and painstaking on the part of a gardener may come to naught by reason of unfavorable weather and bad seasons for growth. In dry summer weather, when it becomes necessary to water the garden and lawn, it is better generally to thoroughly soak the portion where any water at all is applied, and not to repeat until the ground has again become dry to the depth of about three inches. The deeper 
plants root the less likely they are to die in dry weather. Frequent sprinklings in place of a thorough soaking of the soil results in a shallow root growth.

The care of a home garden is an excellent preparation for the college courses in Agriculture that have to do with man's part in shaping conditions so that the earth "may yield her increase". Studies in plant biology, having to do with the processes of plant growth and the perpetuation of plant species, are made far more profitable because of knowledge gained in the care of plants at home.

It is by these labors in the garden, about the home, and in the household that a love for the home place and its surroundings is fostered. This is separate from and yet very closely associated with a regard for those who make up the family circle. It is these ties, wrought out perchance in weariness at the time, which lead many a man and woman in the later years of life to revisit and linger over the old home scenes. Woe betides a nation whose young people grow up and never learn through labor to make better some place that is to them a home. In the surroundings of garden, trees, lawn, and shrubbery, the home owner may find more of enjoyment than in any restless wanderings to and fro in the world. There is a dignity to labor, and a strength in citizenship, closely associated with the maintenance of a home. We may well suppose that the home of Longfellow's Village Blacksmith was not far from the shop where it is said that in honest toil

"He earns whate'er he can,

And looks the whole world in the face,

For he owes not any man."

John Howard Payne's "Home, Sweet Home" may well be sung by each succeeding generation of American citizenship as an expression of a healthy sentiment to cherish. Love of home is a sure foundation for, if indeed it is not 
the chief element in, a patriotism that knows no sacrifice too great for the welfare and the security of one's country whether in times of war or of peace. No sentimental attachments for the home of one's youth, however, should prevent a person from assuming the responsibilities of citizenship in the new land where he may make his permanent home. Though the land in which one dwells be his by adoption rather than his "native land," the ties that centre in a home as one makes it for himself warrant the spirit if not the exact letter of Scott's lines

"Breathes there a man with soul so dead,

Who never to himself hath said,

This is my own, my native land!"

\section{SUMMARY}

The home garden may be made to provide a most enjoyable and wholesome form of open-air exercise. In its care one may have the great satisfaction which comes from witnessing daily the results of a proper care of plants.

Botany as a study in school will yield far larger educational values to those who previously have had some first-hand acquaintance with plants such as may be gained in the care of a garden. Then, too, what is learned in school of plants, and of the conditions for their growth, may in turn be tested out in caring for the home garden.

The industry and perseverance necessary for success in the care of a garden, coupled with that initiative which sees what is necessary to be done and which undertakes its accomplishment, are the very traits necessary to success in all the affairs of life.

It is a part of the history of every nation that ownership of land in connection with the homes of its people, and a cultivation of the soil by its owners, fosters a better home life, a more industrious citizenship, and a greater stability of government.

In caring for a garden no tillage of the soil should be undertaken when the ground is so wet as to be sticky. However, as soon as possible after a rain the surface of the ground during the growing season should be stirred enough to keep a layer of an inch or so of the top of the soil dry and loose. This prevents both the drying out of water from the soil below and the springing up of a new crop of weeds. 


\section{Exercises}

1. In what ways may the care of grounds and garden at home be both a rest and a recreation? What advantages has such an occupation over (a) complete cessation from physical activities; $(b)$ extended travel in pursuit of rest, recreation, and amusement? Name some special benefits sought in vacation trips away from home.

2. What school studies may very profitably accompany the care of gardens by boys and girls? What out-of-door responsibilities at home other than care of the garden may yield both pleasure and profit?

3. Name various fruits that may be grown about the home with no large amount of care. Which in your community yields the best returns annually on an average?

4. How may ignorance, carelessness, or dishonesty in the growth, harvest, and distribution of seeds affect both national prosperity and individual welfare? What supervision is exercised at present so that seeds on the market shall prove true to name, and possess high germinating power?

5. What meaning has the phrase "The dignity of labor"?

6. What is meant by initiative in any of the affairs of life?

7. After an examination of the Table on page 225 , state the value of garden produce such as tomatoes, onions, lettuce, apples, berries, etc., relative to the value of meat, eggs, and wheat flour in protein and in calories of energy. Explain the importance of vegetables and of fruits as an essential part of our foods.

\section{Soll Conditions for Plant Growth}

Mixed with the large and varying proportions of sand, gravel, stones, clay, iron oxide and other more or less soluble substances, there are found in fertile soils small quantities of soluble compounds of sodium, potassium, nitrogen, phosphorus, and a few other chemical elements. Apart from a plentiful supply of water, it is the exhaustion of these lastnamed smaller portions that changes fruitful soils into barren ones. In arid and semi-arid districts the soil may be rich in these soluble mineral compounds accumulated through the ages, the soil not having been subjected to washings from rainfall. Irrigation makes these regions highly fruitful.

Sandy soils are likely to be more or less barren wherever found since soluble material is washed down out of reach of 
the roots of plants. Such soils are said to "leach," and fertilizers applied to them do not permanently enrich them. Their open porous state permits the rapid evaporation of water from them, too, while the access of over much air to the roots of plants is destructive. On the other hand, clay soils filled with water may exclude air from the roots so completely that plants do not thrive. Illustrations of this may often

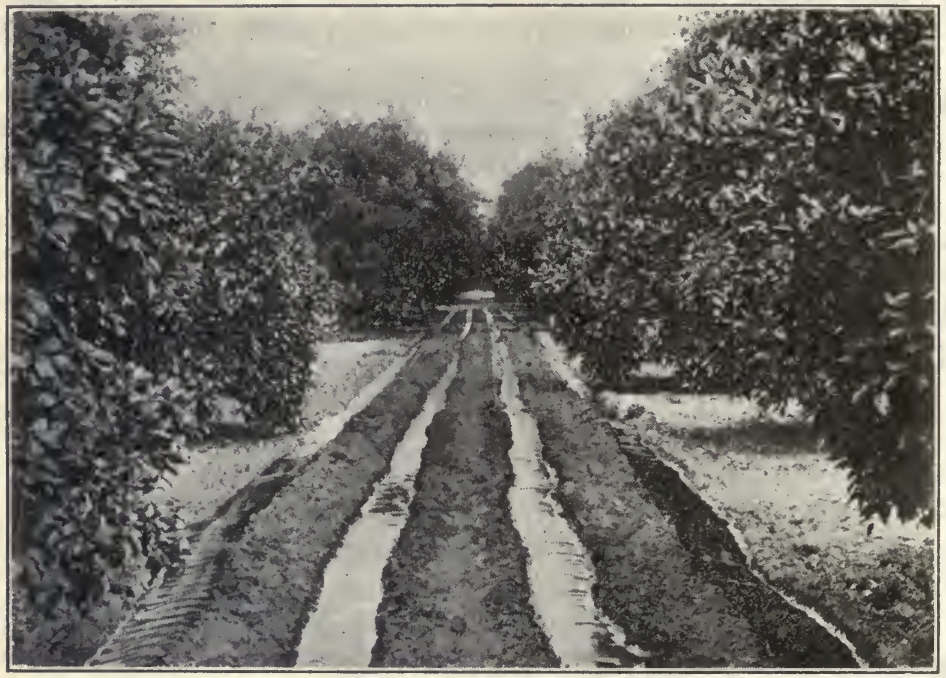

FIG. 80.-Irrigation of trees.

be seen in the stunted growths on low lands that have been overflowed, and where water has stood for some time during the growing season for crops.

Any consideration of the roots of plants, and of the manner of supply of food material to a plant by osmotic flow into the roots, emphasizes the necessity of a finely divided state of the soil. It should be loose and friable enough for the tender root structures to penetrate it readily in all directions, but at the same time sufficiently compact so that the rootlets 
and root-hairs are all the while in the closest contact with the soil particles. They should not be subjected to any drying effect from large air spaces, for osmotic action through and into the root-hairs is harmfully affected and may be wholly prevented by the drying of their thin porous walls. The finer the particles provided they remain apart from one another, the more surface there is presented for an adhering film of water, and the larger the available water content of the soil for the plant ${ }^{1}$.

The working of the soil by use of farm and garden implements constitutes tillage. Its chief purposes are to improve the soil structure, to conserve the water content in the soil, and to destroy growths of weeds. The amount of water that a deeply worked fine soil bed will hold is astonishing. For clay soils when saturated it is said to be twenty pounds or more of water per cubic foot.

Wherever water is in contact with a solid that it wets (clings to), the adhesive force lifts the water more and more until its weight (gravity) counter-balances this adhesion. This is just as true in soils as it is in glass tubes of small size where, in the study of Physics, this phenomenon of capillarity is most commonly noted. It is very commonly a matter of concern for the farmer to conserve the supply of water held in the soil so that plants shall not suffer from lack of sufficient moisture. This is especially true during the growing season with crops that permit tillage. Repeated stirrings of the surface soil interferes with and in a measure prevents the escape by evaporation of water that has risen from below by capillary action. This water thus becomes available for

${ }^{1}$ A quantity of soil when solidified into a cube having a volume of one cubic inch would have six square inches of surface. If we conceive this same a mount of soil as particles in the form of cubes $0.00 \mathrm{I}$ inch on a side there would be $\mathrm{I}, \infty \circ 0, \infty \circ,, \infty \circ)$ soil particles. The combined surface of all these separate particles would be 6000 square inches. If the soil particles were one-tenth of an inch in size there would be but sixty square inches of surface. 


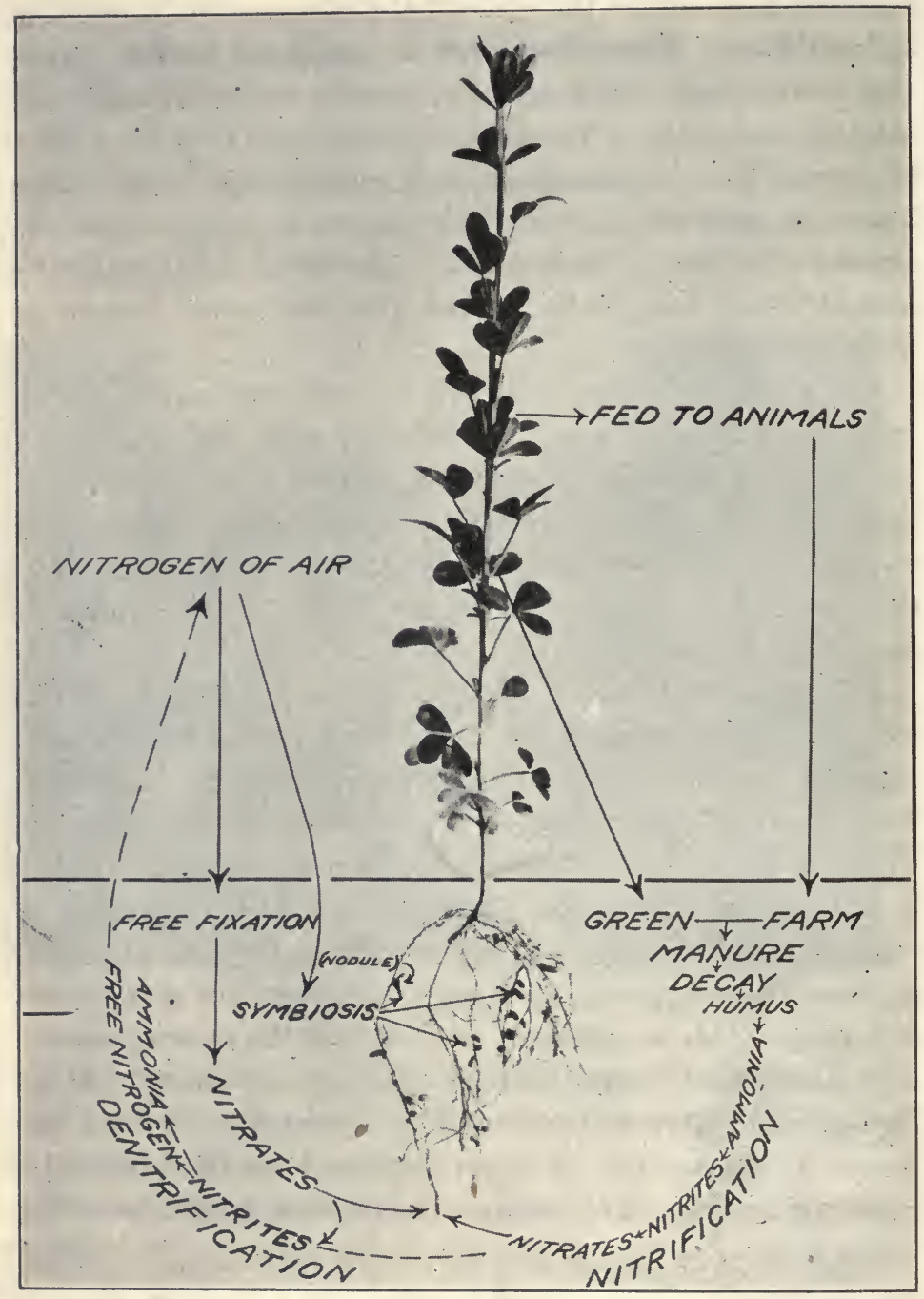

. FIG. 8I.-Nitrogen cycle in the life of an alfalfa plant. 
plant growth. The need of a dust mulch during the hot dry weather of summer is especially true with gardens where the soil is likely to be heavy and compact, and in semi-arid regions where the rainfall is normally deficient.

Enough air must be present in the soil to favor the activity of the bacteria concerned in decay of organic matter as humus, and to furnish nitrogen to the bacteria that thrive upon the roots of peas, beans, clover, alfalfa and other legumes. Although nitrogen as a chemical element is essential to plant growth, plants cannot appropriate it as an element directly from the air. It must be in the form of nitrates or other nitrogen compounds, and these must be dissolved in the soil water. The "nitrogen-fixing" bacteria as a lower form of plant life are active agents in maintaining the fertility of soils. They are an agency in the preparation of food material for the more highly developed forms of plants, even as these higher plants in their turn prepare food for animals. The soil, then, is not to be looked upon as dead lifeless material, but as filled with life and activity. Nitrogen compounds suitable for fertilizing soils are now prepared in several of the countries of Europe direct from the atmosphere by means of electrical discharges in a series of chambers through which an air current is kept moving. Congress has authorized (I9r6) the establishment of a great electrical plant in the United States for the production of nitrogen compounds from atmospheric nitrogen for use in explosives and for agricultural needs.

So important is a proper preparation of the soil before seeding or planting that any amount of later cultivation during the season cannot make good an early neglect.. What the particular preparation shall be for any piece of ground will, of course, depend much upon the soil. College courses in soils and in cereal crops will fail to bring success to any farmer who does not exercise the best of judgment in fitting 
his procedure to the ever-varying conditions of the weather. In all agricultural pursuits, as in business and professional life, success waits upon those who have learned what to do, how to do it, and when it should be done. And then there is always the further requirement that any enterprises under-

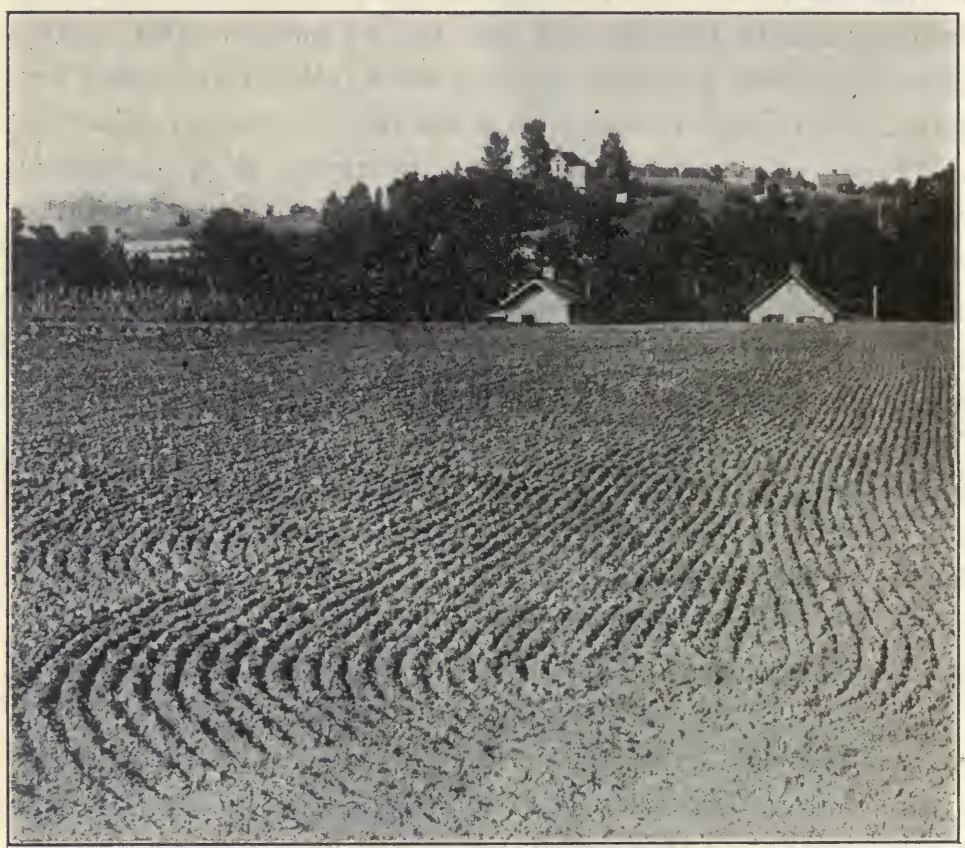

Fig. 82.-A good seed bed.

taken shall be carried through to an end. School training for the farmer as for the artisan, the person in business and professional life, the housewife or anyone else, involves discrimination in judgment and persistence of effort as well as enlightenment in the realm of knowledge. The successful farmer must adapt the course to be pursued day by day in farm operations to changing conditions of soils and of crops. He must take into account the varying needs of the farm, 
and exercise his judgment just as does the business or professional man when called upon to decide what, in view of all known conditions, is a wise course to pursue. The farmer who wrests from the soil an ample return for the capital invested and the labor involved, and who lives comfortably all the time, must be both capable and efficient. An unwise course in the care of the soil, whether from ignorance or from shiftlessness, invites failure. To achieve success, here or elsewhere man must work harmoniously with the forces of nature.

\section{SUMMARY}

The fruitfulness of soils that are plentifully watered is modified greatly by their texture. There should be sufficient compactness to prevent the leaching away of the soluble compounds essential to plant growth. At the same time there should be no large air spaces to allow a rapid drying out of soil water, and a destruction of the rootlets and root-hairs. Then, too, the soil must not be so compact or so watersoaked as to harm vegetation because of lack of soil air.

Tillage of the soil seeks to maintain a loose finely divided condition favorable to the growth of roots through it. If the soil is too loose, it must be made more compact by use of heavy rollers in order to close up the large air spaces. The addition of much finely divided wellrotted fertilizer from the barn yard and compost heap, furnishes abundant raw material for the growth of plants, and aids in securing a soil texture that is desirable.

The surface of the ground is always to be kept loose and dry so far as necessary to conserve the supply of water in the soil, and should be kept free of weeds. Care must be exercised in the cultivation of crops, not to break off or to destroy root systems already formed. This would leave the plants deprived of water, and starved for lack of the food material that the injured roots have been furnishing.

The finer the soil particles the more of them in a cubic inch, or cubic foot, and the far greater combined surface area to which a film of water may adhere. It is from this film of water rather than from water filling the spaces between the soil particles that the root-hairs draw their water supply, and upon it the ability of plants to withstand drouth very largely depends.

Decaying vegetable matter not only contributes toward making 
the soil friable and fine, but upon this decaying material the "nitrogenfixing" bacteria thrive. Through their agency there is left in the soil various soluble nitrogen compounds available for use by plants.

While the farmer and gardener may not be able to make the soils of their lands just what they may desire, it is always possible to so cultivate and fertilize most soils that if well watered they will yield good returns for the labor put upon them.

\section{Exercises}

1. For what several purposes is soil plowed? To about what depth? Why may fall plowing be somewhat deeper than spring plowing?

2. Aside from an unsightly appearance, what two serious objections are there to allowing growths of weeds among crops?

3. What is meant by a mulch for soil, and what is its purpose?

4. What characterizes the so-called "dry farming" of the semi-arid regions?

5. Account for the yellow, brown, and red colorings of clay banks. What commonly gives the black color to soils?

6. What is true of the relative rate of decay of organic matter in soils open and porous, and in compact water-soaked soils? Why so?

7. By what means is nitrogen that is in a free state in the air within the soil converted into compounds suited for plant food? In what way does the free oxygen of the air get into plants?

8. What is the especial function of the root-hairs of plants? Explain the effect on many plants of having the spaces of the soil filled with water. Name any plants that grow in (and under) water.

9. What is $(a)$ humus; $(b)$ silt?

10. By calculation fill out the following table showing the amount of surface in one cubic inch volume when subdivided smaller and smaller. (Cubes are used for ease in calculation.)

Side of cube......... I inch

Number of cubes...... I

Amount of surface....6 sq. in.
0.I inch

60 sq. in. o.or inch

0.001 inch

\section{Tree Planting}

A deplorable waste of natural resources in the United States has taken place in a wholesale wanton destruction of the forests. Succeeding generations will long mourn these unchecked practices as an enormous economic loss both direct and indirect. Millions of acres, unfit for any use other than timber growing, have been so devastated that instead of 
furnishing successive crops of wood and lumber for all time to come they are left treeless, and their soil as the product of ages of rock disintegration has been gullied and washed away from their rugged slopes. The United States Government through its Forest Service is doing something toward reforesting certain areas, and more especially toward conserving the timber supply still standing. The most hopeful outlook is in those areas where new growths have sprung up on lands less despoiled by the erosion that so

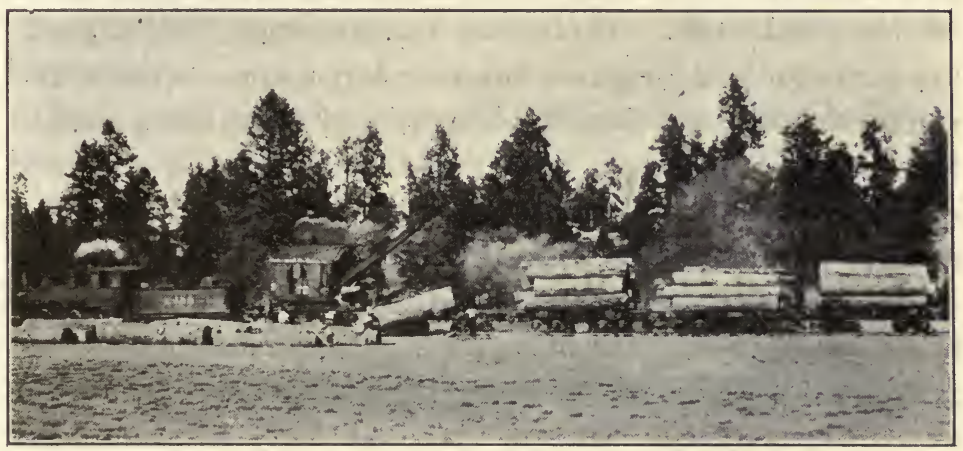

FIG. 83.-Ways of modern lumbering.

often has followed wholesale timber butchery. But reforestation is expensive at the best, both in outlay for labor and in the long period of years before the new growths are large enough for market. So slow of growth are certain trees that it is practically impossible to reforest with them. Under wise management it is possible to get from forest lands a large annual return in wood and lumber, and to maintain at all times an undiminished vigorous growth of timber.

Forest fires cause serious annual losses in the timber supply of the country yet remaining. It has been estimated that they have destroyed fifty million dollars worth of timber 
annually for the last forty years. They are commonly the result of carelessness and indifference on the part of those who camp in the woods, and who fail to take necessary and reasonable precautions against fires. These forest fires not only damage and destroy matured timber, but they destroy the young growths and seedlings, together with the seedbed of rich decaying vegetable matter and its store of seeds which have not yet germinated.

So expensive has lumber already become that large use is now made of iron, concrete, cement, and brick in all kinds of structural work. The outlay for the single item of packing-boxes alone aggregates annually large sums in trade and commerce, and merchandise is more and more being packed for shipment in paper, heavy cardboard, fibre, metal, and other wrappings. Such charges as these over what was necessary when there was an abundance of cheap lumber is one of the items in an increased cost of living. The small home owner finds in the high prices of lumber an outlay that proves a serious handicap in buying and paying for a house and its furnishings. Directly and indirectly as the natural resources of a country are reduced, and their cost price advances, those who pay these larger prices out of the wages received for their labor, whether skilled or unskilled, are more and more at a disadvantage, especially where there is but small advance in wages received.

One direct result of a widespread education, and of an enlightenment of the people that keeps pace with advances in human knowledge and with man's mastery over the forces of nature, should be the husbanding of the resources a nation possesses, and an increase in this store of possessions. It is not only well to make "two blades of grass grow where there was but one before," but two trees should take the place of one in the country at large and two bushels of wheat grown in place of one. 
Scientific forestry like scientific farming requires an enlightened citizenship to apply the principles and follow the procedure that attends upon the advances of science in this field of human effort. It requires the application of business methods where before a reckless and haphazard course has caused waste and destruction, and it involves consideration for the welfare of the country in the years to come. The "science" taught in schools fails in many of its possibilities in education for citizenship where there is failure on the part of those who are taught to make use of the knowledge they have gained for the benefit of the community.

The actual planting of trees by the average householder is usually confined to a few shade trees along the street front of his home and to some fruit trees at the rear of the house. In the crowded limits of dwellers in large cities even this is impossible. In the rural districts there are ample opportunities for the planting and proper care of both shade and fruit trees. Such work is, however, often poorly done or is neglected altogether. Some one has estimated that a shade tree in front of a home, if vigorous and healthy, adds to the valuation of a lot in any town or small city as many dollars as there are square inches in its cross-section near the ground. If its diameter is fourteen inches, its value in the sale of the property might be reckoned as $\$ \pi r^{2}=\$ 31 / 7 \times 7 \times 7$, or $\$ 154$. Some trees about a home are so located, and add so greatly to the beauty and comfort of the place, as to be priceless to the appreciative owner and to the passing public. The man who sees in trees about the home, or standing out prominently in the landscape, only so many cords of wood has missed something of the best in an education.

Perhaps in tree-planting better than in some of the simpler affairs of life there is an exemplification of the adage that "what is worth doing at all is worth doing well." Shiftless, 
unintelligent ways of planting, and an unwise choice of trees to plant, result in unsightly growths of short-lived trees which are all too often worthless for the purposes in mind when set out. The same amount of effort well-directed might have given long-lived trees that in beauty and service would have been to all beholders a joy for generations. There is an almost irreparable loss in those years of growth that have been to little if any purpose.

So many are the years represented in the growth of a fine tree that it is almost unpardonable to harm it by mutilating its top, by cutting off any great limbs, or by injuring its protective covering of bark. As a home for the birds, as a grateful shade for the traveler, and as a source of joy to every passer-by because of the beauty they lend to the landscape, it is no wonder that trees figure so largely in poetry, painting, and song, as well as in the applied side of life's activities. And it is to be remembered that all these blessings to mankind that cluster in trees belong to the passer-by as well as to him who owns the title deed to the ground in which they grow.

\section{SUMMARY}

Scientific forestry removes from wooded lands from time to time only certain portions of the timber for lumber, wood pulp, fuel, etc. It seeks to maintain continuously a sufficient growth of young and vigorous trees.

There are large areas in different portions of the United States where the land is unfit for tillage, but is admirably suited for timber growing. When the timber is taken from steep slopes care should be taken not to destroy the undergrowth, and not to allow erosion of the soil.

Forest fires not only destroy the value of standing timber but by burning the seedlings, and the decaying vegetation which forms a rich seed-bed on the surface of the ground, later forest growths are made improbable.

The national government is setting aside large tracts about the 
head waters of navigable streams in order to regulate their seasonal flow as well as to preserve the natural beauties of those regions.

Shade trees along highways and about homes add to the beauty and comfort of life. A wise choice should be made of the kind of trees set out, and the best of care and judgment should be exercised in transplanting them in order to avoid disappointment in results.

When trees are uprooted for transplanting, the smaller roots and the rootlets are largely left in the ground. It is through the rootlets that the needed soil water is taken into a growing tree. By exposure to sunlight and air the root surfaces become dry and less fit to take up moisture from the ground when again set out. For these reasons the top of a newly set tree must be nearly all cut off. The escape of water from too many leaves, and at a rate faster than the roots at first can supply it, kills the tree before it has had time to develop new roots.

\section{Exercises}

1. What are some desirable shrubs to plant in front yards?

2. Discuss in detail the steps and precautions to be taken in transplanting shrubs and trees.

3. Name two of the common shade trees of your community, and give the characteristics whereby you distinguish them at sight.

4. Make a list of all the ornamental trees and shrubs of your neighborhood known to you by sight, not including any which would be classed as shade trees when grown.

\section{Trees OF THE NeIGHBORHOOD}

We recognize our friends at sight. Chance acquaintances we may come to call by name. In neither case, however, is it commonly true that we could give descriptions of them sufficiently definite to insure their identification by others.

Description of trees in books, if of very much use as a guide in learning to know them at sight, presupposes considerable first-hand knowledge of the trees round about us.

Where any one kind of tree is known by name, and repeated notice is taken of it, there comes not only a more extended but a more detailed knowledge of its characteristics. By contrasting its features with the corresponding ones of other trees whose names have been learned, there comes about in 
time an acquaintanceship with trees similar to that which we have with persons.

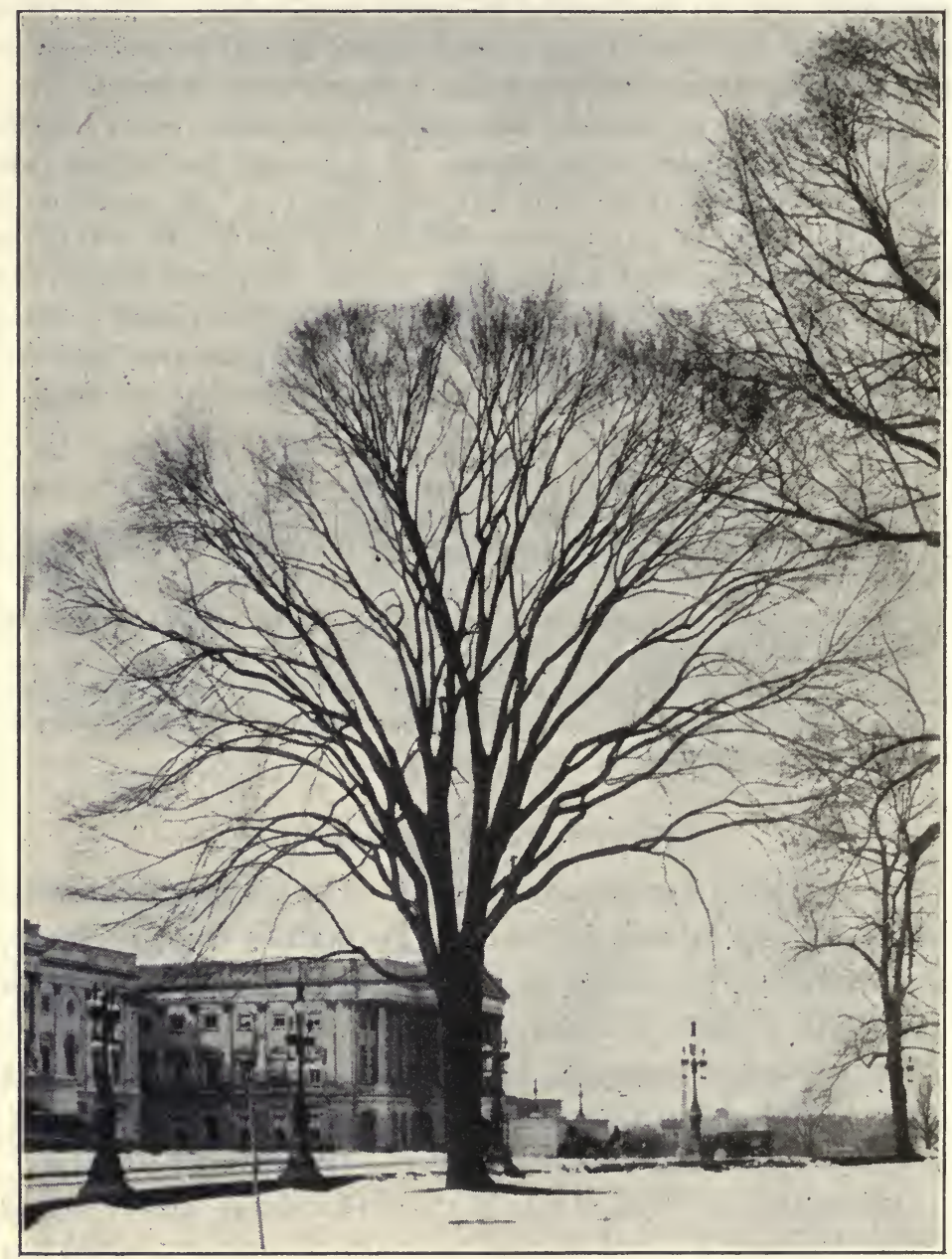

FIG. 84.-An American elm in winter.

One of life's greatest sources of pleasure, and one of its privileges, is to have "speaking acquaintance" with every 
tree, shrub, herb, and weed met in one's daily walks. Recognition of new plants as members of a well-known family is much the same as to learn that a chance acquaintance is a relative of some friend of ours.

In order to describe trees for purposes of identification it is well to make use of some technical terms of definite meaning. All who would have any complete knowledge of plants must study Botany. But it is not necessary to be a botanist in order to know and appreciate trees, any more than it is necessary to be a psychologist in order to know and love our friends. It is probable, however, that one who comes to know trees, and to understand something of the conditions for their growth and well-being, will desire to have a knowledge of Botany. Studies of the plants with which one is more or less familiar may prove an excellent introduction to it.

The general form of trees taken as a whole is one of their distinguishing characteristics. An observer who is acquainted with trees readily recognizes any familiar kind by its form even at a distance. Yet to describe just what is meant by the "form" of any tree is not easy. For one thing trees are classed as having tops spreading (as the apple and white elm), or erect (as evergreens and poplars). The angle which the branches make with the tree trunk is in a general way a noticeable feature; so is the relative amount of smaller branches and twigs (the "spray").

To one well acquainted with trees the appearance of the bark on the trunk and on the younger growths of limbs identifies the kind of tree. The beginner must acquire this ability of recognition through personal acquaintance with different trees, getting it incidentally in connection with other means of identifying them. As trees grow the old bark cracks in a variety of ways often characteristic of the kind of tree, and as new bark forms underneath year by year these 
ridges of older bark are gradually pushed outward. The bark grows more and more rough, and in some trees drops off (is "flaky"). In some trees (as birch and cherry) the bark remains smooth and noticeably marked by horizontal streaks. These result from the stretching of the bark due to growth within, and a consequent change of form in the lenticels or breathing pores of the bark. Some inner barks have characteristic tastes readily identifying such trees as the sassafras, slippery elm, birch, cherry, and some oaks. A characteristic general color or tone of the outer bark as a whole is an aid in distinguishing trees. In this latter case there is a difference between their appearance in summer and in winter.

The leaf scars upon the twigs and smaller branches may be opposite each other at the same node (place where one or more leaves grow), or they may be alternate, with one leaf scar only at a node. These latter are arranged lengthwise of the stem in rows of two or more, and the number of these rows should be determined.

The presence or absence of a terminal bud on the twig is to be noted, together with the general form of the buds and any general characteristics in their color, odor, and any protective coverings such as hairs, gum, or down.

The fruits of the tree in season serve to identify it, and so do the flowers. Good cuts in books aid materially in studies such as these. While by use of a reliable and complete "key" one may become fully assured of the identification of any tree, it must always be kept in mind that an acquaintanceship with trees to be a source of real enjoyment must at first be personal and not bookish. The use of a book in tree studies is like the use of a guide book in one's travels, telling what to look for and its striking characteristics but never taking the place of actual and personal inspection of what is described. 


\section{SUMMARY}

Any knowledge of trees to be satisfactory and complete must be gained by personal acquaintance with them. The use of a "key" for their identification presupposes some knowledge of trees, and is not a substitute for first-hand studies of them.

A "key" tells what to look for, and how quickly and sharply to differentiate between characteristics of trees that are alike in many respects. Good pictures of trees, their leaves, flowers, and fruits, are a great aid in their identification when met in woodland, roadside, and nursery.

School studies of the leaves, buds, flowers, manner of branching, kind of bark, etc., of some few trees make possible the recognition of other trees whose characteristics are noted as different from those studied.

Shrubs, evergreens, and ornamental trees on lawns and in parks should be included in any list of tree acquaintances.

\section{Some Plant Studies}

Any knowledge of the common plants of garden and farm and roadside, though it be of the most general nature, makes apparent the fact that their parts include roots, stem (trunk and branches), leaves, and flowers. So far as the plant economy is concerned flowers and fruit have for an immediate end the maintenance of the species so that plants shall not become extinct. The root, stem, and leaf are directly concerned in the growth and nourishment of the living plant. It may be considered that the chief purpose of the stem of the plant whether of the largest tree or the most insignificant weed of the field, is to secure the largest exposure of leaf surface to air and sunlight. The stem of a leaf (petiole), and its framework of midrib and veins, serves a like purpose.

To the botanist the leaves of a plant are so many laboratories, and to the economist so many factories, whence comes the food supply of mankind. All things we eat come from plants. Just how this is accomplished is discussed in another lesson. Plants alone can take as raw materials carbon dioxide gas from the air, and soil water which has in it in solu- 
tion minerals and nitrogen compounds, and convert these into food for animals and for sustaining the life of the

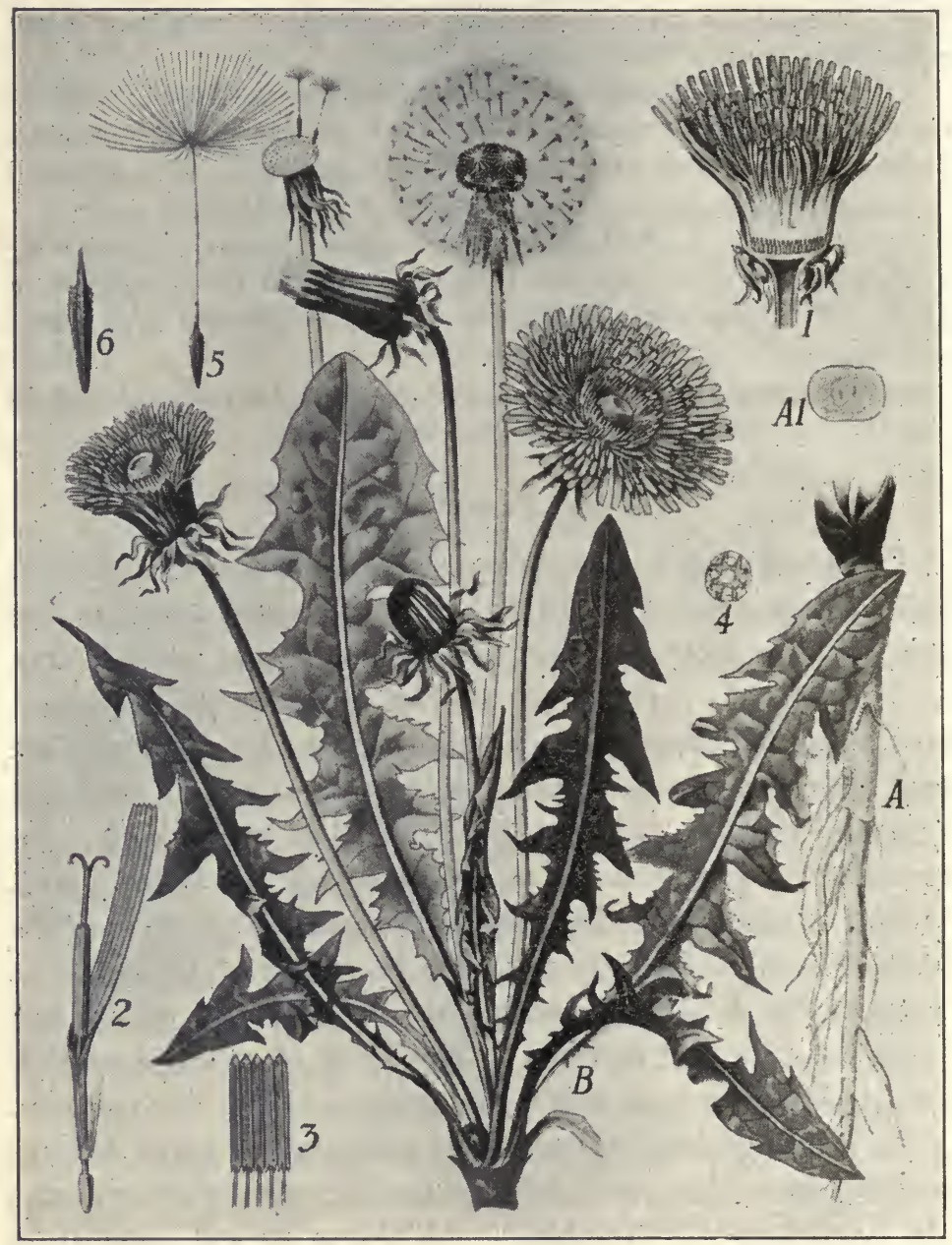

FIG. 85.-Structure of the dandelion.

plant itself. As stored in fruits, seeds, and roots, this food supply is primarily for a later generation of young plants. 
While it is chiefly in the leaves that this food production occurs, in a lesser degree it is carried on in all the green parts of a plant. The energies of plants of the higher order seem to be directed toward maturing seeds for the succeeding generations of their own kind. Wherever seeds occur there must have been flowers. These flowers may have been destitute of the showy petals we so commonly associate with the thoughts of flowers, and some one or more of the other parts of a complete flower may be lacking. Indeed, the study of Botany has very much to do with plants that never have flowers. Many of these non-flowering plants are of microscopic size, and propagate themselves in ways other than by seeds.

Nature's provision for the scattering of seeds, and for their protection till conditions favorable for growth occur, is an interesting chapter in Botany. The fleshy fruits for example are gathered as food by man, birds, and other animals, and their seeds become widely scattered. Many seeds are carried long distances by winds and streams. Where seeds become so thickly scattered that upon germination the young plants are over-crowded, only the most vigorous of the young plants survive in the struggle for existence. The others will be choked and starved out, an example of the "survival of the fittest" in the natural world.

The process of fertilization of the ovules of a flower so that they become seeds which will "grow" introduces us to botanical terms that are best learned in connection with the study of some flower in the laboratory. The pollen when ripened is shed from the anther in which it grew. These anthers are at the outer extremities of the stamens. The pollen grains as carried by winds, bees, and insects generally, may fall upon the stigma of a pistil in some flower of the same kind of plant. Their growth down through the style into the ovules accomplishes the fertilization necessary for the develop- 
ment of the ovules into seeds. In due time the enlarged ovary becomes the ripened fruit, and the ovules ripened seeds. The ovary wall itself may become juicy as in the currant, grape, and tomato, or it may become a shell as in the walnut.

In many plants all these acts of fertilization occur within a single flower; in others the pistillate and staminate flowers occur in different parts of the same plant, and sometimes they are borne on entirely different plants.

The petals taken together form the corolla whose bright colors in many flowers undoubtedly attract insects as agents in pollination. The small green sepals forming the calyx serve in the bud of the unopened flower to protect the enclosed parts from cold and wet and from insect enemies. In the process of the development of the flower the calyx may become greatly modified, even into such structures as the pulp of the apple and pear.

It is to be kept in mind in all studies of flowers, and of plants in general, that variation rather than uniformity is the rule. Any extended study of flowers and plants from the specimens themselves soon reveals the fact that the adaptability of plants to varying conditions affecting their lives is one of the wonderful features of plant development.

Many plants that bear seeds are independent of these seeds for their propagation. Each generation may provide for new plants by the growth of creeping stems or "runners" as in the strawberry, or by bulbs as in the onion, lily and tulip, or by underground stems as in the hop plant and the common potato. Seedless oranges are secured by grafting into small orange trees of the common sort twigs that have been cut from an orange tree whose fruit persistently fails to develop seeds. Bananas are raised from sprouts arising from the old roots. Florists and nursery men use short lengths of the stems of some plants, such as the geranium, 
currant, and grape to start new plants, by bedding the lower ends of these "cuttings" in moist earth till they develop roots.

\section{SUMMARY}

The root, stem, and leaf are the parts, of a plant directly concerned in its nourishment and perfection. Its buds, flowers, and fruit are for the purpose of continuing the species.

The roots hold the plant firmly in place in the soil. Through them comes the water, and the minerals held in solution by the water, out of which in part the plant manufactures material for its own growth, and food for man and other animals.

Through the leaves the plant rids itself of surplus water from the sap by the process known as transpiration. From the air through their leaves plants get carbon dioxide gas which is the other important raw material for the manufacture of food in plant growth.

Only plants can manufacture starch, sugar, oils, and proteins out of water, carbon dioxide, nitrogen compounds, and some few other substances taken from the soil. This chemical change occurs chiefly in the leaves when exposed to sunlight.

Seeds and their protecting envelope constitute the fruit of the plant. While many times these fruits are edible, sometimes seeds and all, in other cases the husks, rind, or shell serves no purpose other than as a protection "to the seeds. Tomatoes, pumpkins, and squashes are fruits by this definition as much as are cherries, apples, and oranges.

At the inner end of the style of a pistil is the ovule which before it can develop into a seed must be fertilized. This is accomplished by the growth of a pollen grain from the stigma down through the style and into the ovule. In many plants the pollen is developed in the anthers of stamens in the same flowers that bear the pistils, and self-fertilization may take place. In other cases the pollen comes from other flowers on other plants and cross-fertilization occurs.

Many plants are propagated naturally by bulbs, by underground stems, by stems above ground known as runners, or by sprouts arising from buds developed around the base of the stem below ground. Plants are propagated artificially by grafting, budding, and by use of cuttings.

In studies of the same kind of plants it soon becomes apparent that there are wide differences other than of size. It is also apparent that plants adapt themselves to varying conditions. . Even the leaves on the same plant often show marked variations in form. 
Without plant life, and its continuous consumption of carbon dioxide from the air, all available carbon of the earth in time would be in the atmosphere. A corresponding amount of free oxygen would have been taken from the atmosphere permanently to form carbon dioxide. In the round or "cycle" of changes for the element carbon, plants appropriate solar energy as heat and light from the sun in the chemical changes that occur in the chloroplasts. This energy in turn becomes available in animals through oxidation of the carbohydrates of the digested food. In a very real sense our power to do work, both physical and mental (brain activity), is from liberated energy derived from the sun and made available to us through the agency of plants. Without plants all this round of transformation of energy would be blocked.

The yield of dry hay from meadow land may be two tons per acre. The growth of corn stalks per acre when dried may weigh two tons or more. A large part of the weight of the stems of grass, of wheat and other grains, of corn stalks, and of the woody stems of all shrubs and trees, is the substance known as cellulose $\left(\mathrm{C}_{6} \mathrm{H}_{10} \mathrm{O}_{5}\right)$. Over 40 per cent of cellulose is carbon. Plants get the food material for cellulose in part from the soil through their roots in the form of water, but the carbon is taken in by the leaves in the form of carbon dioxide gas. A yield of fifty bushels of shelled corn per acre represents a weight of nearly one and one-half tons of the grain. Of this nearly one-half (45 per cent) is carbon. When the amount of carbon gathered in from the atmosphere by the growth of vegetation during a season is estimated in tons per acre, the importance of this one function of the leaves and of the green parts of the stems of plants becomes apparent. In the chloroplasts, under the 
AIR SUPPLIES CARBON; THE PRINĆIPAL FOOD OF THE TREE. TAKEN IN ON

TREE INCREASES EACH YEAR IN HEIGHT AND SPREAD OF BRANCHES BY ADDING NEW GROWT

OF TWIGS.

UNDER SURFACE OF LEAVES.

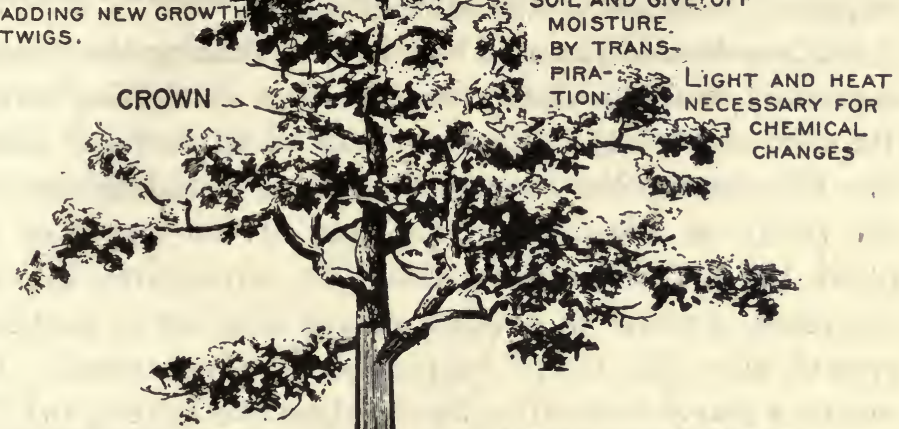

HEARTWOOd (INACTIVE) GIVES STRENGTH

SAPWOOD CARRIES SAP FROM ROOTS TO LEAVES

CAMBIUM (MICROSCOPIC) BUILDS THE CELLS

INNER BARK CARRIES PREPARED FOOD FROM LEAVES TO CAMBIUM

OUTER BARK PROTECTS TREE FROM INJURY

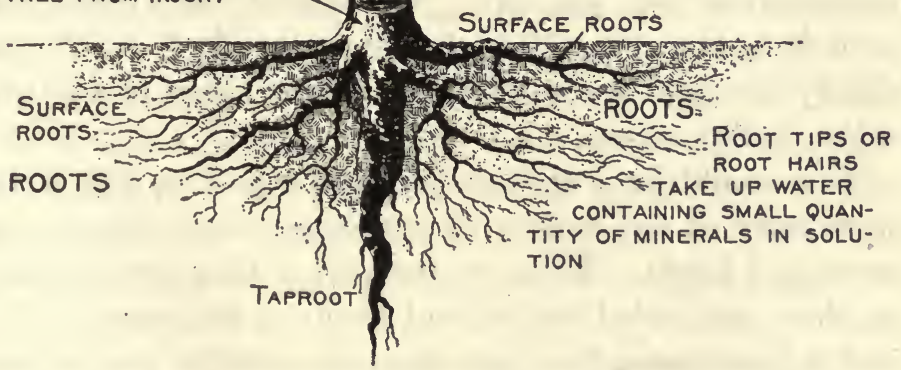

FIG. 86.-Structure of tree, and functions of its parts.

THE ENTIRE TREE; ON LEAVES, TWIGS, BRANCHES, TRUNK. AND ROOTS, TAKE IN OXYGEN.

FLOODING, POISONOUS GASES OR SMOKE MAY KILL A TREE.

TRUNK OBTAINED FROM AIR AND
OBTAREPAR THE FOOD SOIL AND GIVE!OFF MOISTURE. BY TRANS- 
influence of the sunlight, carbon is built into the substances starch and sugar. These are foods for the support of plant growth as well as foodstuffs for animals. The liberated oxygen is returned to the atmosphere.

Carbon dioxide gas used by plants in making their food is a product of the oxidation of substances containing carbon. Its chief sources are the respired air of all forms of animal life, the combustion of vegetable matter including coal, and the decay of vegetation. The loss of the leaves of any plant by hail storms, "worms," or caterpillars, deprives the plant of power to produce enough food for its continued growth after any stored supply has been exhausted. This means a starved condition for the plant that is likely to kill it.

Not least of the activities of the leaves of plants is their liberation of water which has come up to them from the depths of the soil through their roots. A single thrifty sunflower plant gives off into the air by transpiration as much as a quart of water per day. It has been estimated that a large tree with abundant foliage may evaporate through its leaves several barrels of water daily during the growing season. From the grass of lawn and field the quantity evaporated daily at times during the growing season may be estimated as tons per acre. The loss of water from leaves as well as the absorption of carbon dioxide from the air is chiefly through the more open cellular tissue of the under sides of the leaves.

This would be a strange world in which to live if there were none of the variety of landscape due to plants of all sorts and kinds. When to the plants that are familiar to us there are added the myriad forms of microscopic size of which Botany teaches, and when we consider the usefulness of bacteria as man is coming to know more and more about them, studies of the plant kingdom assume an importance far beyond any mere love of flowers for their beauty alone. 
If a written list is made of fruits both domestic and foreign, whether recognized at sight or known only by name, and then the names are underscored of those of which considerable is known and can be told, a lack of definite knowledge of many of them is likely to become at once apparent. If similar lists of grains, of nuts, and of textile plants are made, too, it serves as a test of how much we know definitely about what are commonly called the "useful plants."

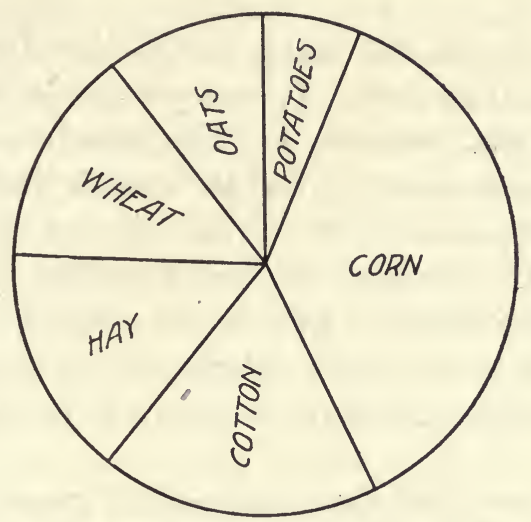

FIG. 87.-Relative importance of the leading crops of the United States.

The cotton plant has long furnished to mankind inexpensive and durable clothing easily adapted to a wide range of uses. With various chemical treatments of the cotton fibre, and the wonderful results achieved in dyeing cotton fabrics in these days, the products of factories employed in converting cotton into manufactured forms amaze one in their variety and their attractiveness. Any list of the cotton goods manufactured for clothing is in itself highly suggestive of the importance to mankind of this one plant. This is true not only in the usefulness of its finished products, but in the employment furnished in the production and manufacture of cotton, and in the transportation of both raw material and manufactured articles. 
The fibre of cotton is contained in the ripened seed-pod ("boll") of the plant. These fibres at their inner ends are attached to the seeds of the plant. The invention of the cotton gin by Eli Whitney for the successful separation of the seeds from the fibre made cotton production on a large scale possible, and with cheap labor highly profitable. The rise of slavery in the United States as a civil and political institution accompanied the development of the cotton-growing industry.

The fibre of the flax plant, unlike that from cotton, is obtained from the stem. If kept water-soaked sufficiently long, the material between the fibres dissolves or rots away. The fibres are then sorted, and the coarser ones are used for twine. Others are used for canvas and tent cloth, while the finest of them are used for handkerchiefs, or in making laces and embroideries. Jute, hemp, and other like tropical plants yield a coarser fibre of large usefulness especially for binding twine, rope, burlap, matting, and the cheaper grades of carpet.

From the seeds of the cotton plant great quantities of cotton-seed oil are produced. This has a large use in soap manufacture, and in the making of those table products which take the place of butter and lard, such as oleomargarine and cottolene. It is also used as an adulterant of the more expensive oils, including olive oil for table use. The cotton seeds after the oil has been pressed out of them are ground for cotton-seed meal which is used as a food for cattle. From flaxseed is obtained linseed oil widely used in paints. It can be readily spread by a brush in a thin even coat over woodwork and metal surfaces. Upon exposure to the air, and as result of chemical changes that occur, it forms a tough glossy waterproof covering. This holds firmly within it any of the several chemical compounds used to give "body" to the paint, as well as any coloring material used for color 
effects. Lead carbonate ("white lead") used with the oil "covers" well, i.e., it can be applied as a very thin coat of uniform appearance. The thinner the paint coat the less likely it is to peel off. Zinc white, or zinc oxide ( $\mathrm{ZnO}$ ), as a substitute for white lead requires more oil for mixing and spreading. However, it does not blacken so much from the gases containing sulphur that are common where soft coal is burned. Various colors are given to paints by mixing in to them varying. proportions of different minerals as pigments, and these are held suspended in the oil as it dries. Black paint commonly has lampblack or finely powdered charcoal in it. Varnish is a mixture of melted rosin and boiling hot linseed oil. When cooled it is thinned sufficiently with turpentine to be spread easily as a very thin coat over woodwork and metal surfaces. White enamel paint is varnish to which white lead has been added, and various pigments added to this give rise to the colored enamel paints.

Not least among the factors of modern life is the daily newspaper. It is to be noted in this connection that print and wrapping paper is largely if not wholly wood fibre, or cellulose. The wood is treated with hot alkaline liquids to dissolve out any resinous material and to loosen the fibres, and then rubbed ("ground") into a pulpy mass. This pulp is bleached white by the action of chemicals, and pressed into thick layers for transportation from the mills to the paper factories. A single issue of a daily newspaper in one of the large cities may use twenty tons or more of paper. Spruce is the wood most desired, but pine, fir, poplar, cottonwoods, and many other kinds are largely used. Cotton and linen rags are used for the finer quality of book and writing paper, and straw for the "pasteboard" used in box-making.

\section{SUMMARY}

From plants man gets lumber for his dwelling and its furniture, cotton and linen fibre for his clothing, fruits from the orchard, grain 
from the fields, and vegetables from the garden. Indirectly plants furnish him meat and milk for food, and provide food for the horse that does his work and carries him to and fro on business and for pleasure.

Without plants a vast store of the oxygen of the atmosphere would in time become combined with the world's supply of carbon as carbon dioxide gas.

As result of the storage by plants of solar energy in the manufacture of starch, sugar, cellulose, oils, and proteins, the earth's supply of energy to maintain life and to do much of its work is continuously being replenished. The energy liberated in the human body and in animals

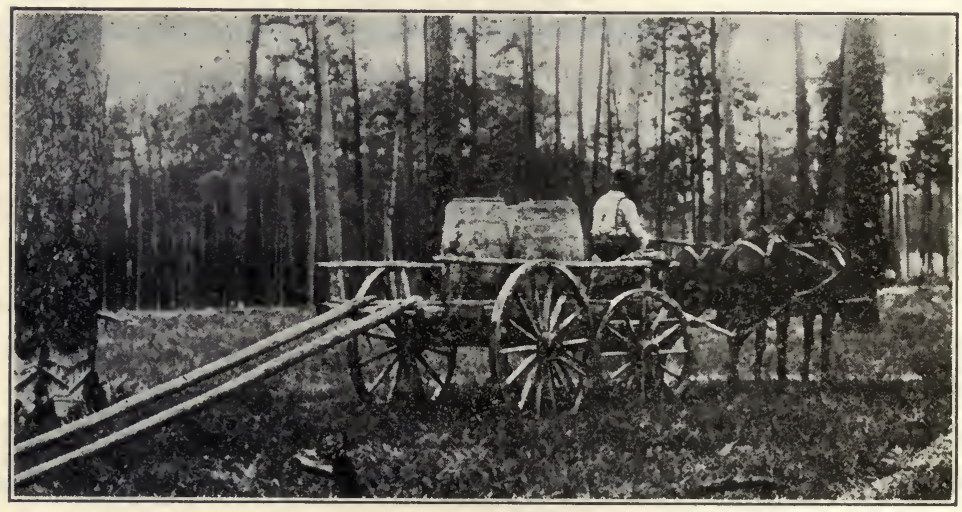

FIG. 88.-The turpentine "orchard".

by the process of oxidation, and in the boiler of the steam engine when coal is burned, is but solar energy stored by plants.

From land surfaces covered by vegetation there is being given back into the air daily by transpiration of plants during the growing season amounts of water computed as tons per acre.

It must not be overlooked in this connection that paper, which in its varied forms has become so indispensable in modern life, is essentially cellulose, whether made from cotton or linen rags, from wood pulp, or from straw. Making record of the days happenings in newspapers, and of the affairs and thoughts of men as set forth in books, taxes the world's supply of cheap paper-making material. 


\section{Exercises}

1. What is meant by vulcanized rubber? What changes are produced in the rubber by vulcanizing it?

2. Describe how the rubber stamps in common use are made?

3. To what uses is old rubber put? Why has it no greater market value? About what is the market value of the pure gum now?

4. Read all available material upon the turpentine industry of southeastern United States. Then write a short description of it, including the care of the trees, the processes of manufacture, the products and their varied uses.

5. What are "mercerized cotton" fabrics? What especial advantage arises from this treatment?

6. Formerly what two plants furnished most of the dyes for cloth? How were different colors obtained from the same dye? At about what date were the "coal tar dyes" first produced?

\section{Birds Around Our Homes}

For beginners to study birds from pictures and printed descriptions is even more unsatisfactory than it is to study trees from books only. In making studies of birds it is likely that the English sparrow will be at hand anywhere. In rural districts and smaller towns other birds are likely to be plentiful. In the zoology departments of some high schools there may be collections of stuffed birds, and mounted skeletons. The study of certain of these in detail may be exceedingly profitable for comparisons of types of bird life. Many city parks have extensive aviaries and museums. Any extended study of birds constitutes a division of Zoology. However, one need not be a scientist in order to have an extended knowledge of the forms and ways of birds, and to enter into the full enjoyment of bird life.

Birds as distinguished from other animals are characterized by a covering of feathers, and by a modification of the forelimbs into wings that are more or less useful for flying. Like man birds are bipeds, and the young experience difficulty in learning to walk as well as in becoming able to fly. For a considerable time after being hatched from the eggs young 
birds need to be fed and brooded by the parents. Chickens and the young of other domestic fowls, however, are able to walk and get food for themselves in a very short time. The rapid growth of their feathers is soon sufficient as a protective covering to keep them warm.

Like the hair or fur upon animals generally, feathers are an outgrowth of the skin. They serve to retain heat within the body of the bird. The body temperature in birds is much higher than it is in man ( $110^{\circ} \mathrm{F}$.). This involves special provisions for respiration quite unlike those in the human body. The amount of energy developed within the bodies of birds is seen strikingly manifested in the longsustained flights of homing pigeons which are estimated to exceed at times eighty miles per hour.

The shedding of feathers at certain seasons is called "molting." The growth of a new coat of feathers is rapid. There is more or less of a change of coloring as the plumage of birds is renewed with "live" feathers. The colorings of the male and female birds are usually different, and the characteristic colorings of the same species is maintained so fully in each successive generation as to be a ready means of identification.

The variety of colors in plumage is largely a matter of the deposition of color materials (pigments) in different portions of the plumage. The change in colors as viewed from different positions is a phenomenon that in Physics is called light dispersion. It is due to the fact that the barbs and barbules of the feathers have surfaces marked by very fine lines so close together as to break up the light that falls upon them into its color elements.

The feathers of the tail and wings of a bird furnish an' excellent illustration of "adaptation" in their use for flight. Two rows of interlocking barbs and barbules are arranged along opposite sides of a stiff mid-rib, the whole forming the 
vane of the feather. The hollow quill is both light and strong.

The legs and necks of wading birds, such as the heron, are greatly lengthened; the feet of swimming birds, such as ducks and geese, have the toes joined by a web. Birds that perch have one toe of the four opposite to the other three even as the thumb is opposite the four fingers of the human hand. With some birds that climb, two of the toes are opposite the other two.

Birds have no teeth. The food when swallowed may lodge and remain for a time in an enlarged portion of the food passage known as the "crop", where it becomes more or less softened. It then passes on into what corresponds to the stomach ("the gizzard") where by action of the strong muscular walls it is subjected to a grinding process. Sand, gravel, and other like material is swallowed by fowls and birds to aid in this.

The horn-like bills (beaks) of birds are of varied shapes and degrees of strength, and are adapted to the kind of food upon which the birds live.

In the humming bird the bill is slender and much elongated; in ducks and geese broad and much flattened; and in hawks and eagles it is powerful enough to tear the flesh of their prey when once their claws (talons) have grasped it. The bill is an important means of identification of species of birds.

Failure in food supply is probably one of the reasons why birds migrate on the approach of winter. Their return to more northerly latitudes in the spring doubtless involves other causes. In preparation for these migrations, even as in nest building, birds exhibit an instinct that occasions wonder. Some kinds gather in flocks numbering thousands, taking their journey only after days of seeming preparation. With some kinds of birds these migrations are made at night, 
either in flocks or in small groups. Few of them will be found in their usual haunts following one of these migrations. These journeys in many cases extend over distances of hundreds and hundreds of miles, and often are over vast stretches of water as well as of land. How birds can be so sure of their course, and how it is that they return as they oftentimes do season after season to the same places of abode, is again occasion for wonderment.

The skill shown by each successive generation of birds in nest building is another evidence of their superior intelligence. This is commonly referred to though not explained by calling it instinct. The manner of nesting is characteristic of the bird, and the nest serves to identify its builder. A pair of young birds building their first nest construct it as other birds of that species have done before them. This remains true even where young birds have been reared wholly apart from their kind. Some birds build nests which are marvels of ingenuity and skill in construction. Their selection of a place for the nest often exhibits the greatest cunning. Many stories are told of the deception and thievery practised by the crow when captured young and tamed at some farm home. Some parrots when trained show a marvelous degree of intelligence.

Birds feed very largely upon weed seeds, and upon insects. The young are fed insects and worms quite exclusively for the first few weeks. Many species of birds live almost wholly upon insects when obtainable, using fruits and seeds only when the other foods fail. The value of birds to man may be calculated not in the number of insects actually destroyed for food during the whole season but in the number which would otherwise have multiplied from those destroyed. The value of birds to man in holding in check insect pests and weed growths is greatly underestimated. The horticulturist is unable to raise marketable fruit without con- 
tinuous warfare upon insect enemies, and insect plagues cost the country millions of dollars a year in a decreased yield of the farms. These losses have close relationship to the wholesale warfare that has been carried on for years against birds. Much of this killing has been mere wantonness under the name of "sport." Very largely it has been and continues to be in utter disregard of public interests, and it is a waste of public wealth. Birds are necessary to conserve the food supply of the country.

Aside from these interests, birds rightly claim protection and considerate care by reason of their beauty of form and movement, and the great enjoyment afforded in their songs. Collections of birds' eggs by school children should not be allowed. National legislation against traffic in the plumage of birds for millinery should be strictly enforced. Some of the kinds of birds of most beautiful plumage, both in this country and abroad, have been largely or wholly exterminated by the demands of fashion. Cats and squirrels are natural enemies of birds. The English sparrow brought to this country in $185^{\circ-} 5^{\mathrm{I}}$ is a good illustration of the survival of those forms of life best fitted to existing conditions. But it is a poor exchange to lose our American songsters and to get this quarrelsome nuisance as the representative of bird life in our daily round of life experiences.

\section{SUMMARY}

Studies of birds can very successfully be carried on by comparison after having made a detailed study of some one or more kinds as types. A study of some one of the domestic fowls may be included in this list.

Birds may be characterized as feathered bipeds hatched from eggs laid by a parent bird.

The plumage of birds is wonderful in its structure, and in its adaptation for flight, and as a covering to protect from wet and cold. In many cases the plumage is striking in its beauty of coloring and of form. 
Some kinds of birds of most beautiful plumage have become nearly or quite extinct because of their use for millinery purposés.

The necks, legs, feet, wings, and bills in different kinds of birds are so modified as to fit them for their special manner of life. It is an illustration of the effect of environment upon animal life, and of adaptation to needs.

Birds raised entirely apart from any of their kind exhibit what is called instinct in their skill in nest building, and in their migratory habits. They do just as if they had been taught by the parent birds. This transmission of traits from generation to generation, and the certainty with which these traits will be reproduced in succeeding generations, is one of the marvels of all plant and animal life. It is of the utmost importance, too, in mankind.

The migration of birds appears due very largely to failure in the food supply, or to need for an improvement in it.

The great value of birds as a check upon insect pests may be calculated in the vast numbers of insects that might have multiplied from those destroyed early in the season when fruits and seeds are scarce as food for the birds.

\section{Exercises}

1. Upon what do birds largely subsist? Account for their migrations.

2. In what respects are birds $(a)$ useful to men; $(b)$ harmful? Name reasons other than their usefulness for protecting birds and caring for them. What exceptions are there to the rule "Protect the birds"?

3. The extended use of the plumage of birds for millinery has resulted in what conditions? What only has caused any considerable check upon this evil? How is it that extreme cruelty is so often incident to the collection of the plumage of birds for millinery purposes?

4. What is meant by a "closed season" for game birds?

5. Name various natural enemies of the song birds. Tell how some degree of protection against these may be afforded the birds.

6. How do birds make ample returns for the shelter afforded them in the trees about a home? 


\section{SOME CONDITIONS AFFECTING INDUSTRIAL LIFE}

Changes in Manner of Living

By means of the labor of men, either with or without the extensive use of machinery, raw material from the mineral, vegetable, and animal kingdoms is made more and more serviceable to mankind. At the same time it becomes more

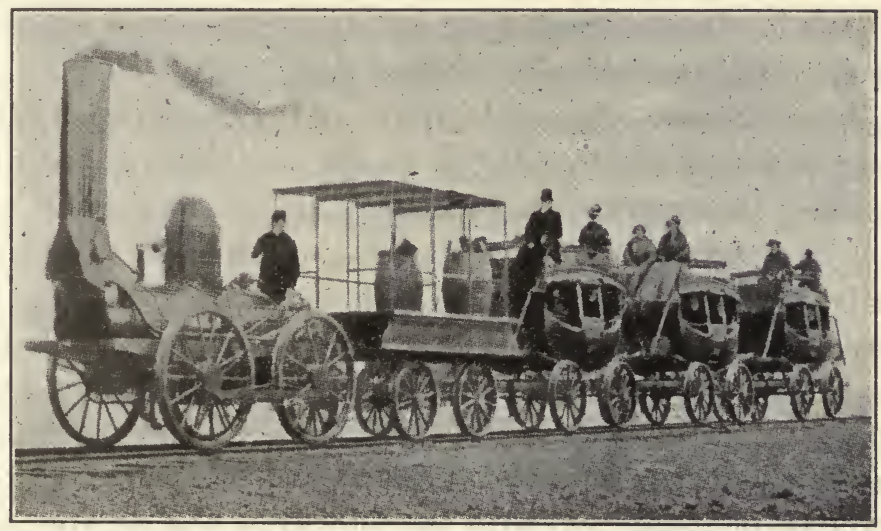

FIG. 89.-The first railway service in the United States.

costly. Manufactures as products of man's labor add to the wealth of the nation that manufactures them. More of the necessities of life can be secured in exchange for them. Passing these same articles on from seller to buyer, without any change upon them other than transportation, also adds much to their final cost to the consumer though the goods remain just as when they left the hands of the producer. Transportation facilities by highways, railways, and waterways directly affect the welfare and prosperity both of the 
consumers in any community and of those who as producers must send their products long distances to market.

People are often classified as either producers or consumers. The agriculturist by expenditure of time, labor, and skill may appropriate to his gain the raw materials from earth, air, water, and sunshine for his crops of wheat, corn, and fruit. He may transform these in turn into meat and dairy products. In a very true sense he is to this extent a producer. The men who dig coal and iron ores, and the iron manufacturer who turns these raw materials into forms indispensable in modern life, are also producers of natural wealth. But at the same time the miners, furnace men, and the iron manufacturer himself as consumers are dependent upon the agriculturist for their daily food.

Those who are engaged in trade and transportation, and those to whom merchandise is finally sold for use, may be classified as consumers. They may in some cases be the very same people who produced the raw material itself on the farm and in the mines. The shoe manufacturer may be considered as a producer of wealth, but he and his workmen are classed among the consumers with reference to food supplies. No studies of the production, transportation, and consumption of raw material and of manufactured products, in connection with the industries and occupations of the people of any community or nation, can be carried far without a discussion of economic problems involving the principles of Political Economy.

A city or nation occasionally faces a condition such as that involved in the "strike" of a large body of those engaged in its transportation service. The railway systems of the country may be paralyzed for lack of men to operate them. At these times not only may the lives of citizens be jeopardized, their comfort and welfare disregarded, but the stability. of government and the enforcement of its laws may be im- 
periled. The complexity of modern life makes necessary a widespread intelligence concerning the questions of hours of labor, of wage earning, and of trade conditions.

This state of affairs is in sharp contrast to the simplicity and independence in manner of life during the earlier years of our country's history. Then it was a common thing for a family to keep a few sheep whose wool when carded was spun at home and woven into cloth there. This cloth was then cut up in the home and made into wearing apparel for the members of the family. Now the spinning and weaving is done in great factories, and all woolen clothing is usually. purchased ready-made.

In those early times when a farmer butchered a beef the meat was cured at home, the tallow was prepared ("rendered") at home and made into candles by the family, and all waste fats were used for making the family supply of soap. The hide of the animal was made into leather at a local tannery, and footwear for the family was made from it by the neighborhood shoemaker. The corn and wheat for family use as food was ground at a nearby mill, and any balance of these foodstuffs was fed to the stock on the home place. To-day the farmer buys shoes and clothing readymade, and the meat and flour he needs are bought from dealers in town.

Such changes as these in the general manner of life of the people of the United States were especially rapid in the last half of the nineteenth century. A new empire of agricultural industry and wealth arose in the valleys of the Mississippi and the Missouri. Chickens in New England and cows in New York State were fed corn, wheat, and mill products grown in Missouri, Kansas, Iowa, Nebraska, and the Dakotas. The cost of these foodstuffs after transportation was less than the cost iof production on the eastern farm. Cattle fattened in the far West were slaughtered at Kansas City, Omaha, or 
Chicago, and the meat shipped to eastern towns for sale at prices as low as the cost of production there.

Any simple statement of changes in the life of the nation due to these causes, and to an annual immigration, often exceeding a million a year, is not broad enough. Any discussion of the economic conditions involved in these changes in production, trade, and industry, and any discussion of the geographical conditions that have directed and modified these new currents of national life, is incomplete in itself. Underlying it all, and interwoven with all this progress toward more of the comforts and conveniences in life and less of its hardships, is a degree of scientific achievement that is marvelous. In its applied form, as translated into terms of machinery, science has multiplied the working capacity. of individuals in many cases a thousand fold, and has shifted the burden of large parts of the world's labor from man to machines. Inventive genius, applying the results of scientific discoveries, has perfected machines that demand workers of the highest intelligence to operate and care for them. Unskilled labor is ever put more and more at a disadvantage in this scientific age.

A striking illustration of development of natural resources under stimulus of applied science and invention, and of a revolution wrought in the social, agricultural, and industrial life of the United States in connection with such development, is seen in the widespread use of automobiles, motor trucks, and gasoline-driven machinery of all kinds. Man's mastery of the air waited upon the development of light but powerful engines using petroleum oils for fuel. It was necessary that these heavier-than-air machines be given a velocity not only sufficient to sustain themselves, but to make long flights possible even when carrying passengers or other load. Marvelous as was the rapidity in introduction and use of gasoline machinery for factory, farm, and highway, the development 


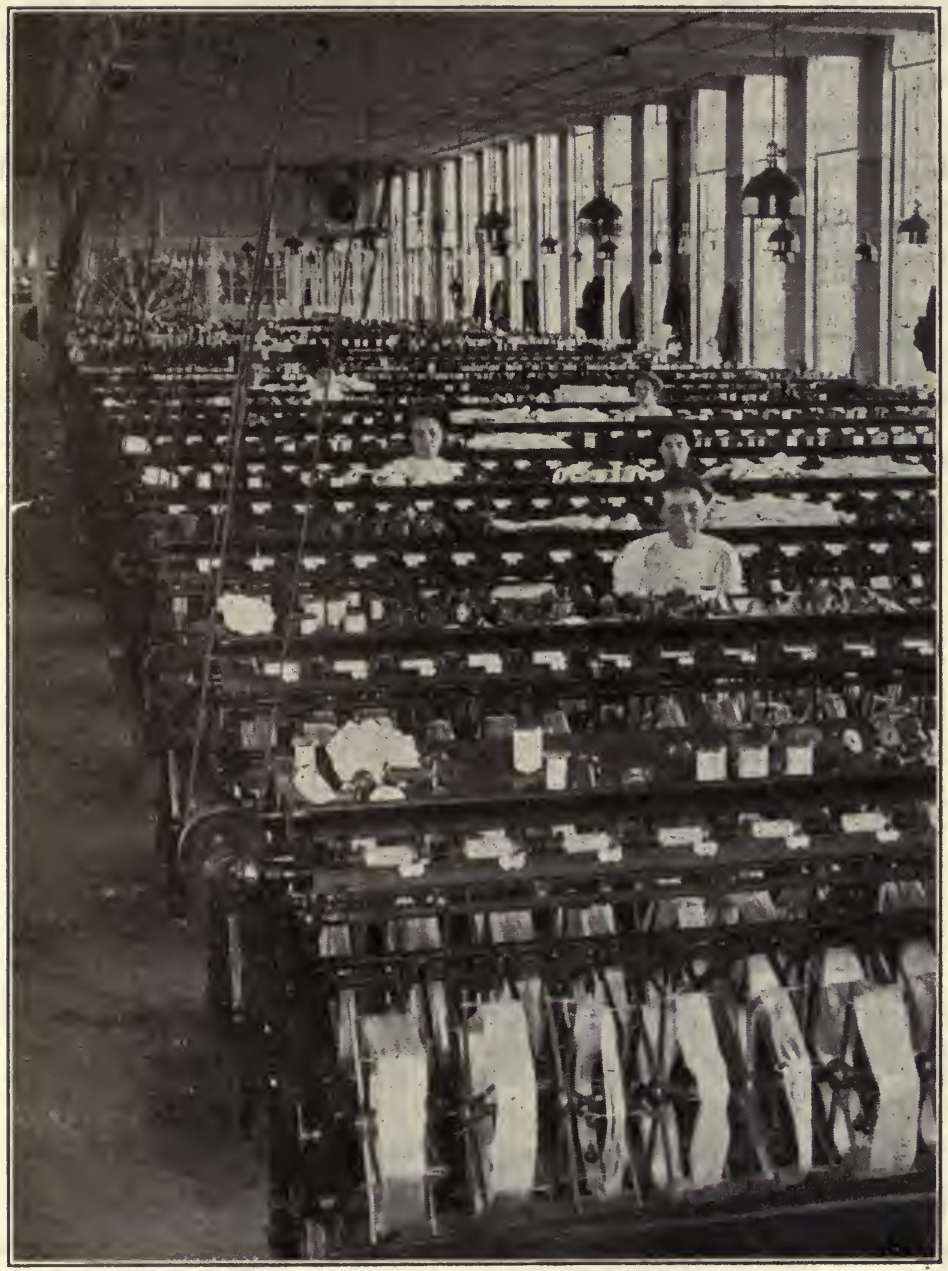

FIG. 90.-Interior of a silk mill. (By Underwood and Underwood.). 
of aerial navigation under stress of a world war, and its assured usefulness in times of peace, is occasion for even greater wonder.

Petroleum as obtained from deeply drilled wells is a heavy liquid of a characteristic disagreeable odor, and often times is greenish in color. The rise of the petroleum industry in the United States dates from wells driven in 1859 near

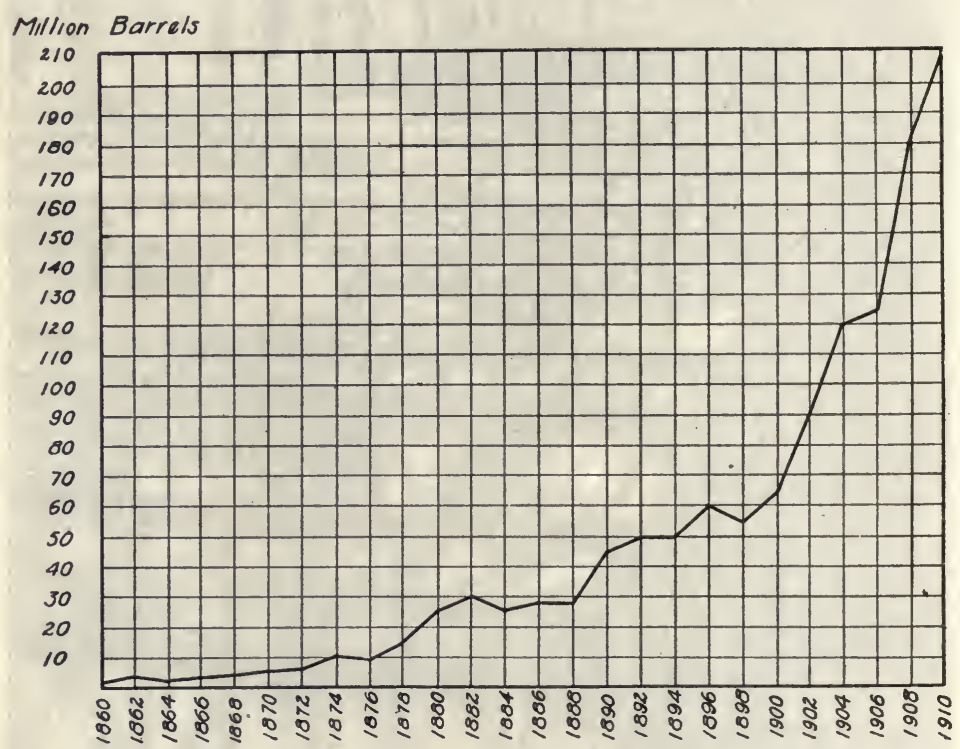

FIG. 9r.-Production of petroleum in the United States from 1860 to I9ro.

Titusville, $\mathrm{Pa}$. The accompanying graph shows the rapid increase in its production in this country. For years kerosene was one of the most important products of the refining of petroleum. Its use in lamps for household illumination became world-wide. Knowledge of the importance of numerous other products from the refining of petroleum, and of the manner of their separation from one another, may be gained in the study of Chemistry. Among these products 
are the aniline dyes, and long lists of substances handled in the drug trade.

The oil fields of Indiana were opened in 1897, of Texas in I90I, of California in I903, and of Oklahoma in I905. The petroleum from the Texas and California fields has extensive use as fuel supply for shipping and for locomotives in railway service. So important is an ample supply of petroleum

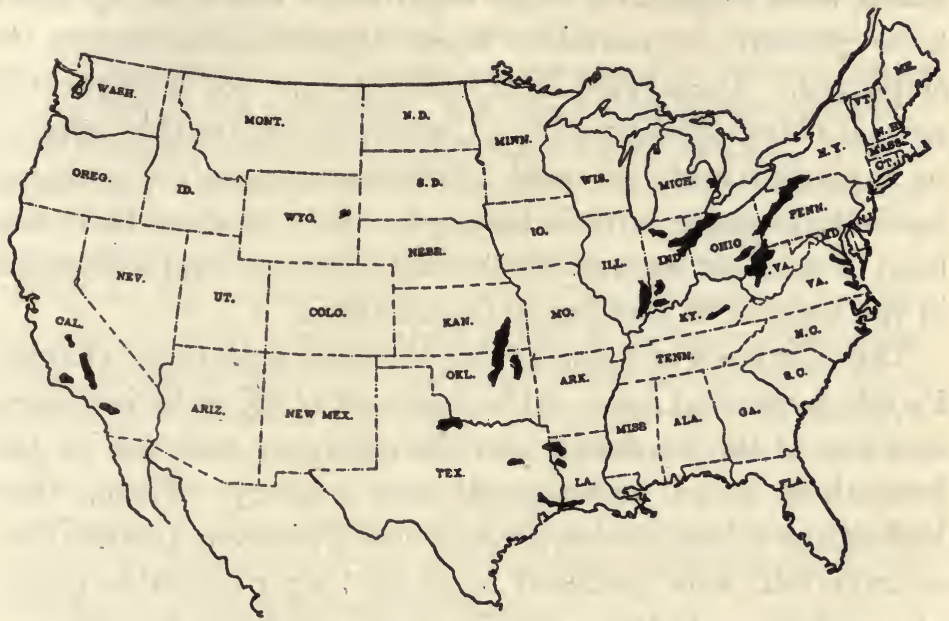

FIG. 92.-Location of the larger oil fields of the United States.

for the navies of the world and for shipping generally that all large sources of its supply, including on this continent the rich oil fields of Mexico, are subjects of greatest concern in international relationships.

From the development of the petroleum industry in the United States has come great added wealth to the nation as a whole. But it has concentrated vast fortunes in the hands of a few individuals, and has given rise to business organizations exercising far-reaching influences in trade and commerce, and in the social and economic conditions affecting the lives of people generally. As in the case of coal with which it is so closely related in chemical nature and geological 
history, petroleum is a natural resource limited in amount. Its restricted production and possible exhaustion may reasonably be forecasted.

The use of farm machinery when operated by horses has more than doubled the area of farm land that one man can cultivate. Because of the wide use of farm machinery not as many men are needed in the farming districts. Farms which were sufficiently large when labor was done by hand have proven unprofitable when expensive machinery is employed. Abandoned farm buildings are not infrequently seen in many sections of the United States, bearing witness to a readjustment of rural conditions inevitable, perhaps, but not altogether satisfactory. In many sections there has been a marked increase in the size of farms, and a decrease in the number of families living on them.

The standards of living during this time underwent change. People demanded more of the comforts of life in their homes, and less of the hardships and the drudgery endured by the forefathers in an undeveloped new country. Farms that had supported successive generations of prosperous American country-folk were declared to be no longer desirable places of residence. Better schools were provided for children in the towns. There was the possibility in towns and cities of steady employment in office, store, shop, mill, or factory for women as well as men. An income from wages was not subject to losses by bad weather and crop failures. All these conditions, together with the various advantages that town life offered in other ways, contributed to a phenomenal drift in population from the farms to the cities, especially in the eastern portion of the United States ${ }^{1}$. There was a radical

${ }^{1}$ The Census Reports of the United States by decades show the percentage of the population of the country resident in cities and towns of 2500 or more inhabitants as follows:

I 880

29. 5 per cent
I 900

40.5 per cent
I9IO 46.3 per cent 
change in the character of the rural population and of rural life generally over widespread areas.

\section{SUMMARY}

The relationship is very close between the geography of any region, the occupations of its people, and their advancement in trade, industry, and civilization.

As the population of a country becomes more dense, complex questions arise affecting transportation, cost of living, and employment of labor. There must be adjustments of government to varied interests that are more or less conflicting. Some knowledge of the college subjects of Economics and of Sociology becomes highly desirable. But one does not have to make a study of these branches in order to understand a great deal about the mutual dependence of the people of different sections of any country, and of the people of all parts of the world.

Within the half century following the Civil War a marvelous development occurred in the United States affecting its industries, population, wealth, and the manner of life of its people. The history of this period will strongly emphasize the development of natural resources that took place, and the extensive changes and readjustment of conditions that occurred, incident to the introduction and use of machinery. An understanding of these changes in the life of the American people is impossible without a knowledge of the scientific achievements of this period, and of the years just preceding it.

\section{Exercises}

1. Mention some of the differences involved in making a living by business or professional life, and by working at a trade.

2. What general relationship exists between transportation facilities and the size of towns?

3. What very largely affects the choice of location and the development of any particular manufacturing industry?

4. What are the serious disadvantages to any country in having its industries centralized rather than widely distributed?

5. Give some of the principal reasons why people move into towns and cities to live. What are some of the decided advantages of life in rural districts?

6. What conditions affecting the workers in mill, factory, or shop correspond to the uncertain returns from farming? 
7. If an annual inventory be made by the wage earner and by the farmer, even as by the business man, what in each case would constitute a showing of profits?

8. Upon what besides taxable property does the wealth of any community depend?

\section{Social and Economic Conditions Affecting THE WAGE EARNER}

Incident to the rapidity with which changes in industrial life have been brought about in this country have come many

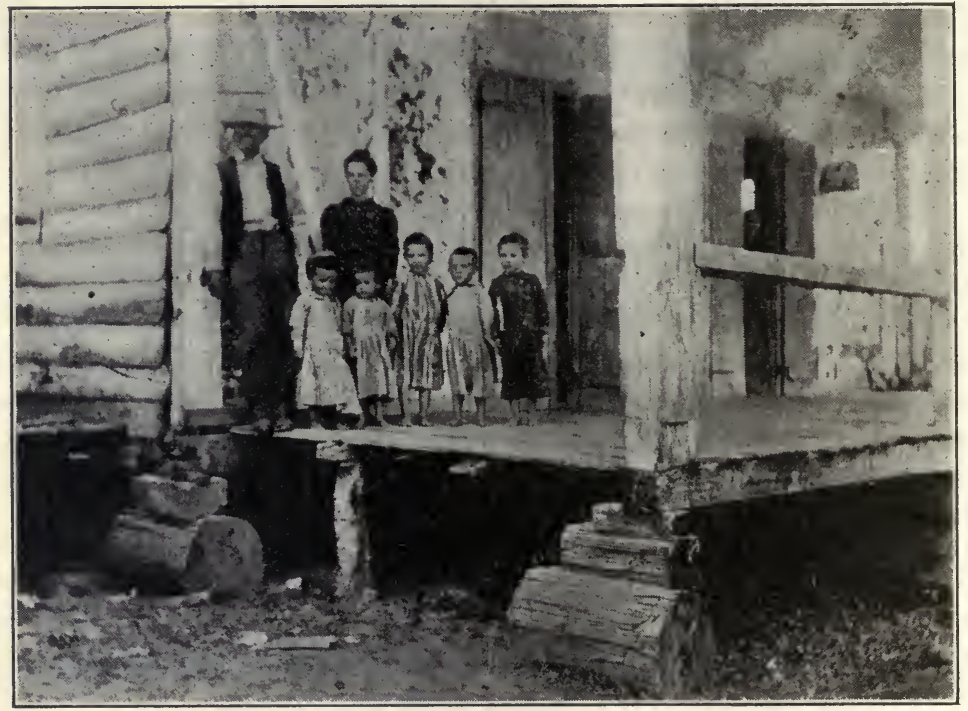

FIG. 93.-Thriftlessness and poverty.

evils. Enlightened citizenship demands that provision be made for sanitary conditions of life everywhere, especially in the over-crowded sections of great cities. Ordinary prudence demands such thrift that when periods of depression come to the business and industrial world, even as crop failures come to the farmer, no extreme poverty and distress will be experienced. Poverty is a common accompaniment 
of thriftlessness and inefficiency, and freedom for many hours a day from all demands of labor is not necessarily conducive to better living.

We wonder at statements made by competent authorities that four millions of people in this country are dependent upon charity, public or private, and that ten millions more are underfed and handicapped in life because of the conditions under which they live. Much can be done to remedy these conditions by means of public enlightenment and far-reaching economic legislation. The individual himself, however, is always responsible for making the most of all opportunities for self-betterment, and for avoiding whatever wastes his time, means, and health ${ }^{1}$.

1 The following are the "Financial Life Records" of one hundred average men who at twenty-five are healthy, vigorous, of good mental and physical capacity, and without means of support other than their own ability and efforts, as shown in data compiled and published by the Savings Bank Section of the American Bankers Association:

\begin{tabular}{|c|c|c|c|c|c|c|}
\hline \multirow{2}{*}{ Dead... } & 25 & 35 & 45 & 55 & 65 & 75 \\
\hline & $\ldots$ & 5 & I6 & 20 & 36 & 63 \\
\hline 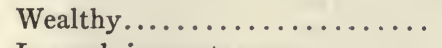 & $\cdots$ & I0 & 3 & $\mathbf{I}$ & 5 & 3 \\
\hline In good circumstances......... & .. & 10 & .. & 3 & & $\cdots$ \\
\hline In moderate circumstances...... & $\ldots$ & 40 & $\ldots$ & $\ldots$ & $\cdots$ & $\cdots$ \\
\hline Those without financial means... & 100 & 35 & 65 & 46 & 6 & $\ldots$ \\
\hline Not self-supporting........... & $\ldots$ & $\ldots$ & .6 & 30 & 53 & 34 \\
\hline & 100 & 100 & 100 & 100 & 100 & 100 \\
\hline
\end{tabular}

Of the sixty-three dead at seventy-five years of age, sixty left no estate (property of value sufficient for matter of record). Those listed as not selfsupporting were more or less dependent upon children, relatives, or charity.

Records of Surrogate's Courts show that for every roo men who die the estates of three are $\$ 10,000$ or above; of fifteen are from $\$ 2,000$ to $\$ 10,000$; of eighty-two are of no considerable value. Of every 100 widows eighteen are left in comfortable circumstances; forty-seven are obliged to go out to work for a living; and thirty-five are left dependent, or in want.

In I $_{914}$ in the United States there was spent for tobacco 520 millions of dollars, and for alcoholic beverages 1720 millions of dollars. 
The hours of freedom from labor, both of men and of women, should yield rest and refreshment and intellectual advancement, and not be spent in ways that dissipate money, time, energy, or ability. The thrifty farmer a half century ago was astir at five o'clock in the morning, and abed at eight o'clock at night. Few if any of these intervening

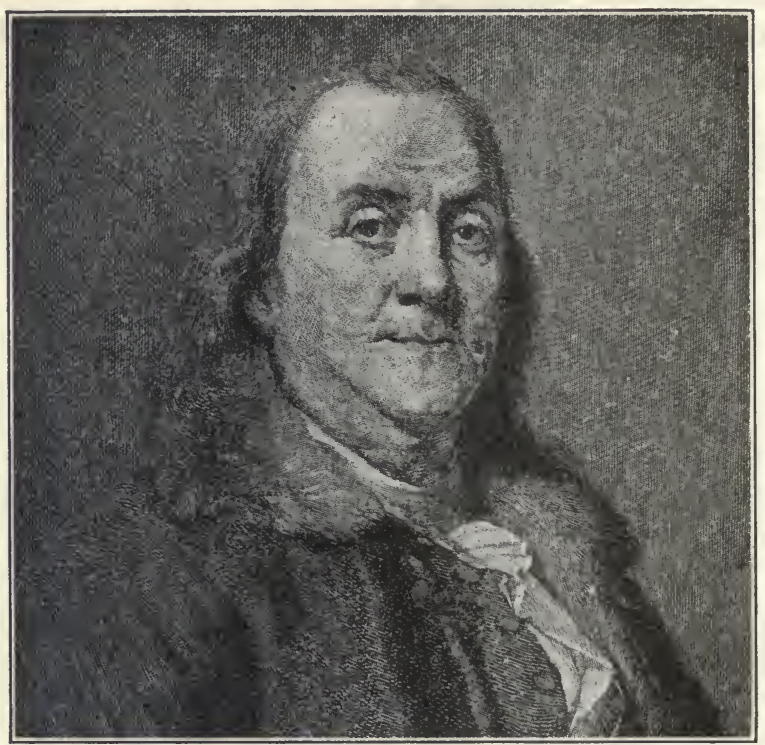

FIG. 94.-Benjamin Franklin

hours had been used for anything other than labor for the family welfare. The hours of a day's labor for the housewife were even longer. The vigor and vitality, the worth and excellence of these people, made possible the conditions of life that we enjoy. Right use of the time and energy secured by a release from the drudgery of life means a higher civilization, and larger individual happiness; its wrong use may mean degradation for the individual, and destruction to society. One great purpose of attendance upon schools is to learn 
what are wise courses to follow in life, and how most advantageously to use the accumulated knowledge of mankind.

The lessons of chief importance in school and home alike are those that teach the wisdom of the ages concerning human conduct - that knowledge which the later experiences of life only verify and emphasize. Any education is faulty and incomplete which does not include instruction and practice in those ways of life often referred to as its "virtues". These cannot be fully taught or sufficiently practised in school alone. Maxims such as are named below characterize a well-ordered life. They are applicable to all individuals in all the walks of life:

Avoid those indulgences that lead one to live beyond his means. Choose those pleasures in life which are healthful, and which cost little in money and effort.

Abhor waste of any kind-waste of strength, or time, or means. Remember that one's savings rather than his income measures his increase in wealth, and that more wisdom is necessary to spend wisely than to save.

Choose that kind of an education which shall aid in living a more efficient and wisely ordered life. The worth of an education to anyone is largely measured by what kind of a person it helps him to become, and by what he is enabled to accomplish because of it.

Make no exchange of health for pleasure, wealth, or position. He who makes so bad a bargain finds his attainment worthless for lack of health.

Avoid any conduct, any business practice, any traffic legal or illegal, that advances the interests of one person or class at the expense of another, and results in harm to others rather than their good ${ }^{2}$.

"Sayings" such as these sum up invaluable experiences of mankind. They correspond to the truths or "facts"

${ }^{1}$ Every generation of American boys and girls should become familiar with the form and significance of some of the sayings of Benjamin Franklin statesman, publicist and scientist. Some of his "wisdom" as it affected American home life of earlier generations may be found in "Poor Richard's Almanac". (Houghton, Mifflin Company: Boston. Paper, fifteen cents.)

'Such courses may be classed as criminal in character whether as a business, trade, or practice. However, there is need to distinguish carefully between practices fundamentally criminal, though often legalized, and the person engaged in them who may be innocent of any criminal intent. 
upon which the scientist must base his theories, and the various other facts which business and professional men take into consideration in formulating their procedure in the affairs of life. It is as necessary to take them into account in one's manner of living as it is for the scientist to take account of the facts that affect his theories and his practice. To ignore the realities of human existence, and to fail to adjust conduct to them, is as if the scientist failed to make his theories fit the facts to which they relate.

There should be direct relationship between the training of the laboratory in high school science, and a preparation for those activities in which one may engage later in life. This relationship can be wholly apart from any skill acquired in handling apparatus and machines. In the affairs of life, as in the laboratory and study room at school, the particular difficulty or "problem" that demands attention at any time requires ability to get the facts bearing upon it, and ability to discriminate in the relative importance of these facts. It is necessary to decide, too, the course to be pursued in view of one's understanding of the facts so that labor of hand and head shall count most. When any such plan of action fails to give the results desired, then there must be ability and willingness to review the whole situation, to correct errors in fact and in judgment, and to undertake anew the application of the changed plan. This in a simple way is the procedure of the scientist in making advances in learning. It is the course pursued by successful business and professional men, and it is a course which begun in school may be continued throughout life. It is to be remembered that one's school days are but a beginning in becoming educated.

No acquaintanceship with books and their stores of human learning is a substitute for industry. Health and efficiency attend upon the combined exercise of body and brain. Habits 
of industry like other habits, and correct notions of the dignity of labor, are largely formed in childhood and youth. Idleness too commonly leads to vice, and the energies of youth demand a healthful outlet in employments suited to age and strength. To expect a boy or girl to grow up in idleness and without responsibilities till sixteen years of age or thereabouts, and then at once to become a steady efficient worker, is to ignore human experience and the power of habit.

\section{SuMMARY}

No nation can be considered truly prosperous, and no social conditions are satisfactory, where everyone regardless of occupation may not have wholesome surroundings of life if they will, together with ample provisions to safeguard health and life.

Perhaps at no time in the world's history have its workers who are industrious and thrifty been able to possess so much that contributes to comfort and well-being as now. To this condition scientific achievement has contributed largely, putting within reach of those of moderate means what in former times was available to few if to any. Many of the comforts and conveniences and furnishings of an unpretentious modern home were unknown less than a century ago.

The large use of machinery for doing the work of the world has contributed to lessening the hours of labor, and doing away with much of life's drudgery. Whether work is a curse or a blessing to individuals, and to people generally, depends upon whether or not it uplifts them in physical, intellectual, and moral well-being. Freedom from labor, and many hours of leisure because of shortened hours of labor, must be judged in the same way. The same rule, too, can be applied rigorously to those who because of the possession of wealth find it unnecessary to labor for a livlihood.

Advances in civilization, and improvement in the life of any individual, depend in large measure upon avoiding the mistakes of those who have learned by experience. It is foolish not to be guided by what others have learned. One of the chief purposes of schools is to bring this knowledge before the pupils of each generation for their benefit and use. 
There are ways of acquiring and applying knowledge that are peculiarly scientific, and not least of the worth of a training in science studies is a "scientific attitude" of mind toward all the affairs in life. One of its characteristics is in basing opinions upon facts only, and in testing out these opinions to see that they are in accord with facts. This requires ability to collect and associate all available information gained from personal experiences, from experimental work, and from books. Conclusions thus reached may be followed in any of the affairs of life with reasonable assurance of success. 


\section{THE FARM}

\section{Poultry AND EgGS}

One of the noticeable differences between meat from the hen, and that from wild fowls generally, is its color. The domesticated fowl has a large amount of white meat as result of less use of the muscles, and a consequent lessened supply of blood to them. This is especially true of the muscles of the breast which are used in flying. The great weight of the domesticated hen makes flight for any considerable distances impossible. The same thing is largely true of domestic turkeys, geese, and ducks. The bone structure of the domesticated fowls is denser and stronger in order to support the heavier weight of body. The mounted skeletons of birds of flight, such as the various songbirds, show when examined a remarkably light structure, the bones commonly being hollow. The quill feathers, too, strong but light, show a wonderful adaptation for use in flying.

The hen walks on her toes which terminate in nails (claws) very serviceable in scratching for food. The scaly and more or less featherless part of the leg corresponds to the human foot. Through it pass tendons that move the toes. The muscles of the "drumstick" from which these tendons arise exhibit in their color and development the great use the hen makes of her feet. The drumsticks correspond to that part of the human leg from knee to ankle, while the thigh bones of a fowl are closely joined to its body and are covered by the body skin. 
The wings correspond to the arms of people, and both upper and lower arm bones are coveredfby the skin of the body. Imagine a person with the whole length of arm to the wrist doubled upon itself and tied close down against the body, and the fingers and hand covered with feathers. Then consider the difficulties experienced in efforts to feed one's self and to keep clean. The neck structure in fowls gives a wonderful variety in movements and in serviceableness, securing both strength and flexibility. One use of the bill (beak) by birds and fowls is in keeping their feathers clean and in place.

The leg structure of birds that perch (roost) is such that the weight of the body causes the toes and claws so to grasp the support that when asleep they cannot fall off. Differences in the kinds of domestic fowls due to breeding is a matter of importance to poultrymen.

When combined with the care of the home garden, the responsibility associated with the keeping of poultry provides for both boys and girls an educational training at home as valuable as any "course" in schools. There is an abundance of literature of great worth upon both Gardening and Poultry Raising, much of which may be had at slight outlay. But the educational value of these occupations for boys and girls lies in the initiative, the persistence, and the good judgment demanded by the home work. It combines physical and mental effort in a manner similar to that which characterizes advancement in first-hand study of the sciences, and success in the affairs of life generally.

Agriculture as a school subject needs application of its teachings even as does Home Economics. It may be secured in part at least through the care at home of a flock of fowls, and of the vegetables in the garden. This is in addition to caring for the lawn, the fruit and flowers, the trees and shrubbery about the home. Along with the increase in skill and 
ability in this work there should be developed business habits and enterprise quite as valuable as that gained in other life experiences.

Both poultry raising and gardening have become highly developed industries in many localities. This is especially true in the vicinity of cities that afford good markets. In both fields of effort capital, executive ability, and a clear understanding of the conditions and details of the business, are necessary to success. The value of the egg production

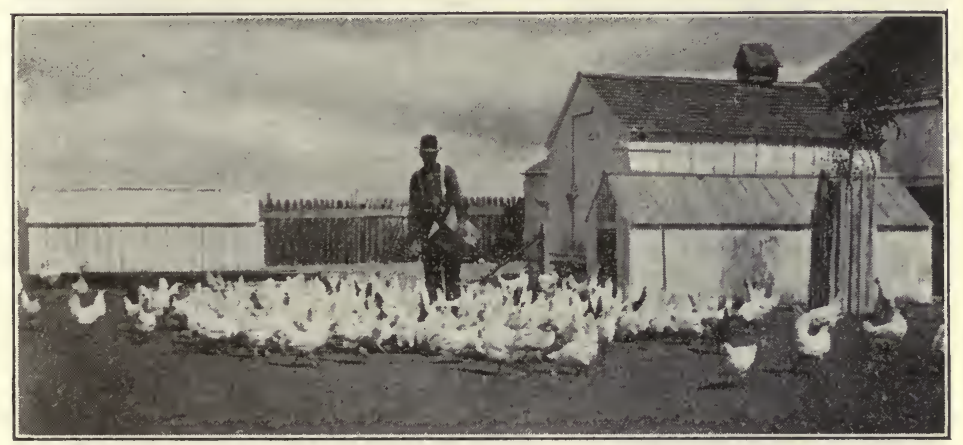

FIg. 95.-Feeding the flock.

in the United States amounts to millions of dollars annually. This seemingly negligible source of national wealth is an item of importance in the cost of living and in the wholesomeness of diet.

A chicken when hatched has bone and muscle, beak and claws, skin and feathers, eyes and internal organs. All these have been developed from the material stored within the shell as food for the life germ or embryo. The more one considers it the more wonderful this seems. The white of the egg is largely albumen and water, and the yolk contains much albumen. This albumen is one of the important substances in the class of foods known as proteins. It hardens 
when heated as in the familiar case of eggs hard boiled. In the process of digestion when acted upon by the gastric

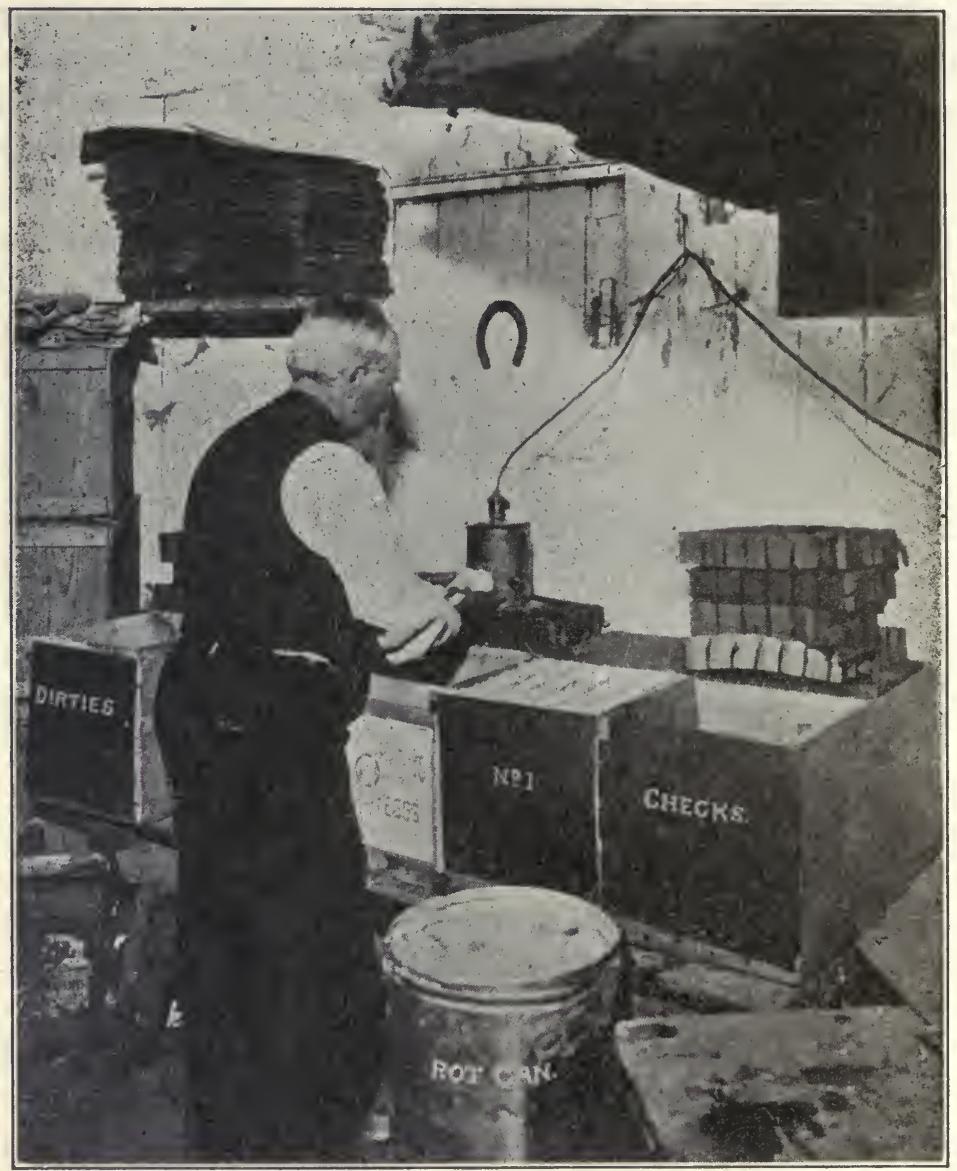

Fig. 96.-Candling eggs.

and pancreatic fluids it is changed to peptone which more readily dissolves and osmoses. Chemically albumen is very closely related to a substance gluten found in 
grains and to casein found in milk. (See pages 222, and 328 .)

When a food solid is treated with strong nitric acid, any protein is colored yellow. If it is then washed free of the acid and dipped into strong ammonia water, the color may change to orange. A piece of white silk ribbon shows these same tests for protein, while a white cotton fabric is unaffected. The cotton is cellulose, a vegetable fibre, and contains no protein.

The preservation of eggs from times of over abundance and low prices to other times when the supply is much less, has been solved for the large centres of population by keeping great quantities of eggs in cold-storage warehouses. From these storehouses they can be supplied for sale as the market requires. Their food value is unchanged if they have been properly cared for, though they may be somewhat less palatable than when fresh. Eggs for storage should be chosen with care, and any not strictly fresh must be rejected. There is much more food in a dozen large eggs than in the same number of small ones, and size may very properly be considered in the sale price of eggs.

The quality of an egg as to age and fitness for food can easily be determined by holding the egg between the eye and a strong light, preferably an electric light shining out through a hole in a box within which the light is placed. This testing should be carried on in a darkened room, too, so that one's sight is unaffected by any light other than what comes through the egg. With a little practice eggs may be graded almost as fast as they can be handled since with a little experience the condition of the egg is known at a glance.

For family use on the farm the home product is often stored in large jars filled with a solution of "water glass", or sodium silicate, by means of which the pores of the shell are closed to air and to the germs that cause decay. In 
this case as in cold storage the eggs should be turned from time to time that the yolk may not settle to one side and become attached to the shell. Brooding hens turn the eggs upon which they are sitting, and when eggs are hatched in an incubator they must be turned one or more times.

\section{Summary}

The hen as type of all domestic fowls illustrates the modifications accomplished in animal structures by long-continued selective breeding. Certain characteristics in build, coloring, and egg production have been intensified by retaining in the flocks year after year only those fowls which exhibit the desired characteristics in most marked degree.

If domesticated fowls were turned loose and allowed to run wild in an uninhabited region, few if any of them would be likely to survive the conditions for which they long before had become unfitted. It is likely, however, that if any should survive their successive generations would rapidly revert to the smaller more active forms seen in the different kinds of game birds.

A study of the skeleton of a hen in comparison with the skeleton of a human being shows that the hen walks on her toes. The lower, scaly, and often featherless part of the leg corresponds to the human foot.

Where fowls are kept too closely penned up, and without sufficient freedom of range, they are less hardy, more likely to sicken and die, and are often infested with vermin. Shelter from cold and wet is essential to their healthy state.

Most of the contents within an egg is material for the nourishment and growth of the embryo. The chick in due time, when the necessary conditions for hatching have been favorable, acquires the strength to break the shell enclosing it and to make its way out.

The growth of the young chick from the embryo stage is by cell division just as growth occurs in the human body and in plants. A wonderful thing about it, however, is the variety of the organs (masses of cells doing the same kind of work in the body) that are made out of the material stored in an egg.

Eggs may have in them all this stored material and yet be worthless for the hatching of chickens because destitute of the embryo. Its development when the egg is forming involves fertilization, which corresponds to the fertilization of the ovules of flowers (page 265). Seeds 
that lack the embryo, regardless of the supply of food stored in them to nourish the growth of a young plant, never can germinate.

The storage of eggs for considerable periods of time in condition fit for food takes into account the fact that their shells are more or less porous, and are an insufficient protection from the germs which cause decay. By sealing the pores in the shells with water glass, or by storing eggs at a temperature too low for the germs to multiply, the fitness of eggs for food may be maintained for long periods of time. They may be kept from times when eggs are abundant and low in price till when more scarce and of higher market value.

Much of the value in the sales of eggs and poultry in the United States, amounting as these sales do to millions of dollars annually, represents thrift. Non-productive labor, and food materials for fowls which otherwise might be wasted, are thus turned into profit for the individual and wealth for the nation.

Where poultry raising is carried on as a business, rather than an occupation incidental to general farming or as a pleasing home employment, careful attention to all details of it is necessary, and considerable business ability is required in order to make it a success.

In agricultural colleges courses in poultry raising are given for college credit. Much helpful literature is available free or at little cost, however, so that ordinary intelligence, coupled with painstaking care and an exercise of good judgment, will win success in the school of experience.

\section{Exercises}

1. Is there any relation between the food value of eggs and the color of their shells?

2. What are the best ways of preserving eggs on a commercial scale? State what strength of solution of "water glass" is used to preserve eggs. Which are the best months for the storage of eggs? What purposes are accomplished in the storage of eggs?

3. Reproduce a diagram showing the cross-section of an egg, and on the diagram locate $(a)$ the shell; $(b)$ the outer and inner membranes; $(c)$ the thicker and thinner parts of the white; $(d)$ the chalaza; $(e)$ the lighter and darker parts of the yolk; $(f)$ the germ (embryo).

4. What food constituents of large value in eggs? For what foodstuff are eggs a substitute? What foods are best served with eggs at table? What are the digestive solvents for the albumen of eggs? What per cent of water is there in eggs? 
5. Name several cooked foods that have eggs in their make-up. Of what use are eggs in making coffee? Why is it that the fresh shells may serve a like purpose?

6. What eggs other than those of hens are used for food? To what uses are spoiled eggs put? How is this possible?

7. Describe how eggs are "candled". What is the purpose of the air space found in the large end of the egg? What is the relative size of this air space in fresh and in stale eggs?

8. To what countries are eggs exported from the United States? Account for their export to Canada which is an agricultural rather than a manufacturing or commercial country.

9. Name the various tissues of the body of the chick when hatched. Out of what substance within the egg have these been developed? Ascertain the literal meaning of the word protein.

10. In some general and striking way express the annual value of both the poultry and egg production of the United States (or of your own State).

11. How does the extent of the poultry industry exhibit national as well as individual prosperity?

12. Why is raising ducks and geese so much less common than raising hens? Why are so few turkeys raised?

13. What advanced high school science includes a study of the structure of domestic fowls? Why should studies of poultry be included in a high school course in agriculture?

14. What is true of the physical endurance necessary in raising poultry as compared with the demands of general farm work?

15. Name several of the breeds of fowls commonly kept for profit by poultry raisers. Mention some of the well-defined characteristics of each kind.

\section{The Horse}

Any discussion of the farm would be incomplete without a study of the horse. As one of man's most faithful and serviceable domesticated animals, the horse has long contributed in large measure toward the production and distribution of the world's food supplies. It is but a few years since the horse was relieved from the tasks of transportation on street-car lines, and as the sole source of power in moving boats over inland waterways. The stage coach was long ago replaced by the railway, and now even in warfare the motor truck lessens the need for horses. The part played by the horse in the world's history, as used by man in the 
ways of peace and for purposes of conquest, would make a most interesting narrative.

The horse belongs to the vertebrates, or animals with spinal columns, and is in the division known as mammals. To this group belong such domestic animals as cattle, sheep, pigs, dogs, and cats, together with various wild beasts such as bears, wolves, lions, tigers, and elephants. The whale, too, is a mammal and suckles its young, and man himself belongs to the mammals. On the other hand, fish and birds hatch from eggs.

From studies of the remains of animals found buried in the earth's strata geologists are able to give a detailed story of the ancestry of the horse. This history runs back through geological periods to animals entirely different in appearance from the horse of historic times. This evolution of the horse as it is called is an illustration of the changes that have occurred in plant and animal forms during countless ages. Those forms best adapted to changing conditions have survived. They have perpetuated the characteristics and organs which have best served their needs and have been in most frequent use. Man himself has developed and perfected various breeds of horses, cattle, poultry, and other animals, and a no less wonderful change has been wrought in the kinds and qualities of plant life by selective breeding. The achievements of the last half century in improving plants and animals for man's use and enjoyment has been scarcely less than marvelous. Horticulture, animal husbandry, and general agriculture especially have profited largely by welldirected persistent applications of scientific knowledge in these respects.

The teeth of the horse in front are powerful incisors in both upper and lower jaws, enabling it to bite off grass rather than pull it off as the cow must do because of lack of the upper incisors. The back teeth of both horse and cow have 
grinding surfaces suited for the use of coarse dry fodder. Both horse and cow belong to the "order" of animals known as the herbivora, as contrasted with the flesh-eating carnivora such as the dog, cat, and tiger. The teeth of mammals vary widely in number, form, and arrangement. The canine teeth of the carnivora are fitted for grasping and tearing their prey. Instead of being set closely together as in human

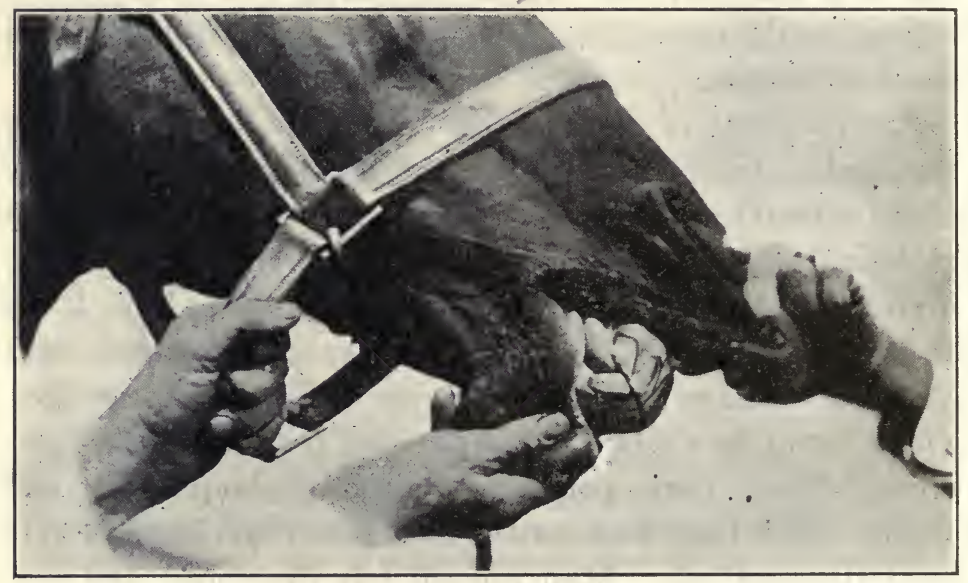

FIG. 97.-Teeth of a horse.

beings the teeth of mammals generally are more or less scattered along the jaws. In the horse the absence of teeth between the molars in the back of the jaw and the incisors in front leaves a place well suited for the bits of the harness.

\section{SumMary}

Unlike birds and the domestic fowls which hatch from eggs laid by the parent bird, horses belong to the group known as mammals which bring forth their young alive, and nourish them on milk from the body of the parent.

In the jaws of mammals generally the teeth are more or less scattered. Advantage of this is taken when the horse is harnessed for driving. The bits are put into its mouth in a place where teeth are lacking. 
The teeth of flesh-eating animals are characteristically sharp pointed, fitted for grasping and tearing their prey. But the horse belongs to the herbivora with broad flat molars suited for grinding coarse vegetable fodder, and with chisel-shaped incisors for biting off grass in feeding.

The horse ranks as one of the most intelligent of the lower animals, and is capable of being highly trained. As one of man's most useful servants, and as a companion obedient to all demands made upon him, the horse has played a prominent part in the affairs of mankind.

\section{Exercises}

1. What has early training, or lack of it, to do with the behavior of horses?

2. What constitutes "good habits" whether in persons or in horses?

3. Name several uses of horses for which automobiles are not well suited.

4. What considerations of public health make fewer horses in town and city a desirable thing?

\section{COWs, AND THE DAIRY INDUstry}

The cost of meat as a regular part of the food supply of an individual and a family is a matter of serious consideration. The industrial development of the country and the consequent increase in its population of consumers, together with the conversion of lands once cheap and devoted to cattle raising into high-priced farms devoted to other agricultural pursuits, operates even in times of peace to raise meat prices to a point almost prohibitive to those of small incomes.

So complete is government supervision of the meat products of the great packing houses that there is little need of any fear of the wholesomeness of meat sold in the markets. It is in the prepared forms of meat, such as sausage, that there may be use of preservatives and of adulterants (cheaper material as a "filler").

No meat should ever be used without having been thoroughly cooked. From insufficiently cooked lean pork trichince may be introduced into the human body causing sickness and death. Tapeworms come from uncooked fish, 
beef,-and pork. The high temperature of the cooking process kills these larvæ, and at the same time destroys any other living germs.

The milk supply is a much more serious problem so far as purity is concerned. It is one of the chief foodstuffs of people, especially for infants and small children, and it may easily become a menace to health. The dairyman is indeed a neighbor to us all in his care, or carelessness, as these affect

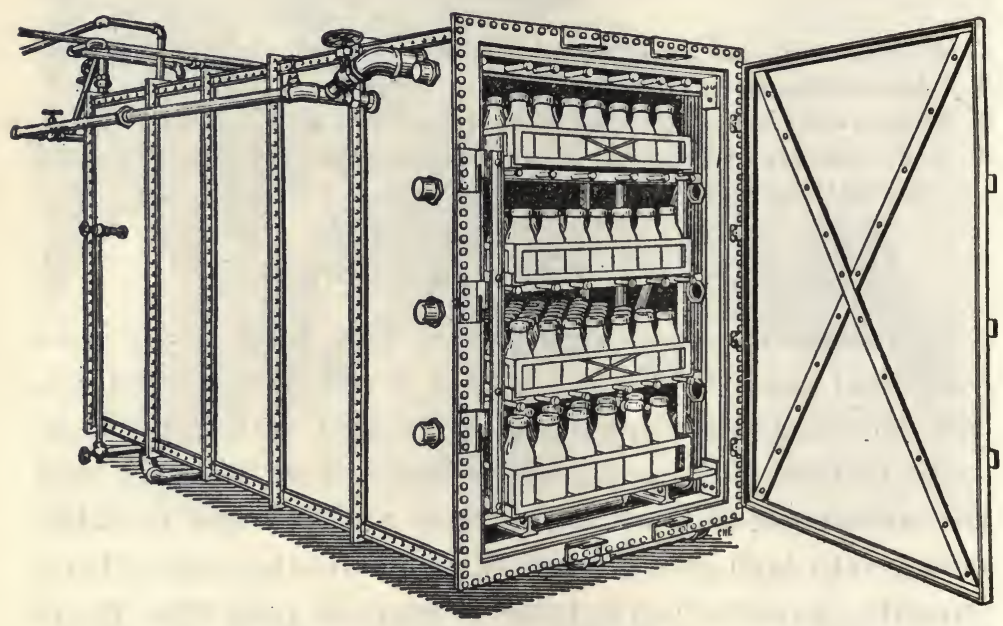

FIG. 98.-Pasteurizing milk. Heating and cooling done by circulation first of hot and then of cold water.

our health. Since it is almost inevitable that town dwellers are dependent upon the milkman for their daily supply, city authorities acting as Boards of Health exercise close supervision over the conditions under which milk is sold in a city. The use of stoppered bottles for milk should always be insisted upon. But this is no sufficient guarantee that the bottles may not have been carelessly sterilized, or washed in water containing disease germs. The germs of typhoid, 
diphtheria, scarlet fever, and possibly of tuberculosis may be carried by milk that has not been pasteurized, i.e., heated from $150^{\circ}$ to $160^{\circ} \mathrm{F}$. and kept at that temperature for twenty minutes. Milk peddled in open cans and buckets

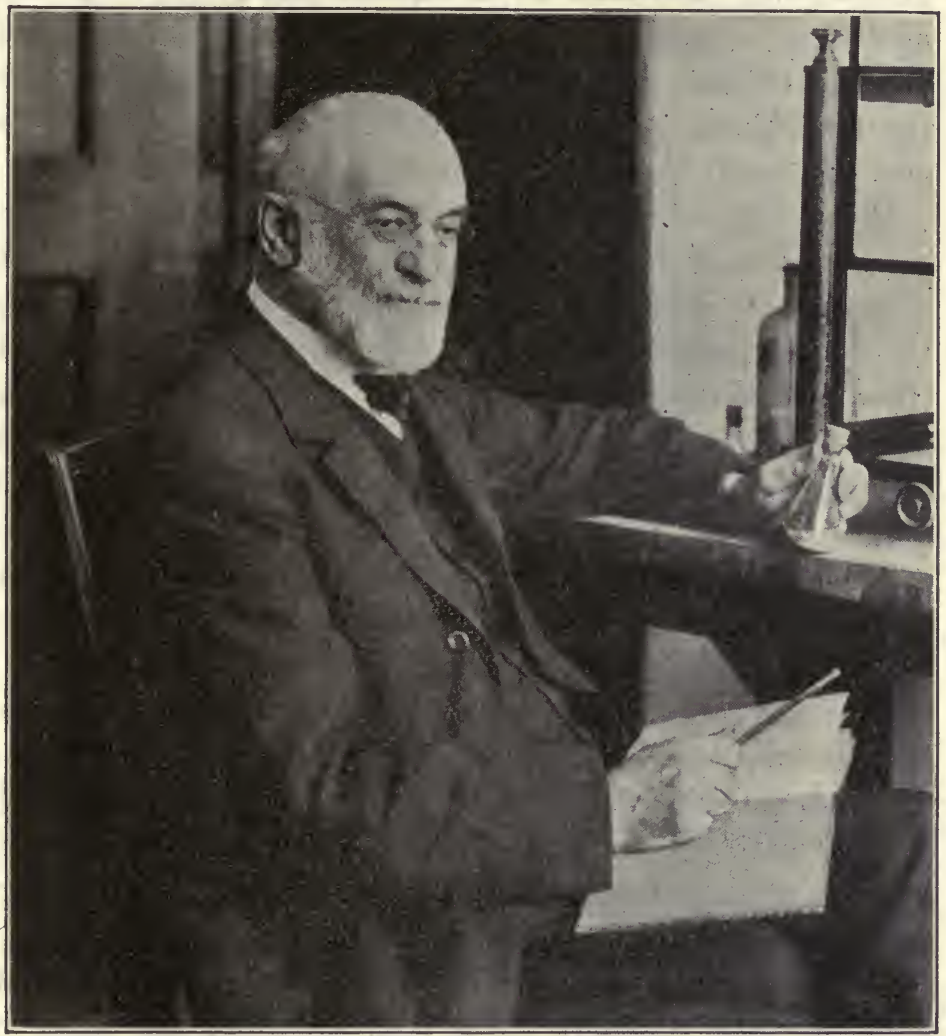

Fig. 99.-Dr. Stephen N. Babcock, inventor of the test for determining the per cent. of butter fat in milk. (Courtesy of A gricultural College, Uuiversity of Wisconsin.)

is always to be avoided. The demand for a pure milk supply of necessity increases the cost of milk to the consumer.

Modern dairy farming with its high-priced high-bred cows, its expensive dairy outfits and farm buildings, expensive 
farm lands, and high wages for labor, requires large capital and much business ability to make it a success. There must be no waste in by-products, no heavy outlays for feed that can be produced on the home farm, no waste in fertilizer for keeping this farm land at its highest productive stage, and no failure to make the products of the dairy yield the best financial returns. In other words successful dairying requires the intelligence and business ability in all its details that any successful business demands.

Illustrative of the industrial changes wrought in the last generation in this country as a result of the widespread use of machinery, it is interesting to note that a large share of the butter product of the country is now made up in the cities rather than on the farms as was formerly the case. Suspended in the watery part of the milk are finely divided fat particles. They are held in this condition by the protein in milk known as casein. Liquids of this character are called emulsions. By the use of cream separators at the dairy farm the butter fat is taken from the milk and sold to representatives of some creamery, located it may be in a distant city, where the butter is made in great quantities by machinery instead of hand labor. The milk thus left on the farm is fed to pigs and calves. The drudgery of buttermaking has been transferred from the women folks on the farm to an admirably equipped factory where every stage of the manufacture into butter is clean and sanitary.

The cow in lying down kneels on the front legs first, with the hind quarters down last, reversing the order in getting up. In the case of the horse, the hind quarters go down first and are raised last.

Scarcely any of the non-edible portions of the carcasses of cattle are wasted. The fat is not only used in cooking as suet, but for making oleomargarine. Portions unfit for these uses are valuable in candle-making and in the manu- 
facture of soap. The hides are converted into leather. From the hoofs, horns, bones, and the scrap parts, gelatine and glue are made. The bones are ground for chicken feed, and for fertilizer, or are charred to be used as boneblack in refining sugar to make it white. Both the hair and the blood have their uses.

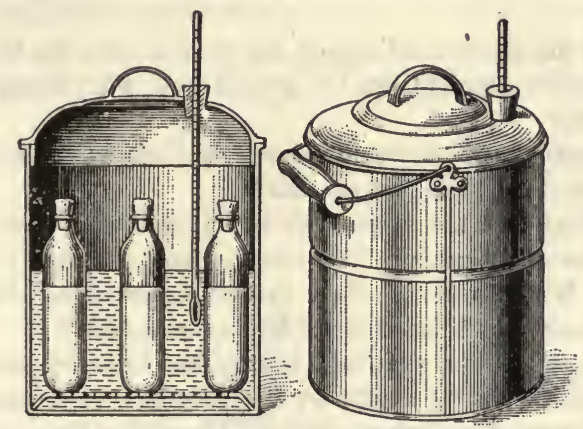

FIG. I00.-Pasteurizing apparatus for use in a home.

\section{SUMMARY}

Meats of all kinds must be thoroughly cooked to destroy any trichinæ there may be in the lean meat from the hog, or tapeworms in the lean meat from cattle. Cooking is likely to render harmless any poisonous products present.

So readily does milk serve as a carrier of germs of such diseases as typhoid and diphtheria that utmost precautions must be observed concerning the care of it from milking time to its delivery to the consumer. No one having an infectious disease should be permitted to have anything to do with handling milk. All dairy utensils must be thoroughly sterilized before use, and only water known to be uncontaminated should ever be used in washing and rinsing them.

Milk from which the butter-fat has been separated for sale to buttermaking establishments is kept on the farm for use as food for calves, chickens, and pigs, and these animals become added sources of income in connection with the dairy industry. 


\section{Exercises}

1. Tell what difficulties are experienced in providing and distributing an ample supply of pure milk in large cities. Why is it that milk more than other foodstuffs may become responsible for much sickness?

2. What constitute sanitary conditions for a farm dairy?

3. What becomes of the cows found unprofitable for dairy use because of age or other reasons?

4. In what respects is dairy farming as a life occupation (a) rather attractive; (b) undesirable? In what respects is there less of drudgery about it than formerly?

5. To provide an ample food supply the year around for his cows, and to avoid excessive expenditures for ground feed, what crops may the dairy farmer raise?

6. Name several important considerations that largely determine whether or not a region is well adapted for dairying.

7. From livestock sold and shipped to distant packing houses for beef, what is the farmer as a consumer likely to buy back eventually in one form or another? Why are not all these various forms of foodstuffs and manufactured products prepared in the home community?

8. How has it come about that both the tanning industry and the manufacture of shoes are carried on at a few centres only, involving as this does the expenses of transportation to and fro of the raw material and of the manufactured product?

9. From what parts of the world are there importations of hides and beef?

10. What has caused the great increase in creamery-made butter, and the lessened amount of the "country-made"? Aside from the taste given to butter by salt, what purpose is there in its use?

\section{LESSONS ON CORN}

To travel all day by train through the corn fields of the Middle West at a time when the crop is in its stage of most luxuriant growth gives one an idea of bounty, prosperity, and promise that cannot be gained by any reading of crop statistics. The development of the agricultural resources of the corn-growing states of this country, and their growth in population and wealth within a half century, constitutes a wonderfully interesting chapter in the history of the United States. They have become in a very real sense the granary of the nation. 
Corn was once the sole crop of the season on the western farms as cotton has been on the southern plantations, and there was an accompanying impoverishment of the soil. Financial distress followed from crop failures and from low prices. As diversified farming has replaced this practice more and more, and suitable rotation of crops has taken the place of a one-crop system, improvement in agricultural conditions has been marked.

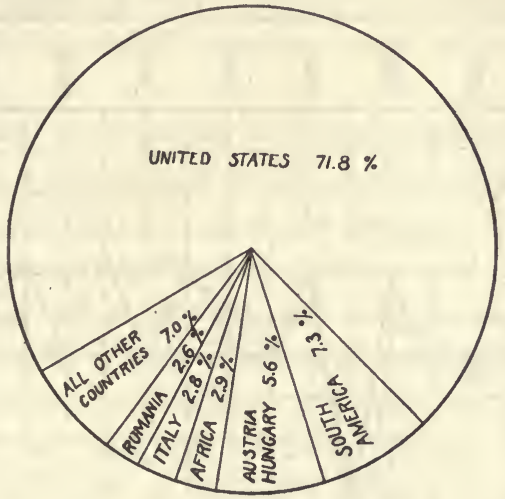

FIG. IoI.-Corn production of the world. (Robbins.)

In 1916 the world's production was $3,818,700,000$ bushels. (U.S. Department of Agriculture.)

Need of conservation of the fertility of soils that were formerly regarded as inexhaustible in crop capacity has become too apparent to ignore. It has been found that by the use of alfalfa (or other plants of the same family of legumes), and by the rotation of crops, materials for plant food are restored to the soil. Through the agency of "nitrogen-fixing" bacteria, soil fertility can be maintained in a degree somewhat comparable with the improvement of soils in the dairy districts through the use of barnyard fertilizer.

The corn-growing districts of the world are limited by 
reason of climatic conditions. To mature the crop requires about four months from the late frosts of spring to the early freezes of fall. So vigorous is the growth of the corn plant that abundance of water and of plant food must be available. The demand for moisture is especially heavy at the time when the ears are forming. The corn plant has a most extensive root system of the fibrous form penetrating the soil to long distances in all directions. In the growing season the

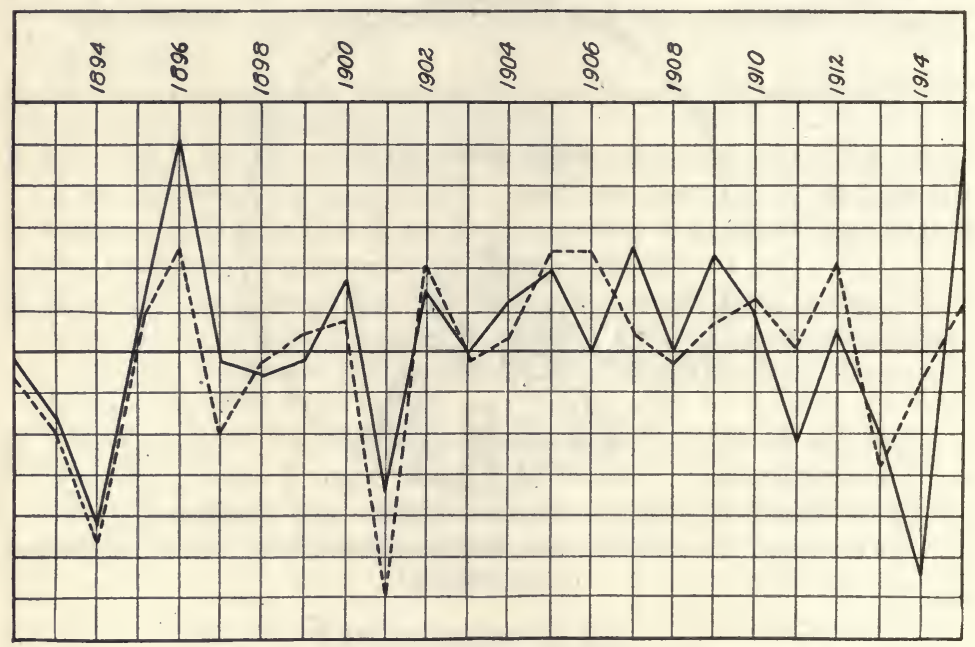

FIG. I02.-Relation of corn crop (dotted line) to rainfall (solid line).

quantity of water that passes from the leaves into the air by transpiration demands an excessively large supply daily from the soil. To conserve the moisture content of the soil requires that the surface layer be kept finely pulverized, and that the ground be kept free from weeds which rob it both of moisture and of food material. The corn plant has a relatively large amount of leaf surface, and a correspondingly large amount of chlorophyll by means of which the production of food for plant growth occurs. 
Corn is a good example of plants bearing two kinds of flowers. Those of the "tassel" at the top of the plant have stamens in whose anthers an abundance of pollen is produced. Lacking the part of the flower known as the pistil they are staminate flowers. The "silk" of the corn consists of unusually long styles of pistillate flowers at whose outer ends are the stigmas. At the inner end of each style is an ovule, which develops 'into a grain (kernel) of corn. The corn ear is a mass of seeds securely enveloped by leaves (husks) closely crowded together.upon a much shortened stem.

The development of the ear and the consequent production of a crop of corn depends upon the fertilization of the ovules by the pollen cells that fall upon the stigmas. Any complete discussion of the fertilization of flowers, and of the fascinating teachings of plant growth and reproduction, requires a study of Botany. There are many examples of pistillate flowers on one plant and staminate flowers on another. This is true of the cottonwood, poplar, willow, and box-elder trees. When a union of the parts from the pollen and the ovule has occurred, there results a new cell capable of development under favorable conditions. into a new plant of the same species. The seed consists of this new plant as an embryo, together with a store of food for it when germination occurs and a protective covering for both.

The corn depends upon the wind to scatter its pollen so that every ovule may be fertilized, and the ear of corn have no missing kernels. That this is commonly accomplished is illustration of the lavish provision of nature in the supply of pollen. A large amount of it must inevitably be wasted. Unfavorable weather conditions at the time when the pollen is being shed, either very dry and hot, or a long continued rainy period, may seriously cut short the crop of corn. 
Whether corn-raising is profitable or not depends upon the cost of production relative to the market value of the crop produced. To increase the number of bushels grown per acre on the farms of the nation without any corresponding increase in cost of production adds to individual and national wealth. The agricultural colleges of the country are engaged in experimental work to this end. They also give courses of instruction concerning the character of soils and their improvement, the nature of tillage for particular crops, the selection and advantageous use of seed in crop growing, the cultivation of growing crops, and the manner of harvest and storage and disposal of these crops. To these courses in Soils, Crops, and Farm Management, are added others in Dairying, Animal Husbandry, and Horticulture, thus illustrating the diversity of interests involved in general agriculture. As preparation for these courses there is need of some knowledge of high school Botany, Chemistry, Geography, and Physics.

The list of uses of corn is a long one. The dry stalks with their leaves are excellent fodder for cattle. Cut into short lengths when green, the whole stalk with its leaves is extensively used for filling silos to furnish feed for cattle, especially on dairy farms. Less hay is needed where silage is provided, and the quantity of milk from dairy cows is increased. The corn itself (as ground feed preferably) may be worth more to the farmer when converted into beef and pork than when marketed as corn.

Bread, cakes, puddings, and hominy are appetizing corn foods. Corn meal by reason of lack in gluten requires wheat or rye flour mixed with it in making corn bread. Corn starch both for table and laundry uses, corn syrup, grape sugar, and corn oil are all extensively manufactured. Sweet corn from the garden and in cans adds variety to the vegetable food supply. 


\section{SumMary}

Corn can be raised only in those regions where the growing season is four months or more free from frost. Its vigorous growth is most noticeable during the long summer days of hot sunshine, and when it is warm throughout the nights.

The demands of corn upon the soil for moisture are very heavy, especially at the time when the ears are forming. So wide and deep does it root that where the soil was thoroughly prepared in the spring, and when the surface is kept loose and free of weeds, a corn crop will stand a long period of dry weather without serious harm.

The long streamers of leaves are admirably adapted for exposure to sunlight, and for absorption of large amounts of carbon dioxide from the air, and for ridding the plant by transpiration of the large quantities of water required in its growth. The so-called veins running parallel and lengthwise of the leaves are a continuation of woody fibres found in the stalk.

The corn plant bears two kinds of flowers. The ovules after being fertilized become kernels of corn, and they are arranged along a shortened stalk or cob. The pollen is so abundant that under all ordinary conditions every ovule is fertilized, and there are no kernels lacking on an ear. The value of the corn crop exceeds that of any other product of the United States.

So important is the selection of seed corn, its proper care till planted, and the testing of it for its power to germinate, that special instruction is given in all these details in agricultural colleges. By careful attention to improving the kind of corn best suited to any region, larger returns per acre may be had with the same outlay. This is a matter of profit to the owner of the crop, and an increase in the wealth of the nation.

Starch for cooking purposes, and for laundry uses, is made in enormous quantities from corn. So are glucose as a syrup for table use, for cooking, and for confectionery, and grape sugar with all its varied uses.

One variety of corn when well popped gives delicious and wholesome eating. Sweet corn in season has much use as a vegetable fresh from the garden, and as green (unripened) corn it is canned in enormous quantities.

\section{Exercises}

1. What is the meaning of the term "corn" in the Bible?

2. What is the first that is known of maize, or Indian corn? Give the 


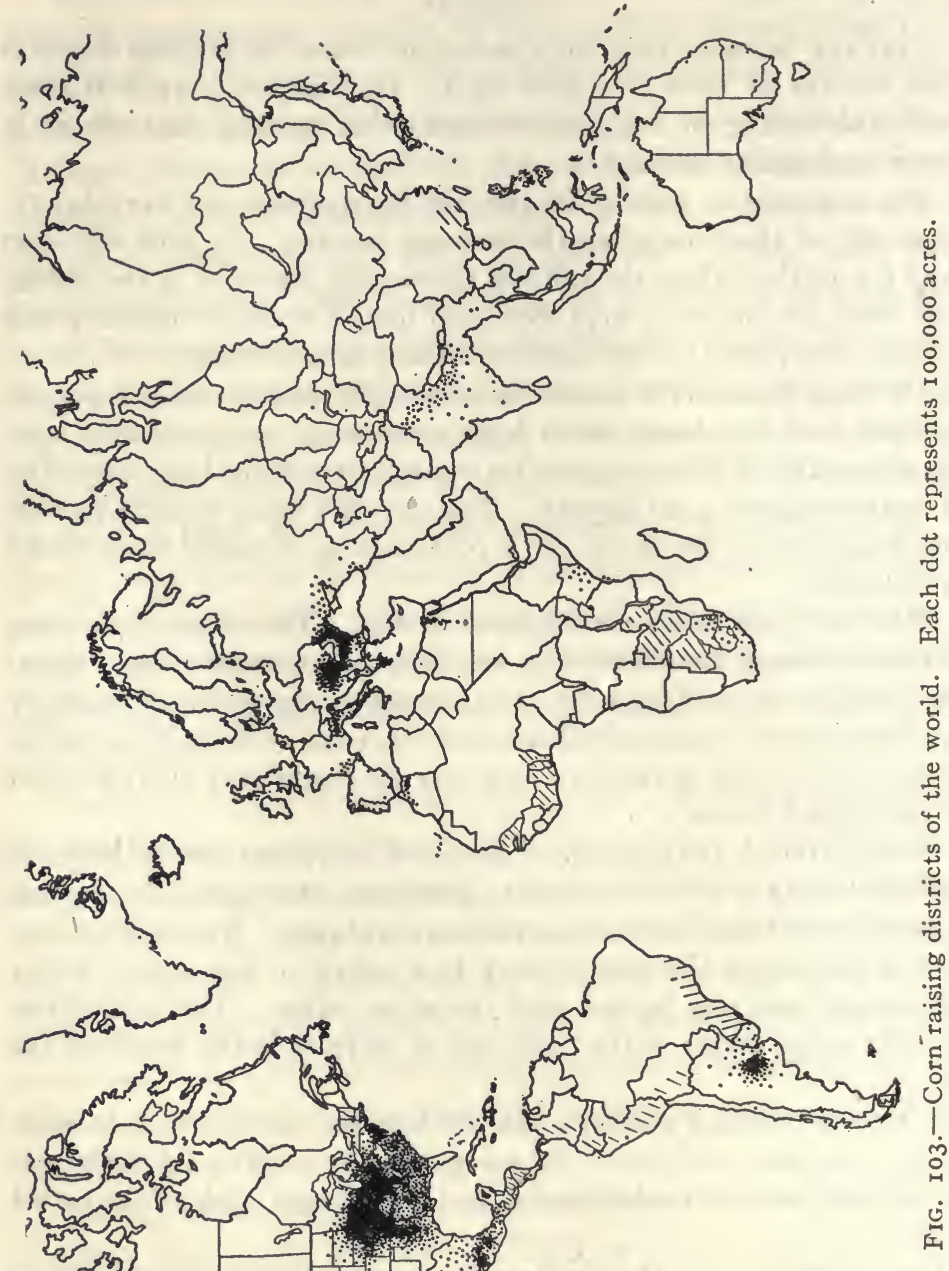


Indian legend of the origin of maize as told in Hiawatha. Tell something of corn in connection with the history of the early settlements in this country.

3. Name seven of the greatest corn-raising states of the United States. What portion of the world's supply of corn (maize) does the United States produce? Where are the corn-raising districts of the world? Why do such limitations upon its production exist?

4. At what season of growth is considerable rainfall indispensable to the corn crop? What is true of the amount of sunshine (clear days) required by corn as a crop?

5. What kind of soil, and what kind of land surface, favor the raising of corn on an extensive scale?

6. Which portion of the kernel is relatively rich in starch?

7. What is $(a)$ hasty pudding; $(b)$ hominy; $(c)$ corn syrup; $(d)$ grape sugar?

8. Name several of the forms in which corn is put on the market as a food. Discuss the manner of preparation of some one of the "breakfast foods" made from corn.

9. What is denatured alcohol? Why is it denatured? What are some of its uses?

10. Describe a scheme for testing seed corn as taken from the ear. Why not use corn which has been long shelled for seed? What per cent should germinate before it is considered good enough to plant? Why test corn at all?

11. What is kaffir corn? How is it unlike maize?

\section{Apple Raising as an Industry}

When at a fruit stand one purchases an apple to eat or orders home from the grocery a bushel of apples for family use, there is occasion to wonder why this product of farm and orchard in a large part of the United States should be so expensive as compared with the cost of tropical and semitropical fruits shipped in from more distant regions. In the earlier history of this country apples were available in most homes for generous use, oftentimes the year around. There was apple sauce and baked apples for the table, together with apple pies and apple puddings. From bins and barrels in cellar and cave there were apples to eat at all times in accordance with one's choice in flavor and in quality. The apple in some one or more of its many uses as food formed an important item of diet. 


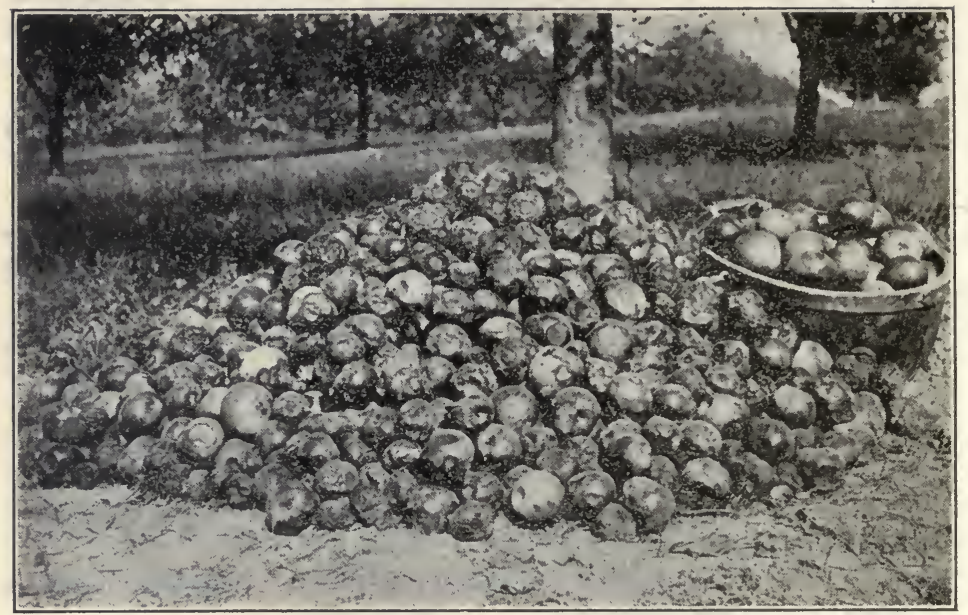

FIG. I04.-Apples from a tree unsprayed. Only those in the basket are marketable.

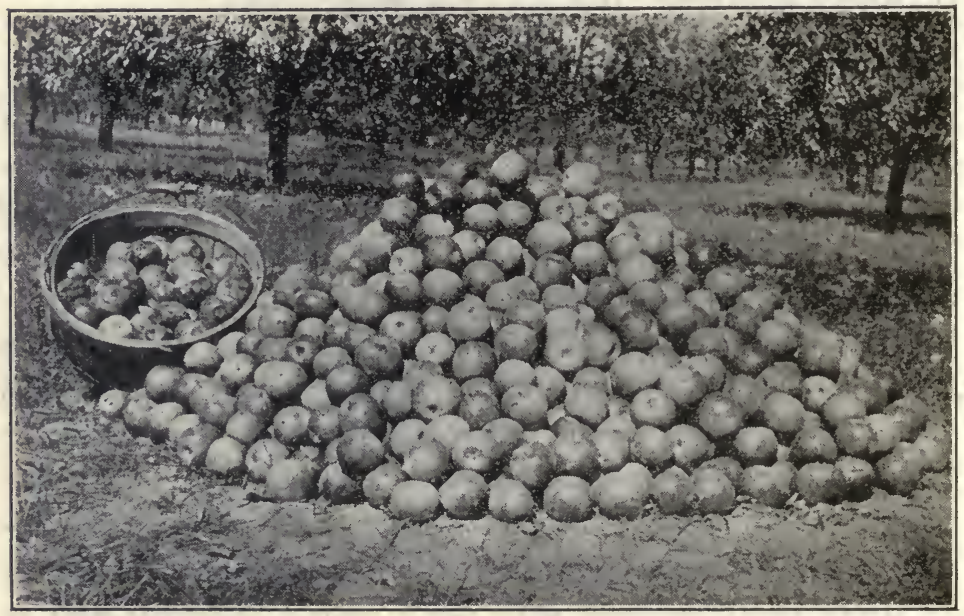

FIG. 105.-Apples from a tree sprayed. Those not marketable are in the basket. 
By reason of the codling moth, whose larvce (lär'-vē) are the "worms" found in apples, the production of marketable apples without the labor and expense of spraying

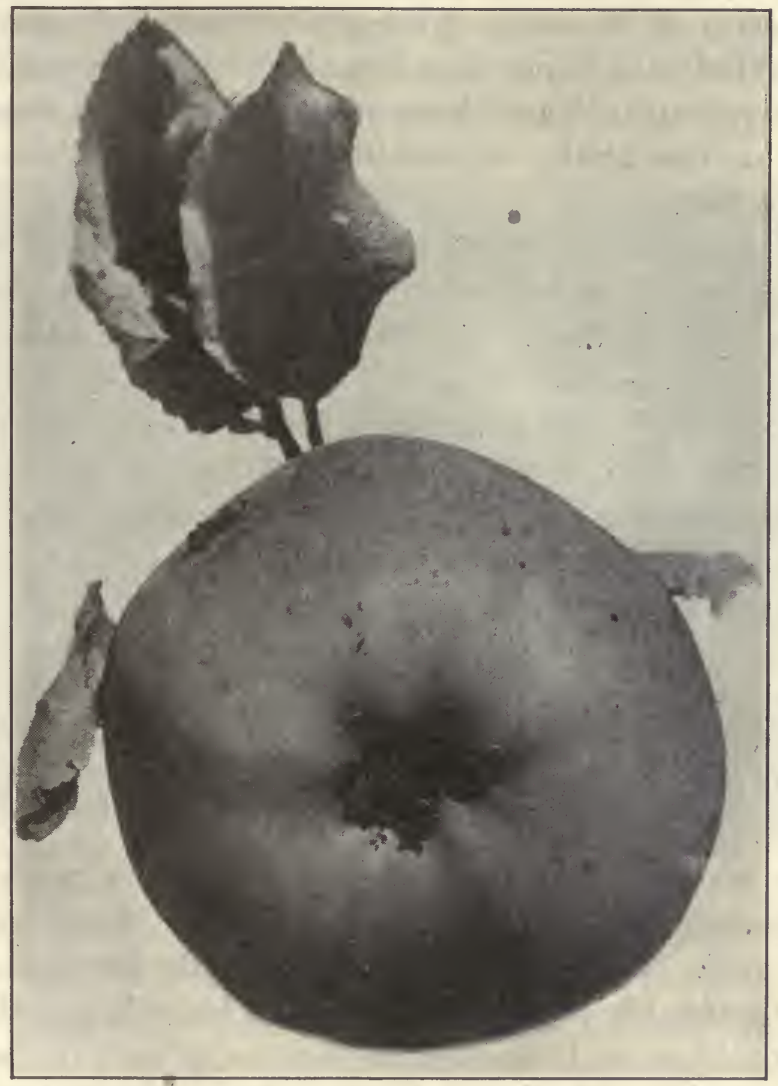

FIG. ro6.-Work of the codling moth.

the trees several times in a season is almost impossible. This insect pest is an importation from the apple-growing districts of Europe, and its advent has caused the loss of millions of dollars annually in the apple crop of the country. 
Many of the old time orchards have been allowed to go to destruction, given over to the ravages of worms and to such diseases as the fungus growth called "apple scab." Formerly every home had its apple trees about the house, and every farm its orchard. Now apple raising is a highly specialized industry employing a large investment of capital and expensive outfits in machinery and appliances. It demands much business ability successfully to finance, raise, and market the crop.

The agricultural colleges of the country have done much in their courses in horticulture to make possible the success that to-day attends the effort to supply again to the American people an abundance of apples as a most wholesome and appetizing fruit. To fight successfully the insect pests that attack the crops of the farmer, and the various parasitic growths like the apple scab, the rust on wheat and oats, and a long list of bacterial diseases, there has been rapidly developed the need of a scientific education in agriculture as an occupation. Biological and physical sciences as applied in agriculture are an indispensable preparation for successful farming. Instruction once gained only through experience on the home farm is now given as courses in college.

The material used as a spray for the codling moth commonly contains some compound of arsenic. Paris green is often used. The purpose is to coat both the leaves. and the fruit (preferably just after it has been formed, and shortly after the blossoms have fallen) with a fine spray of the poisonous material. The larvæ hatched from eggs laid by the moth in the early spring are killed by feeding upon the foliage and fruit. "Lime when slaked is a fine white powder, and when mixed with the water containing the Paris green and applied to the foliage in the spray, shows by its whitening effect just how evenly and completely the application has 
been carried out. Any material for the purpose of destroying insect life on plants is known as an insecticide.

. "Bordeaux mixture," containing copper sulphate along with some lime in the water, is used as a spray for the purpose of destroying fungus growths. It is a fungicide. To apply these sprays in the form of a fine mist that shall completely cover the foliage, twigs, and young fruit, requires

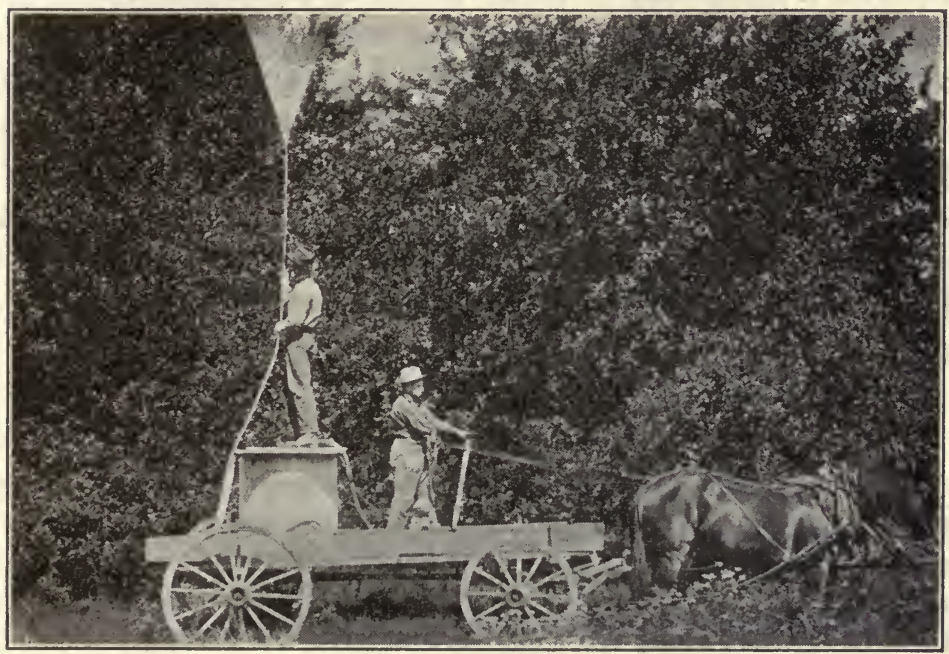

FIG. 107.- Spraying the trees. An outfit suitable for a small orchard.

a force pump operated at a pressure of one hundred pounds or more. The expense of equipment, and the amount of labor required to keep apple trees healthy and their fruit fit for use when grown, is a serious handicap in fruit growing on a small scale.

To the botanist the group of plants known as the fungi is of the greatest interest. They have in them no chlorophyll for the manufacture of food for themselves. They live and thrive upon what they appropriate from other plants or from animals. The yeast plant is a fungus, and 
so are the moulds that grow upon foodstuffs, and the rusts and mildews that are so destructive of grain crops. They are parasites (see page 40), and are the cause of losses in agriculture estimated at hundreds of millions of dollars annually.

Bacteria form a class of plants closely related to the fungi. In man's struggle for existence the microscope has made possible a knowledge of these hidden agencies which have so long worked havoc with his food supply, with his health, and with life itself. In the field of agriculture science has scored some of its greatest triumphs. Intelligent as well as persistent efforts are necessary in order to be assured of success in a never ending warfare against insects and plant diseases. It must not be forgotten that in this warfare the birds are man's friends, and an active agency in the destruction of insects.

\section{SUMMARY}

It is an easy matter to buy and set out apple trees, and to get them to grow till large enough to bear. But there is occasion to wonder why the apples growing upon them are so poor oftentimes, and the trees so short lived. It is only by persistent efforts that the destruction wrought by the codling moth can be combated successfully. Various fungus growths sap the strength of the trees, and finally kill them.

To spray successfully trees with large tops, using the poisonous compounds either as a liquid or as dust, requires a powerful force pump, or a compressed air outfit. To move the equipment and the materials used from tree to tree through an orchard, and to furnish the necessary labor for several applications every season, involves much expense. But it is only by spraying that the trees and their fruit can be saved.

The fungi are a class of plants wholly destitute of chlorophyll, and therefore utterly unable to prepare food for themselves from the raw materials of sap water from the ground and carbon dioxide from the air. As parasites the fungi thrive by living upon the food prepared by other plants that do have chlorophyll, thus robbing those other plants and possibly in time starving them to death. The annual losses in the agricultural productions of this country from fungus growths on 
various fruits ${ }^{-}$and cereals are estimated at hundreds of millions of dollars.

Oranges, lemons, and other like fruits, have rinds that protect them from the bacteria which cause decay. But the skin on apples is thin and easily broken. In spite of a wax-like covering that in some apples is quite noticeable, not only does water escape through the skin so that the apple shrivels, but bacteria penetrate it and cause rot. When apples have been carefully selected and handled, wrapping them separately in paper lessens the likelihood of their decay.

\section{WheAT AND Wheat GROWING}

So common has been the use of wheat flour in the United States that it is difficult to readjust the manner of living when compelled to do without it either wholly or in part. So widely distributed geographically are the wheat-growing regions of the earth, and such is the range of climatic conditions under which different varieties of wheat may be grown profitably, that a world-wide crop failure is unlikely. But it is quite possible under normal conditions that the world's demand for wheat may increase more rapidly than any increase in its production, resulting in a rise in its price, and of the flour made from it, until the cost of wheat bread is prohibitive for many.

Better methods of wheat culture may increase the average yield per acre materially through better tillage, and more careful selection of seed. It is possible that large areas of land now considered unfit for wheat growing, especially in the semi-arid regions, may be brought into use with newly propagated varieties of wheat suited to these unusual climatic conditions. It is possible that scientific farming may secure increased fertility of soils in spite of repeated croppings with wheat. Any gains of this nature are, however, likely to be slow. They can only serve to delay the coming of the time when wheat bread with butter or with 

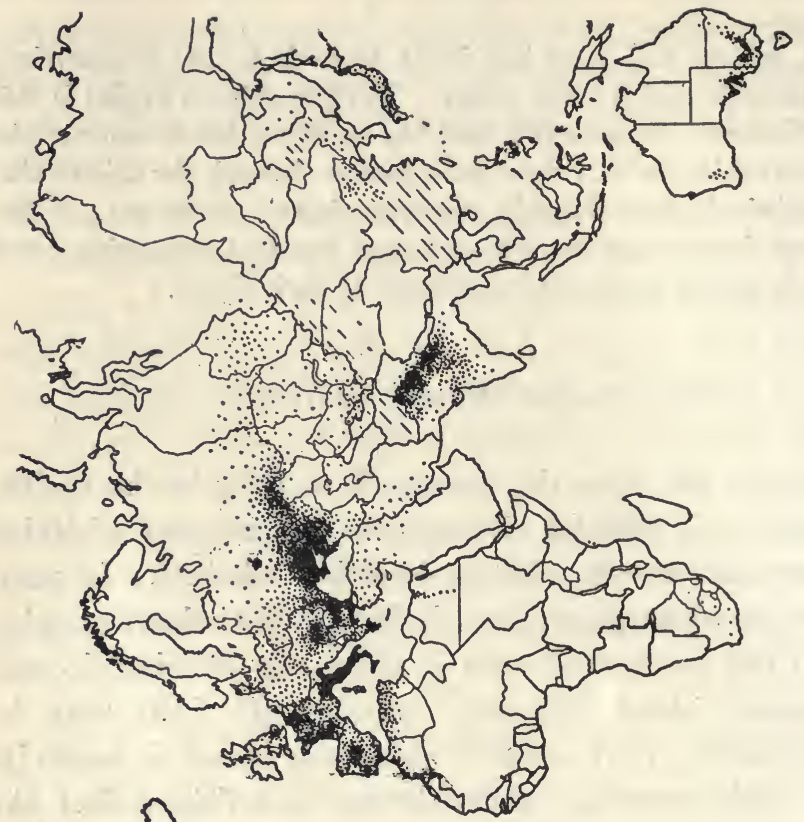

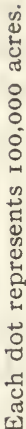
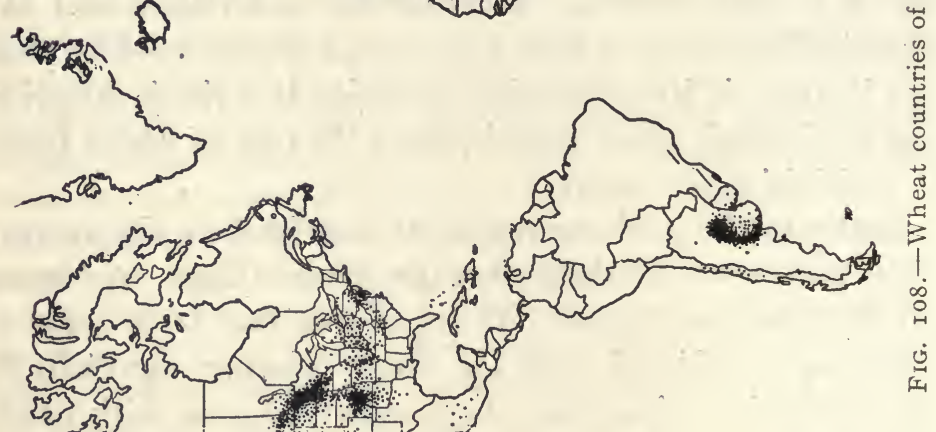
milk shall no longer serve as a simple and well-balanced food supply, inexpensive enough to come within the means of every one who is willing to work.

With the development immediately following the Civil War of the trans-Mississippi region, and then later of the great Canadian Northwest, together with the use of the wheat lands of Australia and of Argentina in South America, the wheat supply of the world increased much faster annually than did the wheat-eating population of the world. But there are no longer any such extensive areas of fertile soils waiting the plow to convert them into wheat lands ready for the seeding.

During all this period of relatively cheap wheat and flour it is estimated that one-third of the earth's population has subsisted chiefly upon rice as a cheaper grain. It is owing in part, also, to the large use of machinery to plow, to reap and bind, to thresh and market the grain economically, so far as labor is concerned, that the prices have been maintained at so low a level. With farm lands increasing in value, and with a higher price for labor in the wheatgrowing districts, there is an increased cost of production.

The need of labor is very great at the harvest seasons. At other times a relatively few men with modern outfits of farm machinery can give the necessary care to the largest wheat farms. This condition does not operate to distribute the population of the country, nor to make easy the problem of bringing together the work that needs to be done in agricultural districts and the men who are' seeking work. Where wheat raising can be carried on with corn growing, and with other and diversified farm interests, the requirements for labor are better distributed throughout the year, and employment is given to more persons the year around.

The large per cent of gluten in wheat gives it a food value 
far in excess of corn or rice. Gluten is a protein food of great worth for tissue building. It is the gluten, too, that gives to flour when mixed with water the peculiar consistency that makes possible its being "raised" into the familiar forms seen in loaves of bread and cake. When once raised, and then subjected to sufficient heat in the process of baking, the loaf retains its shape by reason of the hardening of the gluten. The wheat kernel is rich, too, in those mineral constituents which build up the bones of the human body. These compounds, to become available for bone building, must be dissolved. Other grains less extensively grown than wheat, such as oats and rye, are also rich in gluten and in mineral content. Rice is almost wholly a starch food, and as such lacks in tissue-building value.

In the milling process it is possible largely to eliminate the gluten. The flour is somewhat whiter in appearance and makes whiter bread, but it has less of food value. The bone-building value is likely to be deficient in these white flours. From the big flour mills, such as those in Minneapolis, flour is shipped to all parts of the world. The daily output of one mill may be thousands of sacks. The outer part of the kernel as separated from the pulp is sold as feed for farm animals under the name of bran. The mill product known as "shorts" contains much of the bran along with considerable of adhering starchy portions. Dairymen in the past have bought and fed to their cows large quantities of both bran and shorts. Under stress of war conditions much of these parts of the wheat are retained in the flour and other wheat products for human consumption. The oldtime grist-mill has largely disappeared from rural communities where it was found in the earlier days. In the great wheat districts the crop is loaded from elevators into cars, and railway transportation enters into the problem of feeding the millions who use wheat. 


\section{SuMmary}

The leaves of the wheat plant like those of corn are lance-shaped and parallel veined, and at their base form a sheath about the stem. The roots, too, are fibrous as in corn, but the stems are hollow rather than filled with pith. The general characteristics are such as to class the wheat plant among the grasses. The same is true of the cereals generally. The hollow stem of the grains gives a maximum of strength for the amount of material necessarily provided by the plant in the growth of the straw.

An increase in the wheat-growing areas of the world through development of varieties of wheat suited to regions where it cannot now be grown successfully; an increase in the yield per acre of the varieties now

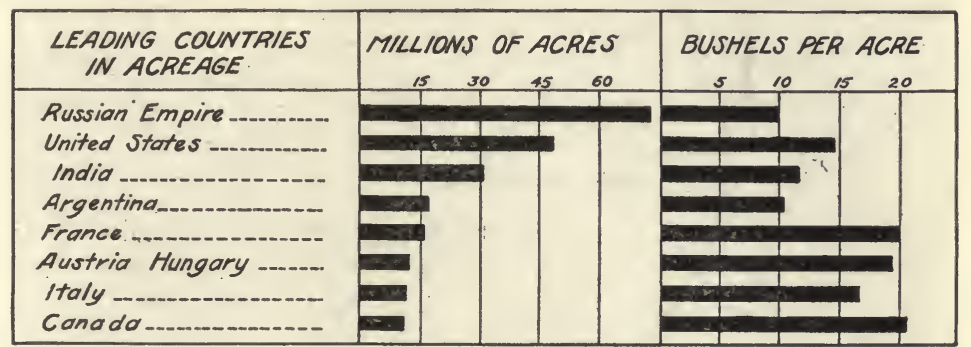

FIG. I09.- Wheat production of various countries, and bushels per acre. In 1916 the world production was $3,823,667,000$ bushels. (U.S. Deparlment of Agriculture.)

raised; and the maintenance unimpaired of the fertility of wheatgrowing soils, are problems of the greatest importance in feeding the world's population now and in the future.

While other cereals such as rice and corn are rich in starch, the large content of protein in the gluten of wheat makes all the wheat foods especially valuable as body builders.

On the great wheat farms of the United States and in Canada so much of the labor of raising the crop is done by machinery that the demand for labor is small except at harvest. At that time the crop must be gathered within a few days' time to prevent loss. Not infrequently harvesting goes on during moonlit nights. The extra help needed during the harvest must at other times of the year find employment elsewhere. Diversified farming on the other hand provides employment for laborers the year around. 


\section{Exercises}

1. Name the chief wheat-growing states of this country. In what parts of the United States is wheat not largely grown? What apparent reasons for this difference in crop interests? Compare conditions for corn and wheat raising as to $(a)$ climate; $(b)$ character of soil.

2. Name in order of production the wheat-growing countries of the world.

3. Why is it that wheat is not grown more extensively? What possible substitutes are there for wheat in the feeding of people?

4. What are the earliest records of wheat raising? When was wheat introduced into this country?

5. Name several kinds of breakfast foods wholly or largely made of wheat.

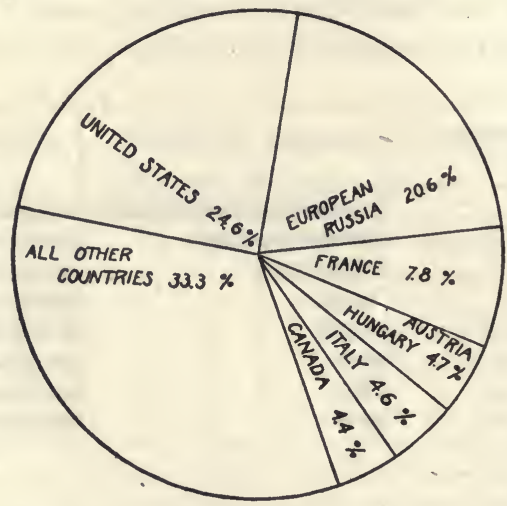

FIG. II .-Percentage of the wheat crop of the world (I9I5) grown in different countries. (Robbins.)

6. What period of time under favorable circumstances is required for the germination of wheat?

7. Upon what does the market price of wheat largely depend aside from the cost of production?

8. At what times in the year does the wheat crop require most labor? What attention is given it at other times? How does the labor required compare with that bestowed upon a corn crop? What labor conditions necessarily exist in wheat-growing sections?

9. What variety of wheat is most largely grown in your section of country? Name some other varieties. Give their respective merits, and any special conditions necessary to their growth. What is meant by "hybridization" in plant growth?

10. Describe in detail $(a)$ the preparation of land for wheat raising; $(b)$ the methods of seeding; $(c)$ any cultivation or other care of the crop till harvest; $(d)$ the harvesting of the wheat. 
11. What were the early methods of wheat harvesting? What has been the effect of harvesting machinery $(a)$ on the labor required to raise wheat; $(b)$ on the cost per bushel?

12. How much wheat is used per acre as seed? How deep is it put into the ground? When is wheat fit for harvesting?

13. Describe early methods of threshing? What advantages are there from threshing in the field immediately after harvest? In what sections only can this practice be followed? What are several purposes in stacking wheat or in housing it in barns before threshing? What is the "chaff" when wheat is threshed?

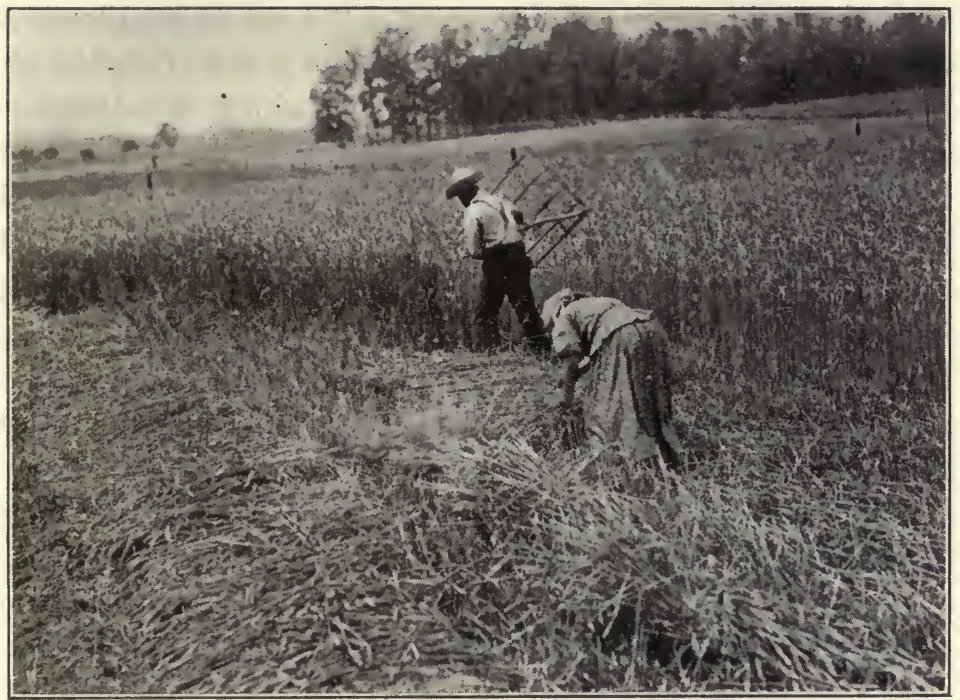

FIG. IIr.-Cutting and binding wheat in the old way.

14. What is the range in yield of wheat per acre in the United States? At eighty cents per bushel, what value is represented in the 900 million bushels of the r9r4 wheat crop? Allowing six bushels per person for home consumption in the United States, what was the excess for export?

15. Describe the various steps in making wheat flour. What is meant by the "bolting" of flour?

16. In milling wheat, about what per cent is separated as bran? How does bran differ from shorts? What is "whole wheat flour," and how does it differ from graham flour? What is "self-raising" flour? 
17. Of what nature is the "rust" on wheat? What harm results from it? What is meant by parasitic plants? What course may be pursued to save wheat from rust? What treatment of seed wheat may be employed to lessen "smut?"

\section{Origin AND Nature of SoILS}

To the careless and indifferent mind the term soil may have little significance. As dust it gets into our eyes, and it makes the life of the house-keeper a burden. As mud it clings to one's shoes, and it makes travel and transportation by highways both irksome and expensive. To the botanist, however, soil is the source whence the higher types of plants get their food material in large part, and in which the mightiest oak and the tiniest violet alike find root. To the zoologist it is the abode of innumerable forms of animal life. To the farmer engaged in raising crops the depth, the texture, and the chemical nature of the soil tilled by him is of utmost importance. He must have knowledge of the kind of crops likely to be most productive. He must learn ways of conserving the fertility of the soil, and of managing it most profitably. Courses in agricultural colleges involving a study of the origin of soils, their waste and restoration, their characteristics and management, and the effect upon soil structure of plant and animal life, require a knowledge of Chemistry, Geology, Physical Geography, and Physics.

In an attempt to classify and name soils, no mere description can take the place of actually handling some well-chosen types, and of learning through first-hand acquaintance to recognize and name all local varieties of soil. Very largely soils may be described by making combinations of the terms gravel, sand, clay, and loam, along with descriptive adjectives advisedly chosen, e.g., a light sandy loam, a stiff clay soil. Silt is composed almost exclusively of very fine particles of earthly material such as the sediment from running waters when their current is checked. When dry it crumbles read- 
ily. Clay consists largely of yet finer particles that rub between the fingers when dry much as does flour, and when wet form a soft plastic mass which hardens into lumps on becoming dry. A loam is characterized by no particular size of particles, but is loose and friable even when quite wet.

Running water as an agent in erosion has been discussed in a preceding lesson. It is to be noted here, however, that in the transportation of eroded soils there is accomplished a sorting of material according to fineness which results in beds of sand in some places, a mud deposit as silt in another, and clay banks elsewhere. From an agricultural point of view this sorting is an unfortunate one when these lands come under cultivation. It is one of the problems of scientific farming to know how best to modify any particular soil by the addition at least possible outlay in time, labor, and capital of those materials which improve its fertility, structure, and conditions for tillage.

Any sample of soil gathered from field, garden, or roadside commonly has in it vegetable matter in different stages of decay. This may be burned out by keeping a weighed sample of the soil at a red heat for some time in an open iron or porcelain dish. Any loss of weight due to this treatment of a thoroughly dry soil represents the amount of organic matter of both animal and vegetable nature that was in it. The very large per cent of the soil sample remaining is the mineral portion. Rock material in a finely divided state constitutes very largely the "soil" in which plants root themselves. From it they obtain the water and all other food material necessary to their life and growth except carbon dioxide.

Soils have been formed by disintegration of the rocky crust of the earth, a process that has been going on for all the ages. When their fertility (crop productiveness) has once been wasted it is restored naturally only after long periods. The 
nature of these soils, aside from the organic matter in them and the material in the rock originally, also depends upon the chemical changes that may have accompanied or followed the disintegration of the rocks.

Water is perhaps the chief agent by means of which the rocks have been broken down and reduced to a finely divided

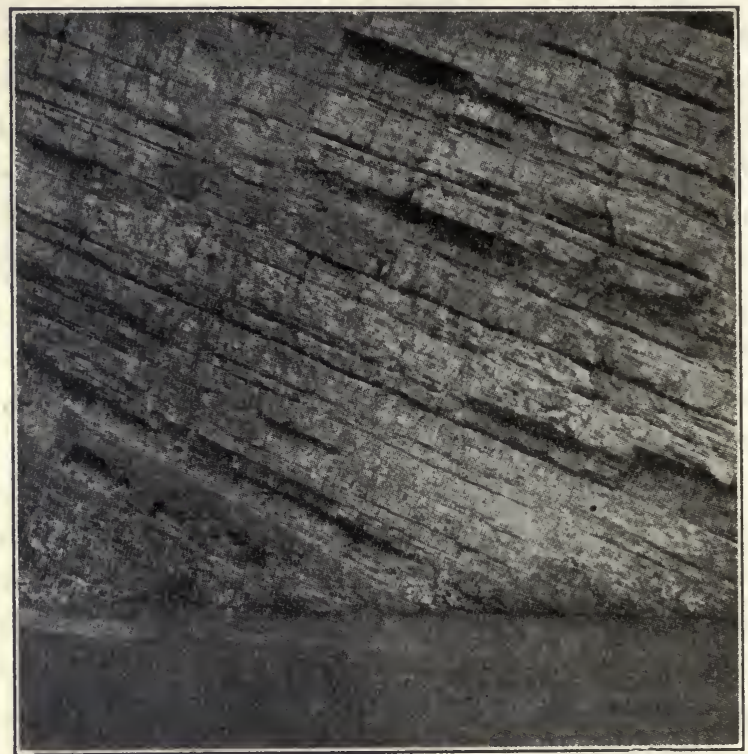

FIG. II2.-Stratified rock, the origin of which dates back to a time when the material in it was deposited as a sediment in layers originally horizontal.

condition. By its freezing and thawing, by its solvent action and its powers of erosion when in motion, even the hardest of rocks are slowly worn away.

Rocks exposed to the direct rays of the sun on mountain sides are subject to rapid expansion and contraction of their surface layers due to daily temperature changes. As they crumble the fragments are blown away, or are washed down the slopes. Carbon dioxide gas in solution, and waters 
strongly alkaline, have rapid solvent action upon certain rock materials, accompanied by chemical changes that contribute to their reduction. Decaying vegetation in the soil yields acids, and these acting on the rock material aid in bringing about its disintegration.

The rock known as granite contains among other constituents the minerals feldspar and quartz each of which has a definite chemical composition. The feldspar when it is exposed to the action of the atmosphere slowly disintegrates, giving rise to clay. The quartz particles as sand grains may remain mixed with the clay to form loam, or may be separated from it by running water and both deposited in beds separately as sand and clay. Vast areas of soil often of great depths have been transported by the action of streams and laid down where we find them. In these soils sometimes clay predominates, and sometimes sand.

\section{SUMMARY}

Rocks are a mixture of various chemical compounds such as quartz, feldspar, hornblende, gypsum, and "limestone". The rock constituents of definite chemical composition are called minerals.

It may be supposed that originally the earth's land surface was composed of rock only. By reason of expansion and contraction due to temperature changes, by the expansion of water in the rock crevices when it froze, by the chemical action of carbon dioxide in the air combined with water as carbonic acid $\left(\mathrm{H}_{2} \mathrm{CO}_{3}\right)$, and by various other agencies, this rock crust became broken and pulverized giving rise to soils.

So long as it remained in place this soil covering protected the rock below from further weathering. Running water, however, transported this broken rock material elsewhere, and deposited it in enormous quantity and to varying depths as sand, clay, and loam.

Mixed with the earthy material of the soil is more or less of vegetable material in all stages of decay. And in and through it, especially the surface layers, are varied forms of animal and plant life so that instead of being dead inert material the soil commonly may be considered as teeming with life. 


\section{PHENOMENA OF LIGHT}

\section{SHADOWS AND ECLIPSES}

The illumination in front of the headlight of a locomotive or of an automobile, or one caused by some powerful searchlight, is a familiar sight. The effect is the more startling when the air is filled with minute water particles at times of a fog, or when there is much fine dust or smoke in the air. If into the space thus strongly lit up a large opaque body enters, there will be a region of shadow extending outward from the body and away from the source of illumination. This shadow is the space from which the light is cut off by reason of the opaque body. A cross-section of this shadow region gives a form or outline like that of the body. If a screen is placed outward beyond the opaque body to receive the shadow form (cross-section), and it is moved further and further outward, it will be found that when the opaque body is larger than the light-giving body the shadow reaches outward indefinitely far. The area of its cross-section increases all the time. If the opaque body is smaller than the light-giving body, the cross-section grows smaller and smaller, and the umbra of the shadow has a definite end.

The astronomer thinks of a body belonging to the solar system, and receiving its light from the sun, as at all times having on the side opposite the sun a shadow region projected outward into space. The shadow of any planet always accompanies it in its course around the sun, as does the shadow of any satellite in its course around a planet. To the astronomer an eclipse of the moon is simply the passage of the moon into the shadow of the earth. In 
the somewhat indefinite but distinctly circular outline of this shadow he sees confirmation of his belief that the form of the earth is spherical. A so-called "solar" eclipse is to him the result of the moon coming between the observer and the sun. The shadow of the moon overspreads him as an observer, and it is really a case of an eclipse of the observer. It would be so called by observers elsewhere than on the earth itself. In those somewhat infrequent occurrences where the moon comes directly in line between sun and earth, the astronomer is given a very few minutes of time when the sun's disc may be completely covered by the moon. He then has an opportunity to observe through the telescope the phenomena of the sun's atmosphere as it extends far out into regions not hidden by the moon. By aid of the telescope it is possible to get photographs of these appearances. The description of what is seen at these times of a total eclipse of the sun, and the interpretation of this as given in texts on astronomy, makes fascinating reading. Some knowledge of the beliefs of astronomers concerning the universe, and of the basis for such beliefs, should be included in the schooling of all persons.

It was from a study of the times of disappearance of one of the moons of Jupiter which suffers eclipse every few days, and from his interpretation of what these signified, that Roemer calculated the velocity of light as about I86,000 miles per second. So exact are the calculations of astronomers, and so regular are the movements of the heavenly bodies, that it is possible to state (from calculations) the time of occurrence of any eclipse in the past or in the future, its duration, and where visible. The astronomer deals with distances and periods of time too great to be comprehended readily. But so exact are his measurements, and the calculations based upon them, that any slight departure of his observations from calculated results leads to 
search for some unknown cause of the variation. Neptune, one of the eight planets of the family of the sun to which our earth belongs, was located (discovered) by astronomical calculations. The telescope verified its existence when the instrument was directed toward that part of the heavens where the hitherto unknown planet had been mathematically located.

\section{SUMMARY}

A shadow is the space from which light is more or less completely shut off by an opaque body. It extends outward from the body on the side opposite the illumination. The forms seen on screens and walls, and commonly called shadows, are cross-sections of the shadow region.

An eclipse is a phenomenon where an illuminated body darkens or completely disappears by reason of its entering the shadow of another body. An eclipse of the moon occurs when by reason of its revolution it comes into the shadow of the earth. Astronomers can calculate the times of occurrence of eclipses with the greatest accuracy.

The outer portion of the sun is an atmosphere of gases and vapors thousands of miles deep, and this atmosphere is so highly heated as to be luminous. From this "solar atmosphere" light and heat come to the earth. In it are found in gaseous form nearly all known chemical elements.

The existence of non-luminous bodies far out in space, and wholly invisible because they are non-luminous, is made known to astronomers by the effect they have upon the motions of bodies which can be seen. Where the actual position or path of motion of a luminous body differs materially from its calculated place, astronomers feel justified in asserting the existence of one or more invisible bodies whose pull of gravitation occasions the change in position or in motion.

\section{Images by Reflection in Plane Mirrors}

For a satisfactory understanding of the common phenomena of image formation in plane mirrors such as lookingglasses, a knowledge of the theory of light as taught in Physics is required. Whatever light may be (page 344 ), it is very 
evident that the mirror has served to change its course, and to reflect it (throw it back) into the eye where the optic nerve is affected and sight as a sensation results. Studies in Physiology and Psychology as well as Physics have to do with what occurs after light enters the eye, but it is the study of light before it enters the eye that concerns us here.

It is evident that the location of the image in a plane mirror is determined by the light direction after reflection. The image as an apparent reproduction of the object is found to be located back along the lines of light that have come from the mirror into the eye. No matter to how many different eyes (people) this reflected light from the mirror comes, it appears to originate in an image of the real object that has the same position behind the mirror for all observers. To draw straight lines from the eyes of all observers back through the mirror to any single point in that image means that the light which originated at the corresponding point of the object, must have

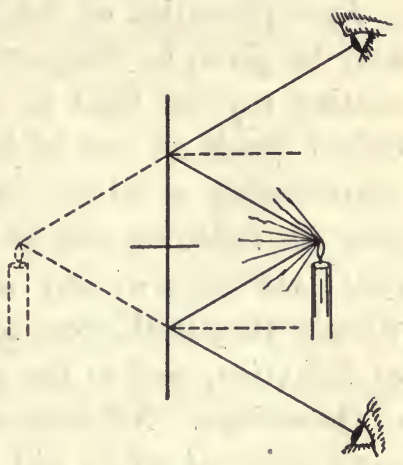

FIG. II3.-An image of any point as seen in a plane mirror has the same location for all observers. Object and image are equidistant from the mirror surface, and corresponding points in both are in the same perpendicular (normal) to that surface.

been incident upon all parts of the mirror surface. In this way only could it be reflected to all observers so that the image of the point is at one and the same place for all.

The complexity of this conception is much simplified by conceiving that from every point in either a luminous body, or of one illuminated (shining by reflected light), there is sent off a continuous series of every expanding light waves whose form is that of hollow concentric spherical shells. Now to represent the directions in which such waves are sent out, 
lines can be drawn outward in all directions from the point of origin as a center. There will be as many of them as there are radii (rā'-d̆́-i $)$ from the center of any sphere-an innumerable number. Wherever any one of these lines comes to the surface of the mirror, at that point there is a change of direction. The incident line of light then becomes a line of reflected light. These reflected rays, then, are as many as there are points in the reflecting surface.

An explanation of this location of images in plane mirrors may be given by diagrams. Let any two radial lines representing rays of light be drawn from the same point of an object (such as one of its extremities) to points on a line representing a mirror surface ${ }^{1}$. These rays or directions after the reflection will still be diverging lines. If they both enter the eyes of any one observer, the apparent source whence they both seem to come will be back along both lines of reflection, and at the point of the apparent intersection of these lines. All observers getting reflected light from this same point of origin will locate in like manner all images of it at the same image point. An image of the opposite extremity of the same object as a source of light is fixed in the same way. So are all intermediate points. Any observer getting at least two rays of light from every point on the side of the body toward the mirror will locate in the same way the image of every one of these points. These image points will have the same order of arrangement with reference to one another as was true for the points whence the light originated. For diagrams in the class room the images of the two extremities of an object only are located, and the parts between are filled in without construction work.

With polished surfaces it is believed that the effect of the mirror is simply to change the direction of "the lines or rays of light at the mirror surface, their directions relative to one

1 Preferable these points should be close together. 
another remaining the same. But when light falls upon unpolished surfaces, the reflection is of such a character that the reflected rays no longer maintain the same relative directions to one another. They are so scattered in their relative directions as to make image formation as discussed above impossible. Reflection of this sort is called diffusion. It is to diffused light that we owe the freedom from images in all smooth surfaces by which we are surrounded, and the evenness in distribution of light within our rooms and out of doors.
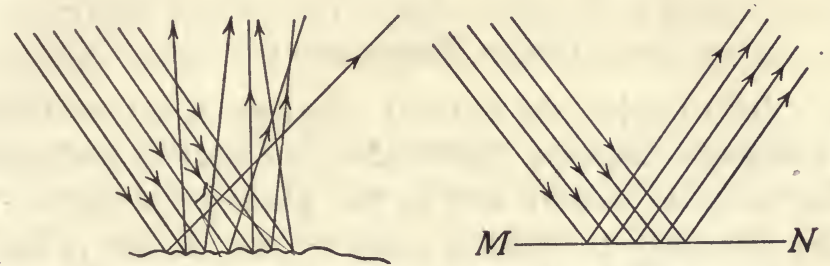

FIG. I I 4. -Diffusion of light is scattered irregular reflection owing to roughness of the reflecting surface. (Tower, Smith \& Turton.)

\section{SUMMARY}

In reflection of light the ether waves are thrown back from the reflecting surface into the same medium whence they came. But a change in their direction due to their passage obliquely from one medium into another of different density is known as refraction.

An image is an apparent reproduction of an object. This appearance is due to the fact that the light which originally comes from the object itself enters the eye in a direction such that it seems to originate in the image position.

The image of any point of an object is at the place of intersection of two or more lines of light from that point after they have been reflected or refracted. This intersection is often apparent rather than real as in case of images in plane mirrors. All these image points have the same relative position to one another as do the corresponding points in the object, thus reproducing the object so far as form and general appearance goes.

Where light is reflected from surfaces not sufficiently smooth, the relative directions of the light rays is not the same after reflection as 
before. This phenomenon is known as diffusion, or diffused reflection. No images are formed as result of it.

Some of these image positions are such that a screen placed there will show the image upon it. One could lay hold of the image by grasping it in the hand if it were only something tangible. Such images are said to be real. . Virtual images are those where this is impossible, their positions being apparent and not real. The light does not even get where the virtual image seems to be.

In plane mirrors the virtual image of an object is so located that every point in the image is as far back of the reflecting surface as the corresponding point of the object is in front of it, and a line connecting these two points forms a right angle with the mirror surface.

\section{Color Phenomena}

In order to enjoy the natural colorings of sky and cloud and landscape, and the marvelous combinations and blendings of color in flowers and in the plumage of birds, it is neither necessary to make a study of Physics nor to understand the theories by which scientists explain color phenomena. One may become skilled as a painter of landscapes, of historic scenes, or of portraits; he may be a master in the art of dyeing, and produce the brilliancy and variety seen in the various fabrics, and at the same time know nothing of the scientific explanation of these color effects. But the explanations of the nature of light and color as given in Physics simplify what otherwise would remain an inexplicable and bewildering number of unrelated phenomena. The teachings of science concerning color phenomena is a good illustration of how advancement in learning by individuals and by mankind in general becomes possible through the efforts made by scientists to ascertain the nature and meaning of the various phenomena of life.

When a beam of sunlight is passed through a glass prism, and into a room from which all other light has been excluded, it is possible by a proper adjustment of the prism to get on a screen or a white wall a band of overlapping colors like 
those of the rainbow-the so-called solar spectrum. The screen or wall serves simply to intercept and throw the "colors" back into the eyes of observers. These colors were in the sunlight that passed through the prism, and they were changed from their straight line direction as they passed in to the glass and again still further as they emerged from it. This change in direction of the light is caused by change in density of medium. The color elements contained in sunlight are bent unequally, and they diverge more and more the farther the screen is away from the prism. This makes the spectrum longer and longer without completely separating the colors, or preventing their blending into one another.

If now in the path of the emergent ray a blue glass plate is held, it is the blue light of the spectrum only (or largely) that gets through the plate. The other colors are almost wholly absorbed by the coloring material in the glass. If a piece of common window glass is used all the colors pass through it, while with red glass nearly all the colors but red are stopped by the glass. When both blue and red plates are put in the emergent beam together, none of the colors appear on the screen. Each of the plates has absorbed the colored light which the other let pass. By choice of the proper pigments to go into glass, and by varying their proportions, beautiful color effects indoors may be obtained with windows by combining in varied patterns glass of different colors. We say that glass is blue or red or any other color according to the kind (color) of the light it transmits.

When only the blue light of the spectrum appears on the screen, and a sheet of paper (or any white object) is held in its path, the paper in a darkened room appears blue. But if a red screen be used instead of a white one, it looks black as result of absorption of the blue light. There is then lack 
of light to be reflected. If a red glass be used in the spectrum beam, any blue object upon which the red light falls will appear black, and a white body as a screen will look red in the red light which falling on the screen suffers reflection. Color in itself is just a light phenomenon due to the kind of light affecting the eye. Color as a property of bodies is determined by what color elements of any incident white light are reflected from it, and in what proportions. Thus it is that "selective absorption" accounts largely for the colors of objects round about us with all their wonderful variations. An object is said to be white when it reflects all the color elements of the white light incident upon it.

Light reflected from bluing left in cotton cloth, combined with the yellowish light reflected by the natural coloring material in the cotton fibre, causes when received into the eye quite the same color sensation as does sunlight when reflected from a white wall. It is an illustration of what is meant by "complementary colors."

The theory that light is wave motion in an ether medium explains color phenomena. The mathematical accuracy of the theory is very striking. Briefly, the theory for color is that the nerves of sight seem to be attuned to respond to certain very definite numbers of vibrations per second coming to them as "ether waves". The eye is able to distinguish more or less sharply between at least seven different sets of these vibration rates-the so-called spectrum colors. This is very much the same condition for the eye as that which enables the ear to distinguish vibration rates coming to it through the air or other material medium as the "tones" of music. The richness (quality) of any sound is increased by the blending of certain combinations of sound waves per second, making possible all the variations whereby we are enabled to distinguish the voices of our friends and acquaintances wherever heard. In like manner the blend- 
ing of ether waves of different frequency (number per second) gives rise to all color effects, however wide their range in beauty and character. The waves per second said to give rise to the colors of the spectrum from red at one end of the scale to violet at the other extreme, are numbers so great as to be incomprehensible. This does not in any way make the theory less tenable, or its mathematical relationships less sure. It has been mathematically demonstrated that when once the wave theory is accepted all these color positions in a spectrum follow naturally. Spectrum analysis in Physics, in Chemistry, in Astronomy, and in the arts and industries, with its arrangement of color lines in order of refrangibility, makes possible a knowledge of the chemical composition of highly heated bodies at distances as great as that of the sun. Even the stars, at distances enormously greater, reveal in their stellar spectra, something of their composition and of their motions.

The fact that the solar spectrum not only contains the different colors distinguishable by the eye, but that they blend imperceptibly into one another in order of wave frequency, suggests that in the sunlight there are all lengths of ether waves ${ }^{1}$. The prism serves to sort out and group those of the same or approximately the same frequency. Not only does light from different sources vary in the number of the color elements present, but it varies even more in the proportions in which these are blended.

When physicists make studies of the solar spectrum in a room from which all other light is excluded, they find that in the region beyond the violet end there is evidence of the existence of ether waves of greater frequency (shorter wavelength) than the violet. These waves are of too great fre-

${ }^{1}$ The lengths of the various ether waves causing color sensations is calculated by dividing the velocity of light (about $\mathrm{r} 86,000$ miles per second) by the number of waves per second for any color. 
quency for the eye to recognize. Photographic plates put out in this ultra-violet region, and kept wholly screened from any light (ether waves capable of affecting the eye), suffer much the same changes as when exposed to sunlight. In fact the best part of sunlight for photographic purposes is that of the violet end of the spectrum. It is said to be rich in actinic rays.

At the other end of the spectrum, and beyond the red of the spectrum sufficiently far to be in a region destitute of light, delicate thermal (heat) instruments detect the existence of long ether waves (waves of lesser frequency). These waves are incapable of affecting the eye to produce light sensations, but they are capable of heating effects. Not only are there ether waves recognized by us as heat and light, but there are electric waves propagated through space which are intimately related to the other wave motions. Perhaps the best illustration of this to-day is the transmission of electric signals through the ether medium in wireless telegraphy. There is suggested in all this the possibility that all the socalled "forces," or forms of energy, transmitted through space without dependence upon any material medium, are closely related to one another and to the ether as a medium of transmission. It suggests, too, the possibility of forces wholly unknown to man as yet, and perhaps never to become known by reason of lack of any means by which to comprehend them.

\section{SUMMARY}

Light is one of the forms of energy, and is capable of affecting the eye to cause sight or vision. Without eyesight knowledge of the existence of light would be impossible. At the same time light exists whether or not there be any eye to receive and take note of it. The study of light in Physics has little to do with sight as a sensation.

The accepted theory concerning the nature of light supposes the existence of a medium known as ether, and the transmission of the 
light energy as a series of waves in this medium. The number of these waves per second (the wave frequency) may so vary as to give rise to all manner of wave lengths entering the eye from a luminous body. The eye, however, responds to only a relatively narrow range of these ether impulses. It recognizes but seven different colors or color groups in the solar spectrum. There is no sharp line of separation of these colors from one another.

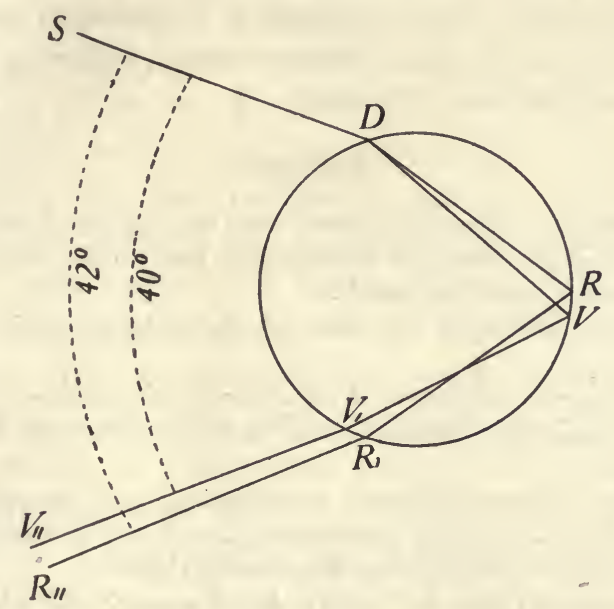

FIG. II 5.-Dispersion of light as it enters at $D$, and again as it leaves a falling raindrop at $V^{\prime} R^{\prime}$. The internal reflection of this light at $R V$ rather than its transmission through and beyond the falling drop makes possible a rainbow in the east when the sun is in the west in late afternoon. (Tower, Smith \& Turton.)

The great variety in colors coming from bodies results from the blending of different wave lengths in different proportions, giving rise to color sensations of a composite character.

It is quite possible that there are other forms of energy transmitted through the ether medium unrecognized by man because of a lack in his own body of any "receiving apparatus." Advances in science may, however, succeed in arresting and so transforming any such forms that their existence and nature will become apparent. Wireless telegraphy, and the use of the dynamo for the production of electric currents, are illustrations of the uses made by inventors of the discoveries of scientists. The discovery of "X-rays" and of radium, and the 
applications already made of these advances in scientific knowledge, suggest that much is yet to be learned about forms of radiant energy.

If objects reflected all the light incident upon them their colorings would be wholly dependent upon the kind of light that came to them. However, it is found that varied proportions of the different wave lengths are absorbed into bodies upon which they fall according to the material in the bodies. This phenomenon, known as selective absorption, results in color waves being reflected from a body that may be entirely unlike those which fell upon it. Color then in some cases actually does become a characteristic of bodies, indicating the presence in them of certain kinds of matter.

\section{Exercises}

1. In the formation of rainbows where must the dispersion occur? Explain how it is that the dispersed sunlight gets back to the observer from the part of the sky where the bow is.

2. Account for differences in color of the adjacent parts of petals of flowers.

3. Why are upper cloud masses of an advancing thunderstorm often silvery white in appearance, while the under surfaces of the same clouds may be inky black?

4. Distinguish between reflection, transmission, and absorption of light. Since ether waves may be transmitted through bodies, what must be true of the existence of an ether medium within them?

5. Why are heat and light said to be forms of energy? By what means are both supposed to be sent on (propagated) through space? Distinguish between sight and light. 


\section{THE EARTH AS A PLANET}

\section{DAy AND Night, AND the EARTh's Rotation}

It is not strange that the ancients believed the earth was the center around which the sun, moon, and stars revolved, or that from the time of Ptolemy (A. D. I00-I70) to Copernicus (1473-1543) it was taught that the earth was the centre of the universe. In these days we believe that the earth's rotation accounts for the daily round of the heavenly bodies as they rise, pass meridian, and set. But it is necessary to make a more or less conscious effort really to think in terms of the Copernican rather than of the Ptolemaic teaching. The very language we use tends to preserve the older views. We say that the sun sets, the moon rises, etc., and we fail to devise any better expression of our meaning. It is not wholly a misfortune, however, that so much of mental effort has to be made to distinguish between what is real and what is apparent in the phenomena occasioned by the earth's rotation. In the study of Astronomy there are ever recurring demands actually to "see" (to visualize) motions of celestial bodies in space that are similar to those of the earth. The development of an imagination based upon known realities, and of a power to grasp abstract mathematical notions, is of greatest educational importance.

If the earth as a spherical body were to become fixed in space (to stand still), then for an observer at any one place all objects above his horizon would remain in sight all the time, and objects below that horizon would always be hidden. In case the observer were to travel about, his horizon would change with the place of observation. New bodies would come into view as his horizon dipped below them in whatever 
direction he advanced, while others at the same time would be passing out of sight below the opposite horizon (the direction from which the observer is moving). If, on the other hand, an observer remains at the same location, and is carried round and round by reason of rotation of the earth, the same phenomena of the rising and setting of celestial bodies is experienced.

Why the rate of the earth's rotation is what it is must remain unknown. But this rate is uniform, and its period for one rotation is the natural time unit known as a day. The rate of rotation so far as known varies for the different planets, and their day periods differ somewhat from ours.

The whole of the earth's surface moves on together in its motion around the axis. Those portions at and near the equator, which have a much longer circumference to be carried through in the same time of rotation, must have a correspondingly greater eastward velocity. Near the poles the number of miles through which any position on the surface must be carried to make a completed round of motion is less, and the eastward velocity there of the earth's surface is relatively small.

Because of the earth's spherical form, as an observer travels northward his northern horizon dips lower and lower. The North Star, which at the equator is approximately upon the horizon, seems to rise higher and higher as he advances northward. Its altitude (distance above horizon) is for him all the time the same as his distance from the equator (his latitude). Both the altitude of the star, and the latitude of the observer, are expressed in degrees.

\section{Summary}

The rising and setting of the sun, moon, and stars is a direct result of the rotation of the earth. As the earth in its rotation carries us as observers around on its surface, our eastern horizon passes star after 
star in turn and moves on beyond them. This causes them to seem to rise and pass across the sky. In due time our western horizon passes them shutting them from our sight, and we say that they have "set."

In like manner the earth's rotation brings the sun above the horizon of an observer, causes it to pass across the sky, and then to disappear from view as the western horizon passes it. Thus day and night as periods in which the sun is above or below horizon follow each other in endless succession, and will continue to do so as long as the earth continues to rotate.

Places at the equator are carried eastward by the earth's rotation at the rate of over one thousand miles per hour. This velocity lessens toward the poles where it has a zero value. Directly related to these rotation rates are the directions of the great atmospheric and oceanic currents.

It is because of the rotation of the earth that we have a basis for use of the terms axis, poles, equator, and parallels of latitude in connection with earth studies.

\section{Rotation Combined with Revolution, AND Changes in Seasons}

It is difficult for one who lives in the middle latitudes to realize what is true of seasonal changes in the far north or in the Torrid Zone. Experiences gained through travel assist in comprehending them. .To understand the revolution of the earth about the sun, whether studied in Physical Geography or in Astronomy, requires more than mere reading about it. Long sustained observations of celestial phenomena as "studies of the sky" when intelligently pursued afford a good basis for such an understanding.

The lessened meridian altitude of the sun at noon-time, from June to December, and the consequent increase in obliquity of the sun's rays, is accompanied by lessened heating effects day by day. But the lowest temperatures of the season occur later than December because of the cumulative losses in solar heating. Accompanying these changes are shortened periods of sunshine (shorter "days"), intensifying 
the results of a lessened insolation and of the ever increasing losses of heat by reflection as the angle of obliquity increases.

The daily path of the sun rises continually higher in the heavens from December to June, the sun rising farther and farther north, crossing the meridian higher and higher up from the south point of horizon, and setting farther and farther north. This makes an ever enlarging diurnal circle

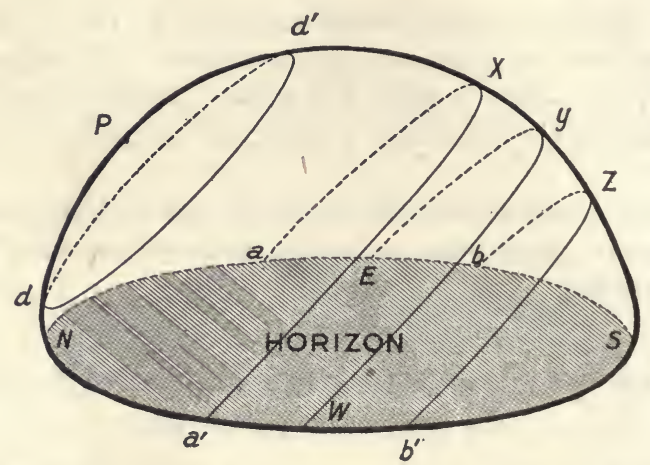

Frg. II6.-Diurnal circles of the sun at different seasons: $a x a^{\prime}$, at summer solstice (June 2I); $b z b^{\prime}$, winter solstice (December $2 \mathrm{I}$ ); $E y W$, vernal and autumnal equinoxes (March $2 \mathrm{I}$, and September 2I). $d d^{\prime}$ is the diurnal circle of a star which for an observer in northern latitudes never rises nor sets, i.e., a star always above horizon.

above the horizon, and longer and longer daytimes. Upon these changes in obliquity of the sun's rays, and upon the duration of the periods of sunlight, depends the changes of seasons.

These changes are scarcely considered from day to day, and less frequently are they given their real significance in terms of the revolution of the earth about the sun. When one looks out toward the sun at any time, it is difficult to realize that the distance between the earth and the sun is approximately the enormous value of $93,000,000$ miles. So distant is the sun from the earth that of the heat given off by the sun only about one two-billionth part is received by the 
earth. Yet great as is this distance, the earth in six months time will be at an equal distance on the other side of the sun. In other words the earth will have traveled about half way around in its orbit. When one calculates the number of miles in half of the earth's path about the sun, and divides the result by the number of minutes in six months of time, it is not surprising to find that the earth's velocity in its orbit is about one thousand miles per minute. This is about a thousand times faster than the swiftest express train.

In this revolution of the earth about the sun it must be kept in mind that the moon accompanies the earth in its advance. The earth is at all times in rotation as it moves on, and the moon is all the time revolving about the earth as a centre. Though the rate at which the earth moves varies considerably in different parts of its orbit, the time period for complete revolutions is of unvarying length, and it constitutes the natural time unit known to us as the year. In this year period there are about three hundred sixty-five and one-fourth days. In the arrangement of days into months to make up the calendar it has been necessary to let every fourth year ${ }^{1}$ contain 366 days, February then having in these "leap years" twenty-nine days. The times of changes of seasons are thus made to occur on the same dates every year. The periods of revolution of the other planets or their "years" vary widely, depending upon their distances from the sun. Mercury, the innermost of them, gets around in about eighty-eight of our days, while Jupiter requires twelve and Neptune one hundred sixty-five of our years.

\section{Summary}

The paths of the sun across the sky are not the same day after day. It is a matter of common observation that from June to December the

${ }^{1}$ An exception to this is that the first year of each new century as 1800 , $\mathrm{r} 900,2000$, etc., is a leap year only when divisible by four hundred. 
sun rises farther and farther south on the eastern horizon, is lower and lower down from the zenith at noontimes, and sets farther and farther south on the western horizon. From December to June these changes are in reversed order. The duration of the sunlight period, i.e., the length of the days ${ }^{1}$, varies with these changes.

In the northern hemisphere the longest days are in June when the sun's path across the sky is highest up toward the zenith, and the days are shortest when those "diurnal circles" are lowest down toward the south. This is due to the progress made by the earth in its revolution about the sun. The observer is brought into new positions in the earth's orbit day by day from which to look out toward the sun as the earth's rotation brings him around on the daylight side.

Upon the duration of the period of sunlight, and upon the obliquity of the sun's rays for any observer, depends the amount of solar heat received by him, and the changes of seasons for that locality.

The year as the period of the earth's revolution, and the day as the period of the earth's rotation, are natural time units of unchanging values. It is true that the earth's velocity in different parts of its orbit varies, but the length of the year period does not change. The earth is "on time" so far as completion of its journeys of revolution are concerned.

The lengths of the times from passage of the centre of the sun's disc across the meridian of any observer till it is next on meridian vary a little at different times of year. This necessitates the use of an imaginary day known as the "mean solar day." Its length is the average of the lengths of all the solar days of a year. Our clocks and watches keep mean solar time.

\section{Exercises}

1. Why do we experience so much difficulty in realizing the fact that we live upon a rotating earth?

2. What is meant by $(a)$ horizon; $(b)$ sunrise?

3. Since the daily paths of the stars across the heavens, i.e., their diurnal circles, result from the earth's rotation, and since the direction of the earth's axis is at all times parallel to itself and always points toward the same place in the heavens, what must be true of the relative positions of the diurnal circles $(a)$ of different stars; $(b)$ of the same star?

${ }^{1}$ It usually is possible to distinguish from the context whether the word "day" has reference to the period of the earth's rotation ( 24 hours), or to the duration of daylight (not night-time). 
4. Distinguish between rotation and revolution for the earth. What is meant by the orbit of the earth?

5. How much nearer the sun is the earth in our winter season than in summer time? What is true of the relative lengths of the times of revolution of the earth, i.e., of the lengths of the years? What does this argue of the averages of the earth's velocity in its orbit, and of the extent (length) of that orbit year by year?

6. Why are those circles of the earth known as the Tropics located $231 / 2^{\circ}$ on either side of the earth's equator rather than some other distance?

7. Account for eclipses $(a)$ of the moon; $(b)$ of the sun.

8. The diameter of the earth is 8000 miles; of the sun 880,000 miles. How many times greater volume has the sun ${ }^{1}$ ?

9. What is the cause of the varying obliquity of the sun's rays as found in the lesson on Solar Heating?

\section{The Moon, And Its Phenomena}

It is in the changing phases of the moon, and in its varying angular distances from the sun, that we can actually see the revolution of one celestial body about another. The moon is only 240,000 miles from the earth, a small distance in the scale of the celestial sphere. In its revolution about the earth the moon comes in between earth and sun (though seldom in a direct line), and moves on away from the sun farther and farther as measured in degrees along the curved background of the sky. When it is on the side of the earth opposite the sun, and $180^{\circ}$ from it, an observer on the earth sees the side of the moon that is illuminated. Then as the moon continues in its path around the earth it approaches closer and closer to the sun as seen from the earth till once more it is on the same side as the sun. The dark side of the moon is then toward the earth. The moon has no light (or heat) of its own.

There is an abiding satisfaction in being able definitely and quickly to grasp the relationship of sun, moon, and earth in space as the moon's form and its position relative to the sun are noted. It makes an excellent preparation for

${ }^{1}$ The volumes of spheres are to each other as the cubes of their diameters. 
any later studies in Astronomy. In estimating distances in degrees on the surface of the sky, it is helpful to remember that from the south point of the horizon to either east or west points, or to the zenith, is $90^{\circ}$. The diameter of the full moon is about $12^{\circ}$, and the distance between the "pointers" in the bowl of the "Big Dipper", by means of which the North Star is readily located, is about $5^{\circ}$.

The full moon is always on the side of the earth opposite the sun. In winter-time the sun rises far to the south of east, and sets far to the south of west. This is because the north pole of the earth is then tipped away from the direction of the sun. It follows that the rising of the full moon at sunset will be far northward of the east point of the horizon. $B y$ reason of the earth's motion of rotation the diurnal circle of the full moon then will be high up in the heavens, and down to a point of setting far northward of the west point of the horizon. This occasions the long and very bright moon-lit nights of midwinter. These are in marked contrast with those of summer when the path of a full moon across the heavens is much lower toward the south, and the light of the moon much less intense because of the greater obliquity of its rays. To attempt to reason out what must be true of natural phenomena such as these requires always the check of actual observation at every opportunity till one is assured that his conclusions accord with the facts. Acquiring a clear understanding of the phenomena presented in the changing positions of the moon, and verifying one's conceptions by repeated observations, enables one to catch something of the spirit of the scientist as he seeks to master what has hitherto been unknown.

In many respects the moon itself is an uninteresting subject for study. Astronomers have been unable to detect any evidences of life upon it, or to note there the physical conditions essential to life like that known here on the earth. 
There is no atmosphere, no water, no protection from the intense solar heating. For two weeks at a time the sun shines continuously on the same places. There are no clouds in the sky to prevent radiation of this heat, and it must become extremely cold through the two weeks of continuous absence of sunshine that follows. A lunar landscape lit up

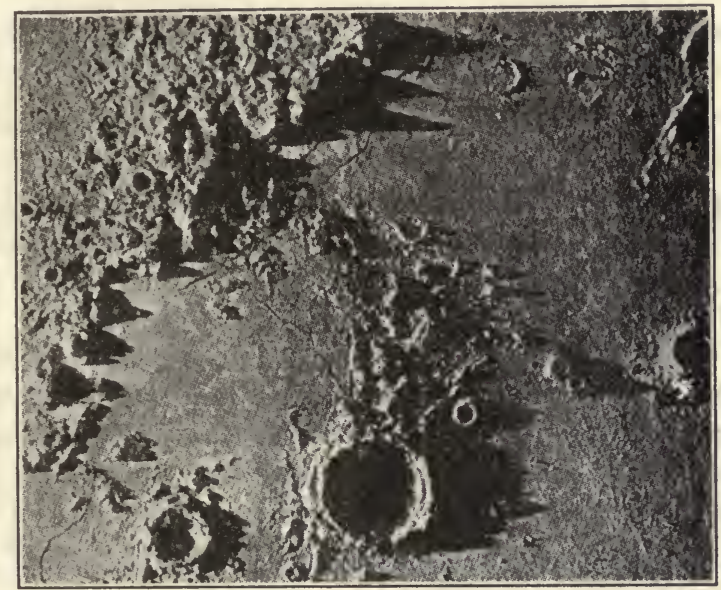

FIG. II7.-A portion of the moon's surface as seen in a telescope. Note the shadows cast by mountains, and others within the craters of lunar volcanos now extinct. The sunlight is from the left side.

by the sun's rays in such a way as to throw into shadow reliefs the rugged mountainous surface of the moon is, however, a most interesting sight when viewed through a good telescope. Photographs of the moon's surface when made by aid of the telescope give a good idea of what the astronomer beholds.

Our moon has a diameter of about two thousand miles, or one-fourth that of the earth's diameter. Its volume then is approximately $(1 / 4)^{3}$ or $1 / 64$ that of the earth. Its weight, however, as calculated by astronomers is but $1 / 80$ of that of the earth, showing that the material of. which the moon 
is composed has less density than the earth. How it is that astronomers calculate the masses of the planets and their satellites, their volumes and their relative densities, is exceedingly interesting to those who have considerable knowledge of mathematics. While the earth has but the one satellite or moon, Jupiter has nine, and Saturn nine or ten. Some of these have been discovered only within recent years.

\section{SUMMARY}

In the changing positions of the moon relative to the direction of the sun from the earth we can actually see the moon's revolution about the earth. This change in distance of the moon from the sun must be measured in degrees upon the curved surface of the sky.

As the moon moves on in its orbit its illuminated side as lit up by the sun is at times toward the earth. It then appears as a "full" moon circular in outline. At other times the dark side is toward the earth, while the crescent and gibbous phases are views of but portions of the illuminated spherical surface. The change in extent of the sunlit side visible from the earth varies chiefly by reason of the moon's changes of position in its orbit.

Lack of water and of atmosphere, and a probable extreme range in temperature from a time of two weeks of continuous sunshine to a two weeks' absence of sunlight, makes it unlikely that any forms of life such as are known here on earth can exist on the moon.

The duration of the hours of moonlight, and the variation in its intensity, depends as with sunlight upon how high up toward the zenith of any observer the diurnal circles of the moon are. In this northern hemisphere it is in the winter time that the full moons "run high" in the heavens, and long bright moonlight nights occur.

While the crescent moon as seen in the west at sunset is to the east of the sun, and the crescent moon seen in the morning before sunrise is to the west of the sun, it does not follow that the moon has passed the sun and changed sides with regard to the sun. Such a change does occur at the "dark of the moon," and just before "new moon." In the former "case what has occurred is that the waning crescent of the "fourth quarter" is coming nearer and nearer to the sun, both its 
distance and its direction now being measured from the opposite edge of the sun's disc.

Easter is the first Sunday following the first full moon that occurs next after the Vernal Equinox (time in the spring when the days and nights are equal).

\section{Time, and Time-keeping, and Standard Time}

Time-keeping resolves itself into a choice of convenient units as subdivisions of natural time periods, and the use of devices for counting and registering these smaller units

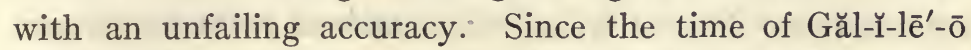
$\left({ }_{5} 64-1642\right)$ use of the vibration periods of pendulums (or those of coiled springs in watches) has displaced the hourglass and other devices of the ancients for measuring time. They had the years and the days for large time units the same as we, but accuracy in the measurement of smaller time units waited upon the discovery of the laws of the pendulum.

It is quite indispensable that the time-pieces of a community-its homes, shops, factories, mills, and schoolsshall be so set and regulated that they show at all times the same readings. Railway service in all parts of any section of the country requires the same time standard by all concerned in its administration, and travelers must adapt their times to this standard.

Since the earth rotates through $360^{\circ}$ of circumference in twenty-four hours, its rate of rotation is $15^{\circ}$ per hour. Any place $15^{\circ}$ eastward of an observer has noon by the sun (that instant when the sun's centre is on the meridian of the place) just one hour earlier than noon with the observer, or four minutes earlier for every $I^{\circ}$ of distance. Places westward of the observer have their meridians come to and pass the sun four minutes later for every degree farther westward. Observers living east and west of one another will have different "local time" whether their time-pieces are kept 
with it or not. It is more convenient, and in all ways more practical, for all the people in any certain section of country to have all time-pieces read twelve o'clock when it is noon at places situated on some one geographical meridian chosen as a standard. By having these standard meridians $15^{\circ}$ apart the time-pieces in adjacent time-belts will be exactly one hour apart. A traveler going from one such section into another will change his watch reading just one hour at some convenient or established place, leaving the readings of the minutes and the seconds unchanged. If the traveler journeys eastward, his watch is set ahead an hour for every change from one time-belt into another in order that its readings may conform to the time of the belt into which he has come. In going westward the watch must be set back an hour each time.

It is interesting to note what befalls a traveler in the matter of time-keeping who makes long journeys east or west around the earth. If changes of one hour at a time are made from time-belt to time-belt as discussed above, the watch readings will conform always to the times of the places where the traveler may come. But confusion soon arises as to what day in the week it is.

The day period from noon to noon (or midnight to midnight) is lengthened in going westward. The traveler has need to set his watch back one hour for every $15^{\circ}$ passed over, and while the time at the place whence he started might show one whole day passed, the traveler's watch after being set back shows but twenty-three hours passed. $\mathrm{He}$ has "lost" an hour. To travel $30^{\circ}$ westward means a reading at the place where the journey began two hours later than at the place where the traveler then is, or two hours lost. To complete the $360^{\circ}$ of the earth's circumference and the twenty-four changes of watch that this requires involves the loss of one whole day. In other words, at the 
place where the journey began there has been recorded twenty-four hours or a whole day more of time than has been counted by the traveler with his repeated "setting back" of his time-piece. He is a day behind the calendar upon his return. While his watch reading is in accord with the time at the starting place, his day of the week is made right only by passing over one day in the calendar. If his return is on Tuesday evening by his reckoning, then he must consider the next day Thursday. As a matter of custom this jumping over one of the days of the calendar is done by west bound travelers when crossing the Pacific Ocean, and when near the so-called international date line.

To travel eastward involves a similar series of changes and adjustment of days. But in this case the watch must be set ahead an hour at a time, and at the international date line two days in succession have the same name. There has been a day gained by the traveler, and his calendar is a day ahead of the places to which he comes, making it necessary to live one of his days over again so far as the name of the day is concerned.

Each new day upon earth may be considered as having its beginning at this international date line, and as traveling around the earth westward. When this same day is just beginning at places on that side of the date line to reach which the day "has traveled around the earth," it is twenty-four hours old on the beginning side of the line. The whole earth will then be covered by the same calendar day. But at that very instant the next succeeding day is beginning on the "east side" of this imaginary line to pass on in turn around the earth, while the preceding day is growing older and finally is to pass off from earth when the new day in turn comes to the "west side" of the date line.

It is not so strange as at first it may appear that newspapers, with headlines that tell of startling events in Europe 
or the Far East, are on sale in cities of the United States at hours in the day earlier than these events are said to have occurred. Telegraphic transmission of news has out-stripped the earth's rate of rotation, and the differences in time of the continents gives ample opportunity for publication of the news apparently "before it happened." To visualize such conditions as these, and to be able concisely to express in detail these relationships of time-keeping over the world, is a worthy test of one's ability to think clearly and surely to conclusions based upon involved data.

\section{SUMMARY}

The calendar as a system for time-keeping makes use of the periods of rotation and of revolution of the earth - the day and the year-as unchanging time units. Shorter units are obtained by an arbitrary division of the average length of solar days into hours, minutes, and seconds.

Pendulums and springs, by proper adjustment of their lengths, may be made to vibrate at an unvarying rate of once per second, or any other short period desired. By means of wheelwork the number of these vibrations can be shown on a dial as so many hours, minutes, and seconds past noon or past midnight.

A ready means of remembering the relative times of places east and west of one another is to recall that "east clocks are fast clocks," the noons of places east occurring earlier than at places west of them.

To travel west with the sun has the effect of lengthening the day of the traveler, so that in going around the world he has had one less number of days in that period of travel than has another person who has remained at home. The traveler has "lost a day," and somewhere on his journey westward must drop a day from his calendar. In journeying eastward around the earth the traveler's days are shortened as he goes to meet the sun, and as the result he has gained a day in making a journey around the earth. It thus becomes necessary somewhere in the journeying to have in succession two days of the same name, i.e., to set his calendar back a whole day.

"Standard time" is a system of time-keeping whereby the clock readings throughout a whole section of country are the same regardless of the actual time at these different places as indicated by the sun. 
All time-pieces are set to read noon throughout the time-belt when only the places on a certain meridian running through the central portion of this region really have the sun on meridian.

While in theory these time-belts are seven and one-half degrees of longitude in width on both sides of each of the time meridians, as a matter of fact there are great departures from any such arrangement to conform to the convenience of the traveling public.

Sunrise during the Spring and Summer is so much earlier than the hour fixed by custom for starting the wheels of the nation's industries that in many ways it is advantageous to have the industrial day for people generally begin at six o'clock rather than at seven A. M. This makes the mid-day meal come at eleven instead of twelve o'clock. Many difficulties, both civil and legal, would be involved in any change in the hours established by custom and by statute for beginning and closing the varied activities of life's affairs. Instead, a "Daylight-Saving Plan" now followed in the United States and in other countries decrees that at a certain date in the Spring all clocks shall be set ahead one hour, and then set back one hour at a fixed date in the Fall.

The round of daily activities during the Spring and Fall then actually begin one hour earlier every day and close one hour earlier at night than during the other part of the year. But the times as shown by the clock remain the same the year around. During the Summer under this plan the sun is yet an hour's time from meridian when the clock reads noon. People order their ways of life by clock time rather than by sun time. 


\section{THE HEAVENS}

"The heavens declare the glory of God, and the firmament sheweth his handiwork. Day unto day uttereth speech, and night unto night sheweth knowledge. There is no speech nor language where their voice is not heard".

Ps. XIX: vv. I, 2, 3 .

Poets and philosophers in all ages have gained inspiration as they have contemplated the heavens, and striven to formulate and express the thoughts of the Infinite to which these studies have given birth. Early literature contains numberless allusions to astronomical myth and fact. To catch the subtle meaning of many a passage of literary excellence requires some acquaintance with Astronomy. A knowledge of high school physics renders comparatively easy the reading of books on general astronomy.

But one does not need to be an astronomer in order to know something about the universe outside the earth, and to comprehend something of the significance of what is visible to him of the celestial sphere both by day and by night.

Not only may a person become more appreciative of the beauty of the sky as apparently it moves in ceaseless round above him, but some definite knowledge of what is seen enriches and stimulates his intellectual life. An intimate knowledge of plant growths by field and forest and stream makes life more enjoyable to us; intimate acquaintances among people gives pleasures to life which no crowds of those unknown to us and to whom we are indifferent can give. So an acquaintanceship "amongst the stars" yields an everincreasing pleasure as the years go by. To be an astronomer one must become skilled in mathematics; but there is available to every one in the realm of Astronomy a vast fund of 
quickening non-mathematical knowledge of an elementary character.

So vast are the values for time, space, and size in the celestial sphere, values that approach the infinite in their magni-

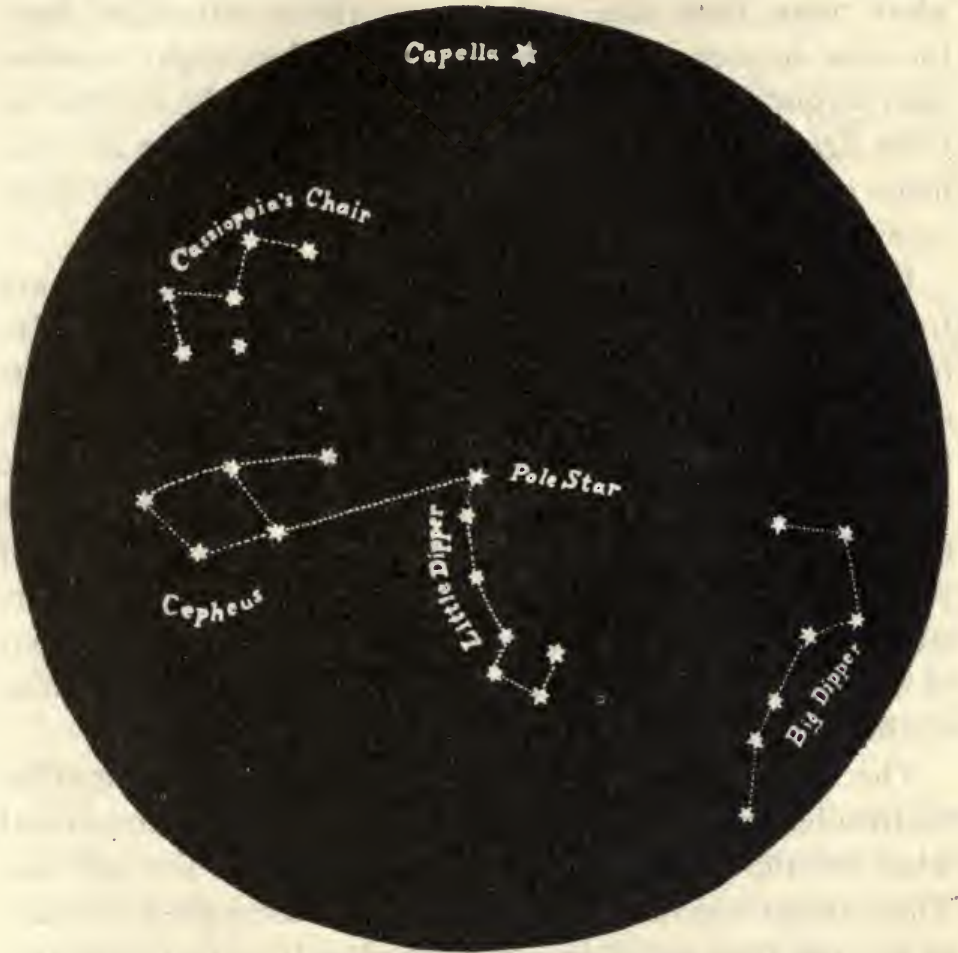

FIG. II 8.-Constellations of the northern heavens always above horizon in most parts of the United States.

tude, that the human mind must resort to comparisons involving enormously large units in many cases. Only a few of the more serviceable of these numbers need be remembered, and these only as approximate values. The velocity of light, I86,000 miles per second ${ }^{1}$, serves the astronomer as

${ }^{1}$ The velocity of sound is only a little more than one-fifth mile (I Ioo feet) per second. 
a convenient substitute for a yardstick. This velocity of light is so great that to encircle the earth $(25,000$ miles $)$ it would require but one-seventh of a second. To reach the earth from the moon (240,000 miles) light requires somewhat more than one and one-fourth seconds, and from the sun $(93,000,000)$ somewhat more than eight minutes (499 seconds). It is interesting to compute the number of miles light travels in one year in view of the fact that astronomers calculate the distances of the stars as so many "lightyears" from the earth.

From the star believed to be nearest the earth we are told it requires light more than four years to reach the earth; from Sirius the "Dog Star" that is so conspicuous in the southern sky in a winter evening more than eight years; from the North Star about forty-seven years; and from those stars most distant, and yet visible on photographic plates made by aid of the telescope, perhaps many hundreds of years. When we consider that a star whose light we are still getting - that we still "see"- - may have been blotted out of existence unnumbered years ago, something of the extent of the Universe is borne in upon the human mind.

The number of the stars, while not at all a "countless multitude," is nevertheless so great as to cause amazement when we think of them as light-giving bodies like our sun. The number visible to an observer with the naked eye only at any one time and place is perhaps less than two thousand, or about five thousand in the whole heavens since many just above the horizon are not readily seen. But the number of stars that may be counted on photographic plates of the whole heavens as made by use of the largest telescopes is perhaps several hundred millions. In an exercise of the imagination based upon such facts as these, and that is at all times in accord with facts, there is developed the noblest 
powers of the human mind, enabling man "to think the thoughts of the Almighty after Him."

Perhaps the readiest way in which to recall at any time the relative distances of the planets from the sun is to make use of the following device known as Bode's Law:

\begin{tabular}{|c|c|c|c|c|c|c|c|c|c|}
\hline Name & $\begin{array}{l}\text { Mer- } \\
\text { cury }\end{array}$ & Venus & Earth & Mars & $\begin{array}{l}\text { Aster- } \\
\text { oids }^{1}\end{array}$ & $\underset{\text { ter }}{\text { Jupi- }}$ & Saturn & Uranus & $\begin{array}{l}\text { Nep- } \\
\text { tune }\end{array}$ \\
\hline \multirow[t]{3}{*}{ Symbol } & $\bar{q}$ & 우 & $\oplus$ & $\sigma^{7}$ & & 4 & $b$ & $\hat{\oint}$ & $\Psi$ \\
\hline & 4 & $\begin{array}{l}4 \\
3 \\
\end{array}$ & $\begin{array}{l}4 \\
6 \\
\end{array}$ & $\begin{array}{r}4 \\
12 \\
\end{array}$ & $\begin{array}{r}4 \\
24 \\
\end{array}$ & $\begin{array}{r}4 \\
48 \\
\end{array}$ & $\begin{array}{r}4 \\
96 \\
\end{array}$ & $\begin{array}{r}4 \\
192 \\
\end{array}$ & $\begin{array}{r}4 \\
384 \\
\end{array}$ \\
\hline & 10 4 & 7 & IO & I 6 & 28 & $5^{2}$ & 100 & I96 & 388 \\
\hline $\begin{array}{l}\text { Relative } \\
\text { distances }\end{array}$ & .4 & 0.7 & I. 0 & I . 6 & 2.8 & $5 \cdot 2$ & Io.0 & I9. 6 & 38.8 \\
\hline
\end{tabular}

Assigning 93,000,000 miles as the unit distance for the earth, the distance of the sun from any one of the other planets is readily found in round numbers by multiplying the earth's distance by the number given in the bottom row. A marked exception exists in the case of Neptune where the multiplier used must be 30 rather than 38.8 .

It is interesting to calculate the intensity of light and heat from the sun upon some of these other planets relative to that received by the earth. The intensity of light and heat at Neptune, thirty times more distant than the earth, is $(1 / 30)^{2}$ or one nine-hundredth as much, while on Mercury which is only $7 / 10$ as far away the light and heat intensity is $(10 / 7)^{2}$ or about twice as great.

1 The asteroids are small planetary bodies revolving about the sun at distances approximately as indicated. They may be considered as fragments of a planet which for some unknown reason either failed to unite or to remain united as did the other eight planets. 
The table below gives for purposes of comparison the diameters of the eight planets, and the times required by them for one revolution about the sun (their year periods):

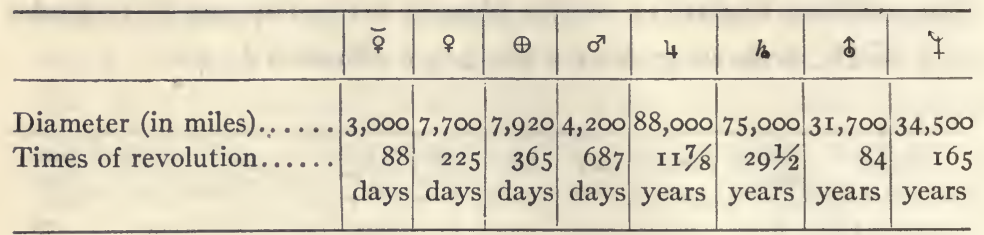

The astronomer considers our sun as a star, and the stars as so many suns. The little heat and light received on the earth from the stars results from their enormous distances. Many of them must be vastly larger than our sun. If any of them have planets circling about them, these planets must remain invisible because of the distances involved (page 366). Even from Neptune the light is too feeble to be made out by the naked eye, although it is approximately only thirty times the sun's distance from the earth, and consequently is but $30 \times 499$ light-seconds (or 4 light-hours) away as contrasted with 4 light-years for the nearest star.

Astronomers believe, too, that our sun with all its attendant planets, asteroids, and satellites, is moving onward through space more or less free of the controlling influence of other celestial bodies. This independence in motion is true of all the stars, but so vast are the celestial spaces that collisions, though possible in long periods of time, are unlikely. The theories given in Astronomy of the structure of the Universe, as well as of the origin of our Solar System, merit the thoughtful consideration of all students.

\section{Summary}

So distant are many of the stars that their light is too faint to affect the eye sufficiently for them to be seen. The great telescopes are as it were enlarged eyes, gathering up a far greater amount of light than 
does the unaided eye. Photographic plates made in connection with use of the telescope multiply enormously the stars that can be numbered. There is reason to believe, however, that the number of the stars is not limitless.

Bode's so-called "law" probably has no value other than as a device for making an easy calculation of the distances of different planets from the sun. It is to be noted that the number to be added to each of the four's is in every case double the preceding number.

The existence of so many non-luminous companions of the stars has been established that it is not unreasonable to conceive that at least some of the stars are centres of solar systems even as our own sun is. However, astronomers lack sufficient evidence to warrant any such assertion. The human mind naturally wonders if in all the immensity of space, and out of all the multitude of celestial bodies corresponding to what we know as satellites, planets, and sun, our earth alone is in. habited by intelligent beings like ourselves.

Scientists are very careful to avoid teachings that lack sufficient evidence in known facts to warrant their acceptance. On the other hand, imagination based upon facts, and tested at every stage so far as possible by what is known to be true, enables the human mind to compass the universe. And when the limit of human knowledge is reached, as so quickly it is, the reverent mind readily believes that within the shadows standeth God "Keeping watch above His own." 


\section{APPENDIX}

\section{SUGGESTIONS TO TEACHERS}

A good "method" for any subject in school, and for the affairs of life generally, attains the ends desired with a minimum of waste in time and effort. In school work the teacher's personality and preparation, the varied experiences and natures of pupils, and the different conditions under which instruction must be given, all enter into the teaching problem as variable factors. Any one best way of teaching a secondary school science is out of question. "Diversity in method but unity in aim" may well be a motto for science teachers. Nevertheless, until through much experience a science teacher establishes a procedure peculiarly his own, yielding better results than any other ways employed, it is well to follow plans found satisfactory by others.

In his own class work the author seeks to keep before the minds of prospective teachers that the teaching process is something more than a mere discussion of any group of facts, however great their values as knowledge material. It is of primary importance that pupils be trained to acquire facts for themselves, and that they become able to discriminate in the relative worth of these facts. A natural spirit of inquiry concerning the significance of nature's ways is thus stimulated and directed.

Teaching conditions will commonly make necessary the use of a text as the chief source of information for pupils since it gives relationships of greatest educational worth likely to be foreign to their thought, and conclusions of utmost importance not likely to be reached by them. But it is the author's belief that large emphasis should be laid upon laboratory procedure in the teaching of General Science. There is a wide difference in educative values for the beginner in sciences between what he learns through experiments and through the experiences of life, and what he gets from books alone. To make beginning work in science a study of books only is contrary to the spirit of the work, and destructive of its ends. Later in the school course, with acquired 
abilities and enlarged powers of interpretation of language, pupils may be turned more and more from studies of natural forms and phenomena to what is told about them in books. It is the teacher's problem to know when and how rapidly to do this.

Laboratory exercises constitute in large measure a preparation for the class period. Text requirements and reference readings are made supplementary to the life experiences called forth by the laboratory requirements. Whether the experiments are performed by the individual pupil, or by the teacher before the class as a whole, is far less important than is an insistent demand for a discernment of the significant facts, and of their relationships to one another and to previous knowledge.

It is to be noted in this connection that the pupils are to do the observing, and to the limit of their ability are to be required to interpret the significance of what comes under their observation. It is the province of the teacher to direct in these exercises, to guide in the thinking, to aid in the expression of thought and in the mastery of a science vocabulary. It is the teacher, too, who so plans and executes that results of largest educational value are secured in the shortest time and in the most direct ways. In the class period when the results of the laboratory exercises are under review, there is opportunity for the teacher to bring into the discussion much closely related matter that is unsuited for study by observation.

It is at this stage that texts and other books for supplementary reading furnish an inexhaustible wealth of information. From the use of these the pupils may acquire a more extended outlook, and may satisfy a growing desire for more definite knowledge. In this use of texts and reference material there is relief, too, for the teacher otherwise overburdened by the heavy demands of instruction. In the selection and assignment of any reference readings no less care should be exercised with regard to their educational worth, and their adaptation to teaching ends, than in the choice of laboratory exercises.

Teaching conditions are often such as to make impossible any extended use of reference books in General Science. Provision can always be made, however, for individuals to do much outside reading. The field of General Science is so broad that no one book is at all adequate as a text. Some of the books and bulletins listed in this Appendix should be provided for supplementary assignments, and the teacher should become thoroughly familiar with their contents. In them and in other like books a wealth of valuable information may be turned to 
good account in general science teaching. Pupils should learn from the first to use the Index of any reference book for finding quickly what is desired as information. Certain of the chapters of this text as listed in the Table of Contents have been starred(*). In the author's judgment they contain matter likely to be difficult for beginners. Their use in a general science course will in nowise render unnecessary their more extended discussion later in the particular science to which they pertain, especially the lessons in Physics and Chemistry. An introduction of pupils to these difficulties at this early stage in their science studies should so materially aid them later in any discussion of these same and of other related topics as to justify the inclusion of these lessons. It will be for any teacher to judge whether under teaching conditions as they exist it is profitable to discuss them.

\section{REFERENCE BOOKS}

I. Text-books in high school and college sciences provide a large amount of usable material for "study hours" in General Science. These should include texts in Agriculture, Astronomy, Biology, Geology, Home Economics, Hygiene, Meteorology, and Zoology as well as in Botany, Chemistry, Physical Geography, Physics, Physiology, together with some of the different texts in General Science. A simple, non-technical presentation, other things being equal, is desirable ${ }^{1}$. Accuracy of information is essential within the limits of discussions necessarily of an elementary character. Text and other reference books which pupils enjoy when reading, and which they "can understand," are at a premium so long as these characteristics are not gained at the expense of scientific and pedagogical worth.

2. Many publications of the United States Government are available free or at a nominal price. It is usually best to order these through the Congressman of one's home district, especially if several copies of any one publication are desired. Before ordering, however, application should be made to the Department concerned for a List of Publications suited for use by teachers in public schools. Lists of Farmers Bulletins,

${ }^{1}$ In providing a library of reference books for use in General Science much disappointment and waste will be avoided by ordering so far as possible only books with whose contents in a general way at least the teacher has become well acquainted. Printed lists of books secured from different sources are no exception to this rule however helpful these lists may be in narrowing one's choices for examination. 
and of various other publications of great value in teaching General Science, may be had on application to the Division of Publications, Department of Agriculture, Washington, D. C.

3. These books have been found helpful:

Bailey (Mac.) $)^{1}$

Bigelow (Mac.)

Comstock (Com.)

Coulter \& Patterson (Ap.)

Eldridge \& Briscoe (Long.)

Harrington (Ap.)

Parloa (Cent.)

Price (Wi.)

Snyder (Mac.)

Walters (Heath)

Weed (Am.)

Wilson \& Warburton(Webb)
Sanitary and Applied Chemistry,

Revised................\$1 .50

Applied Biology.............. I.40

Handbook of Nature............. 3.65

Practical Nature Study......... I.40

First Aid in Laboratory and Workshop............................... 0.75

About the Weather............. 0.70

Home Economics.............. I. 50

Handbook on Sanitation.......... I.50

Chemistry of Plant and Animal Life, Revised................... I.50 Principles of Health Control....... I.60 Chemistry in the Home......... I.20

${ }^{1}$ Publishers of books as listed above are: (Mac.) Macmillan Company, New York; (Com.) Comstock Publishing Company, Ithaca, N. Y.; (Ap.) Appleton \& Co., New York; (Long.) Longmans, Green \& Co., New York; (Cent.) Century Company, New York; (Wi.) Wiley \& Sons, New York; (Heath) D. C. Heath \& Co., Boston; (Am.) American Book Co., New York; (Webb) Webb Publishing Co., St. Paul, Minn. 
.

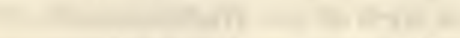

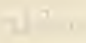

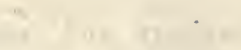

$$
\text { I +1 + }
$$

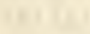

10 (n)

$+$

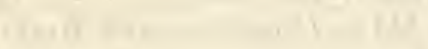




\section{INDEX}

\section{A}

Absolute temperature, I42, I46

Absorption, 98

Accidents, 233-239

by automobiles, 239

liability for, $237-238$

Acids (bases, salts), 180-183, 190I9I

definitions, $182-183$

formulæ for, I 8 I

Adenoids, 6

Adulterations, 48

Agriculture, courses in, 303,3 I 6 , $317,322,332$

Air, as respired, $19-23$

compressed, 56, I 20-1 22

constituents of, 23 , II 2

in soils, $25 \mathrm{I}$

liquid air, II6-II8

properties of, IIO-II3

weight of, II 2

Air-brakes, I 22-I 23

Air drills, I22-I 23

Alcohol, 72-76, 78, 21 2, 238

effect on nerve centres, $76,79^{-}$ 80,238

Alkali, I 78, I89, I9r

Aluminum, I88-I89

Ammonia, uses of, II6, II 8, I77

Amusements, 68

Anæsthetics, 78

Antiseptics, 39

Antitoxins, 37, 4I, 60

Apple raising, 319-325
Asbestos, 145

Atmosphere, IIO-I3I

currents in, II 3, I23-I 3 I

density of, III, I 23

depth of, III, II 3

Atmospheric moisture, effect on heat

from sun, II 2

in relation to health, $20, \mathrm{II}_{3}$, I $35-136$

Atmospheric pressure, II $4^{-I} 3_{2}$

applications of, II9-I 23

currents due to, I23-ז 26

effects on persons of changes in,

I I 5 , 22

measurement of, II4

relation to altitude, II 5

to density, II 8, I26-127

to wind velocity, I 44

Atoms, I73

\section{B}

Bacteria, 36-45, I 75, 25I, 324 nitrogen-fixing, 44, 254, 3 I 3

Balanced diet, 209, 213, 219-224

Balloons, II5

Barometer, II4-II5, II8, I3I

Bathing, 28

Batteries (cells), I 70, I84, I87, I89 storage, 187

Birds, 275-280, 297 bills, and feathers, $276-277$ migrations, $277-278$ usefulness of, $278-279$ 
Blood, circulation of, 34

pressure, 34

Bluing, laundry, 178

Board of Health, 43

Bodily wastes, 7, I 74

Body, human, as a machine, 68, 7273

Boiling, 86-87

Brain, 9, 65-66, 72

Bread, 232, 325

Breathing, 5-6, 19-25

artificial, 23-24

effects on digestion, 22

Burns, treatment of, $235^{-236}$

Business success, 252-253, 293-295, 298

Butter, and butter making, 342

substitutes for butter, 272

\section{C}

Caissons, 120

Calendar, 353, 362

Calorie, 95

Capillarity, 249

Carbohydrates, 27, 226-23I

Carbon dioxide, 16, 18-19, 23, 190I9I, I94-I95, 268

monoxide, I7, 201

Casein, 30r

Catarrh, 6

Caves (caverns), I94

Cells in living bodies, $31,64-65,68$,

$$
7 \mathrm{I}-72, \mathrm{I} 75
$$

effect of heat on, 27

Cellulose, 226-228, 23I, 268, 273

Cement and concreto, $62^{-}-63,{ }_{3} 92$

Character, traits of, 8, 243, 252, 293295

Chemical changes, I73-I79, 202

agencies in, $174-176$

by electricity, $184-190$

equations for, I $79,182,184,191$

factors (and products) in, 182 ionization in, $181-182$
Chemical changes and radicals, 182 valency in, $188_{3}-184$

Chemical elements and compounds I 73-174, 197

Chemical formulæ, I79, I8I-I84, I9I, 227

Chest walls, $2 \mathrm{I}-22$

Chlorine, uses of, I $75^{-1} 76$

Chlorophyll, 226, 3I 4

chloroplasts, 226-227, 268

Cisterns, 54-55

Citizenship, duties of, 47, 245-246

Clay, I98, 247-248

Cleaning, $177-179$ dry cleaning of clothing, 177

Climate, I34-I 37 in relation to civilization, $\mathrm{I} 35$ in relation to latent heat, 96

Clothing, 28-29, 209, 2 I3, 272

Clouds, 90, 94, I38-140

Coal (and solar energy), I96-199, 2I $5^{-2} \mathrm{I} 7$

Codling moth, $32 \mathrm{I}-322$

Coefficient of expansion, I4I-I42

Colds, 5, 28-29, 77

Color, $342-348$ in plumage of birds, 276

selective absorption in, 343-344

Combustion, I6-18

Compressed air, I I9-I 22

Condensation, 90-96

heat from, $95^{-96}$

Congestion, I I , 28, 34, 65

Conservation, of forests, 254-259

of soils, 103-105, 255

of well-being, I4, 210-213

Constipation, 7, 22

Consumers, $28 \mathrm{I}-283$

Corn, 3I2-3I 7

climate for, 3 I $3-3$ I4

flowers of, 3 I 5

products from, 316

value of crop, 3I3, 3I 7

Correlation of forces, 346 
Cost of living, 209-213, $25^{6}$

Cotton, 27I-272

Cows, 310-3II

Crop rotation, 3 I 3

Crystallization, 92

"Cures" for ailments, 77

Cyclones, I30-I3I

\section{D}

Dairying, 309-3 10

Days (and nights), I48-I 49, 350-35 I, $354,361-362$

lengths of, 354

place of beginning, $36 \mathrm{I}$

subdivisions of, 362

Density of bodies, $153,357-358$

of water and ice, 88, I4 I

Diaphragm, $2 \mathrm{I}-22$

Diffusion, 98-100

Digestion, 6-7, I74, 219-22 I, 225, 228

Diphtheria, 39, 4 I

Disease, $3 \mathrm{I}-33,36-45,49,54,58-6 \mathrm{I}$, 308, 3 I I

Disinfection, 43-45, т 76, 208, 235

Dissipation, 7 I , 73, 80

Distillation, 93 natural, 94, го6

Diurnal circles, I48-I49, 350-35I, $354,356,35^{8}$

Drowning, 23-24

Drugs, habit-forming, $75-80,82$

Dwellings, 206-209, 218

Dynamo, I68- 72

E

Earth, the, 157, 193, 349-354

Easter, 359

Eclipses, 337-338

Economic conditions, 28I-296, 327

Education, I7, 80-8I, 210-212, 25 \%, $284,293^{-294}, 298,349$
Efficiency, 31-32, 65-69, 72-75, 83, • I63, I67, 207, 2II-2I3

Eggs, 279, 299-303 candling of, $30 \mathrm{I}$ preservation of, $30 \mathrm{r}-303$

Elasticity (and plasticity), I 55

Electric lights, 21 8-2 I9

Electricity, I68-172, I84-I90

Electrolysis, I84-I90

Electromagnets, I68-I 72

Electro-plating, I 70, I85-186, I90

Embryo, 302, 315

Emergencies, 233-239

Emetic, 234

Emulsion, I77, I 79, 3 10

Energy, I60-I63

electrical, I68, I 72, I90, 2 I 8

molecular (and heat), 143, 147, I6I, 218

of ether motion, 346-347

of the human body, 26-27, 29, $31,40,67,134$

solar, I6I, 217

in relation to plants, 268,274

transformation of, I60-I6I

transmission of, I60-I6 3

Enzymes, 174-175, 23I

Equilibrium, 165, 167

Erosion, 103-108, 333

Ether medium, I44, I6 $2-16_{3}, I_{72}$, 2 I $8,344-348$

absorption of motion of, 147,162 wave frequency in, $\mathrm{I}_{2}$

Evaporation, 86

Evolution, plants and animals, 302, 305

Exercise, physical, 31, 36, 65-69, 72,

$$
\text { I 75, 24I }
$$

Exercises (see Questions).

Expansion (see Volumes of bodies coefficient of, I4 I-I42

Eyes, and their care, IO-I5

parts of, IO-II

Eye-strain, I2-I5 
Faraday, I68

Feathers, 276, 297

Ferments, and fermentation, 6, I 75

Fireless cooker, I45

Fires, $235^{-236}$, 239, 254-256

Flame, I 7-5 8, 235-236

Flies, 57-60

Flowers, $265-266,3$ I 5

Food inspection, 47-49, 5I

Foods, classes of, 27, 222-224 quantity needed, 2 I9-220

Food stuffs, 45-48, 209, 220 adulteration of, 48,226 composition, table of, 225

Forces, I 5 I, I 55, I 57, I60, I6 3

Forests, $254^{-258}$

Friction, 154

Frost, 92, 94

Fruit, 262, 267

Fuel, 2I 4-2I 7

Fungi, 322-325

Fusion, heat of, $95-96$

G

Garbage, 6 I

Garden, 24I-246

Gases, 86, 98-99

liquefaction of, II6-II8

pressure of, II $7-\mathrm{I}$ I 8

temperature due to compression and expansion of, 90, II7II $8, I_{25}, I_{3} 8$

Gasoline, I77, 235

Gluten, 300, 327-328

Gravity, and gravitation, $155^{-1} 58$, 338

Growth, 64, 7I, 83, 302, 315-3I6

Gypsum, I95
Habit formation, $74-76,80-84,219$, 295

Hand, structure and uses, 2-3

Headache powders, 77

Health, I, 29, 3I-36, 42-43, 49, 58, 6I-69, 72-74, 208-209, 219$221,223-224,237,241,293$ in relation to weather, II $3, \mathrm{I}_{33}$ I 37

Heat, II6-II 7, I43-I47 and electricity, $16 \mathrm{I}, 218$

as molecular energy, I43-I44, I6I conduction and convection of, I $43-\mathrm{I} 45$

liberated by condensation or compression, 95, II 7

measurement of, 94-95

of solution, 99

of vaporization, $95^{-96}$

radiation of, I44-I45, I47

reflection of, 149

solar heating, I I 2, I49, 35 I-352, 367

specific heat, 87

Heat equator, $\mathrm{I} 3 \mathrm{I}$

Heavens, the, $364-369$

"Highs" and "lows," I 29-131, I 37I 40

direction of their movements, I 29- $33 \mathrm{I}, \mathrm{I} 38-\mathrm{I} 40$

Homes and their surroundings, 206,

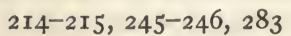

heating and lighting, 2I4-2I5, 218-219

rooms and their furnishings, 206-208

Horizon, I47-I49, 349-35I

Horse, 304-307

Humidity, 20, 93-94, I36-1 37

Hygiene, I, 25, 32, 35-36, 42-43, 65$69,72-79$

Hypothesis, 98, ror 
Ice, 50, I 6

density of, 88

Images by reflection, $33^{8-}-342$

how located, 340

Immune, 36-37

Incandescence, I8, 2I 7-21 8

Industrial life, $28 \mathrm{I}-290$

Industries, chemical, 188-192, 195,

$$
\text { 199-203 }
$$

iron, $197-204$

petroleum, $284-287$

relation to coal supply, 196-I99, 216

Inertia, I 54

Infection, 36-54, 6I, 208, 236

Initiative, 243

Insects, $57-62,278$

Instinct, $277-278$

Insurance, 235, 239

Intemperance, 66,69

Ions, and ionization, I8I-183, I86, 190

Iron (and steel), 197-204

cast iron, 92, 20I-202

galvanized, 203

pig iron, 201, 204

properties of, $20 \mathrm{I}-2 \mathrm{O} 2$

tempering of (as steel), 203-204

uses of, 196-197, 202-204

Irrigation, 105, 108, 244, 247

\section{K}

Kerosene, I 7, 235, 286

Knowledge, $83-84,2$ Io

\section{L}

Labor, 28I-284, 288-289, 292-295 on farms, $327-328$

Laws, of correlation of forces, 170 of definite proportions, I 6
Laws, of gravitation, $155-156$

of life, 68

of machines, 167

of science, 98

of "survival of the fittest," 265 , 279

of weather, 137

Leaves, $262,264,267,270$

Levers, $163-167$

Life, $64-68,7$ I , 78, 356

Light, diffusion of, r 79, 341

in relation to heat, $217-218,346$

phenomena of, 336-348

reflection of, 339-34I, 344

refraction of, 34I, 343

velocity of, 337

Lime, in water, $178-180$

for builder's uses, I9I-I92, I95

Liquids, 86 .

Literature, relation of to science, I I I $242,258,364$

Litmus, $180-182$

Lumber, $255^{-256}$

Lungs, and their capacity, 22, 25

Lymph, $7 \mathrm{I}-72$

\section{M}

Machines, I63-I64, I66-I67, I69I 70, I96, 239, 284-285, 288, 295

for farm uses, 310, 327-331

the human body as a machine, 26, 29, 66

Magnetism, I70-I72

Malaria, 38, 6r

Mammals, 305-306

Manhood, $8 \mathrm{I}-83$

Marble, I93-I94

Mass, I $_{2}$, I $_{55^{-1}} 5^{6}$

Matches, friction, 176

Matter, ${ }_{5}{ }^{I-I} 5^{8}$

indestructibility of, $\mathrm{I}^{2}$

living matter, $15 \mathrm{I}-\mathrm{I} 52$

properties of, $15^{2-155}$ 
Medicines, purpose of, $33-36,65,78$

Mercury, boiling and freezing tem-

peratures, 142

coefficient of expansion, I4 I

properties of, I4I-I42, I46-I47

Metabolism, I74-I 75

Metals, $188-189,194^{-205}$

importance of, I96-197

Milk supply, 226, 308-3 I I pasteurization of, 309

Mind, 8-9, 65-66

Molecules, 85-86, I 73-I 74, I8I

Moment, I65-I67

Momentum, I66-167

Moon, $157,353,355^{-}-35^{8}$

number of moons for other planets, $35^{8}$

phases of, $355,35^{8}$

physical characteristics, $357-35^{8}$

Mosquitoes, 39-40, 6c-6r

Mouth, 4-6, 8-9

connected parts, $4-5,9$

Narcotics, $73-79$

Natural resources, 103-105, 107, 218,

$$
254-256,284-287
$$

Nerves, 2-3, 5, 8-9, 31, 33, 79

nerve shock, 236, 239

Nitrogen, II 2-II3, 257

$\mathrm{O}$

Obliquity of solar rays, $147^{-1} 49,35^{-}-$

$$
352
$$

Oils, 23I, 272-273

Ores of the metals, 194-20I

Osmosis, 99-10 I

osmotic pressure, roo

Oxidation, I6-18

Oxygen, I6-I8, I 75, 226

liquid oxygen, II 7-I 18

\section{$\mathrm{P}$}

Pain, II , 33, 35

Paint, 203, 208, 272-273

Paper, 273-274
Parasites, 40

Pasteur, 36, 39

Patent medicines, 76-77, 79

Pendulum, 359, 362

Perspiration, 27-29

Petroleum, 284-288

Phenomena, 152

Planets, 337-338, 353, 367-369

Plant growth, conditions for, 243,

$$
\text { 247-25 I, } 253
$$

Plants, studies of, $263-274$

flowers, $265^{-2} 66$

leaves, $263-265,267-270$

propagation of, 266-267

roots, $243-244,248-249,263,267$

seeds, $265-266$

usefulness of plants, 255-259, $263-265,268-274$

Play, 69-7I

Pollen, 265-266

Potato, 229

Poultry, 297-303

structure of bodies of fowls, 297-298

Poverty, 73, 21 2-2I3, 290-29I

Preservatives, $47-48,5 \mathrm{I}, 307$

Producers, $28 \mathrm{I}-283$

Proteins, 27, 220, 222-225, 231, 299300,328

test for, $30 \mathrm{r}$

Protoplasm, 64, 71 , 79, 222, 226

Protosynthesis, 228

Protozoa, 36-38, 40

Ptomaines, 4I, 47

Public health, 47-5I

Pulleys, I64

Pumps, 122

Pure foods, 48, $5^{\text {I }}$

Q

Quarantine, 43, 45

Questions, lists of, $15,30,5^{1-52}, 63^{-}$ $64,84,97$, го1, Jо8-109, 123, I31-132, I40, I50, I 58-159, 
Questions, lists of $163, I 68, I 72, I 80$, 2 I 3-2 I 4, 232-233, 239-240, $247,254,259,275,280,289$ 290, 303-304, 307, 312, 3173 I8, 329-332, 348, 354-35்

\section{R}

Rainfall, 90-92, 94, I36, I38-139

Rats, 6r-63

Recreation, 68-72

Refrigeration, I I8, I45

Resistance, I54, I64, I67

Respiration, 19, 24, I I I

Rest, II, 66-72

Revolution of earth, I48, I54, I57, 35 I -355

"leap year," 353

lengths of years, 353

velocity of, 353

Right living, 65-84, 207-208, $21 \mathrm{I}-$ 2 I 3

Rocks, $334-335$

limestone (see Gypsum), I92196, 202

sandstone, 194

stratification of, $192-193$

Roots, 243-244, 3I4

Rotation of earth, I28, I3I, 349-35 I rate of, $35^{\circ-}-35^{\mathrm{I}}$

\section{S}

"Safety first," 238-239

Saliva, 6

Sand, $247-248$

Sanitation, 46-5 I

Schoolrooms, conditions in, I3-I4, 2O-2I, 23, 4I

Schools, purposes ot, $26,42,49,5 \mathrm{I}$, 68, 80-82, 84, 207, 2 II-2I 2, $252,257,292-296$

Science, achievements of, 284,289 , 295
Seasons, $35^{\mathrm{I}-354}$

Seeds, $265-267$

Serums, 37, 4I, 45

Sewage, 56

Shadows, 336-337, 357

Sickness, $32-33,35,42,57,65,74$, I 75

by inheritance, 32

treatment of, 33

Silos, 316

Sleep, 19, 25, 32, 66-68, 72

Soap, I 77-I 78, I9

Social welfare, $4 \mathrm{I}-43,46-49,6 \mathrm{I}-62$, $69-7$ I , 74-75, 287-288, 290295

Soda, manufacture of, I90-I9I, I95 Soils, 247-254, 332-335 classes of, $247-248,25 \mathrm{I}, 332-333$ fertility of, $25 \mathrm{I}, 3 \mathrm{I} 3$ humus in, 25I, 333 origin of, $333-335$ sorting of by water, 333 temperature when water-soaked, 96

tillage of, $243,246,248-254$

water content of, $248-249$

Solar heating, and obliquity of rays,

$$
\text { I 42-I } 49
$$

Solar spectrum, 342-347

Solids, 86, 98

Solutions, 88-90, 98-99, ror

Specific heat, 89, I46-1 47

Spectrum analysis, $345-346$

Sports, 70

Sprains, 3

Sprays and spraying, I 22, 321-323, 325

Standard time, 359-363

Starch, 222, 226-229, 231, 31 7, 328

Stars, $366,368-369$

Sterilization, 45, 234, 236, 3 I I

Stimulants, 72-99

Storage batteries, I20, 187

Strain (and stress), I54 
Streams, 103, I06

Sublimation, 92

Submarines, I I9-I 20

Sugar, 222, 224, 227-231

Sun, $35 \mathrm{I}-354,367-369$

atmosphere of, $337-338$

distance of, $35^{2-}-353$

\section{$\mathrm{T}$}

Teeth, 8, 10, 277, 305-307

Telegraphy, wireless, 172

Temperate living, $67-70,73-74$

Temperature, 86, I40-147

boiling, and freezing, 86, 99, I 46

in relation to volume, I40-I4 I

of human body, 27-29

Tempering, 203-205

Tenacity, 555

Tendons, 2

Theories, as to light, $33^{8-} 339,344^{-}$ 347

in astronomy, 337

of conduct, 293-295

of education, 294, 296-29 :

of science, 7I, I52, I60, I62, I $8 \mathrm{I}-\mathrm{I} 82, \mathrm{I} 86$

Thermometers, I40-142, I46-I47

clinical, 35

Thermos bottle, I I 7, I 45

Thrift, I34, 209-2 I3, 235, 290-20.3

Timekeeping, $359-363$

international date line, $36 \mathrm{I}$

local time, 359

standard time, and time belts, $360-363$

Tobacco, 74, 79, 2 I I

Tonsils, 5

Tornado, I 25-1 27

Toxins, 40-4I, 45

Transpiration, 270, 314

Transportation, $53,85,28 \mathrm{I}-283$

Trees, 254-263

planting, and uses of, $256-259$

studies of, $259^{-263}$
Tuberculosis, 25, 39

Typhoid, $37-38$

\section{$\mathrm{V}$}

Vaccination, $37-38$

Vaporization, $90-96$

heat of, $94-96$

Varnish, 273

Veins, valves in, 34

Velocity, I57, 337, 350-35 I

Ventilation, 20-21, 23-25, I 22

Volumes of bodies, changes in, 20,88 , 93, II6-I $24, \mathrm{I} 4 \mathrm{I}-\mathrm{I} 42, \mathrm{I} 46$ I 47

\section{W}

Wage earning, $283-284, \quad 290-291$, 295

Washing powders, 178 , I9 1

Waste, 26, 29, 32, 35, 42, 49-50, 6I$62,66-68,74-75,82$, 103105, 134, 160, 206, 21 2, 218 , $257,279,293$

Water, and plant growth, 269

as a drink, $7,49,224$

carbonated, 88-89

"hard" water, I 78-1 80

in the breath, 23

in relation to health, $53-57$

peculiar behavior of, I4 I

properties of, 86-90

purification of, $53-57$

sources of infection, 50, 53-54, 56

supply of, $53-57$

uses of, $52-53,56,85$

Water in the atmosphere, 93-94, I $23-126$

Weather, I33-140

and health, I1 $3,133-136$

due to highs and lows, I37-I40

forecasts of, $\mathrm{I} 37-\mathrm{I} 39$

protection from, $\mathrm{I} 33$

Weight, ${ }_{5} 6$ 
Wells, 54

Wheat, 325-328 food value of, $327-328$ regions where grown, $325-328$

Winds, 94, IrI, II3-II4, I23-I3I, I37-r39
Winds, constant and variable, 128 I 30

Wood pulp, 273-274

Work, $160-163$ Y

Yellow fever, 39-40 




\section{UNIVERSITY OF CALIFORNIA LIBRARY}

This book is.DUE on the last date stamped below.

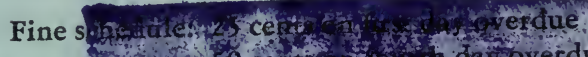


ghet If somet
YC 22703

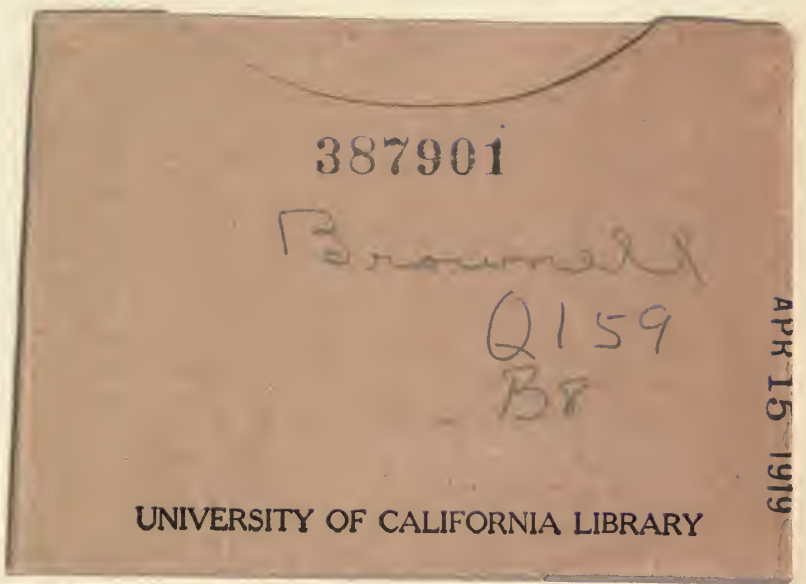


uston 